\title{
Development of an Improved Extruded Dielectric Cable Rated 230 KV
}

Final Report

\author{
Leo D. Blais \\ Richard T. Traut \\ George N. Bolden
}

Kaiser Aluminum and Chemical Corporation

Portsmouth, Rhode Island

$$
\text { Date Published-May } 1977
$$

This report was prepotice

sponsored by the United States an account of work the United States nor the United State. Nejther Research and Development Ad Uniled States Energy their employees. nor any of theion, nor any of subcontrectors, or their employects contractors warranty, express or implied, or assumes any any Uabily or responsibility for the accuracy, completeness or usefuiness of any information, apparatus, produet infringe primatedy or represents that its use would not

\section{Prepared for the \\ Energy Research and Development Administration \\ Office of the Assistant Administrator for Conservation \\ Division of Electric Energy Systems}

\author{
Work Performed Under Contract \\ No. EC-76-C-01-20:
}

$9503^{3^{9}}$ 


\section{DISCLAIMER}

This report was prepared as an account of work sponsored by an agency of the United States Government. Neither the United States Government nor any agency Thereof, nor any of their employees, makes any warranty, express or implied, or assumes any legal liability or responsibility for the accuracy, completeness, or usefulness of any information, apparatus, product, or process disclosed, or represents that its use would not infringe privately owned rights. Reference herein to any specific commercial product, process, or service by trade name, trademark, manufacturer, or otherwise does not necessarily constitute or imply its endorsement, recommendation, or favoring by the United States Government or any agency thereof. The views and opinions of authors expressed herein do not necessarily state or reflect those of the United States Government or any agency thereof. 


\section{DISCLAIMER}

Portions of this document may be illegible in electronic image products. Images are produced from the best available original document. 
2.0 Introduction 2

3.0 Program Objectives 6

4.0 Circuit Design Concepts $\quad 8$

5.0 Extruded Solid Dielectric Cable For 230kV Operation $\quad 12$

6.0 Voltage Endurance and Current Cycling Tests on 230kV

Extruded Solid Dielectric Cable 29

7.0 Research Program in 230kV Jointing 64

8.0 Terminations For Use On 230kV Extruded Solid Dielectric Cable 180

9.0 Summary and Conclusions

REFERENCES:

Section 1.0

Section 2.0

Section 3.0

Section 4.0

Section 5.0

Section 6.0

Section 7.0

Section 8.0

Section 9.0

APPENDIX 5.1 Test Procedure For Evaluating Inter-Facial Adhesion of Two Adjacent Layers 


\section{TABLE OF CONTENTS (Continued)}

APPENDIX 5.2 Photographs of Failed Sections Showing Conductor Shield Disturbances

APPENDIX 7.1 230kV Jointing Research Program - ERDA Contract (As Written, January 1976)

APPENDIX 7.2 Formula For Joint/Cable Ampacity In Free Air

APPENDIX 7.3 Computer Aids - Joint Design Programs For Electrical and Thermal Fields

APPENDIX 7.4 Kaiser Standards For Underground Transmission and Distribution Connectors For Aluminum Conductors 
Table 5.1

Partial Discharge Values Obtained On Section of 230kV

Cable 80 Feet in Length. Second Production Run

Table 5.2 Adhesive Strength At Interface Of Conductor Semi-Conducting Shield and Primary Insulation At Room Temperature - 230kV Cable - Production Run ${ }^{\#} 3$

Table 5.3 Electrical Tests Performed On 230kV Cable Having 1050 Mil Wall Cross-Linked Polyethylene Insulation and $1000 \mathrm{kcmil}$ Aluminum Conductor

Table 6.1

Preliminary Dielectric Measurements

41

Table 6.2 Dielectric Measurements After Initial Current Loading at 90 and $130 \mathrm{C}$

Table 6.3 Dielectric Measurements After Second 90C Load Cycle

Table 6.4 Dielectric Measurements After Fourth 90C Load Cycle

Table 6.5 Dissipation Factor and Capacitance Measurements With Conductor at $90 \mathrm{C}$

Table 6.6 Dielectric Measurements After Sixth 90C Load Cycle

Table 6.7 Dielectric Measurements After Third I30C Load Cycle

Table 6.8 Dielectric Measurements After Fourth I30C Load Cycle

Table 6.9 Dissipation Factor and Capacitance Measurements With Conductor at I30C

Table 6.10 Dielectric Measurements After Seventh I30C Load Cycle

Table 6.11 Dielectric Measurements Prior To Cyclic Periods at $233 \mathrm{kV}$ and $.90 \mathrm{C}$

Table 6.12 Summary of Extended $60 \mathrm{~Hz}$ and Current Cycling Tests (Before Installation of Joint)

Table 6.13 Initial Dissipation Factor and Capacitance Measurements on Entire Circuit (After Jointing) 


\section{LIST OF TABLES (Continued)}

Page No.

Table 6.14 Initial Dissipation Factor and Capacitance Measurements on Joint Only

Table 6.15 Dissipation. Factor and Capacitance Measurements at Room Temperature After Current Loading at 90C (After Jointing)

Table 6.16 Dissipation Factor and Capacitance Measurements During 5lst Load Cycle (After Jointing) at 90C

Table 6.17 Dissipation Factor and Capacitance Measurements After 51st Load Cycle (After Jointing) at Room Temperature

Table 6.18 Initial Corona Discharge Measurements (After Jointing)

Table 6.19 Corona Discharge Measurements (After Jointing)

Table 6.20 Corona Discharge Measurements at Room Temperature After Current Loading at I30C (After Jointing)

Table 6.21 Corona Discharge Measurements on Entire Circuit During 5lst Load Cycle (After Jointing) at 90C

Table 6.22 Corona Discharge Measurements on Entire Circuit After 5lst Load Cycle (After Jointing) at Room Temperature

Table 6.23 Summary of Voltage-Hours and Load Cycles After

Installation of Taped Joint

Table 6.24 Impulse Withstand Test (Sample \#I)

Table 6.25 Impulse Withstand Test (Sample \#2)

Table 6.26 Impulse Withstand Test (Sample \#2 With Taped Joint Installed)

Table 6.27 Cable Shield Resistance Measurements at Elevated Temperatures 57

Table 6.28 Cable Shield Resistance Measurements at Elevated Temperatures. 58

Table 6.29 Temperatures of Cable Components and Accessories at Elevated System Temperatures 
Table 6.30 Volume Resistivity Measurements

Table 6.31 Solvent Extraction Tests On Samples From 230kV Cable

Table 7.1 Electrical $60 \mathrm{~Hz}$ Stresses in 230kV Transition Joints in Comparison to $138 \mathrm{kV}$ Waltz Mill Design

Table 7.2 Test Procedure for Evaluation of $69 \mathrm{kV}$ Vulcanized Polyethylene Splices

Table 7.3 Dissipation Factor Measurements of Ten $500 \mathrm{kcmil} 69 \mathrm{kV}$ Vulcanized Polyethylene Joints

Table 7.4 Partial Discharge Characteristics of a $69 \mathrm{kV} 500 \mathrm{kcmil}$ Test Circuit Including Ten Vulcanized Polyethylene Joints

Table 7.5 Format for XLPE Splice Insulation Data Recording

Table 7.6 Typical Test Joint Data - $69 \mathrm{kV} 500 \mathrm{kcmil}$ Vulcanized PE Joint

Table 7.7 Radial Electrical Stresses in Vulcanized Polyethylene Joint Designs

Table 7.8 Tangential Electrical Stresses in Vulcanized Polyethylene Joint Designs

Table 7.9 Conductor Program Master Data Sheet -- Typical

Conductor Temperature 
Figure $5.1 \quad 1000 \mathrm{kcmil}$ Die-Sized Aluminum 230kV Cable With Standard Shield Design 22

Figure 5.2 Electrical Test Report - Factory Tests On 230kV Cable 23

Figure 5.3 $X-Y$ Recording of Partial Discharge Test On 230kV Cable 24

Figure 6.1 Graph of Cable Shield Resistance Vs. Elapsed Time During Transition From 90C

Figure 6.2 Graph of Cable Shield Resistance V.s. Elapsed Time During Transition From 130C

Figure 7.1 138kV Kaiser Taped Splice Designs : . 66

Figure 7.2 Maximum Radial $60 \mathrm{~Hz}$ Stress in Taped Joint Designs 67

Figure 7.3 Tangential $60 \mathrm{~Hz}$ Stress in Taped Joint Designs 67

Figure 7.4 Longitudinal $60 \mathrm{~Hz}$ Stress in Taped Joint Designs 68

Figure 7.5 $60 \mathrm{~Hz}$ Average Creepage Stress in Taped Joint Designs 68

Figure 7.6 DC and Impulse Average Creepage Stress in Taped Joint Designs 69

Figure 7.7 Average Radial DC and Impulse Stress in Taped Joint Designs 69

Figure 7.8 Identification of Electrical Stresses in a Taped Joint $\quad 70$

Figure 7.9 Graph - Ratio of Joint/Cable Rca' 73

Figure 7.10 Design of a 230kV Taped EPR Joint With Electrical Stresses Not Exceeding Those of I38kV Waltz Mill Design 75

Figure 7.11 230kV Taped EPR Design \#1 77

Figure 7.12 230kV 2500/1000 kcmil Transition Joint Design 79

Figure 7.13 Left Side of 230kV Taped Design \#I Showing Thermocouple Location For Step F Thermal Study 81

Figure 7.14 Same as 7.13, for Adjacent Cable 82 
Figure 7.15 230kV Taped Joint Design \#I, Cable Loading To 90C

Figure 7.16

230kV Taped Joint Design \#1, Cable Cooling From 90C

Figure 7.17

230kV Taped Joint Design \#I, Cable Loading To I30C

84

Figure 7.18

230kV Taped Joint Design \#I, Cable Cooling From I30C

Figure 7.19

230kV Taped Joint Design \#I, Cable 100\% Emergency Overload

Figure 7.20

230kV Taped Joint Design \#I, Cable 120\% Emergency Overload

Figure $7.20 \mathrm{~A}$

230kV Taped Joint Design \#1, \% Dissipation Factor as a

Function of Time at Rated Load Current

88

Figure 7.20B

230kV Taped Joint Design \#I, \% Dissipation Factor as a Function of Time at Emergency Overload Current

Figure 7.21 $69 \mathrm{kV}, 500 \mathrm{kcmil}$ Kaiser Vulcanized Polyethylene Splice Design

Figure 7.22 II5kV $1500 \mathrm{kcmil}$ Vulcanized Splice Design

101

Figure 7.23 Thermal Processing Profile of $115 \mathrm{kV} 1500 \mathrm{kcmil}$ Vulcanized Polyethylene Joint Insulation

102

Figure 7.24 Thermal Processing Profile of $115 \mathrm{kV}$ ' $1500 \mathrm{kcmil}$ Vulcanized Polyethylene Joint Connector Shielding

Figure 7.25 Comparison of Vulcanized Polyethylene Joint Processing For Two Cable Sizes With Aluminum Conductor

103

Figure 7.26 230kV Kaiser Vulcanized Polyethylene Joint Design \#|

Figure 7.27 Thermal Processing Profile of $230 \mathrm{kV} 1000 \mathrm{kcmil}$ Vulcanized Polyethylene Joint Connector Shielding

106

Figure 7.28 Thermal Processing Profile of $230 \mathrm{kV} 1000 \mathrm{kcmil}$ Vulcanized Polyethylene Joint Insulation

Figure 7.29 Basic Design of a Nitrogen Pressure Process Chamber

107 
Figure 7.30 Cross-Section of a Cable Splice Tensioning Device For Nitrogen Chamber

Figure 7.31 Comparison of Thermal Process Characteristics Using Two Different Splice Insulations

Figure 7.32 Profile of Vulcanized Joint Tapers Showing Points for Calculation of Tangential Stresses for $69 \mathrm{kV}$ and $115 \mathrm{kV}$ Designs 116

Figure 7.33 Profile of Vulcanized Joint Tapers Showing Points for Calculation of Tangential Stresses for I38kV and $230 \mathrm{kV}$ Designs

Figure 7.34 Composite Graph of $1000 \mathrm{kcmil}$ Die-Sized Class B Aluminum Conductor Heating/Cooling Characteristics in Free Air

Figure 7.35 Thermal Profile Test Assembly-Connectors

Figure 7.36 $1000 \mathrm{kcmil}$ MAC M TAP 1000 NE Connector Test Data

Figure 7.37

$1000 \mathrm{kcmil}$ T\&B \#1000 AS 150 Connector Test Data

Figure 7.38 $1000 \mathrm{kcmil}$ Cadweld Connector Test Data

Figure 8.1 Detailed Assembly Drawing of G\&W 230kV Terminator

Figure 8.2 Detailed Assembly Drawing of Joslyn 230kV Terminator 
This report details work performed on developing an Improved 230kV Extruded Solid Dielectric Cable, the techniques of jointing such cables and the testing of terminations suitable for operation at that voltage level.

Difficulties were encountered during manufacture in applying the semi-conducting extruded conductor shield. It was first thought that the difficulty was related to machine alignment but this was found not to be the case. A new higher melt point compound gave good results.

A joint capable of operating at the $230 \mathrm{kV}$ level was developed but showed a deficiency under voltage impulse testing while the conductor was at elevated temperature. A reduction in contract scope terminated the effort but it is felt that further work could have corrected the deficiency without appreciable reduction in 60 Hertz capabilities of the joint which were found to be acceptable based on the minimal amount of testing that was performed.

Two terminals rated for $230 \mathrm{kV}$ were found to be commercially available from domestic manufacturers. The limited testing performed showed them to be compatible with the cable cross-linked polyethylene insulation and electrically sound under $60 \mathrm{Hertz}$ testing. No direct voltage or impulse voltage testing was performed on the terminations.

A sample circuit, consisting of cable and joint was subjected to impulse voltages at both room temperature and normal conductor operating temperature of $90 \mathrm{C}$. While cable only was able to withstand voltage impulses in excess of the Basic Impulse Level (BIL) at room temperature, it failed at BIL while conductor was heated to $90 \mathrm{C}$. In like manner, a cable and joint circuit was assembled. Similar voltages were impressed at room temperature without incident. The joint failed at $90 \mathrm{C}$ conductor temperature.

Cable, joint and termination were assembled in a simulated circuit and subjected to conductor loading to elevate temperature while $60 \mathrm{~Hz}$ voltages in excess of normal operating levels were continuously applied. 


\section{DEVELOPMENT OF AN IMPROVED}

\section{EXTRUDED DIELECTRIC CABLE}

\subsection{INTRODUCTION}

In 1971, the Edison Electric Institute and the Electric Research Council Task Force on Advanced Concepts in Power Transmission engaged the services of the Arthur D. Little Company for the performance of a systems analysis of methods of reducing costs of underground power transmission. Among other major recommendations, was one for an improved extruded dielectric cable which hopefully would extend the operating range to $345 \mathrm{kV}$ by 1980 (Reference 2.1). Along with this was the desire to develop these cables to include larger conductor sizes, reliable installation and jointing techniques and economically improved manufacturing techniques that provide excellent control of quality.

In November of 1974, the United States Energy Research and Development Administration, still under the Department of the Interior, issued a request for proposals for an improved extruded solid dielectric cable for operation at $138 \mathrm{kV}$ or $230 \mathrm{kV}$. Request for Proposal \#TD 75-04 was intended to cover a time span of from twelve to thirty-six months and involve the manufacture of 5000-feet of cable and provide two joints and two terminals. The basic design of the cable as to materials utilized was left largely to the discretion of the individual offeror.

Kaiser Aluminum and Chemical Corporation was a successful offeror, electing to propose a cable rated at $230 \mathrm{kV}$. The basic construction was cross-linked polyethylene insulated cable employing a $1000 \mathrm{kcmil}$ aluminum conductor and cross-linked polyethylene semi-conducting conductor and insulation shields. The basic premise was to operate this cable at significantly higher voltage stresses thereby reducing the thickness of the insulating wall and effecting a commensurate decrease in the use of raw materials. Designs were also proposed which would have conductor sizes to $2500 \mathrm{kcmil}$ and would further decrease the unit maximum operating stresses and set the stage for even higher voitages in ensuing designs.

In June of 1975, a contract was signed between the United States Energy Research and Development Administration and the Kaiser Aluminum and Chemical Corporation to manufacture the required amount of cable necessary to perform basic testing, to develop suitable jointing techniques and to test commercially available terminations. Work was divided into these three major areas of 
interest and development progressed to a point where considerable difficulty was encountered in manufacturing a suitable amount of cable capable of operating at the higher stresses proposed. The difficulty was traced to gross conductor shield imperfections and attempts to correct the deficiency through normal manufacturing techniques proved futile: Throughout this period of time, work was continuing on the purchase of acceptable terminating materials and on various techniques of jointing.

The project, as originally conceived, assumed that materials and processes available for production of $138 \mathrm{kV}$ cable could be modified to successfully produce $230 \mathrm{kV}$ cable. The results of our work at the 2000 feet test cable manufacturing milestone indicated that this assumption was incorrect and that a major modification of materials and/or processes was required.

Early in 1976, another attempt was made at producing cable which represented the modified approach. Instead of using cross-linked polyethylene as the conductor shield a substitution was made for this component using a high melt temperature thermoplastic rubber (TPR) compound. This attempt appeared to be reasonably successful except that the surface of the semi-conducting conductor shield possessed a granular surface which conceivably could lead to further problems at this troublesome interface with the primary insulation. The sole U.S. supplier of this material indicated that they could produce materials which would provide a smoother extruded surface and present greater adhesion to the overlying insulation without sacrificing any of the properties of the compound. An order was placed in April of 1976 for an additional 1000 pounds of the improved materials. In November of 1976, after repeated promises of performance on delivery, the supplier had not yet fulfilled the requirements. The results to that point dictated a complete re-appraisal of the program.

Preliminary tests on the limited quantity of cable produced using the TPR semi-conducting compound were promising. However, it was considered desirable to conduct a comprehensive survey of materials including the new promising TPR semi-conducting compound prior to manufacture of the cable for which such a comprehensive evaluation program was contemplated. Further, it would have to be established that the TPR semi-conducting material could be made available in development and production quantities.

A review of the results at the test quantity manufacturing milestone led to the conclusion that the project should be reduced in scope to the work completed to that point except that additional testing of the available cable made with the TPR semi-conducting conductor shield should be carried out. 
Considerable investigations were made in the area of splicing. There were five planned approaches encompassing all phases of presently available technology. The largest gains were made in the areas of hand-applied taped joints since this appeared to be the category where the greatest amount of technology was available. The field vulcanized type of joint was worked on and progress in this category was slower since the available information was largely restricted to voltage classes generally considered as medium voltages requiring a larger field of knowledge to be developed. Alternate jointing concepts were also planned as part of the initial program but time did not permit a significant effort along these lines. Some work was done in developing a uniform computer program which would serve as an aid in the design of joints taking into considerátion the selection and compatibility of any and all components which go into the construction of a joint.

A program was started which was designed to determine the capabilities of connectors used in cable joints. The products of three different manufacturers were tested prior to termination of the work.

Terminations were also investigated with emphasis being placed on compatibility of materials and electrical integrity. Since there are a limited number of domestic terminal manufacturers capable of supplying $230 \mathrm{kV}$ terminals, the approach was to search out those suppliers with presently available components. In addition, a close watch was kept on developments in the field to assure that anything new would be considered for acceptability and tested if the development appeared feasible.

In the following sections, work completed on joint development and test, termination testing, and cable design and testing will be discussed. 
1. UNDERGROUND POWER TRANSMISSION, Arthur D. Little, Inc., Contract No. 14-01-0001-1407, ERC Publication 1-72, October 1971, Page 4-15. 
3.1 DEVELOPMENT OF IMPROVED EXTRUDED SOLID DIELECTRIC CABLE

The Principal Objective was to develop an improved extruded dielectric cable system which represented a significant improvement in the current State-of-the-Art and to verify its performance for use in electric utility systems at $230 \mathrm{kV}$.

\subsection{DEVELOPMENT OF $230 \mathrm{kV}$ JOINT}

Another objective was the development of a joint suitable for operation at $230 \mathrm{kV}$ that would be compatible with the improved extruded solid dielectric cable. At least one, and more if possible, methods of jointing were to be developed and performance verified in the laboratory for use on cables in electric utility systems at $230 \mathrm{kV}$.

\subsection{TESTING OF SUITABLE TERMINATIONS}

A third objective was to test terminations to meet IEEE Standard No. 48, for Potheads (REFERENCE 3.I) that are commercially available and are compatible with the improved extruded dielectric cable being developed.

\subsection{SIMULATED TESTING UNDER ACCELERATED CONDITIONS}

The final objective was to set up and test, in a circuit 4a: igned to simulate an actual installation used in electric utility iysrems, the manufactured cable, a joint, and two terminations. The intent was to verify system integrity and performance of the $230 \mathrm{kV}$ system employing extruded solid dielectric cable. 
3.5

REFERENCES TO SECTION 3.0

1. IEEE Standard Test Procedures And Requirements

For High-Voltage Alternating Current Cable

Terminations 


\subsection{CIRCUIT DESIGN CONCEPTS}

\subsection{STATEMENT AND DISCUSSION OF THE REQUIREMENTS}

A 230kV cable system requires logical designs of cables, joints, and terminators which will provide long life at low cost. Practices involving the manufacture of cable must ensure that high quality cable and components are produced which are capable of exploiting newer designs without excessive safety factors. For this purpose, it became mandatory that cables and associated components would be required to operate at higher voltage stresses in order to control the requirement for thicker insulating mediums and reduce thermal paths so that normal and emergency operating temperatures could be maintained. In the case of extruded solid dielectric cable systems these temperatures are generally accepted by the industry as being $90 \mathrm{C}$ and $130 \mathrm{C}$ respectively.

\section{I.I CABLE DESIGN CONCEPTS}

Limiting voltage stresses in cable designs were based on a 60 Hertz average stress of around 90 to 100 volts per mil and a maximum stress of 135 to 175 volts per mil (REFERENCE 4.5). Previous work on $138 \mathrm{kV}$ systems had shown that cables designed to utilize these values of stress were capable of operating for sustained periods of time, at multiples of their design values, without evidence of system deterioration (REFERENCE 4.6). It followed therefore, that designs employing higher stresses could be utilized. Experience indicated that an improvement in the State-of-the-Art could be achieved by increasing design stress levels beyond those generally accepted. Within that context, the proposal was made to manufacture and test a $230 \mathrm{kV}$ cable having a $1000 \mathrm{kcmil}$ aluminum conductor and a 1050 mil wall of natural unfilled cross-linked polyethylene insulation. For that design, the maximum stress at the surface of the semi-conducting conductor shield wo uld be 210 volts per mil and the average stress across the insulation would be 127 volts per mil.

Consideration was also given to cables having conductor sizes of 1500,2000 and $2500 \mathrm{kcmil}$. The increased conductor diameter for these larger conductors would reduce the maximum stress compared to the 210 volt per mil level of the initial design assuming a constant insulation wall thickness. As an example, the $2500 \mathrm{kcmil}$ conductor would operate at a maximum stress of 183 volts per mil. Any of those conductor sizes would operate at maximum stresses which were lower than those sustained in prior accelerated test experiments. 


\subsubsection{JOINT DESIGN CONCEPTS}

As in design considerations for cable, attention was given to voltage stresses in a number of critical areas within the joint. Considerable experimentation with joints for $138 \mathrm{kV}$ solid dielectric insulated cables had been done and analysis of test results for hand-applied EPR taped joints showed that the creepage distance, consisting of the prepared portion of the cable, could be reduced to provide a smaller, more economical joint. Original designs required a creepage distance calculated on the basis of $2.75 \mathrm{kV}$ per inch. Final designs permitted a creepage distance of $5 \mathrm{kV}$ per inch. Accelerated voltage and thermal testing over sustained periods led to the conclusion that, as in the case for cables, properly constructed joints could be designed to operate at even higher stresses providing a basis for the feasibility of a joint design capable of operating at $230 \mathrm{kV}$ without sacrificing thermal operating requirements of $90 \mathrm{C}$ normal and $130 \mathrm{C}$ emergency conductor temperatures. The tapes used for that joint were made with an ethylene-propylene-rubber (EPR) compound and thermal tests showed that temperatures at the conductor in the joint were significantly higher than temperatures at the conductor in the cable. For example, when the conductor attained a temperature of $130 \mathrm{C}$ the joint attained a temperature of $170 \mathrm{C}$. Despite this high temperature, results were always such that the joints operated successfully for the entire test programs. In the case of work done on the taped joint under this contact, the program progressed through all phases of test, including installation on the $230 \mathrm{kV}$ cable and a moderate amount of voltage testing.

The program outlined called for investigations into other jointing techniques. These included field vulcanizing of joints with cross-linked polyethylene materials and with EPR based materials. For these portions of the investigation a substantial amount of effort was expended but it did not lead to building or testing of joints at the $230 \mathrm{kV}$ voltage level. There were some significant results. Our work at making vulcanized joints rated at $69 \mathrm{kV}$ on a $500 \mathrm{kcmil}$ conductor led us to conclude, after visual analysis, that this was probably the limit which could be attained without a pressurized vessel to control void formation. Work was initiated on the design of that pressure vessel which would allow curing of the joints under constant pressure in a dry nitrogen atmosphere. The use of heat shrinkable semiconducting tubing, in lieu of semi-conducting vulcanizable tapes for use as conductor shielding also gave good results and appeared to be a significant development. Work was also done on the use of tapes made of an ethylene-propylene rubber compound and field vulcanized. Another form of field vulcanized joint, the Hotsplicer technique, was considered as a part of the overall program (RE FERENCE 4.I). A $138 \mathrm{kV}$ splice was installed and accumulated accelerated voltage life. The Hotsplice organization, a division of the Hexcel Corporation, has not yet developed an insulating material which they feel is satisfactory for use at $230 \mathrm{kV}$ voltages. As a result, our effort was confined to the work at the $138 \mathrm{kV}$ level. 


\subsubsection{0kV TERMINATORS}

The approach for this undertaking as it relates to terminators was to assess the market for commercially available $230 \mathrm{kV}$ terminators. $230 \mathrm{kV}$ terminators, of a different design, manufactured by the G\&W Electric Specialty Company, Blue Island, Illinois, have been used for years in our laboratory (REFERENCE 4.2). This terminator was designed for oil-filled cables and was adapted for use on extruded solid dielectric cables. That work was primarily in connection with impulse and steady-state over-voltage testing of $69 \mathrm{kV}, 115 \mathrm{kV}$, and $138 \mathrm{kV}$ cables. The paper-oil approach was not totally suitable for use on extruded cross-linked polyethylene cables because of the larger thermal expansion characteristic of the polyethylene cable. A pre-assembled slip-on type terminator was developed for use on systems through 138kV. G\&W Electric Specialty Company was confident that the design could be modified to be adapted for use at 230kV. In the end, the approach was to purchase the necessary stress control materials to assembly a G\&W $230 \mathrm{kV}$ terminator in the laboratory.

The Joslyn Manufacturing Corporation, Chicago, Illinois, (REFERENCE 4.3), was another manufacturer of terminators that were suitable for use through $138 \mathrm{kV}$ voltage classes and, they too, were confident that a design could be made available for evaluation as part of the program. In the case of the Joslyn design, no laboratory porcelain was available to use so a completely assembled unit was purchased on the basis that it could be returned to the manufacturer, after testing, to be refurbished and forwarded to ERDA as partial fulfillment of contract requirements. We were assured of the opportunity to evaluate designs of at least two manufacturers as part of the program.

It was further envisioned that a periodic review of new available designs would be made and a program of test would be worked into our program as situations demanded. Along this line, a design developed by the Raychem Corporation; Menlo Park, California (REFERENCE 4.4), was tested with good results as part of a test sequence established for proving out field vulcanized cross-linked polyethylene joints at the $69 \mathrm{kV}$ voltage level. This type of terminal was experimental above $69 \mathrm{kV}$ and no further work was performed within the scope of this program. 
1. HEXCEL CORPORATION

Hotsplicer Division

Electrical Products Department

5I3I Santa Fe Street

San Diego, California 92109

2. G \& W ELECTRIC SPECIALTY COMPANY

3500 West 127th Street

Blue Island, Illinois 60406

3. JOSLYN MANUFACTURING \& SUPPLY COMPANY

155 North Wacker Drive

Chicago, Illinois 60638

4. RAYCHEM CORPORATION

300 Constitution Drive

Menlo Park, California 94025

5. John P. Lozes, Jr., "Special Report on Development of $138 \mathrm{kV}$ Cable Systems For Tests EEI Waltz Mill Station", IEEE Transactions, Power Apparatus and Systems, Volume PAS 91, page 1422, Table II, 1972.

6. Leo D. Blais, "Development and Installation of $138 \mathrm{kV}$ Cable For Tests at EEI Waltz Mill Station: Cable 24", IEEE Transactions, Power Apparatus and Systems, Volume PAS 91, pp 1448-1456, 1972. 


\subsection{EXTRUDED SOLID DIELECTRIC CABLE F OR 230kV OPERATION}

Three attempts were made at manufacturing the cable intended for use at the $230 \mathrm{kV}$ level. The first two attempts ended in failure, the cause for which was attributed to severe conductor shield disturbances in the extruded semi-conducting layer. The third attempt proved successful by changing the type of material used for that application.

\section{I INITIAL MANUFACTURING RUN}

In the first manufacturing run, 2365 feet of cable, in three lengths of 1260,575 , and 530 feet,was manufactured and brought through final manufacturing processes and final electrical test. The cable had the following geometry:

\section{Component}

1000 kcmil Die-Sized Aluminum

Conductor

.008" Nylon Semi-Conducting

Half-Lapped Tape

Extruded Semi-Conducting

Conductor Shielding

Natural Unfilled Cross-Linked

Polyethylene Insulation

Extruded Semi-Conducting

Insulation Shield

2- .005" Bare Copper Tapes

Black PVC External Sheath
Thickness

Added

$-$

1.117

I. 117

Added

Cumulative

Diameter
.060

.013

.151
.014

028

.120

2.130

1.265

1.065

(1)

3.395

1.145

.

$\cdot$




\subsection{MATERIALS}

5.2.1 Material used for conductor shielding and insulation shielding was manufactured by Union Carbide Corporation and is known in the trade as compound numbers HFDB-0580 and HFDB-0590, both of which are semi-conducting vulcanizable polyolefin copolymer compounds (REFERENCE 5.I).

5.2.2 Material used for insulation was manufactured by Union Carbide Corporation and is known in the trade as compound number HFDB-420I, which is a natural unfilled vulcanizable polyethylene compound.

5.2.3 The conductor was made from aluminum made by Kaiser Aluminum's Ravenswood, West Virginia Plant, drawn and stranded at the Portsmouth, Rhode Island Facility, having a conductivity of $61 \%$ International Annealed Copper Standard (IACS). (REFERENCE 5.2)

5.2.4 The cable construction, as manufactured, had a $1000 \mathrm{kcmil}$ aluminum conductor and an insulation wall of 1.050 inches. A cross-sectional drawing of the cable is shown in Figure 5.I.

The two lengths measuring 575 feet and 530 feet were subjected to a $250 \mathrm{kV}$ ac Withstand Test of 5 minute duration and both successfully withstood the test. The 530 foot length was further subjected to a dc Test of $730 \mathrm{kV}$ dc and suffered four successive failures at, or slightly below the desired potential level. It was then decided to abandon that length of cable since any future work would be viewed with suspicion, having successfully withstood the desired ac potential but constantly failing the desired de potential level. Simultaneously, the length measuring 1260 feet was subjected to an ac voltage of $250 \mathrm{kV}$ and it failed after 2.5 minutes into the test. After removal of the failed section, the remaining portions were tested and both failed either at or slightly below the $250 \mathrm{kV}$ ac level.

At that point, the decision was made to abandon any future attempts at testing and to re-schedule a new production run of 2000 feet.

All failed sections were examined microscopically and all failures were attributed to the conductor shield imperfections noted. It was anticipated that corrections for the defects would be achieved through modifications in the manufacturing processes and no changes in the basic design were being considered. 


\subsection{SECOND MANUFACTURING RUN}

The second manufacturing run of cable was attempted in December of 1975. Although it was known that the causes of failure in the first cable manufactured were attributable to imperfections in the conductor shield, there was not a full appreciation of the existing problem at that time. The technique of analysis employed was in cutting a short sample of the cable into a continuous helix, with adjacent wafers approximately .025" thick, and examining the wafers for degree of conductor shield disturbances. This technique provided an appreciation of the degree of amplitude in the radial direction but failed to consider the axial dimension. When the practice was started of looking at this interface with the sections cut longitudinally rather than in helical wafers, it revealed streamers of semiconducting material that were broken away from the main body of the extruded conductor shield and separated from it by a thin layer of insulation. Under further microscopic examination, it was found that the surface of the extruded semiconducting layer was not smooth. There appeared to be a gentle waviness with some kind of regular periodicity. These high spots were causing excessive stresses within the primary insulation wall and were considered responsible for the voltage failures.

A review of the manufacturing process with respect to machine speeds, compound, and extruder temperatures indicated that the most likely cause for the problem was related to the flow of compound through the extruder head. A small modification was made to the cable design. The thickness of the extruded semiconducting conductor shield was increased to .100 inches from its original thickness of .060". It was felt that this increased wall would provide a more stable process operation by allowing higher operating speeds in the tandem extruder being used to apply the layer. In addition, a considerable number of measurements were made on the extruder system in the belief that this also might be contributing to the faulty condition. Although some minor adjustments were made, it was concluded that the major portion of the problem did not lie in the machine itself but rather in the process. Nevertheless, prior to the start of the second run, all possible precautions were taken to assure that the root cause of the problem did not exist in the extruder system itself but rather in the process. Parameters such as movements of one portion of the system with respect to a baseline were carefully examined during the start-up operation after the extruder system components had been optically aligned prior to start-up. The start-up operation confirmed the fact that movement in any direction was minimal and that if the strand shield problem still existed that it would be due to other causes. The condition of the semi-conducting strand shield was excellent after application with only very minute specks appearing on the surface. It was felt that this would be a totally acceptable condition if the surface were to remain in that state. There appeared to be no rubbing or chafing on the main extruder head tooling and it seemed as though that run would achieve a fair degree of success. After approximately 500 feet had been manufactured, that length was cut. 
The insulation/conductor shield interface appeared significantly rougher than desired. The run was cut again after 1000 feet and also after 1500 feet had been made and the surface condition at the interface seemed to be getting progressively worse. At that point it was decided to abort the effort.

Before securing the machine, some work was done to see if it could be determined if the conductor shield deformation was taking place as a result of the conductor rubbing on the extruder tooling as it passed through the head. By shutting down the main extruder and running the tandem extruder so that only the conductor semi-conducting layer was being applied, the cable was drastically buffeted within the main extruder head. It was found that the applied layer could withstand significant movement without experiencing damage to the degree witnessed in the finished product. This led to the conclusion that some other phenomenon was being experienced and that the cause of the problem would have to be resolved by other means.

\subsubsection{ELECTRICAL TESTING}

A systematic investigation was made of the condition of the semiconducting conductor shield considering both the radial and axial dimensions. The same general condition was found as was observed in samples of the first cable run. An 80 foot length of the cable was assembled for corona testing with the following results.

\section{TABLE 5.I PARTIAL DISCHARGE VALUES OBTAINED ON SECTION OF 230kV CABLE 80 FEET IN LENGTH. SECOND PRODUCTION RUN.}

$\begin{array}{cccl}\begin{array}{c}\text { Applied Voltage } \\ (\mathrm{kV})\end{array} & \begin{array}{c}\text { Percent of Rated } \\ \text { Voltage }(\%)\end{array} & \begin{array}{c}\text { Partial } \\ \text { Discharge }(\mathrm{pC}) *\end{array} & \text { Remarks } \\ 50 & 38 & \mathrm{NM} & \\ 70 & 53 & \mathrm{NM} & \\ 80 & 60 & \mathrm{NM} & \\ 86 & 65 & 13 & \text { Ignition Vol tage } \\ 82 & 62 & \mathrm{NM} & \text { Extinction Voltage } \\ 100 & 76 & 13 & \\ 133 & 100 & 20 & \end{array}$

* The calibration pulse (equal to 5 pico-coulombs per inch) is a reference against which any discernible discharges are compared. Where no visible discharges are evident, the letters NM (notmeasurable) are shown. Measurable discharges are denoted by an actual numerical value. 
The high discharge values tended to corroborate our findings of the existence of defects within the cable system. This was further substantiated when the section of eighty feet in length, was subjected to an ac voltage of $250 \mathrm{kV}$ and failed after 2.5 minutes. Analysis of the faulted section revealed the severe strand shield disturbance and projections of semi-conducting materials from the strand shield into the main body of the insulation.

\subsubsection{VISUAL ANALYSIS IN THE AXIAL DIMENSION}

A section of the cable, two feet long, was next set up in a lathe and most of the main insulation was machined away from the section about 10 inches long. The remaining material was machined off in .005 "layers until the highest point in the extruded semi-conducting conductor shield was exposed. Layers were then removed in thicknesses of .0025 " so that a reasonably good idea of the degree of roughness could be formed by gradually exposing the black semiconducting compound and contrasting it against the white color of the main insulation and by noting the thickness of white insulation remaining between the machined surface and the constructed interface.

Samples of the material were then immersed in hot silicone oil and the insulation allowed to stabilize at the $150 \mathrm{C}$ temperature of the hot oil. At this temperature, the insulation becomes transparent while still remaining intact. After examining several samples in this manner, two conditions were found to exist. The first was a longitudinal abrasion largely restricted to a section of the circumference of the cable. The second condition observed was a rippled and folded effect that completely encircled the conductor shield. It was first believed that the former condition was caused by the cable rubbing on the extruder tooling while the second condition was caused by the hot semi-conducting compound being softened as it transited the head in the main extruder and being moved as it interfaced with the main insulation entry into the head. As mentioned earlier, testing was performed at the conclusion of production run number two which seemed to exclude the possibility of damage due to rubbing or chafing of the conductor against the extruder tooling. It is now felt that both conditions observed were the result of a single occurrence related to thermal softening and relative velocities of the materials as they interfaced in the extruder head.

Our analysis finally led us to conclude that a higher deformationresistant material was required for the semi-conducting conductor shield. In February of 1976, a third production run of 2000 feet of cable was started. A change was made from Union Carbide 0590 compound to Uniroyal \#TPR-065 compound for the conductor shield material (REFERENCE 5.3).

\subsection{THIRD MANUFACTURING RUN}

The same precautions were taken in this manufacturing run as for the \#2 
run. It was necessary to make several modifications to the tandem extruder material delivery system to deliver the TPR compound to the tandem extruder head. The extrudability of the TPR compound was first tested and found to be acceptable. Special precautions were required since head temperatures were in the range of $232 \mathrm{C}$, significantly higher than temperatures used for extruding polyethylene. The surface of the semi-conducting TPR compound was shiny and relatively uniform but a graininess was noted which was improved but not totally eliminated by a minor change in the temperature profile of the extruder. The production run was then started and closely monitored. When the conductor core exited the vulcanizing tube, samples were cut for examination of the interface between the extruded semiconducting conductor shield and the insulation. Observation of the conductor shield/insulation interface, after this change was made, revealed a substantial improvement of the surfaces. In essence, the surface condition of the extruded semiconducting materials exiting the main extruder head was substantially the same condition as when entering the head. The problem of interfacial disturbances which caused troublesome interfacial undulations, streamers, and protrusions to occur was no longer present. Since new materials had been used, it was deemed prudent to investigate the interfacial adhesion between the semi-conducting and insulating materials. A firmly bonded surface is important to avoid the possibility of gaseous voids forming which in turn could produce discharges and possibly destroy the cable under operating conditions.

The first checks of interfacial bond revealed that little or no bond existed at the interface. The cable core at this time, however, possessed little or no cure since it was early in the production run. When samples were taken from a section of cable that had received a full time period under the specified steam pressure of 150 pounds per square inch, it was found to possess a measurable bond. The steam pressure was then increased to 250 pounds per square inch and measurements of adhesion were found to be in the same general range. In all, approximately seven hundred feet of cable was run, 500 at the 150 pounds per square inch pressure and 200 at the 250 pounds per square inch pressure. After the run of cable was completed samples were taken at various points in the run and the interfacial bond was again checked and found to be at a tolerable level. Since no prior data was available as to what constitutes a tolerable level it was felt that measurements would be acceptable if the force exceeded 10 pounds per inch of width. In all, about 400 feet of cable was finally selected, in one continuous length for processing through the finishing manufacturing process. The balance of the manufacturing run was scrapped. The large amount of waste was a result of the numerous cuts made for examinations and tests. Concentricity of the separate components of the cable core was found to be very good. Values of the forces measured of the interfacial adhesion are given in TABLE 5.2. The procedure used for testing is given in APPENDIX 5.1. 
TABLE 5.2 ADHESIVE STRENGTH AT INTERFACE OF CONDUCTOR SEMICONDUCTING SHIELD AND PRIMARY INSULATION

AT ROOM TEMPERATURE - 230kV CABLE.

(CABLE SAMPLES FROM PRODUCTION RUN \#3)

$\begin{array}{cccc}\begin{array}{c}\text { Sample } \\ \text { No. }\end{array} & \begin{array}{c}\text { Extrusion Pressure } \\ \text { (psi) }\end{array} & \begin{array}{c}\text { Bond } \\ (\# / \text { in.) }\end{array} & \text { Remarks } \\ \text { I } & 150 & 28-31 & \\ 2 & 150 & 22-26 & \\ 3 & 150 & 15-18 & \\ 4 & 150 & 16-22 & \\ 5 & 150 & 12-20 & \\ 6 & 150 & 21-26 & \\ 7 & 150 & 22-30 & \\ 8 & 150 & 28-32 & \\ & & & \\ \text { IA } & 250 & 20 & \\ \text { IB } & 250 & 10-16 & \\ 2 & 250 & 24-32 & \\ 3 & 250 & 18-24 & \\ 4 & 250 & 17-21 & \\ 5 & 250 & 22-25 & \text { Sample Broke } \\ \text { 6A } & 250 & 18-24 & \text { Sample Broke } \\ \text { 6B } & 250 & 17-23 & \\ \text { 7A } & 250 & 14-19 & \\ \text { 7B } & 250 & 28-35 & \end{array}$

Being satisfied that sufficient bond existed at the interface, it was planned to proceed with electrical testing of a short sample approximately 80 feet in length. The sample successfully passed a corona level test achieving a reading of 3 pico-coulombs at $200 \mathrm{kV}$ with a circuit sensitivity of 5 pico-coulombs per inch of deflection on the Cathode Ray tube of the corona detector. The maximum allowable discharge was 5 pico-coulombs at $200 \mathrm{kV}$ ( $150 \%$ operating voltage). The corona level test was followed immediately by a 5 minute ac voltage Withstand Test at $230 \mathrm{kV}$ which was successfully passed. Finally, the 80 foot section was subjected to a dc voltage Withstand Test of $655 \mathrm{kV}$ positive polarity for 15 minutes and it met this requirement. Additional dc testing was performed to voltages as high as $750 \mathrm{kV}$ dc for sustained periods and it successfully withstood these test levels. 
The remaining section of cable, approximately 320 feet in length, was then completed through manufacturing and subjected to the production proof tests outlined above. The cable satisfactorily met all electrical tests. These tests are summarized in TABLE 5.3, which gives the test results of all tests attempted on the three production runs of cable for comparative purposes. A copy of the test report is included in FIGURE 5.2, along with a copy of the $X-Y$ recording for the partial discharge test, FIGURE 5.3.

Photographs showing the conditions existing at the semi-conducting conductor shield/insulation interface for each production run are given in APPENDIX 5.2. Photos are also shown of the breakdown paths for the first two production runs. 
5.5 REFERENCES TO SECTION 5.0

I. UNION CARBIDE CORPORATION

River Road

Bound Brook, New Jersey 08805

2. NBS HANDBOOK NO. 100

Copper Wire Tables, 1966

National Bureau of Standards

Washington, D. C.

3. UNIROYAL CHEMICAL

Division of Uniroyal Inc.

Elm Street

Naugatuck, Conn. 06770 
TABLE 5.3 ELECTRICAL TESTS PERFORMED ON 230kV CABLE HAVING 1050 MIL WALL CROSS-LINKED POLYETHYLENE INSULATION AND $1000 \mathrm{kcmil}$ ALUMINUM CONDUCTOR

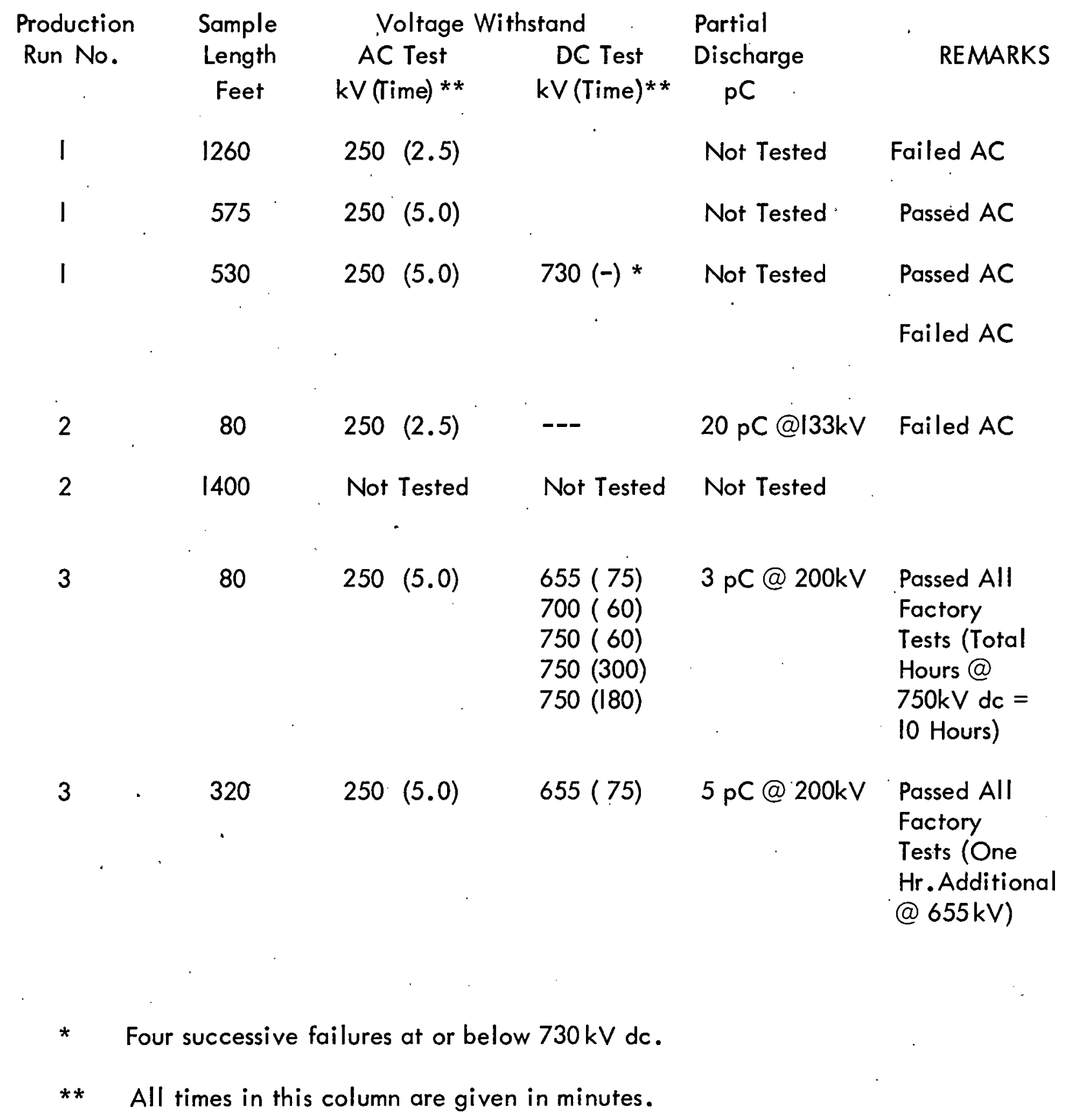




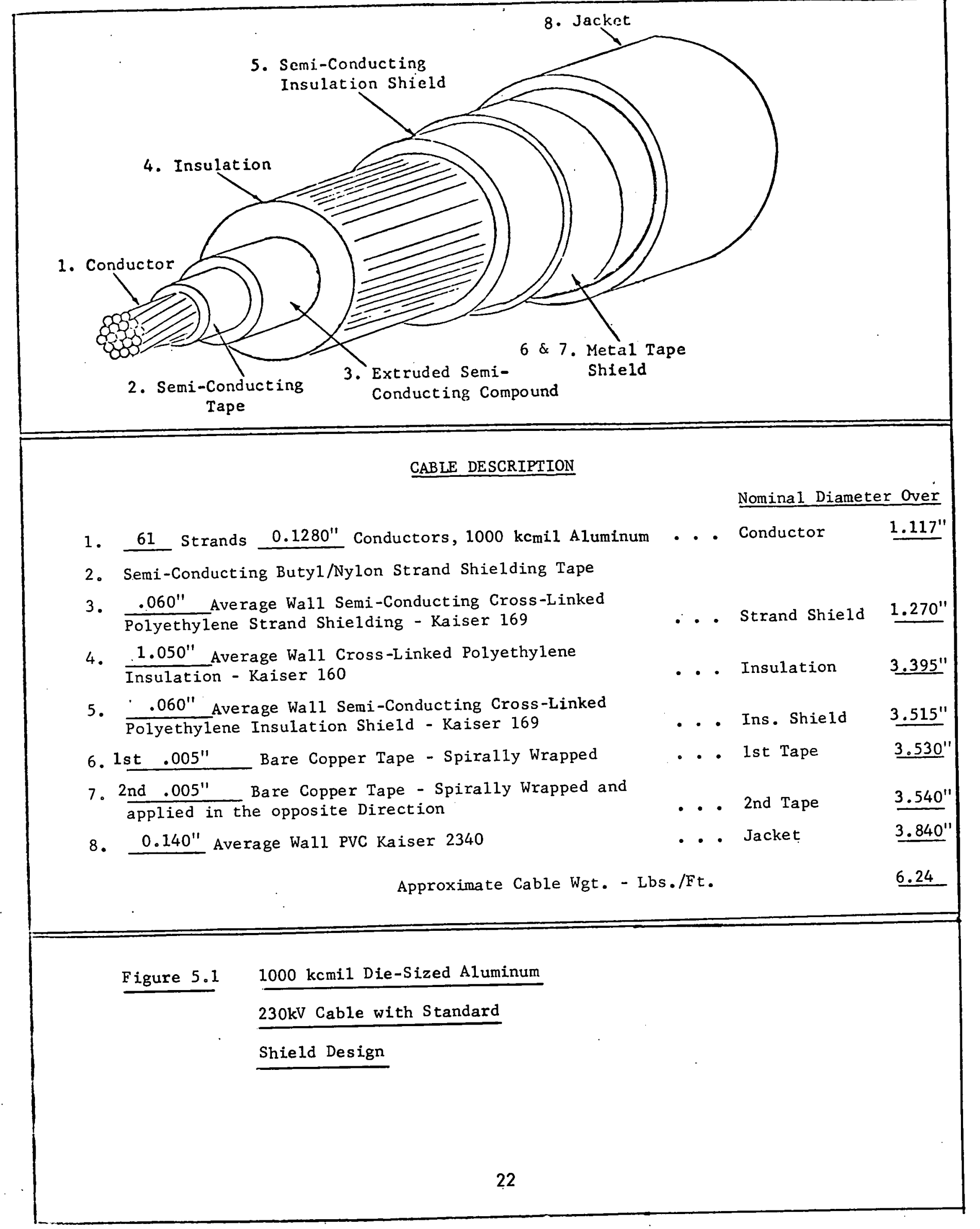


KAISER ALUMINUM \& CHEMICAL CORPORATION

PORTSMOUTH, RHODE ISLAND

FIGURE 5.2

ELECTRICAL TEST REPORT

F.0. 668-789

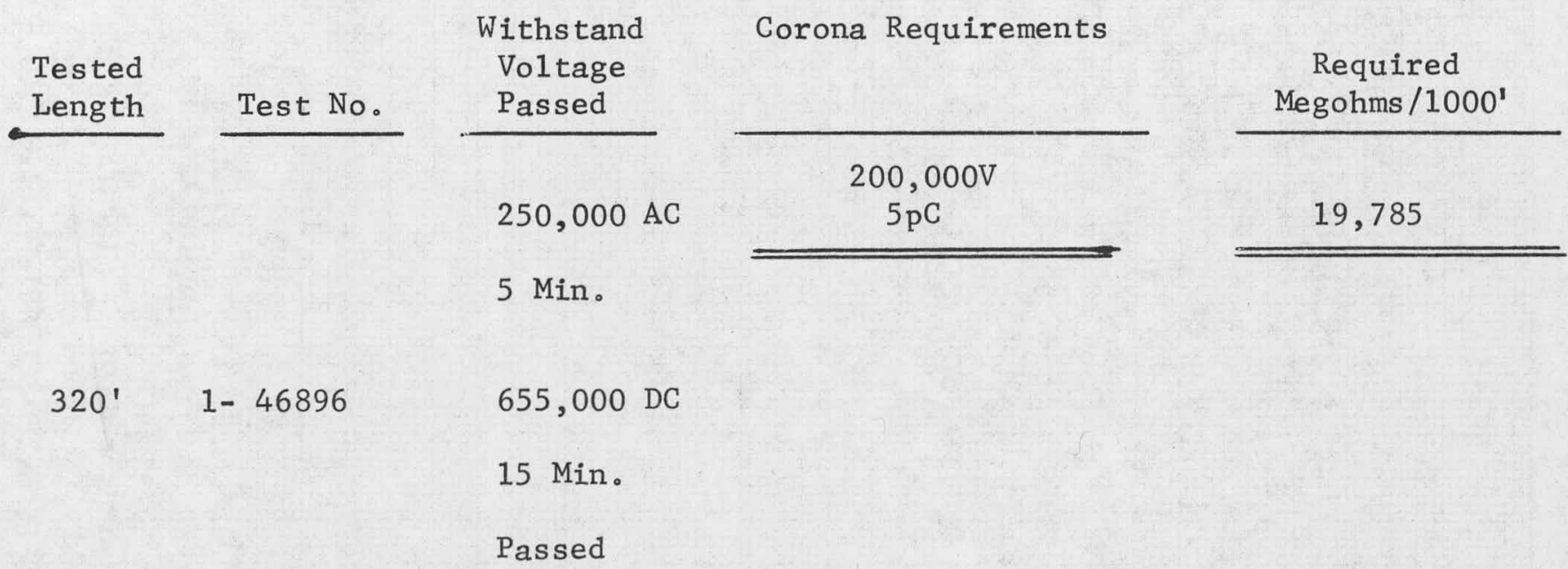




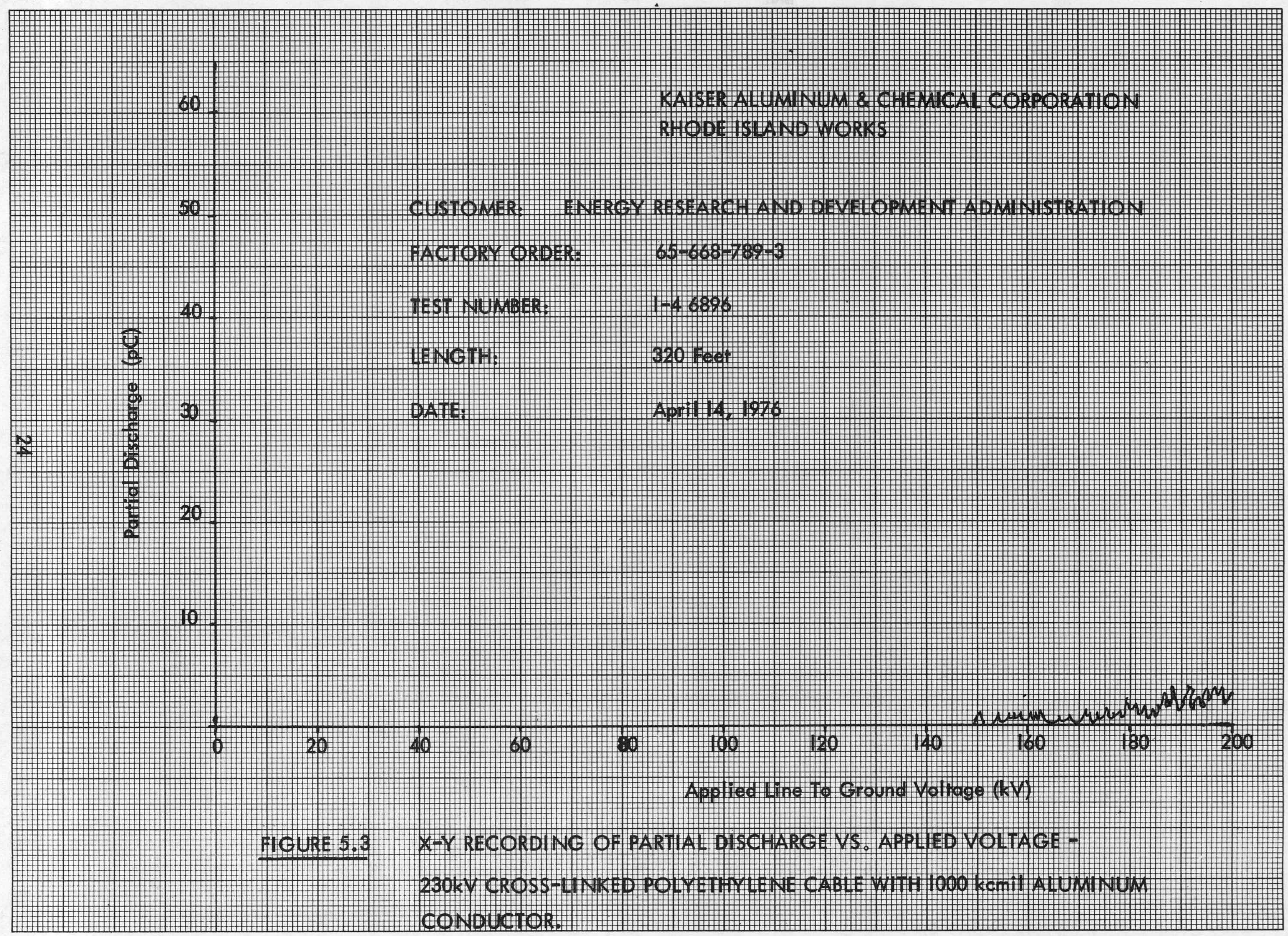


TEST PROCEDURE FOR EVALUATING INTER-FACTAL ADHESION

OF TWO ADJACENT LAYERS

(1) USE A CABLE SAMPLE 12-15 INCHES LONG. PRESS THE CONDUCTOR OUT OF THE CABLE SAMPLE AND DISCARD.

(2) CUT THE CABLE SAMPLE IN HALF, LENGTHWISE, EXPOSING THE SEMICONDUCTING MATERIAL OF THE CONDUCTOR SHIELD.

(3) MAKE TWO CUTS, HALF-INCH APART, IN THE SEMI-CONDUCTING MATERIAL LONGITUDINALLY AND VERTICALLY DOWN TO THE INSULATION.

(4) FOR ATTACHMENT TO A MEASURING DEVICE, REMOVE APPROXIMATELY TWO INCHES OF THE $1 / 2$ INCH STRIP FROM EACH END OF THE CABLE BY PULLING IT AT A $90^{\circ}$ ANGLE AWAY FROM THE CABLE. MEASURE THE PULLING TENSION IN POUNDS BY INCREASING THE FORCE ON THE STRIP UNTIL THE STRIP SEPARATES FROM THE INSULATION AT A SPEED OF APPROXIMATELY $1 / 2$ INCH PER SECOND. PERFORM TWO TESTS AT EACH END OF THE CABLE $180^{\circ}$ APART.

(6) TERMINATE EACH TEST AT CENTER OF CABLE SAMPLE. RECORD MINIMUM AND MAXIMUM PULLING TENSIONS MEASURED AT THE SPECIFIED PULLING SPEED. 
APPENDIX 5.2

\section{PHOTOGRAPHS OF FAILED SECTIONS SHOWING CONDUCTOR SHIELD}

DISTURBANCES

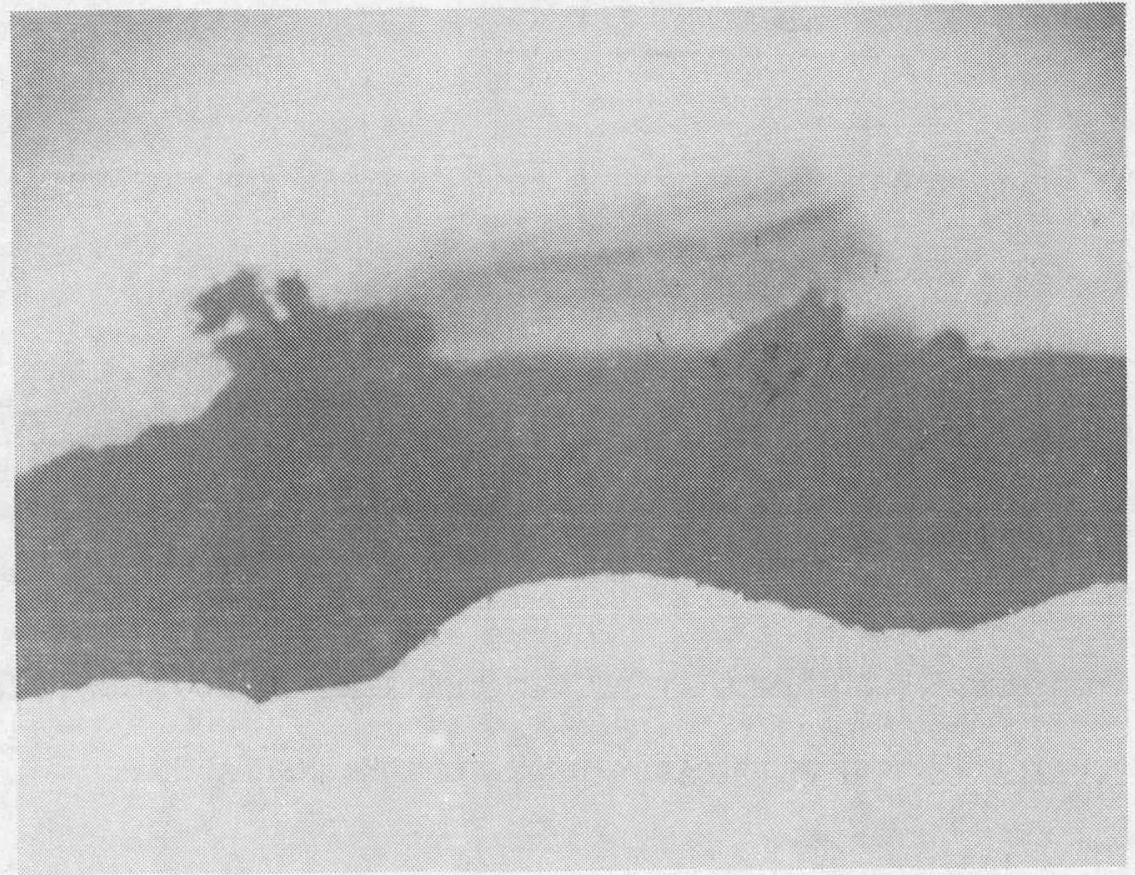

РНОTO 1

RUN 非1: CONDUCTOR SHIELD DISTURBANCE AT INSULATION INTERFACE .

(8x Magnification)

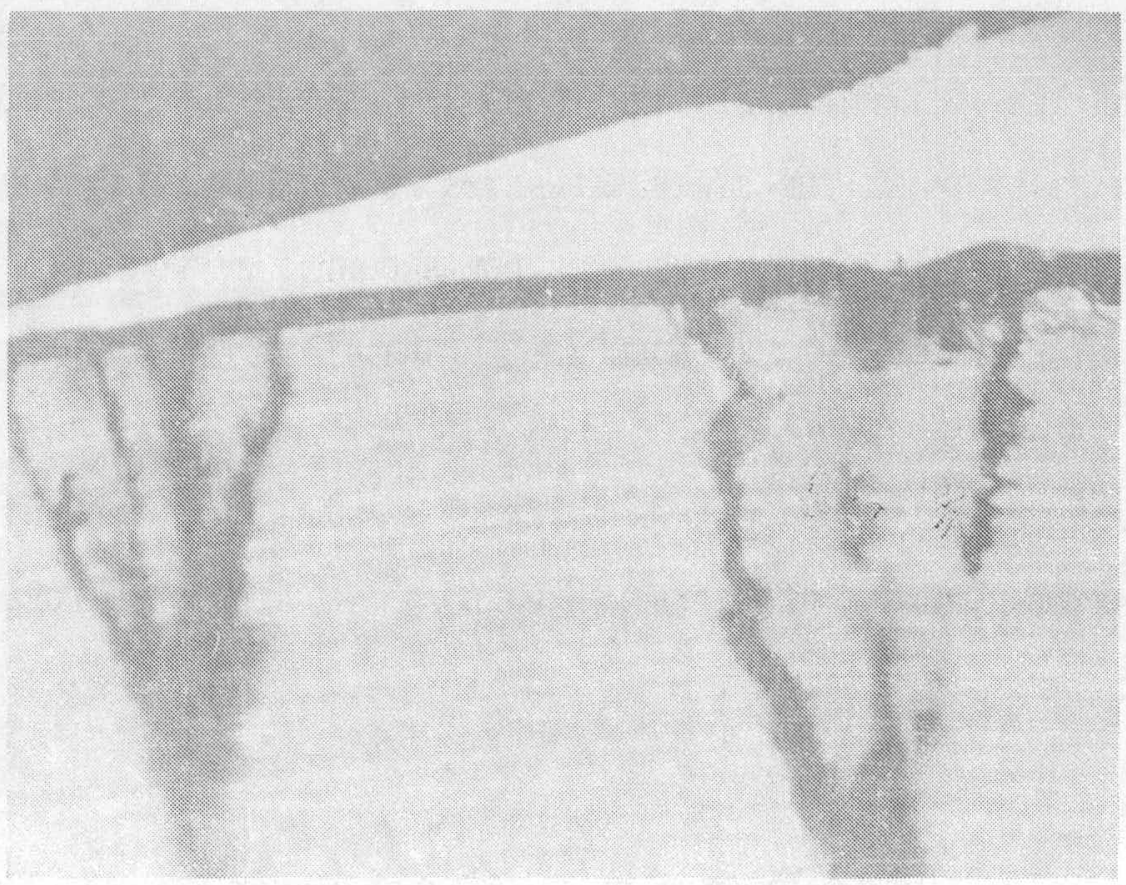

РHOTO 2

RUN 非1: TREE ING

CAUSED BY DC PROOF TESTING SHOWN AT INSULATION SHIELD/ INSULATION INTERFACE ,

DIRECTION OF PROPAGATION IS OUTWARD 。

(8x Magnification) 


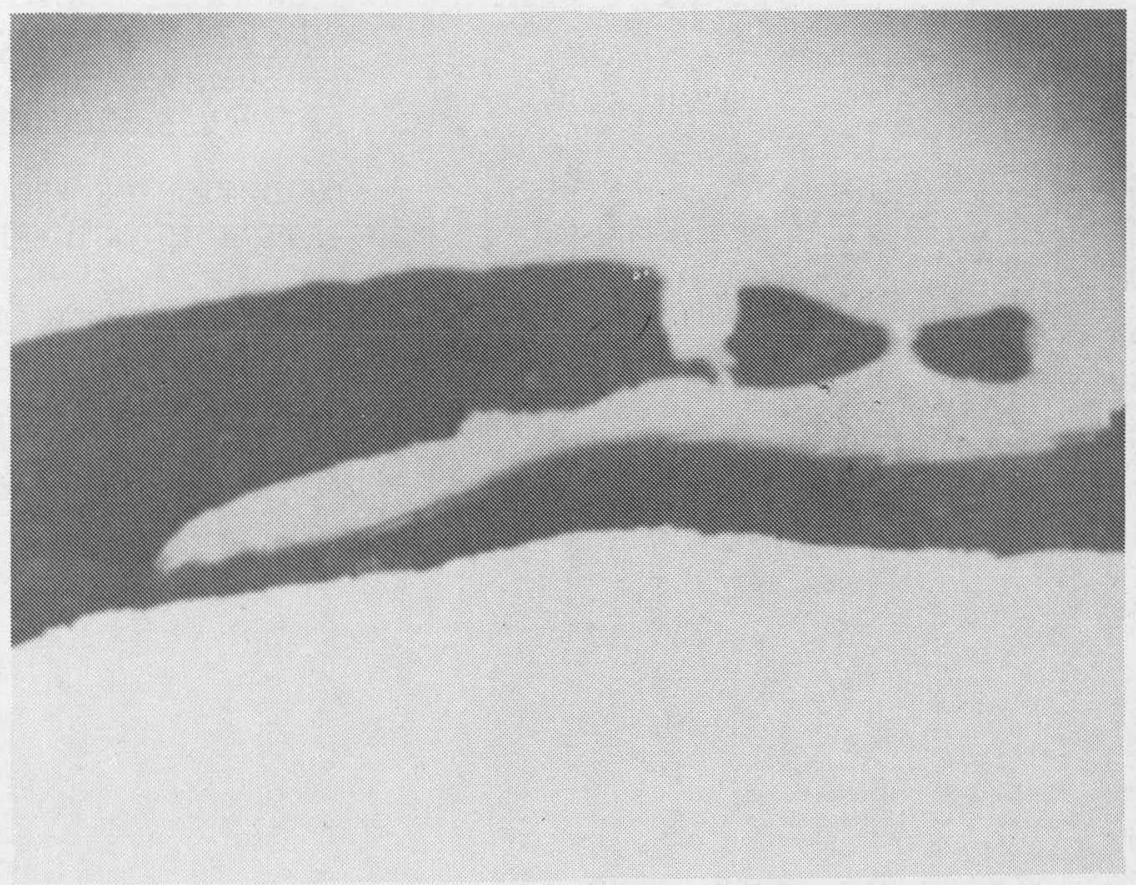

RUN 非: CONDUCTOR SHIELD DISTURBANCES SHOWING MIGRATION OF INSULATION BETWEEN SURFACES OF SEMI-CONDUCTING MATERIALS .

(8x Magnification)

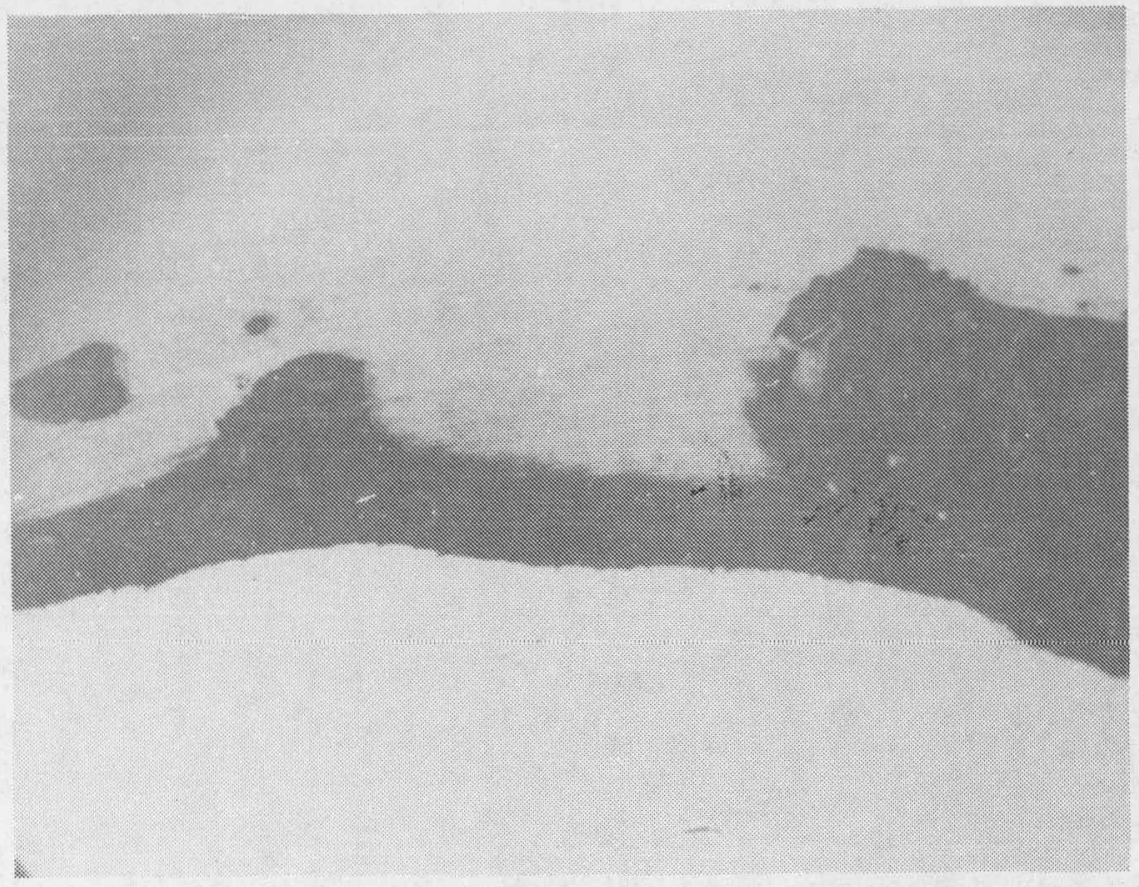

\section{Рното 非 4}

RUN 非2: CONDUCTOR SHIELD DISTURBANCES SHOWING LOOSE PARTICLES OF SEMICONDUCTING MATERIALS .

(8x Magnification) 


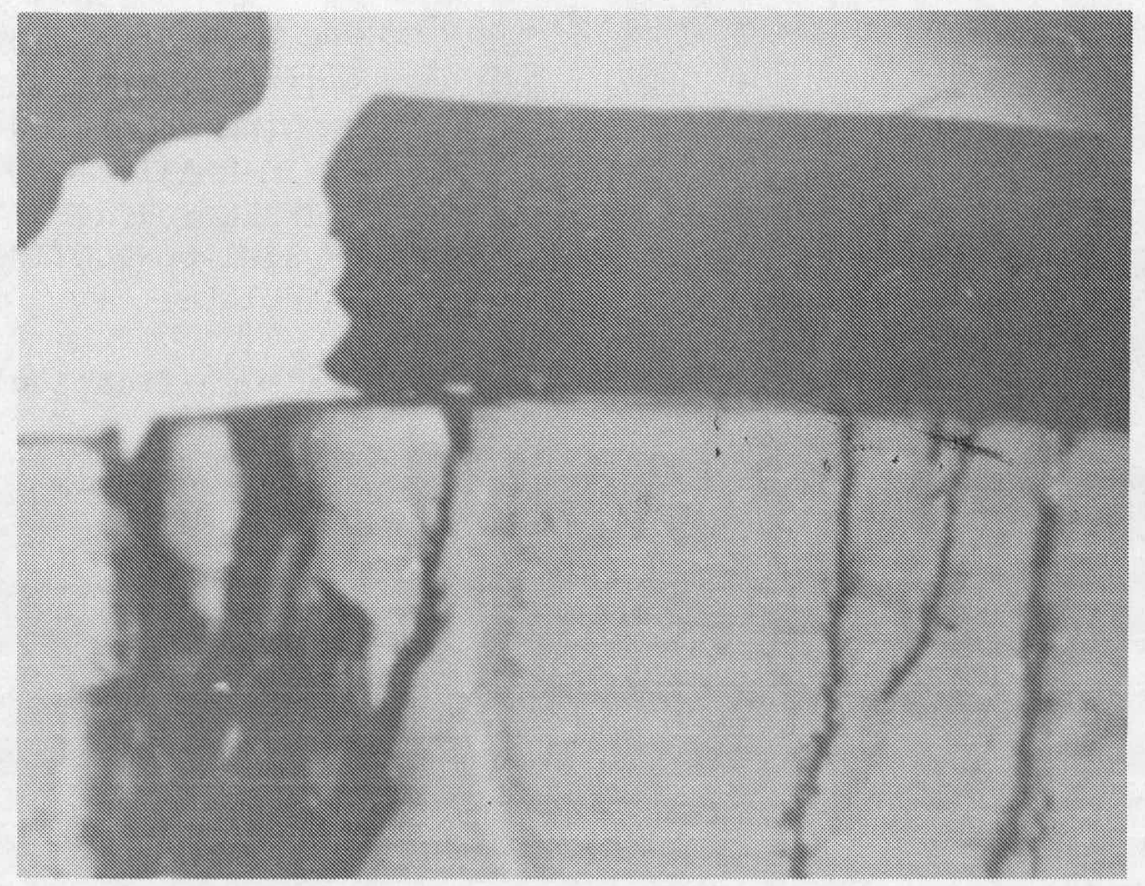

RUN 非2: AC VOLTAGE FAILURE AT $250 \mathrm{kV}$ AFTER 2.5 MINUTES. DIRECTION OF PROPAGATION IS OUTWARD.

INSULATION SHIELD/ INSULATION INTERFACE SHOWN.

(8x Magnification)

PHOTO 非6

RUN 非3: CONDUCTOR SHIELD/INSULATION INTERFACE OF TYPICAL SECTION. CABLE PASSED ALL PRODUCTION PROOF TESTS。

(8x Magnification) 
Upon completion of preliminary factory tests on the approximately 400 feet of completed cable, and after receipt of the terminating components, work began on the preparation of a cable sample for long-term voltage endurance and current cycling. This sample was 70 feet long, which included an allowance of 10 feet for each terminal end, resulting in an active test length of approximately 50 feet.

\section{I CABLE PREPARATION}

Actual cable end preparation involved the removal of the PVC jacket, copper shielding tapes and extruded semi-conducting insulation shield. Stripping dimensions for each component were in accordance with the specifications provided by the terminal suppliers. Considerable care was exercised in the removal of the insulation shield to insure that no physical damage was caused to the insulation. As is our practice, the utilization of knives was kept to a minimum, substituting round files for making circumferential cuts through the insulation shield. This method is employed so as to eliminate the risks of knife cuts in the cable insulation which would, in turn, provide an entrapment for air, resulting in a potential for corona discharges. Open flames were completely avoided as a means of breaking the bond between insulation and insulation shield, in favor of electric heat guns. Therefore, blistering of the insulation did not occur. The final step in preparing the cable ends was to use successively finer grits of aluminum oxide cloth to effect a smooth, highly polished cable insulation surface. The terminations were installed and made operational following the procedures outlined by each manufacturer.

Finally, in preparation for current loading of the cable, aerial lugs were bolted to each terminal connector and a bare $1000 \mathrm{kcmil}$ aluminum conductor installed, effectively closing the loop between the two ends of the cable conductor. This arrangement permitted the more convenient method of inducing desired currents in the cable conductor. In order to prevent the bare jumper cable from emitting corona-like discharges at elevated voltages, the jumper was housed in coupled lengths of 2 inch diameter aluminum pipes. The pipe was expected to provide an effective shield against potential spurious discharges from this bare conductor.

\subsection{EXTENDED 60 HERTZ AND CURRENT CYCLING TEST}

The first electrical tests performed on the cable system were measurements to determine the dissipation factor and capacitance characteristics at several voltage levels. Some instability was noted at $100 \mathrm{kV}$ which was indicative of corona discharge activity. Corona measurements were then made which did reveal massive discharges beginning at approximately $60 \mathrm{kV}$, in the form of air corona. A subsequent scan of the test area with a sonic detector, pinpointed the source of these discharges. The problem was corrected and, thereafter, corona measurements were made up to and including 200kV with no discharges noted. Dissipation factor and capacitance 
measurements were then made at the operating voltage level of $133 \mathrm{kV}$. The results of these initial dielectric measurements are given in TABLE 6.1.

A $60 \mathrm{~Hz}$ proof test was then performed and consisted of the application of $200 \mathrm{kV}$ and $266 \mathrm{kV}$ successively for five minutes each. These voltages represented the $150 \%$ and $200 \%$ operating voltage levels respectively. Following successful completion of the proof test, the system was made ready for initial current loading as follows:

1. Six hours at 945 Amperes followed immediately by

2. Six hours at 1092 Amperes

The given ampere loads were determined through experimentation as those required to raise the conductor temperature to 90 and $130 \mathrm{C}$ respectively. However, because of the physical size and thermal characteristics of the cable, these temperatures could not have been realized in the allotted times. An investigation associated with cable joint development revealed that this construction required somewhat longer periods to stabilize with these ampere loads applied. Due to our concern about the interfacial bond between a relatively unknown semi-conducting material and the cross-linked polyethylene insulation, it was felt that the application of these loads would show a tendency for the two materials to separate if that tendency existed. This initial current loading was done without an applied voltage. The system was allowed to cool for more than twelve hours, then the dielectric measurements were repeated to determine the effects, if any, of the current loading on these cable properties. The results of these measurements are given in TABLE 6.2 and were not suggestive of any significant change.

The system was next energized continuously at operating voltage $(133 \mathrm{kV})$ for $63-1 / 2$ hours, without load. Following these preliminary series of tests, the long-term voltage endurance and load cycling test described by the following, began:

6.2.1 The circuit was load cycled at $125 \%$ of operating voltage (166kV) and $90 \mathrm{C}$ conductor temperature (945 Amperes) for 1 cycle. A cycle was defined as 12 hours of current loading and 12 hours of cooling. Voltage was continuously applied. The voltage was increased to $150 \%$ of operating level $(200 \mathrm{kV})$ while maintaining $90 \mathrm{C}$ conductor loading, for an additional 8 cycles.

6.2.2 The voltage was decreased to $125 \%$ of operating level (l66kV) and current loading was increased to 1092 Amperes, to produce $130 \mathrm{C}$ conductor temperature. Seven cycles were logged under these conditions. 
6.2.3 The voltage was increased to $175 \%$ of operating level $(233 \mathrm{kV})$ and cycled at $90 \mathrm{C}$ conductor temperature (945 Amperes) for II cycles.

6.2.4 The voltage was decreased to $125 \%$ of operating level (166kV) and cycled at $130 \mathrm{C}$ conductor temperature (1092 Amperes) for 8 cycles.

During the course of the load cycling described above, dielectric measurements (dissipation factor, capacitance and corona discharge) were made at frequent intervals. Additionally, temperature measurements of system components and cable shield resistance measurements were conducted. The dielectric measurements were usually done while system was at room temperature. However, dissipation factor and capacitance measurements were made once each while the system was at 90 and $130 \mathrm{C}$ conductor temperature, near the end of the heating portion of the cycle. This permitted us the opportunity to observe the apparent stability of the insulation system relative to a large change in conductor temperature.

No significant changes were noted in the corona discharge characteristics during the course of the test. Five pico-coulombs of discharge was the highest measured at any time, including the one-time measurement at $233 \mathrm{kV}$. These discharges, which varied between a non-measurable value and a maximum of 5 picocoulombs were inconsistent and were believed to have originated outside of the active test system. However, no concerted attempt was made to verify the ultimate source because of the task involved, and the relative insignificance of these discharges at the high voltage levels at which they occurred.

After several cycles at $130 \mathrm{C}$, a significant change occurred in the dissipation factor measurements made at room temperature. During the prior cycling at $90 \mathrm{C}$, the dissipation factor generally ranged between 0.05-0.06\%. However, two successive measuring periods showed the dissipation factor to be increasing noticeably, to a high of $0.11 \%$. It was our suspicion that what we were seeing was not the true cable losses but rather, the effects of a physical change in the cable components as a result of prolonged operation at this high temperature. Specifically, the extruded insulation expands and contracts with significant temperature variations. The extent of the dimensional excursions is a function of the temperature differential; at the $130 \mathrm{C}$ level, this differential is on the order of $105 \mathrm{C}$. This change of $105 \mathrm{C}$ is based on an ambient of about $25 \mathrm{C}$. The insulation expansion causes the surrounding cable components, the copper tapes in particular, to also expand. The extruded cable core through the insulation shield contracts to their approximate original dimensions as the system returns to room temperature. However, 
the contraction of the copper tape is not complete and results in a loose fit around the cable at room temperature. As a result, the contact between semi-conducting. insulation shield and shielding tape is not intimate and the appearance would be that of an increase in the loss angle of the cable insulation.

The preceding was verified by the results of measurements made while the system was at the $130 \mathrm{C}$ level. Here, the values -- although slightly higher than those seen during the $90 \mathrm{C}$ cycling -- were significantly lower than those recorded during the cooling phases of the preceding $130 \mathrm{C}$ cycles. This was verified further by the succeeding room temperature measurement which showed the dissipation factor to have again increased.

The results of dissipation factor, capacitance and corona discharge measurements made during the course of these load cycles are tabulated in TABLES 6.3 through 6.11. Unless otherwise noted, all measurements were made with cable system at room temperature: No provisions were made to allow isolation of the cable or terminals for purposes of determining the dielectric characteristics of any of these three components independently. Therefore all results of dielectric measurements reflect the combined contribution of the cable and each terminator.

A total of 35 current cycles, consisting of 12 hours of current loading and 12 hours of cooling, were logged on this test length. Twenty cycles were with the conductor loaded to achieve $90 \mathrm{C}$, and the remaining 15 cycles loaded for a conductor temperature of $130 \mathrm{C}$. During the course of the test, a voltage was constantly applied except during periods when interruptions were unavoidable. The applied voltage ranged from $100 \%$ of operating $(133 \mathrm{kV})$ to $175 \%$ of operating $(233 \mathrm{kV})$, resulting in an accumulation of approximately 809.5 voltage-hours. A summary of this data is found in TABLE 6.12. 
After completion of the preceding tests described in Section 6.2, the cable length was cut at the approximate mid-point in preparation for installation of a taped joint. The joint - design number $I$ - is illustrated in FIGURE 7.II of Section 7, and the design parameters described in Section 7.1.2.

Following the installation of the joint, the circuit was energized at $200 \mathrm{kV}$ ( $150 \%$ of rated voltage) for 63.5 consecutive hours, with no load applied. Dissipation factor, capacitance and corona discharge measurements were made after concluding the preceding voltage-conditioning period. Included in the design of the joint was a method of interrupting the cable shield at the joint. This discontinuity of the shield effectively permitted the isolation of segments of the circuit, when desired, for dissipation factor and capacitance measurements. These properties therefore, could be measured of the cable joint alone and/or either half of the cable alone. The results of these initial measurements of dissipation factor, capacitance and corona discharge are tabulated in Tables $6.13,6.14$ and 6.18 .

The voltage endurance and current cycling test was resumed and the following was subsequently accomplished during this test sequence:

6.3.1 Sixteen load cycles at a conductor temperature of $90 \mathrm{C}$ (945 amperes) and the following voltage-hours;
a) 20.8 hours@ $@ 133 \mathrm{kV}$ (100\% of rated voltage)
b) 25.4 hours@166kV (125\% of rated voltage)
c) 436.4 hours @ 200kV (150\% of rated voltage)

6.3.2 Sixteen load cycles at a conductor temperature of $130 \mathrm{C}$ (1092 amperes) and the following voltage-hours;

a) 95.8 hours@ $133 \mathrm{kV}(100 \%$ of rated voltage)

b) 291.8 hours @ 166kV (125\% of rated voltage)

6.3.3 Twenty load cycles at a conductor temperature of $90 \mathrm{C}$ (945 amperes) while energized at $200 \mathrm{kV}$ (150\% of rated voltage) for 468.3 hours (culmination of testing).

The foregoing test history is summarized in Table 6.23. Additionally, during the course of the test, dissipation factor, capacitance and corona discharge 
measurements were made at various intervals. The results of these measurements are tabulated in TABLES 6.15 through 6.17 and 6.19 through 6.22. FIGURES 7.20A and 7.20B of SECTION 7.I.3 are graphs of the joint's dissipation factor profile at 90 and $130 \mathrm{C}$ conductor temperature, respectively. These plots reflect measurements' that were made at regular intervals over an extended number of hours, during the transition from room ambient to the desired temperature. Finally, all of the data collected indicated that the joint was compatible with the cable and exhibited good operating stability under accelerated voltages and load currents.

\subsection{IMPULSE VOLTAGE WITHSTAND TEST}

A sample with an active test length of 19 feet - exclusive of terminal ends - was prepared for impulse testing as required by IEEE Standard No. 82, Test Procedure for Impulse Voltage Tests on Insulated Conductors (REFERENCE 6.I). This sample had previously been subjected to prolonged periods of dc testing at voltages up to $750 \mathrm{kV}$ dc. Those tests were reported in TABLE 5.3 and SECTION 5.3. Terminating of the sample was effected by using a taped, resistancegraded method, eliminating the need for the more involved conventional porcelain terminals.

A test sequence was adopted which was somewhat more extensive in scope than the requirements of Standard No. 82. Basically, the impulse test is defined by a waveform having a front (or rise-time) of $1-1 / 2$ microseconds, and a duration (or tail) of 40 to 50 microseconds. The established Basic Insulation Level (BIL) for the $230 \mathrm{kV}$ cable is $1050 \mathrm{kV}$. Standard No. 82 requires that three surges be applied to the test specimen at each voltage level, commencing at $75 \%$ BIL, then $100 \%$ BIL and, thereafter, increasing the voltage in 10 percent BIL steps until a breakdown occurs. The polarity of the impulse wave can be either negative. or positive, at the discretion of the tester. For our tests, this procedure was modified upward by increasing the number of surges applied to five at each voltage level, and using both polarities, for a total of 10 impulses at each voltage level.

Cable breakdown was not established as the objective of this test. Instead, successful completion of the $125 \%$ BIL level (I3I3kV) was the desired objective set for the cable. Sequentially, the test plan was outlined as follows:

6.4.I Impulse the sample with the conductor at room ambient temperature, applying 5 negative and 5 positive waves at $75 \%$ BIL $(788 \mathrm{kV}), 100 \% \mathrm{BIL}(1050 \mathrm{kV})$ and negative waves at $125 \% \mathrm{BIL}$ $(13 \mid 3 k V)$.

6.4.2 Current-load the sample to achieve and sustain a conductor temperature of $90 \mathrm{C}$ ( 945 amperes) and repeat the test of 6.4.1. 
6.4.3 Install a taped joint (design \#I) as described by FIGURE 7.II of SECTION 7. Repeat the test of 6.4.1 above with the cable conductor at room ambient temperature, except discontinue impulsing after completing the $100 \%$ BIL level.

6.4.4 Current-load the sample to achieve and sustain a conductor temperature of $90 \mathrm{C}$ (945 amperes) and repeat the test sequence of 6.4 .1 , except continue beyond the $125 \% \mathrm{BIL}$ level, increasing the voltage in approximate $10 \%$ BIL steps, until a cable, joint or terminal failure occurs.

Following the procedure described by the foregoing, the first test resulted in a terminal failure on the 3rd negative impulse at the $125 \%$ BIL level. The failure occurred prior to performing the positive polarity series at that level. Because of the short length, and the completeness of the failure, this sample could not be re-terminated and submitted to further testing. The conduct of this test is summarized in TABLE 6.24.

A second cable sample with an active test length of 25 feet was prepared for testing. This sample was taken from the reel previously identified as containing 320 feet of cable (SECTION 5.0, TABLE 5.3). This sample successfully passed the room temperature impulse test as outlined. Subsequently, this sample was current-loaded for a conductor temperature of $90 \mathrm{C}$ and that test sequence began. A cable failure occurred in the active length on the first acceptable impulse at BIL $(1050 \mathrm{kV})$. Analysis of the failed section was done by immersing the approximately 6-inch sample (of the area surrounding the fault), in hot silicone oil and visually examining the resulting transparent insulation wall, and the clearly visible strand shield surface. The failure was directed from conductor to insulation shield, as determined from the dendritic structure of the fault. A pimple-like deposit was discovered on the strand shield surface some distance away from, but in-line with, the fault. This deposit was identified as semi-conducting material and although it could not have been related to the eventual failure, it was considered possible that another such imperfection may have been present at the fault site. The strand shield surface was otherwise smooth and no other defects were visually evident. This test sequence is summarized in TABLE 6.25.

The taped joint was installed in this second cable sample and impulsed with the conductor at room temperature. As outlined, this test sequence was not to go beyond BIL. Having successfully passed this test, the sample was current-loaded to $90 \mathrm{C}$ conductor temperature and impulse tested. The joint sustained a fault on the third acceptable negative impulse at BIL. The positive impulse series had not been accomplished. The test is summarized in TABLE 6.26. Subsequently, the joint was cut out, dissected and examined. A discussion of the joint breakdown is con- 
tained in SECTION 7.1.3. Finally, throughout these impulse tests, those surges whose magnitude were not within approximately $10 \mathrm{kV}$ of the particular voltage level desired, were considered unacceptable and not counted in the 5-surge series. However, these surges were recorded for informational purposes.

\subsection{CABLE SHIELD RESISTANCE MEASUREMENT S}

Prior to installing the joint in the test cable circuit, two sets of shield resistance measurements were taken. These measurements coincided with the end of 90 and $130 \mathrm{C}$ cycles respectively. The initial measurements - corresponding to both a 90 and a $130 \mathrm{C}$ cycle - were taken over a one-hour period, starting at the instant the respective heating phase ended. It was apparent, however, that due to the slow cooling rate, a one hour time span was not sufficient to produce significant resistance changes. Consequently, these tests were repeated at intervals during a six hour period.

The results of the six hour measurements suggested relative resistance stability with respect to the temperature differences. The resistance data are summarized in TABLES 6.27 and 6.28. FIGURES 6.1 and 6.2 are plots of these data.

\subsection{CABLE COMPONENTS TEMPERATURE MEASUREMENTS}

Temperature measurements of the various system components were made primarily to insure that no potential thermal run-away conditions existed during periods of conductor loading. In every instance, the components monitored were at temperature levels that were reasonable in relation to the prevailing conductor temperature. For informational purposes, these data are tabulated in TABLE 6.29.

\subsection{VOLUME RESISTIVITY MEASUREMENTS}

Samples taken from both the virgin cable and the test length which had undergone the Extended $60 \mathrm{Hertz}$ and Current Cycling Tests (SECTION 6.2), were prepared and tested in accordance with the procedure of IPCEA Publication S-66-524, IPCEA-NEMA Standards publication Crosslinked-Thermosetting Polyethylene-Insulated Wire And Cable for the Transmission And Distribution of Electric Energy (REFERENCE 6.2). Samples were taken from the test length upon completion of the first test sequence, preparatory to cutting in the taped joint.

Volume resistivity is a measure of the relative resistance stability of a semi-conducting material, at various temperatures over an extended period of time. Although industry standards refer primarily to maximum allowable 
resistivity values, it is equally important that the resistance achieve a degree of stability at the respective test temperature. Similarly, the time required to achieve that stability is a measure of the materials' uniformity.

In accordance with the IPCEA specifications referenced above, the tests involved samples of the insulation shield and the strand shield. The insulation shield sample was approximately 6 inches long -- in completed form, with the conductor, copper shielding tape and the outer coverings removed, exposing the semi-conducting insulation shield. Silver conducting paint was applied in 4 narrow annular bands around the cable sample's circumference and spaced apart as specified by the test standards. The silver paint served as electrodes to which measuring leads from the resistance bridges, were attached. The strand shield sample was prepared by removing the conductor and all outer coverings, exposing the insulation surface of a whole six inch long sample. This sample was then halved longitudinally and the half to be tested prepared by painting electrodes across the strand shield, resulting in half-annular rings to which measuring leads were connected.

After samples were properly prepared, initial resistance measurements were made while the samples were at room ambient temperature. Then, the insulation shield samples were placed in 90 and $110 \mathrm{C}$ circulating air ovens. Similarly, strand shield samples were placed in 90 and $130 \mathrm{C}$ air ovens. After 24 hours at the given temperature, resistance measurements were made, and thereafter, at regularly scheduled intervals during the course of the tests. Table 6.30: gives the results of these tests which spanned a period of 49 days. Shown are volume resistivities in ohm-centimeters, derived through the application of the following formulae:

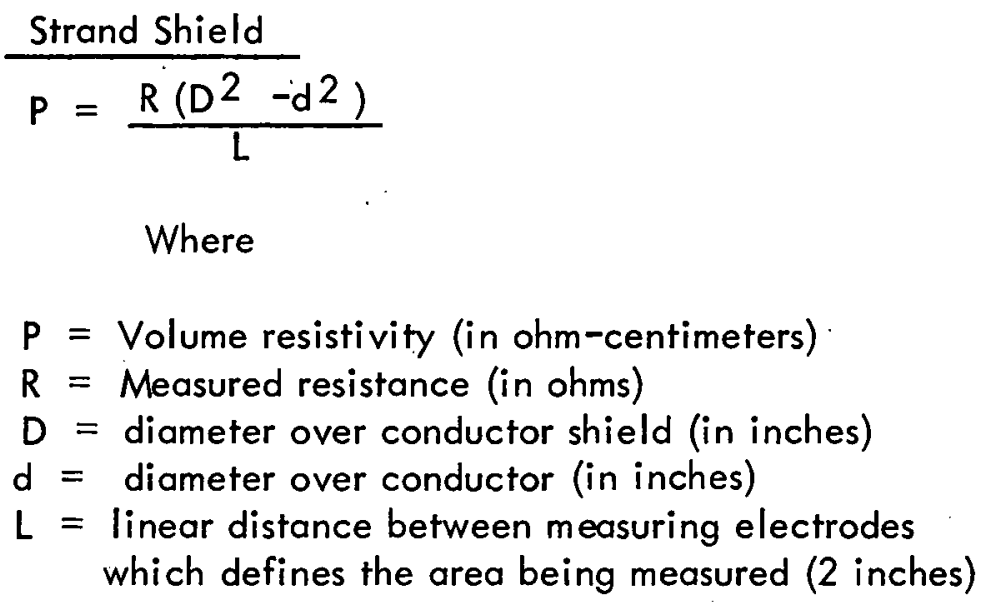




$$
\begin{aligned}
& \text { Insulation Shield } \\
& \begin{array}{l}
P=\frac{2 R\left(D^{2}-d^{2}\right)}{L} \\
\text { where } \\
P=\text { Volume resistivity (in ohm-centimeters) } \\
R=\text { Measured resistance (in ohms) } \\
D=\text { diameter over insulation shield (in inches) } \\
d=\text { diameter over insulation (in inches) } \\
L=\text { Linear distance between measuring electrodes which }
\end{array}
\end{aligned}
$$

The values representing the maximum allowable resistivities are included below TABLE 6.30. The samples tested were well within the specified limits and exhibited good stability. Some divergence from a smooth unidirectional trend in resistivities occurred with all except the $110 \mathrm{C}$ samples on the 28th day measurements. However, that reversal was directly attributable to a power outage which interrupted these tests for an approximate 9 hour period, on the 27 th day. The fact that the low values achieved through the 2 lst day measurements were never achieved again over the remainder of the tests did not detract significantly from the overall excellent results. No explanation is offerred for the apparent lack of repeatability noted here.

Finally, the strand shield was tested to the requirements of thermosetting materials, although it was not in fact a thermoset. A discussion of the strand shield material is included in SECTION 5.4.

\subsection{SOLVENT EXTRACTION TESTS}

Thermoset (or crosslinked) polyethylene insulating and semiconducting materials, differ from thermoplastic polyethylene materials in several ways. The most notable difference results basically from the processing techniques employed. Through the introduction of an additive (catalytic agent), heat and pressure, a chemical bonding takes place between the molecular chains of the polyethylene compound. An infusible, insoluble super-molecular chain is formed; the polyethylene material has been crosslinked. Higher temperature resistance, higher bond density and increased rigidity are some of the advantages thermoset compounds offer. 
The extent to which crosslinking can be achieved during the manufacture of solid extruded dielectric cables with crosslinkable compounds, can vary from one manufacturing run to another. Indeed, it can vary within a given manufacturing run if any of several variables (i.e. heat, pressure, etc.) changes during processing. However, testing methods have been devised and rigid standards established, that permit the rather accurate determination of the degree of cure - by selective sampling - achieved.

The test standard by which crosslinked polyethylene (XLPE) cable insulations are judged, is ASTM D2765-68 Standard Methods of Tests For Degree of Crosslinking In Crosslinked Ethylene Plastics As Determined By Solvent Extraction (REFERENCE 6.3). Three alternative methods are offered, of which Method $B$ is most commonly used, and was the method selected for these tests, the results of which are shown in Table 6.31.

The test results were consistent with those ordinarily seen in typical extractions on properly cured cables. For informational purposes, the thermoplastic strand shield was also submitted to the solvent extraction test -which is applicable to thermoset materials only. However, the strand shield passed the requirements set by the AEIC No. 5-75 Specifications For Polyethylene And Crosslinked Polyethylene Insulated Shielded Power Cables Rated 5 Through 69kV (REFERENCE 6.4).

\subsection{TEST EQUIPMENT USED}

The following are the major pieces of equipment used during the conduct of these tests:

1. Haefely 1000kV, 2 MVA ac Transformer

2. Haefely $3200 \mathrm{kV}, 160 \mathrm{~kJ}$ Impulse Generator

3. Kaiser Model I6kVA Load Cycle Consoles with Hipotronics split-core Current Transformers

4. Hartmann \& Braun Compressed Gas. 500kV Standard Capacitor

5. General Electric 3-Stage Blocking Capacitor

6. General Electric "Direk Read" Dissipation Factor/ Capacitance Bridge

7. F. C. Robinson's ERA Corona Discharge Detector

8. Hewlett-Packard Model 49I7A Ultrasonic Detector

9. J. G. Biddle portable Kelvin Bridge

10. Thermo Electric Multimite Digital Thermometer

II. J. G. Biddle portable Wheatstone Bridge

12. Textronix Model 507 High Voltage Surge-Test Oscilloscope 
1. . IEEE Std. 82. Test Procedure for Impulse Voltage Tests On Insulated Conductors. The Institute of Electrical and Electronics Engineers, Inc., New York, N.Y.

2. IPCEA Pub. No. 5-66-524/Nema. Pub. No. WC 7-|97|. IPCEA-Nema Standards Publication Crosslinked-Thermosetting Polyethylene-insulated Wire And Cable for the Transmission And Distribution of Electric Energy. National Electrical Manufacturers Association, New York, N.Y.

3. ASTM D 2765-68. Standard Methods of Test for Degree of Crosslinking in Crosstinked Ethylene Plastics As Determined By Solvent Extraction. American Society For Testing And Materials, Philadelphia, Pa.

4. AEIC No. 5-75. Specifications For Polyethylene And Crosslinked Polyethylene Insulated Shielded Power Cables Rated 5 Through $69 \mathrm{kV}$. Association of Edison Illuminating Companies, New York, N.Y. 
TABLE 6.1

\section{PRELIMINARY DIELECTRIC MEASUREMENTS}

a) Voltage, Diss.Factor, Capacitance, Sensi- Attenua- Corona Dis$\mathrm{kV} \%$ Farads tivity* tion, $\mathrm{db}^{* *}$ charge, $\mathrm{pC} * * *$

$\begin{array}{lllll}50 & 0.066 & 2.4578 \times 10^{-9} & 12 & 67 \\ 75 & 0.066 & 2.4578 & 12 & \begin{array}{c}\text { Inception of } \\ \text { massive air corona. }\end{array} \\ 100 & 0.068 & 2.4579 & 12 & \end{array}$

b) Voltage, Attenua- Corona Dis- Diss.Factor, Capacitance, Sensi$\mathrm{kV}$ tion, $\mathrm{db} *$. charge, $\mathrm{pC} * * *$ Farads tivity *

\begin{tabular}{|c|c|c|c|c|c|}
\hline 50 & 67 & NM & -- & -- & -- \\
\hline 75 & 67 & NM & -- & - & -- \\
\hline 100 & 67 & NM & -- & -- & -- \\
\hline 133 & 67 & NM & 0.065 & $2.4614 \times 10^{-9}$ & 12 \\
\hline 170 & 67 & NM & -- & -- & -- \\
\hline 200 & 67 & NM & -- & -- & -- \\
\hline
\end{tabular}

* Refers to the sensitivity of the Dissipation Factor/Capacitance Bridge, which ranges from 0 to 12 . The maximum sensitivity corresponds to a detector sensitivity of I microvolt and dissipation factor resolution of $\pm 0.002 \%$.

** Refers to the Corona Discharge Detector, and defines the attentuation required to establish a sensitivity of 5 pico-coulombs $(\mathrm{pC})$ per inch.

*** The calibration pulse (equal to 5 pico-coulombs per inch) is a reference against which any discernible discharges are compared. Where no visible discharges are evident, the letters NM (not-measurable) are shown. Measurable discharges are denoted by an actual numerical value. 


\section{TABLE 6.2}

DIELECTRIC MEASUREMENTS AFTER INITIAL

CURRENT-LOADING AT 90 AND $130 \mathrm{C}$

$\begin{array}{cccccc}\begin{array}{c}\text { Voltage, } \\ \text { kV }\end{array} & \begin{array}{c}\text { Diss. Factor, } \\ \%\end{array} & \begin{array}{c}\text { Capacitance, } \\ \text { Farads }\end{array} & \begin{array}{c}\text { Sensi- } \\ \text { tivity * }\end{array} & \begin{array}{c}\text { Attenua- } \\ \text { tion, db*** }\end{array} & \begin{array}{c}\text { Corona Dis- } \\ \text { discharge,pC*** }\end{array} \\ 200 & 0.068 & 2.4473 \times 10^{-9} & 12 & 67 & \mathrm{NM} \\ 166 & 0.065 & 2.4472 & 12 & 67 & \mathrm{NM} \\ 133 & 0.063 & 2.4472 & 12 & 67 & \mathrm{NM} \\ 100 & 0.061 & 2.4471 & 12 & 67 & \mathrm{NM}\end{array}$

TABLE 6.3

DIELECTRIC MEASUREMENTS AFTER 2ND $90 \mathrm{C}$

LOAD CYCLE

$\begin{array}{cccccc}\begin{array}{c}\text { Voltage, } \\ k V\end{array} & \begin{array}{c}\text { Diss. Factor, } \\ \%\end{array} & \begin{array}{c}\text { Capacitance, } \\ \text { Farads }\end{array} & \begin{array}{c}\text { Sensi- } \\ \text { tivity * }\end{array} & \begin{array}{c}\text { Attenua- } \\ \text { tion, db** }\end{array} & \begin{array}{c}\text { Corona Dis- } \\ \text { discharge,pC*** }\end{array} \\ 200 & 0.064 & 2.4535 \times 10^{-9} & 11 & 67 & \mathrm{NM} \\ 166 & 0.061 & 2.4534 & 11 & 67 & \mathrm{NM} \\ 133 & 0.059 & 2.4534 & 11 & 67 & \mathrm{NM} \\ 100 & 0.057 & 2.4534 & 11 & 67 & \mathrm{NM}\end{array}$

* Refers to the sensitivity of the Dissipation Factor/Capacitance Bridge, which ranges from 0 to 12. The maximum sensitivity corresponds to a detector sensitivity of I microvolt and dissipation factor resolution of $\pm 0.002 \%$.

** Refers to the Corona Discharge Detector, and defines the calibration required to establish a detector sensitivity of 5 pico-coulombs $(\mathrm{pC})$ per inch.

*** The calibration pulse (equal to 5 pico-coulombs per inch) is a reference against which any discernible discharges are compared. Where no visible discharges are evident, the letters NM (not-measurable) are shown. Measurable discharges are denoted by an actual numerical value. 
TABLE 6.4

\title{
DIELECTRIC MEASUREMENTS AFTER 4TH $90 \mathrm{C}$ LOAD CYCLE
}

$\begin{array}{cccccc}\begin{array}{c}\text { Voltage, } \\ \text { kV }\end{array} & \begin{array}{c}\text { Diss. Factor, } \\ \%\end{array} & \begin{array}{c}\text { Capacitance, } \\ \text { Farads }\end{array} & \begin{array}{c}\text { Sensi- } \\ \text { tivity* }\end{array} & \begin{array}{c}\text { Attenua- } \\ \text { tion, } \mathrm{db}^{* *}\end{array} & \begin{array}{c}\text { Corona Dis- } \\ \text { charge, } \mathrm{pC} \text { *** }\end{array} \\ 200 & 0.061 & 2.4528 \times 10^{-9} & 12 & 68 & 4 \\ 166 . & 0.059 & 2.4528 & 12 & 67 & \text { NM } \\ 133 & 0.057 & 2.4528 & 12 & 67 & \text { NM } \\ 100 . & 0.055 & 2.4528 & 12 & 67 & \text { NM }\end{array}$

TABLE 6.5

\begin{abstract}
DISSIPATION FACTOR AND CAPACITANCE MEASUREMENTS WITH CONDUCTOR AT $90 \mathrm{C}$
\end{abstract}

$\begin{array}{cccc}\begin{array}{c}\text { Voltage, } \\ \text { kV }\end{array} & \begin{array}{c}\text { Diss. Factor, } \\ \%\end{array} & \begin{array}{c}\text { Capacitance, } \\ \text { Farads }\end{array} & \begin{array}{c}\text { Sensi- } \\ \text { tivity* }\end{array} \\ 200 & 0.049 & 2.3753 \times 10^{-9} & \text { II } \\ 166 & 0.048 & 2.3754 & \text { II } \\ 133 & 0.048 & 2.3755 & \text { II } \\ 100 & 0.050 & 2.3756 & \text { II }\end{array}$

* Refers to the sensitivity of the Dissipation Factor/Capacitance Bridge, which ranges from 0 to 12 . The maximum sensitivity corresponds to a detector sensitivity of I microvolt and dissipation factor resolution of $\pm 0.002 \%$.

** Refers to the Corona Discharge Detector, and defines the calibration required to establish a detector sensitivity of 5 pico-coulombs $(p C)$ per inch.

The calibration pulse (equal to 5 pico-coulombs per inch) is a reference against which any discernible discharges are compared. Where no visible discharges are evident, the letters NM (not-measurable) are shown. Measurable discharges are denoted by an actual numerical value. 
TABLE 6.6

DIELECTRIC MEASUREMENTS AFTER 6TH $90 \mathrm{C}$ LOAD CYCLE

$\begin{array}{cccccc}\begin{array}{c}\text { Voltage, } \\ \text { kV }\end{array} & \begin{array}{c}\text { Diss. Factor, } \\ \%\end{array} & \begin{array}{c}\text { Capacitance, } \\ \text { Farads }\end{array} & \begin{array}{c}\text { Sensi- } \\ \text { tivity* }\end{array} & \begin{array}{c}\text { Attenua- } \\ \text { tion, db** }\end{array} & \begin{array}{c}\text { Corona Dis- } \\ \text { charge,pC *** }\end{array} \\ 200 & 0.059 & 2.4519 \times 10^{-9} & 12 & 67 & 5 \\ 166 & 0.057 & 2.4519 & 12 & 67 & \text { NM. } \\ 133 & 0.055 & 2.4519 & 12 & 67 & \text { NM } \\ 100 & 0.053 & 2.4520 & 12 & 67 & \text { NM }\end{array}$

TABLE 6.7

DIELECTRIC MEASUREMENTS AFTER 3RD $130 \mathrm{C}$ LOAD CYCLE

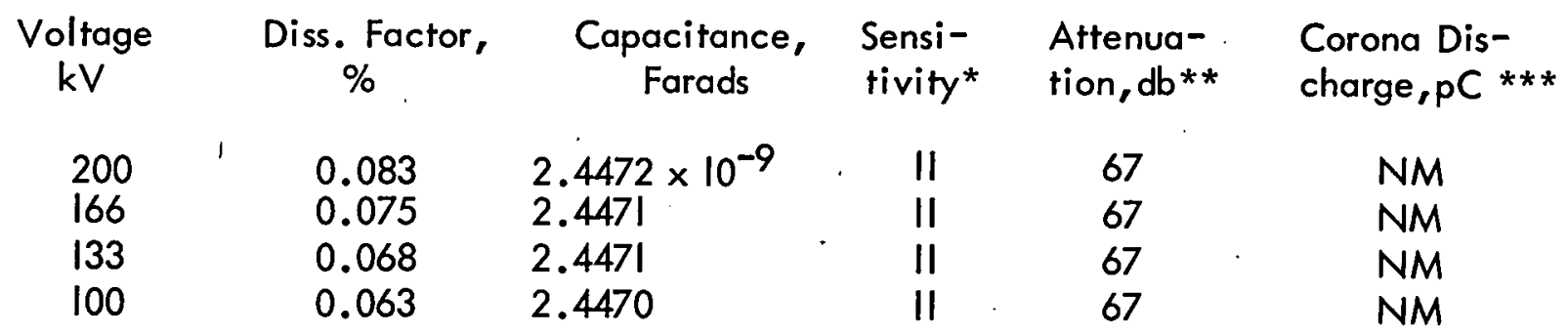

Refers to the sensitivity of the Dissipation Factor/Capacitance Bridge, which ranges from 0 to 12 . The maximum sensitivity corresponds to a detector sensitivity of I microvolt and dissipation factor resolution of $\pm 0.002 \%$

** Refers to the Corona Discharge Detector, and defines the calibration required to establish a detector sensitivity of 5 pico-coulombs $(p C)$ per inch.

*** The calibration pulse (equal to 5 pico-coulombs per inch) is a reference against which any discernible discharges are compared. Where no visible discharges are evident, the letters NM (not-measurable) are shown. Measurable discharges are denoted by an actual numerical value. 
TABLE 6.8

DIELECTRIC MEASUREMENTS AFTER 4TH I30 C

LOAD CYCLE

$\begin{array}{cccccc}\begin{array}{c}\text { Voltage, } \\ \text { kV }\end{array} & \begin{array}{c}\text { Diss. Factor, } \\ \%\end{array} & \begin{array}{c}\text { Capacitance, } \\ \text { Farads }\end{array} & \begin{array}{c}\text { Sensi- } \\ \text { tivity* }\end{array} & \begin{array}{c}\text { Attenua- } \\ \text { tion, db** }\end{array} & \begin{array}{c}\text { Corona Dis- } \\ \text { charge,pC *** }\end{array} \\ 200 & 0.112 & 2.4488 \times 10^{-9} & 11 & 74 & 2 \\ 166 & 0.102 & 2.4487 & 11 & 67 & \text { NM } \\ 133 & 0.093 & 2.4486 & 11 & 67 & \text { NM } \\ 100 & 0.080 & 2.4485 & 11 & 67 & \text { NM }\end{array}$

TABLE 6.9

DISSIPATION FACTOR AND CAPACITANCE MEASUREMENTS

WITH CONDUCTOR AT $130 \mathrm{C}$

$\begin{array}{cclc}\text { Voltage, KV } & \text { Diss. Factor, \% } & \text { Capacitance, Farads } & \text { Sensitivity * } \\ 200 & 0.072 & 2.2635 \times 10^{-9} & 11 \\ 166 & 0.069 & 2.2635 & 11 \\ 133 & 0.068 & 2.2635 & 12 \\ 100 & 0.069 & 2.2634 & 12\end{array}$

* Refers to the sensitivity of the Dissipation Factor/Capacitance Bridge, which ranges from 0 to 12 . The maximum sensitivity corresponds to a detector sensitivity of I microvolt and dissipation factor resolution of $\pm 0.002 \%$.

* $\quad$ Refers to the Corona Discharge Detector, and defines the calibration required to establish a detector sensitivity of 5 pico-coulombs $(\mathrm{pC})$ per inch.

*** The calibration pulse (equal to 5 pico-coulombs per inch) is a reference against which any discernible discharges are compared. Where no visible discharges are evident, the letters NM (not-measurable) are shown. Measurable discharges are denoted by an actual numerical value. 
TABLE 6.10

DIELECTRIC MEASUREMENTS AFTER 7th 130 C LOAD CYCLE

$\begin{array}{cccccc}\begin{array}{c}\text { Voltage, } \\ \text { kV }\end{array} & \begin{array}{c}\text { Diss. Factor, } \\ \%\end{array} & \begin{array}{c}\text { Capacitance, } \\ \text { Farads }\end{array} & \begin{array}{c}\text { Sensi- } \\ \text { tivity* }\end{array} & \begin{array}{c}\text { Attenua- } \\ \text { tion, db** }\end{array} & \begin{array}{c}\text { Corona Dis- } \\ \text { charge, } C^{* * *}\end{array} \\ 200 & 0.106 & 2.4437 \times 10^{-9} & 11 & 70 & 4 \\ 166 & 0.093 & 2.4436 & 11 & 67 & \text { NM } \\ 133 & 0.078 & 2.4436 & 12 & 67 & \text { NM } \\ 100 & 0.060 & 2.4436 & 12 & 67 & \text { NM }\end{array}$

TABLE 6.11

DIELECTRIC MEASUREMENTS PRIOR TO CYCLIC PERIODS AT $233 \mathrm{kV}$ AND $90 \mathrm{C}$

$\begin{array}{cccccc}\begin{array}{c}\text { Voltage, } \\ \text { kV }\end{array} & \begin{array}{c}\text { Diss. Factor, } \\ \%\end{array} & \begin{array}{c}\text { Capacitance, } \\ \text { Farads }\end{array} & \begin{array}{c}\text { Sensi- } \\ \text { tivity* }\end{array} & \begin{array}{c}\text { Attenua- } \\ \text { tion, db** }\end{array} & \begin{array}{c}\text { Corona Dis- } \\ \text { charge, } \mathrm{pC}^{* * *}\end{array} \\ 233 & 0.076 & 2.4366 \times 10^{-9} & 11 & 70 & 4 \\ 200 & 0.068 & 2.4365 & 11 & 70 & 4 \\ 166 & 0.062 & 2.4365 & 12 & 67 & \text { NM } \\ 133 & 0.056 & 2.4365 & 12 & 67 & \text { NM }\end{array}$

* Refers to the sensitivity of the Dissipation Factor/Capacitance Bridge, which ranges from 0 to 12 . The maximum sensitivity corresponds to a detector sensi-. tivity of I microvolt and dissipation factor resolution of $\pm 0.002 \%$.

** Refers to the Corona Discharge Detector, and defines the calibration required to establish a detector sensitivity of 5 pico-coulombs $(p C)$ per inch.

*** The calibration pulse (equal to 5 pico-coulombs per inch) is a reference against which any discernible discharges are compared. Where no visible discharges are evident, the letters NM (not-measurable) are shown. Measurable discharges are denoted by an actual numerical value. 
-TABLE $\quad 6.12$

SUMMARY OF EXTENDED $60 \mathrm{~Hz}$ AND CURRENT CYCLING TESTS (BEFORE INSTALLATION OF JOINT)

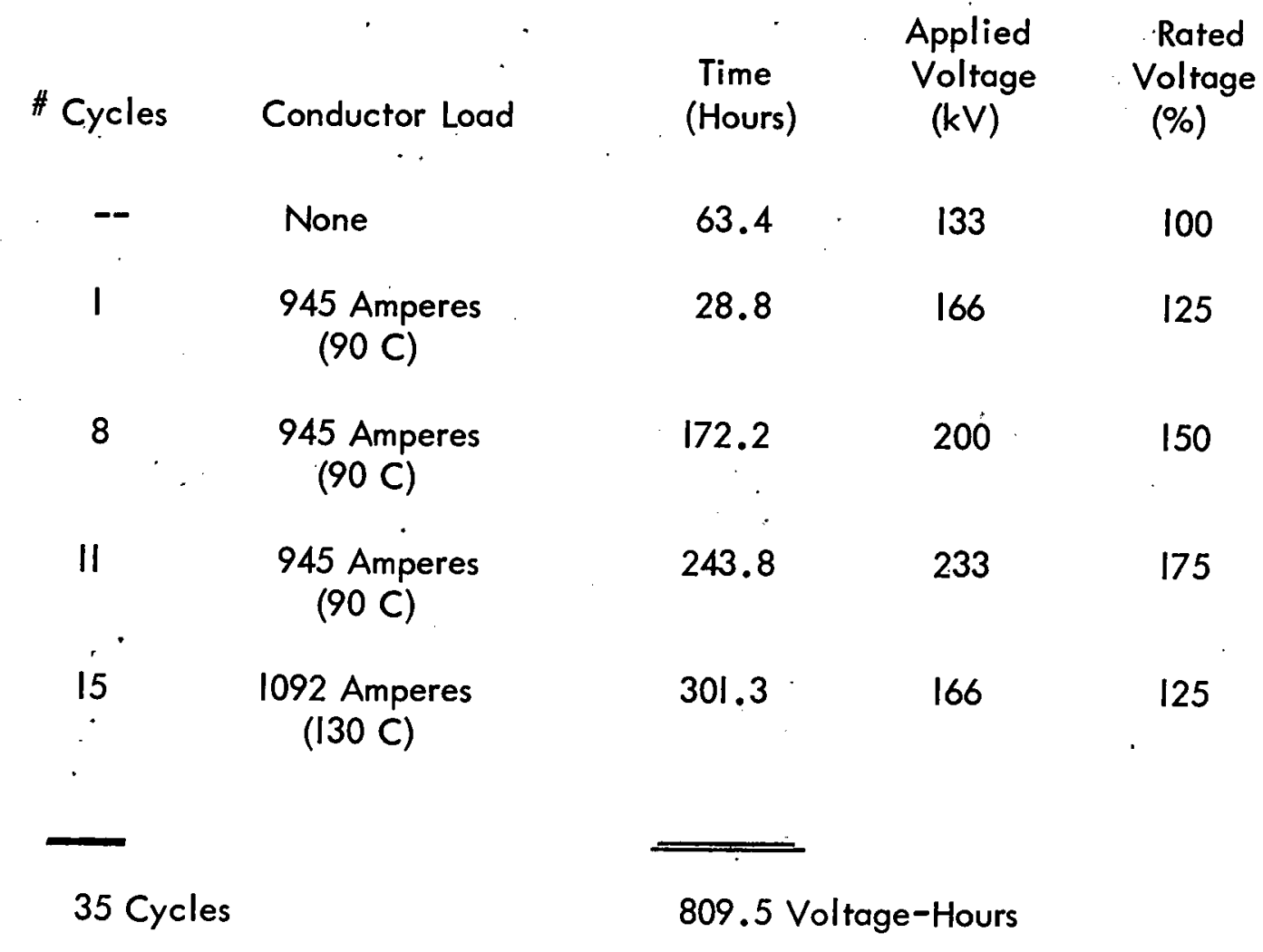

47 
INITIAL DISSIPATION FACTOR AND CAPACITANCE MEASUREMENTS ON ENTIRE CIRCUIT. (AFTER JOINTING)

$\begin{array}{cccc}\begin{array}{c}\text { Voltage, } \\ \text { kV }\end{array} & \begin{array}{c}\text { Diss. Factor, } \\ \%\end{array} & \begin{array}{l}\text { Capacitance, } \\ \text { pico-Farads }\end{array} & \begin{array}{l}\text { Sensi- } \\ \text { tivity * }\end{array} \\ \text { I33 } & 0.060 & 2330.7 & 12 \\ 166 & 0.061 & 2330.7 & 12 \\ 200 & 0.062 & 2330.6 & 12\end{array}$

TABLE 6.14

INITIAL DISSIPATION FACTOR AND CAPACITANCE MEASUREMENTS ON JOINT ONLY

$\begin{array}{cccc}\begin{array}{c}\text { Voltage, } \\ \text { kV }\end{array} & \begin{array}{c}\text { Diss. Factor, } \\ \%\end{array} & \begin{array}{l}\text { Capacitance, } \\ \text { pico-Farads }\end{array} & \begin{array}{c}\text { Sensi- } \\ \text { tivity * }\end{array} \\ 133 & 0.115 & 128.30 & 12 \\ 166 & 0.118 & 128.30 & 12 \\ 200 & 0.121 & 128.31 & 12\end{array}$

TABLE 6.15

DISSIPATION FACTOR AND CAPACITANCE MEASUREMENTS AT ROOM TEMPERATURE AFTER CURRENT-LOADING AT $90 \mathrm{C}$ (AFTER JOINTING)

a) Entire Circuit

$\begin{array}{lccc}\begin{array}{l}\text { Voltage, } \\ \text { kV }\end{array} & \begin{array}{c}\text { Diss. Factor, } \\ \%\end{array} & \begin{array}{c}\text { Capacitance, } \\ \text { pico-Farads }\end{array} & \begin{array}{c}\text { Sensi- } \\ \text { tivity * }\end{array} \\ 133 & 0.061 & 2334.5 & 12 \\ 200 & 0.062 & 2334.3 & 12 \\ \text { b) Joint Only } & & & \\ 133 & 0.111 & 130.84 & 12 \\ 200 & 0.113 & 130.83 & 12 .\end{array}$

* Refers to the sensitivity of the Dissipation Factor/Capacitance Bridge, which ranges from 0 to 12. The maximum sensitivity corresponds to a detector sensitivity of 1 microvolt and dissipation factor resolution of $\pm 0.002 \%$. 
TABLE 6.16

DISSIPATION FACTOR AND CAPACITANCE MEASUREMENTS DURING 5Ist LOAD CYCLE (AFTER JOINTING)

AT $90 \mathrm{C}$

Voltage,

$\mathrm{kV}$

a) Entire Circuit

133

166

200
Diss. Factor, $\%$
Capacitance, pico-farads
Sensitivity *

0.082

2248.4

12

0.083

2248.3

12

2248.2

12

b) 1/2 Cable \& Joslyn Terminal

$\begin{array}{llll}133 & 0.077 & 1018.6 & 12 \\ 166 & 0.076 & 1018.6 & 12 \\ 200 & 0.076 & 1018.5 & 12\end{array}$

c) Joint Only

133

0.420

126.63

12

166

0.433

126.61

12

200

$0.45 \mathrm{I}$

126.59

12

* Refers to the sensitivity of the Dissipation Factor/Capacitance Bridge, which ranges from 0 to 12 . The maximum sensitivity corresponds to a detector sensitivity of I microvolt and dissipation factor resolution of $\pm 0.002 \%$. 
TABLE 6.17

DISSIPATION FACTOR AND CAPACITANCE MEASUREMENTS AFTER 5Ist LOAD CYCLE (AFTER JOINTING) AT

ROOM TEMPERATURE

$\begin{array}{cclc}\text { Voltage, } & \text { Diss. Factor, } & \begin{array}{l}\text { Capacitance, } \\ \text { pico-Farads }\end{array} & \begin{array}{l}\text { Sensi- } \\ \text { tivity * }\end{array}\end{array}$

a) Entire Circuit

$\begin{array}{llll}133 & 0.083 & 2327.0 & 12 \\ 166 & 0.083 & 2327.0 & 12 \\ 200 & 0.084 & 2326.9 & 12\end{array}$

b) 1/2 Cable \& Joslyn Terminal

$\begin{array}{llll}133 & 0.107 & 1054.6 & 12 \\ 166 & 0.106 & 1054.5 & 12 \\ 200 & 0.106 & 1054.5 & 12\end{array}$

c) 1/2 Cable \& G\&W Terminal

$\begin{array}{llll}133 & 0.059 & \mid 141.1 & 12 \\ 166 & 0.060 & 1141.1 & 12 \\ 200 & 0.062 & |14| . \mid & 12\end{array}$

d) Joint Only

$\begin{array}{llll}133 & 0.098 & |3| .2 \mid & 12 \\ 166 & 0.098 & 131.21 & 12 \\ 200 & 0.100 & 131.21 & 12\end{array}$

* Refers to the sensitivity of the Dissipation Factor/Capacitance Bridge, which ranges from 0 to 12 . The maximum sensitivity corresponds to a detector sensitivity of I microvolt and dissipation factor resolution of $\pm 0.002 \%$. 
TABLE 6.18

INITIAL CORONA DISCHARGE MEASUREMENTS

(AFTER JOINTING)

Voltage,

kV

200

166

153

133
Attenuation, *

$\mathrm{db}$

63

72

72

72
Corona Discharge, **

$P C$

10

4

NM

NM

TABLE 6.19

CORONA DISCHARGE MEASUREMENTS

(AFTER JOINTING)

a) Circuit@90 C

$\begin{array}{ccc}\begin{array}{c}\text { Voltage, } \\ \text { kV }\end{array} & \begin{array}{c}\text { Attenuation, * } \\ \mathrm{db}^{\prime}\end{array} & \begin{array}{c}\text { Corona Discharge, ** } \\ 200\end{array} \\ 69 & \text { PC } \\ & 69 & \text { NM }\end{array}$

b) Circuit @ Room Temperature

200

69

5

TABLE 6.20

CORONA DISCHARGE MEASUREMENTS AT ROOM TEMPERATURE AFTER CURRENT-LOADING AT I30 C (AFTER JOINTING)

Voltage,
$\mathrm{kV}$

200

180

174
Atten vation, *

$\mathrm{db}$

65

69

69
Corona Discharge, **

$\mathrm{pC}$.

8

5

NM

* Refers to the Corona Discharge Detector, and defines the attenuation required to establish a sensitivity of 5 pico-coulombs $(p C)$ per inch.

* The calibration pulse (equal to 5 pico-coulombs per inch) is a reference against which any discernible discharges are compared. Where no visible discharges are evident, the letters NM (not-measurable) are shown. Measurable discharges are denoted by an actual numerical value. 
TABLE 6.21

\section{CORONA DISCHARGE MEASUREMENTS ON ENTIRE \\ CIRCUIT DURING 5Ist LOAD CYCLE (AFTER JOINTING)}

AT $90 \mathrm{C}$

$\begin{array}{ccc}\begin{array}{c}\text { Voltage, } \\ k V\end{array} & \begin{array}{c}\text { Attenuation, * } \\ \mathrm{db}\end{array} & \begin{array}{c}\text { Corona Discharge, ** } \\ \mathrm{pC}\end{array} \\ 200 & 69 & \mathrm{NM}\end{array}$

TABLE 6.22

CORONA DISCHARGE MEASUREMENTS ON ENTIRE

CIRCUIT AFTER 5IsT LOAD CYCLE (AFTER JOINTING)

AT ROOM TEMPERATURE

$\begin{array}{ccc}\begin{array}{c}\text { Voltage, } \\ k V\end{array} & \begin{array}{c}\text { Attenuation, * } \\ \mathrm{db}\end{array} & \begin{array}{c}\text { Corona Discharge } \\ \mathrm{pC}\end{array} \\ 200 & 69 & 5 \\ 196 & 69 & \mathrm{NM}\end{array}$

* Refers to the Corona Discharge Detector, and defines the attenuation required to establish a sensitivity of 5 pico-coulombs $(\mathrm{pC})$ per inch.

** The calibration pulse (equal to 5 pico-coulombs per inch) is a reference against which any discernible discharges are compared. Where no visible discharges are evident, the letters NM (not-measurable) are shown. Measurable discharges are denoted by an actual numerical value. 


\section{TABLE 6.23}

\section{SUMMARY OF VOLTAGE-HOURS AND LOAD CYCLES}

AFTER INSTALLATION OF TAPED JOINT

$\begin{array}{lcccc}\text { \# Cycles } & \text { Conductor Load } & \begin{array}{c}\text { Time } \\ \text { (Hours) }\end{array} & \begin{array}{c}\text { Applied Voltage } \\ (\mathrm{kV})\end{array} & \begin{array}{c}\text { Voltage } \\ (\%)\end{array} \\ 16 & & & 133 & 100 \\ & & 20.8 & 166 & 125 \\ 16 & 945 \text { Amperes } & 25.4 & 160 & 150 \\ & (90 \mathrm{C}) & 436.4 & 200 & 100 \\ & & & & 125 \\ 20 & 1092 \text { Amperes } & 95.8 & 133 & 150 \\ & (130 \mathrm{C}) & 291.8 & 166 & \end{array}$

52 Cycles

$$
\begin{aligned}
& \text { 116.6hours@133 kV } \\
& 317.211166 \mathrm{kV} \\
& 904.7 \text { @ @200kV } \\
& \text { I338.5 Voltage-hours }
\end{aligned}
$$


TABLE 6.24

IMPULSE WITHSTAND TEST

(SAMPLE \#I) BIL: $1050 \mathrm{kV}$ Cond.Temp. $25 \mathrm{C}$

\begin{tabular}{|c|c|c|c|}
\hline$\%$ BIL & Polarity & Applied Voltage, (kV) & Waveform \\
\hline 75 & Negative & $796,802,802,796,802$ & $F W, F W, F W, F W, F W$ \\
\hline 75 & Positive & $802,802,802,802,802$ & $F W, F W, F W, F W, F W$ \\
\hline 100 & Positive & $\begin{array}{l}1029,1035,1052,1052 \\
1052,1052,1052\end{array}$ & $\begin{array}{l}F W, F W, F W, F W, \\
F W, F W, F W\end{array}$ \\
\hline 100 & Negative & $\begin{array}{l}864,1029,978,1012,1081 \\
1 \overline{035}, 1 \overline{041}, 1086, \overline{893}, 1035 \\
1069,1064\end{array}$ & $\begin{array}{l}F W, F W, F W, F W, F W \\
F W, F W, F W, F W, F W \text {, } \\
F W, F W\end{array}$ \\
\hline 125 & Negative & $\begin{array}{l}1263,1143,1126,1305, \\
1271,1297, \frac{1297 *}{127}\end{array}$ & $\begin{array}{l}F W, F W, F W, F W, \\
F W, F W, B D *\end{array}$ \\
\hline
\end{tabular}

$$
\begin{array}{ll}
\mathrm{FW}= & \text { Full wave } \\
\mathrm{BD}= & \text { Impulse breakdown } \\
-\quad= & \text { Underlined figures are unacceptable Voltage magnitudes }
\end{array}
$$

* Failure occurred in termination. 
TABLE 6.25

IMPULSE WITHSTAND TEST

(SAMPLE \#2) BIL: $1050 \mathrm{kV} \quad$ Cond.Temp. $22 \mathrm{C}$

\begin{tabular}{|c|c|c|c|}
\hline$\%$ BIL & Polarity & Applied Voltage, $(\mathrm{kV})$ & Waveform \\
\hline 80 & Negative & $848,870,870,876,876$ & $F W, F W, F W, F W, F W$ \\
\hline 80 & Positive & $842,842,843,842,842$ & $F W, F W, F W, F W, F W$ \\
\hline 100 & Positive & $\begin{array}{l}1029,1041,1046,1058, \\
1058,1052\end{array}$ & $\begin{array}{l}F W, F W, F W, F W \text {, } \\
F W, F W\end{array}$ \\
\hline 100 & Negative & $1058,1069,1069,1075,1075$ & $F W, F W, F W, F W, F W$ \\
\hline 125 & Negative & $\begin{array}{l}1254,1246,1280,1280,1288, \\
1 \overline{297}, \frac{1297}{1305}, 1 \overline{305}, \sqrt{305}\end{array}$ & $\begin{array}{l}F W, F W, F W, F W, F W \\
F W, F W, F W, F W, F W\end{array}$ \\
\hline 125 & Negative & $1314,1322,1331,1314,1322$ & $F W, F W, F W, F W, F$ \\
\hline
\end{tabular}

Sample current-loaded (945 Amperes) for $90 \mathrm{C}$ conductor temperature.

\begin{tabular}{|c|c|c|c|}
\hline 75 & Negative & $\begin{array}{l}717,802,756,785,853 \\
8 \overline{08}, 808\end{array}$ & $\begin{array}{l}F W, F W, F W, F W, F W \text {, } \\
F W, F W\end{array}$ \\
\hline 75 & Positive & $830,847,859,876,882$ & $F W, F W, F W, F W, F W$ \\
\hline 100 & Positive & $995,1046 *$ & $\mathrm{FW}, \mathrm{BD}$ * \\
\hline & FW & Fullwave & \\
\hline & $B D$ & Impulse breakdown & \\
\hline & $-\quad=$ & Underlined figures are una & ole Voltage magnitudes \\
\hline
\end{tabular}

* Failure occurred in active cable length. 
TABLE 6.26

IMPULSE WITHSTAND TEST

(SAMPLE \#2 WITH TAPED JOINT INSTALLED)

BIL: $1050 \mathrm{kV} \quad$ Cond.Temp. $22 \mathrm{C}$

\begin{tabular}{|c|c|c|c|}
\hline$\%$ BIL & Polarity & Applied Voltage (kV) & Waveform \\
\hline 70 & Positive & $\begin{array}{l}688,677,734,728, \\
728,7 \overline{39}, 711\end{array}$ & $\begin{array}{l}F W, F W, F W, F W \\
F W, F W, F W\end{array}$ \\
\hline 70 & Negative & $678,682,717,745,711$ & $F W, F W, F W, F W, F W$ \\
\hline 100 & Negative & $\begin{array}{l}1029,955,1012,989,1041, \\
1046, \sqrt{1041}, \frac{1046,1046}{10}\end{array}$ & $\begin{array}{l}F W, F W, F W, F W, F W \text {, } \\
F W, F W, F W, F W\end{array}$ \\
\hline 100 & Positive & $\begin{array}{l}1012,1001,1029,1006,967, \\
927,1018,1052,1052,1039, \\
9 \overline{67}, 1018,841,967,1052\end{array}$ & $\begin{array}{l}F W, F W, F W, F W, F W, \\
F W, F W, F W, F W, F W \text {, } \\
F W, F W, F W, F W, F W\end{array}$ \\
\hline
\end{tabular}

Sample current-loaded (945 Amperes) for $90 \mathrm{C}$ conductor temperature.

90

Negative

$859,995,944,876,927$,

$F W, F W, F W, F W, F W$, $9 \overline{44}, 910,853,9 \overline{44} \quad \mathrm{FW}, \mathrm{FW}, \mathrm{FW}, \mathrm{FW}$

100

$\begin{array}{ll}\text { Negative } & \text { 1029, 104I, 1069, 1080* FW, FW, FW, BD * } \\ \text { FW }= & \text { Full wave } \\ B D= & \text { Impulse breakdown. } \\ -= & \text { Underlined figures are unacceptable Voltage magnitudes }\end{array}$

* Failure occurred in Taped Joint. 
TABLE 6.27

CÁBLLE SHIËLD RESISTANCE MEASUREMENTS AT ELEVATED TEMPERATURES *

Elapsed Time

(Minutes)
- Resistance (ohms)

@ 90 C (21 C Amb.)

@ I30 C (29 C Amb.)

0
1
2
3
4
5
10
15
20
25
30
40
50
60
0.00440
0.00450
0.00454
0.00455
0.00456
0.00456
0.00456
0.00454
0.00456
0.00455
0.00453
0.00450
0.00449
0.00446

0.00554

0.00551

0.00549

0.00547

0.00546

0.00547

0.00550

0.00555

0.00555

0.00560

0.00564

0.00564

0.00562

0.00556

* Measurements commenced simultaneously with the end of the heating phase of the cycle. 
TABLE 6.28

\section{CABLE SHIELD RESISTANCE MEASUREMENTS AT ELEVATED TEMPERATURES *}

Elapsed Time (Minutes)

0

1

2

3

4

5

6

7

8

9

10

15

20

25

30

45

60

75

90

105

120

135

150

180

210

240

300

360

7
5
6
7
8
10
5
5
50
60
75
105
135
50
80
240
300
360

Resistance (ohms)

@90 C (22 C Amb.) @130 C (23 C Amb.)
0.00424
0.00425
0.00426
0.00426
0.00428
0.00427
0.00427
0.00430
0.00430
0.00431
0.00429
0.00429
0.00430
0.00430
0.00428
0.00424
0.00424
0.00420
0.00417
0.00417
0.00415
0.00415
0.00413
0.00411
0.00408
0.00408
0.00406
0.00403

0.00387

0.004 이

0.00405

0.00405

0.00407

0.00407

0.00407

0.00409

0.00411

0.00411

0.00412

0.00416

0.00422

0.00428

0.00434

0.00437

0.00436

0.00434

0.00432

0.00430

0.00426

0.00425

0.00423

0.00420

0.00416

0.00415

0.00412

0.00412

* Measurements commenced simultaneously with the end of the heating phase of the cycle. 
TABLE 6.29

\section{TEMPERATURES OF CABLE COMPONENTS AND ACCESSORIES AT ELEVATED} SYSTEM TEMPERATURES

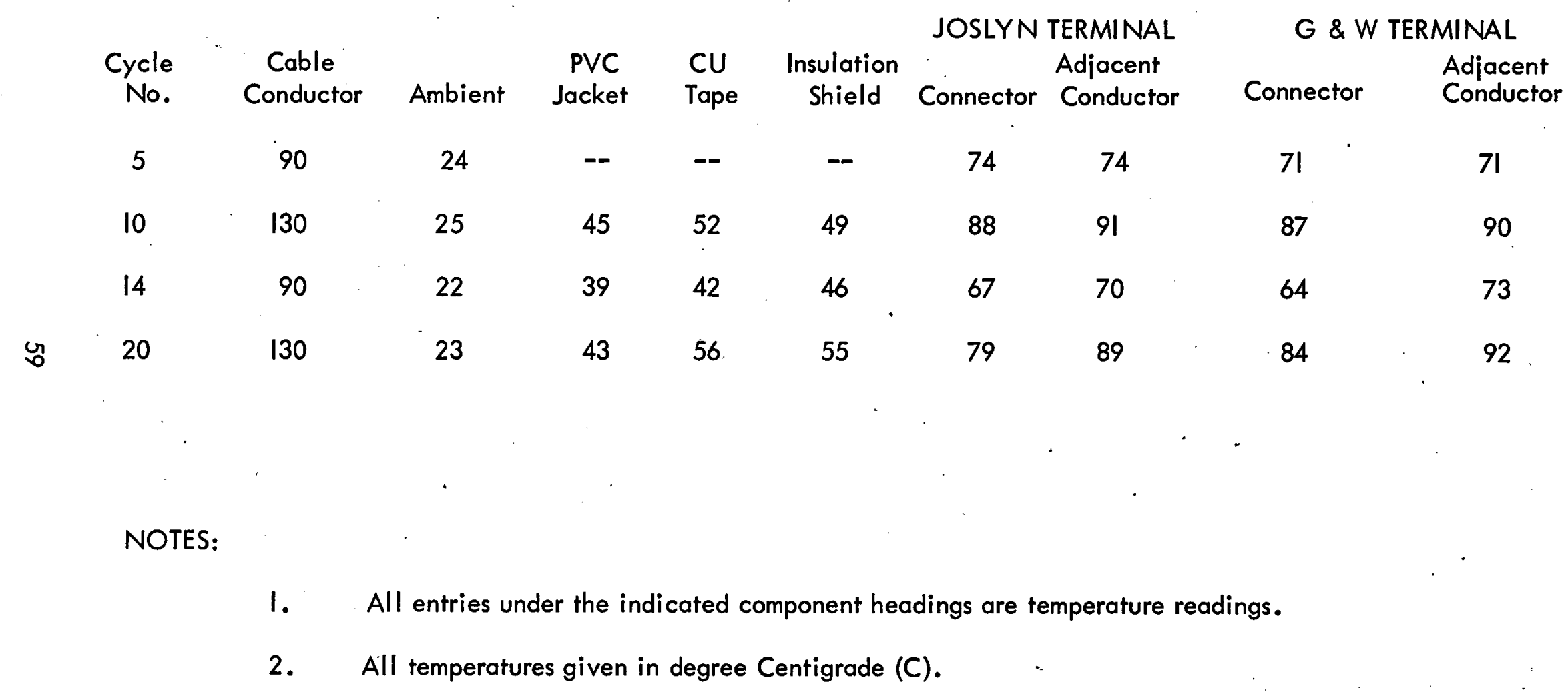


TABLE 6.30

VOLUME RESISTIVITY MEASUREMENTS

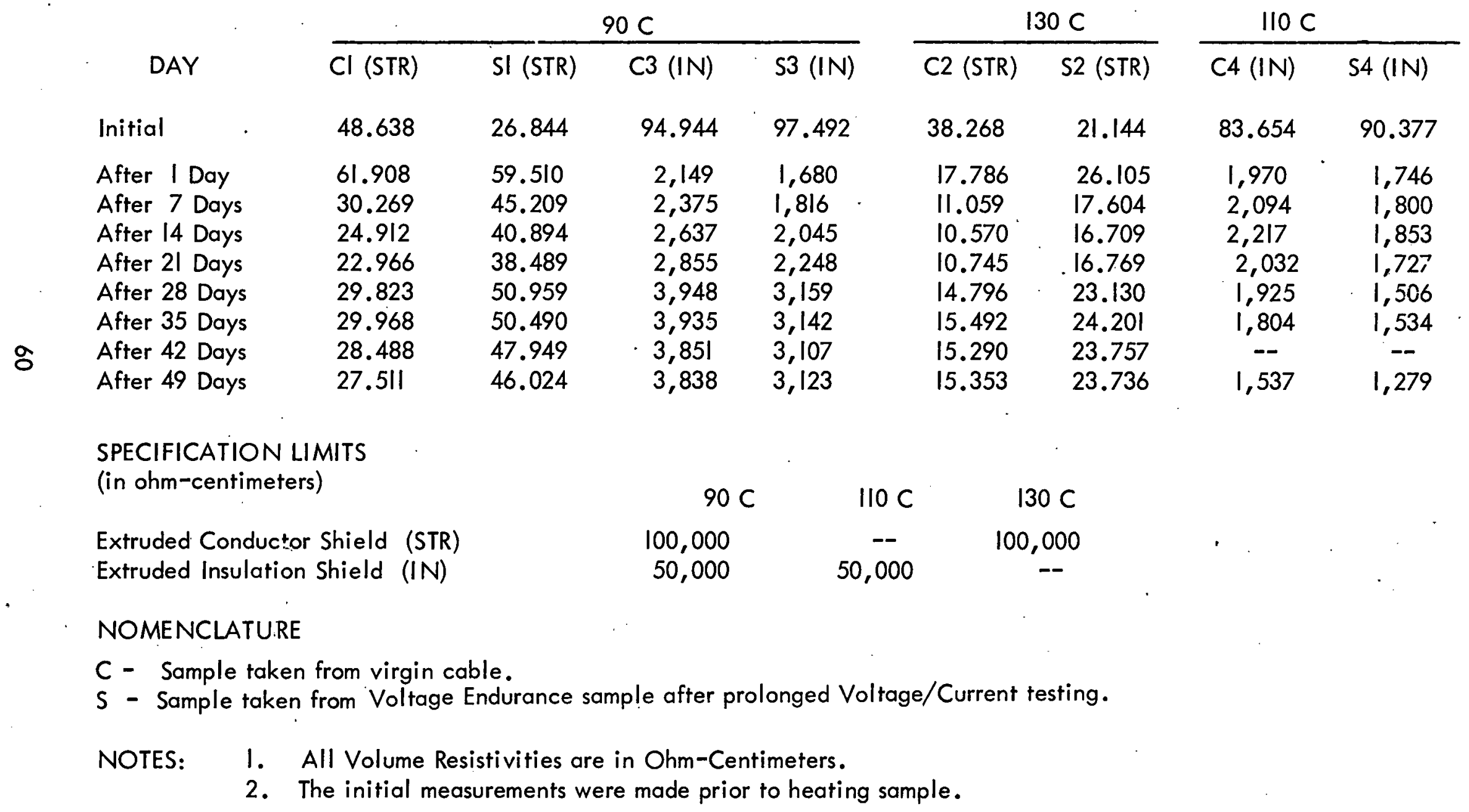


TABLE 6.31

SOLVENT EXTRACTION TESTS ON SAMPLES FROM $230 \mathrm{kV}$ CABLE

SAMPLE LOT \#I *

Sample \#

Sample Description

$\%$ Extractables

$\begin{array}{ll}\text { I A } & \text { Semi-Conductive insulation shield } \\ \text { I B } & \text { Outer 0.100" of XLPE insulation } \\ \text { I C } & \text { Center 0.100" of XLPE insulation } \\ \text { I D } & \text { Inner 0.100" of XLPE insulation } \\ \text { IE*** } & \text { Semi-Conductive strand shield }\end{array}$

17.0

15.7

15.6

22.3

58.5

SAMPLE LOT \#2 **

\begin{tabular}{|c|c|c|}
\hline Sample \# & Sample Description & $\%$ Extractables \\
\hline $\begin{array}{l}2 \mathrm{~A} \\
2 \mathrm{~B} \\
2 \mathrm{C} \\
2 \mathrm{D} \\
2 \mathrm{E} * * *\end{array}$ & $\begin{array}{l}\text { Semi-Conductive insulation shield } \\
\text { Outer } 0.100 " \text { of XLPE insulation } \\
\text { Center } 0.100 \text { " of XLPE insulation } \\
\text { Inner } 0.100 " \text { of XLPE insulation } \\
\text { Semi-Conductive strand shield }\end{array}$ & $\begin{array}{l}18.6 \\
14.4 \\
13.7 \\
19.4 \\
51.1\end{array}$ \\
\hline \multicolumn{3}{|c|}{ Specification Limits -- $30 \%$ Maximum Extractables. } \\
\hline * & \multicolumn{2}{|c|}{$\begin{array}{l}\text { Samples taken from virgin cable length exposed to factory voltage } \\
\text { proof tests only. }\end{array}$} \\
\hline$* *$ & \multicolumn{2}{|c|}{$\begin{array}{l}\text { Samples taken from test length following } 809.5 \text { hours of } 60 \mathrm{~Hz} \\
\text { overvol tage testing and current loading at } 90 \mathrm{C} \text { for } 20 \text { cycles and } \\
\text { at } 130 \mathrm{C} \text { for } 15 \text { cycles. }\end{array}$} \\
\hline$* * *$ & \multicolumn{2}{|c|}{$\begin{array}{l}\text { Strand shield was not a thermosetting material, and not subject to } \\
\text { the requirements of these tests. Extractions conducted for informa- } \\
\text { tional purposes only. However, strand shield samples passed the } \\
\text { requirements of AEIC } 5-75 \text {. }\end{array}$} \\
\hline
\end{tabular}




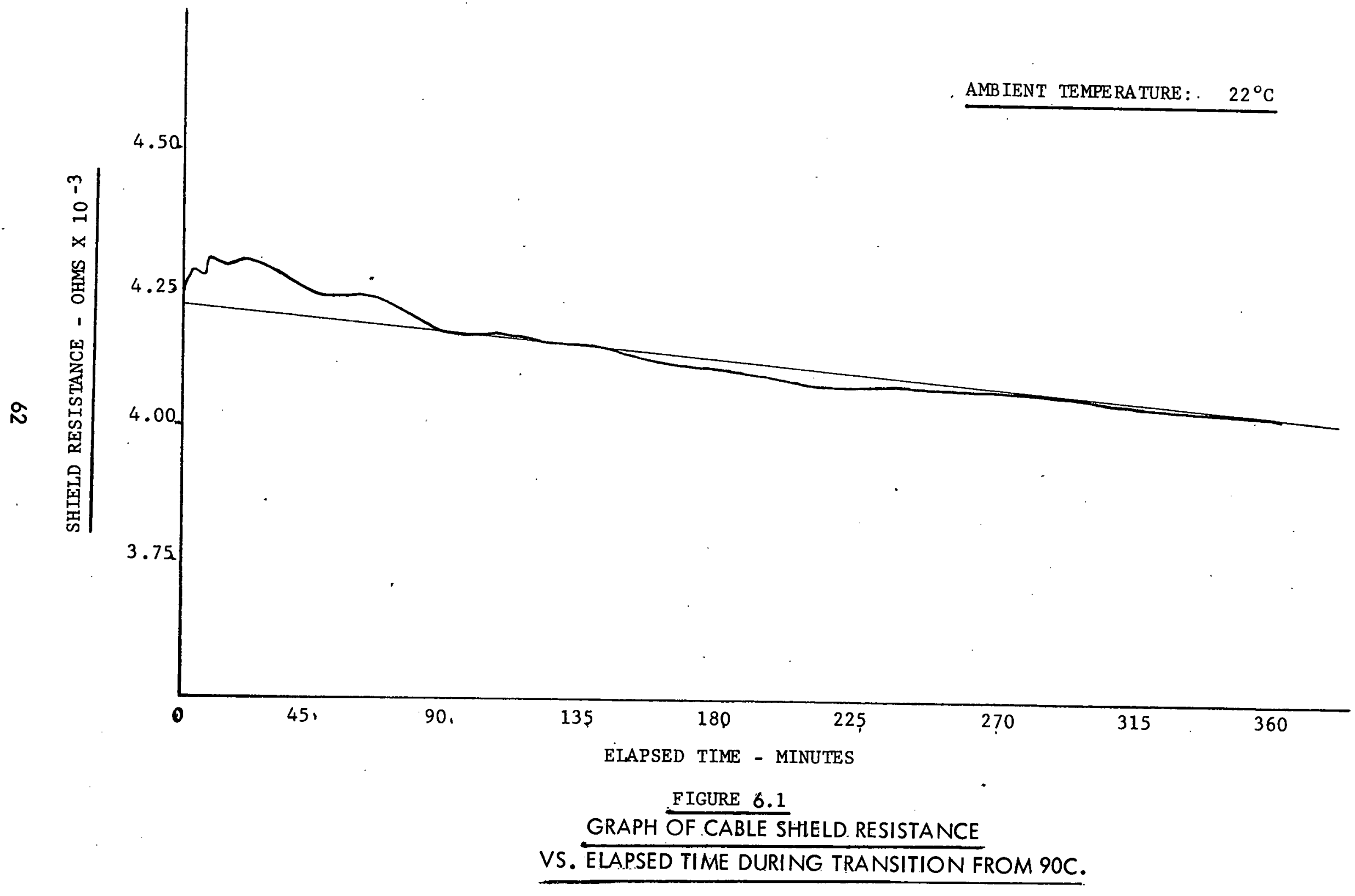




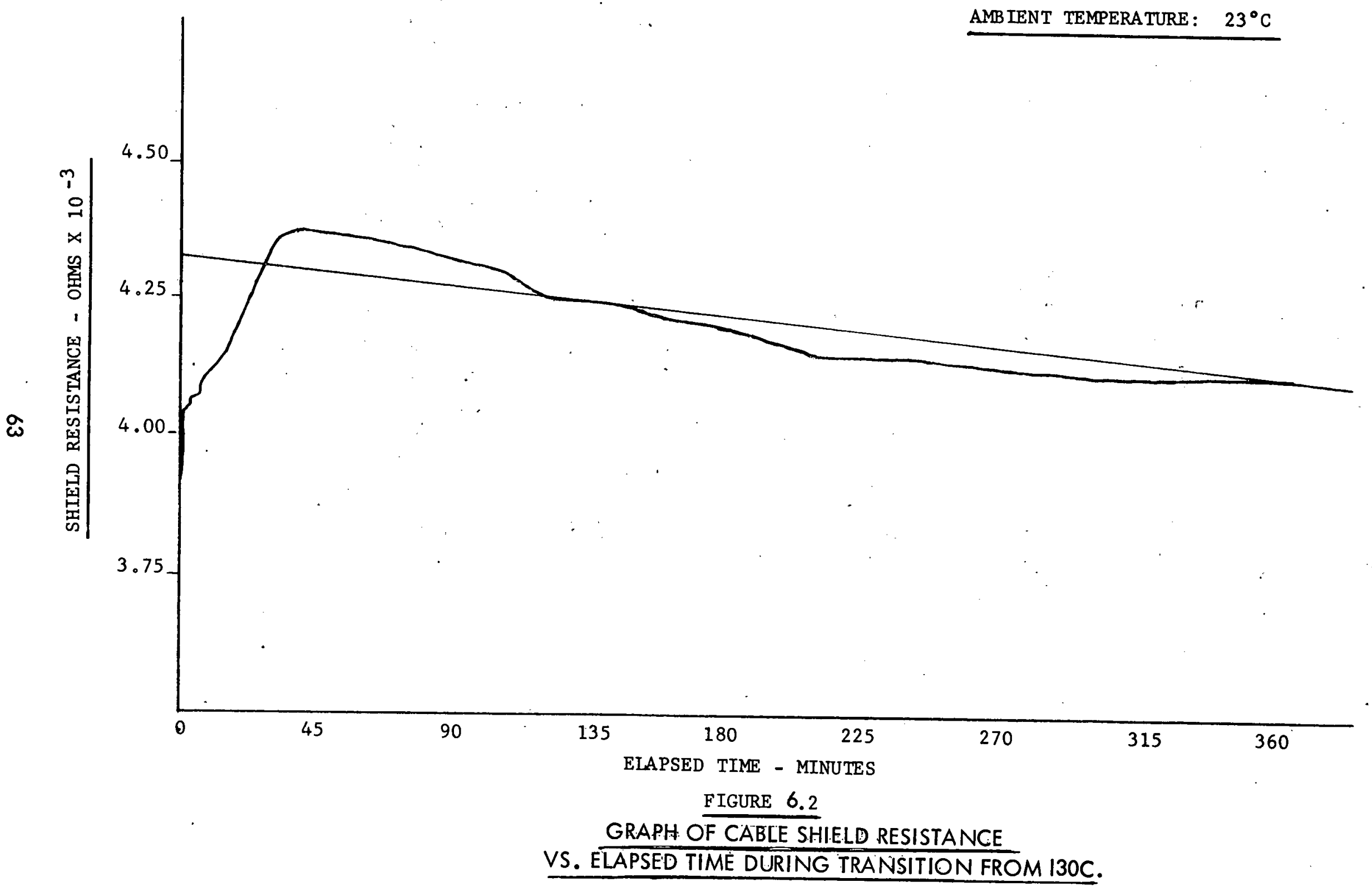


The objective of the jointing research program was to develop at least one fully reliable jointing technique for use with $230 \mathrm{kV}$ solid dielectric cable.

In order to achieve the objective, the program was planned to follow five avenues of research. These divisions of the program were carried on in parallel. They were:
(Category I)
(Category 2)
Taped Joint
(Category 3)
Vulcanized Joint
(Category 4)
Alternate Jointing Concepts
(Category 5)
Computer Programs
Connector Evaluation

The planned program is included as Appendix 7.1. The following report on total progress on the program will be keyed to Appendix 7.1. A background description will precede the detailed report on each of the 5 categories.

\section{I CATEGORY I - TAPED JOINT}

\section{I.I BACKGROUND}

The use of EPR (ethylene propylene rubber) tapes as the means of insulating solid dielectric cable systems rated $138 \mathrm{kV}$, and lower voltages, was proven to be a sound and reliable approach. In general, all taped joint problems encountered in the industry may be broken down into one or more of the following classes:

(A) Improper preparation of cable ends including inadequate sanding and shaping of solid dielectric cable layers and a lack of geometric symmetry. The result of such inadequacies in workmanship is generally the creation of sites for abnormally high electrical stress and/or partial discharge eventually resulting in failure. The proper preparation of cable ends does require work, but is not difficult or unreasonable. The use of proper tooling is a great aid in reducing work time.

(B) Failure to adhere to joint construction directions. Improper tape tensioning, improper application of shielding, inattention to cleanliness, incorrect dimensions, etc., are examples. The obvious result of such deviations from design can be failure. At best the result will be a joint that does not possess the desired design properties. 
(C) Incorrect conductor connection may lead to failure due to mechanical inadequacy or to progressive electrical degradation.

(D) Failure to prevent ingress of water into the joint during and following construction may lead to joint failure. This is prevented by the use of suitable watertight coverings and proper sealing of all ground leads extending through this covering.

(E) Unsuitable design can imply a number of factors. For example, electrical stress levels are reduced by dimensional increases. This dimensional increase can result in excessive mechanical forces in the joint in combination with increased mis matching of the thermal characteristics of the joint in comparison with those of the cable. At the other extreme, electrical stresses may be increased beyond desirable levels, thus minimizing mechanical and thermal problems but making the joint unreliable due to an inadequate electrical design margin of safety. The design of a reliable EPR taped joint must include electrical, mechanical and thermal considerations. The end result of such an approach will be an engineering "trade-off" yielding the best balance of electrical, thermal and mechanical characteristics.

The five classes of failures listed above may also be grouped in terms of construction considerations (Class A-D) and design considerations (Class $E$ ). The factors included in the first 4 classes are simply related to workmanship. Kaiser experience has been that correct workmanship always results in highly reliable joints when laboratory proven designs and materials are used. While mindful of the important construction considerations, developed through considerable laboratory and field experience, the focus of attention in the research and development of a $230 \mathrm{kV}$ solid dielectric cable joint has been on design. In order to study the design of a possible $230 \mathrm{kV}$ taped joint the past experience on $138 \mathrm{kV}$ taped joint development and laboratory testing was reviewed. This work was done using Bishop Electric, Cedar Grove, N.J. (Reference 7.l) products. In particular, Bishop W-962 EPR splicing tapes and \#17 conductive shielding tapes were used. The design of this successful 138kV taped joint is shown in Fig. 7.I. In order to relate the electrical stresses in this design to stresses later used for the $230 \mathrm{kV}$ program the various key electrical stresses are shown in Figures 7.2, 7.3, 7.4, $7.5,7.6$, and 7.7 . In all of these figures, stress values from actually performed tests are shown as solid lines, while designed but untested design stress values are shown as dashed lines. Table I of Appendix 7 .I also shows selected test stress values for 4 different joint designs.

In order to identify the electrical stresses that are design considerations, Fig. 7.8 is a generalized drawing showing the location of each of the key design stresses. 
138-kV KAISER

WALTZ MILL TAPED

SPLICE DESIGN

$400 \mathrm{kcmil}$ ALUMINUM CONDUCT OA

2

SCALE $=1: 3$

138-kV KAISER

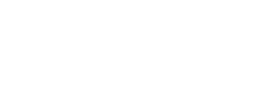

HIGHER STRESS TAPED

SPLICE DESIGN

非W962-75B

$400 \mathrm{kcmil}$ ALUMINUM CONDUCTOR

SCALE $=1: 3$

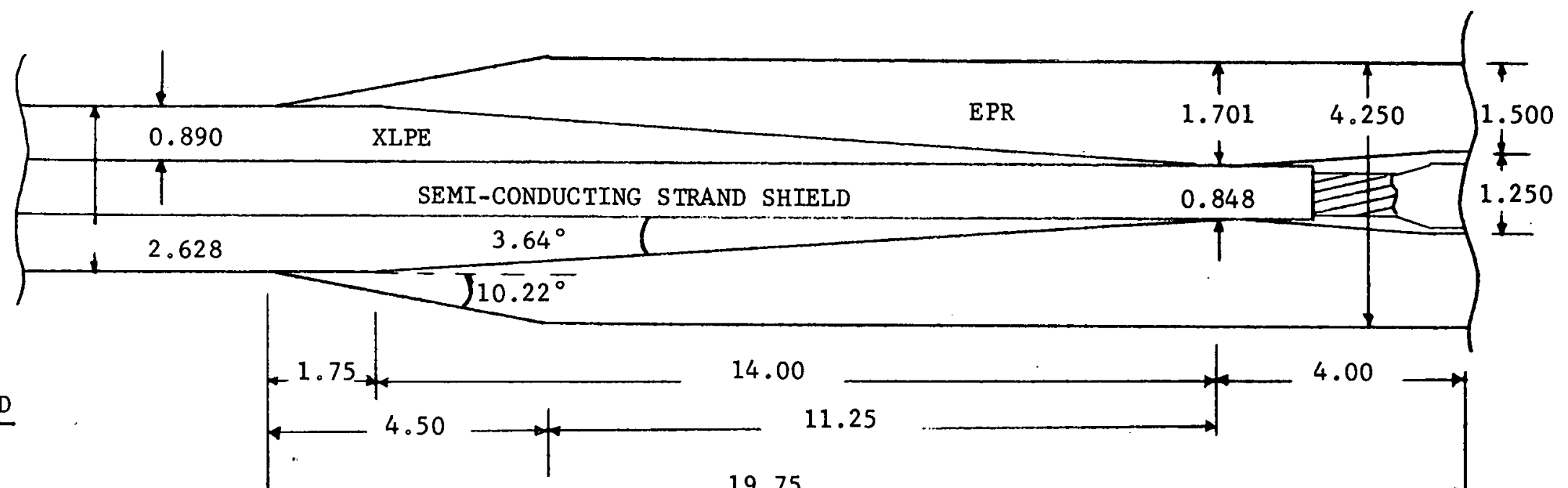

19.75

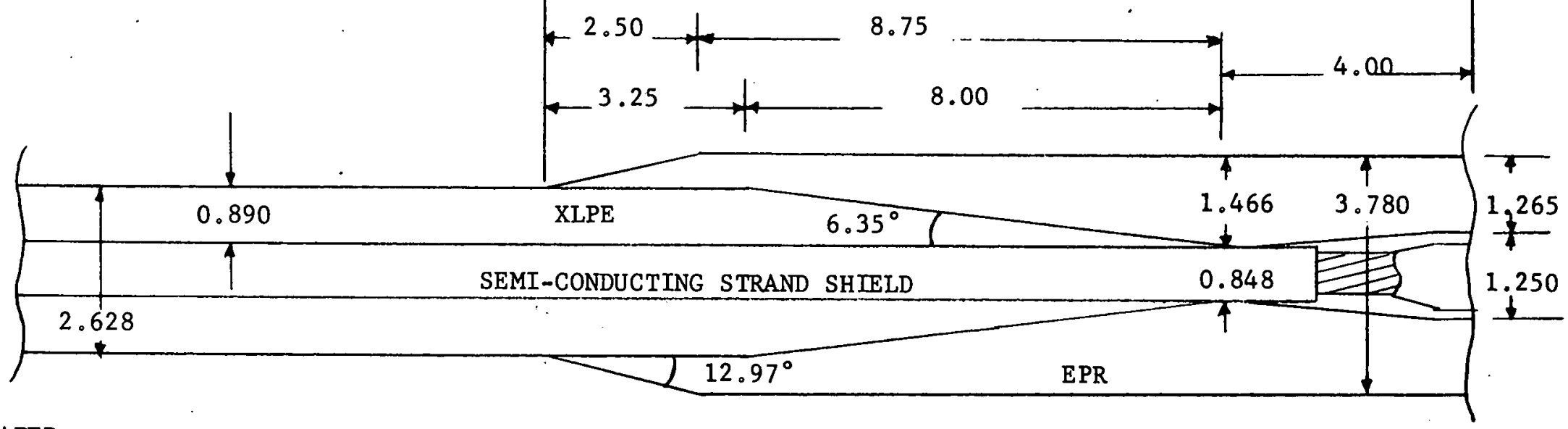

FIGURE 7.1 


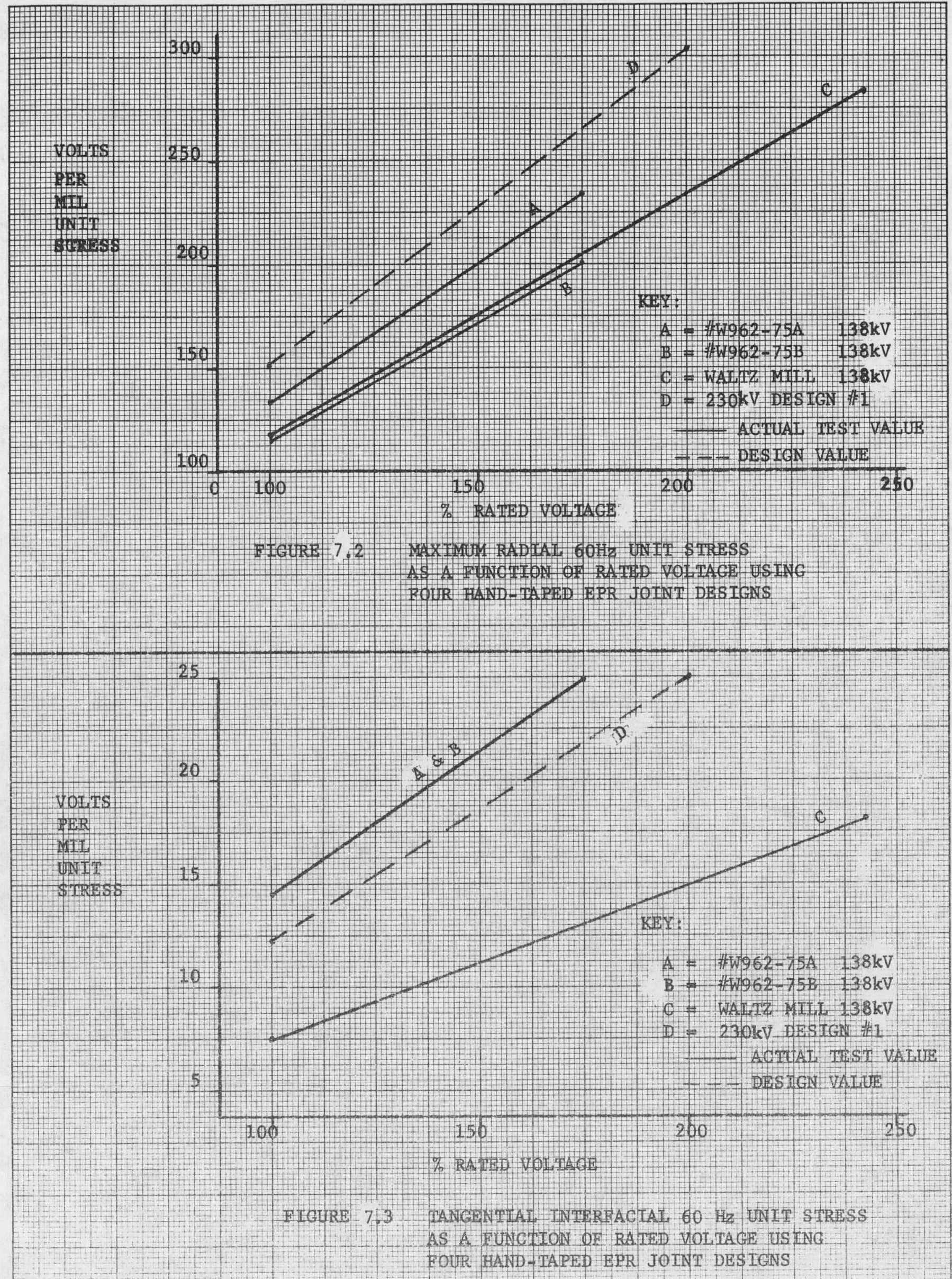




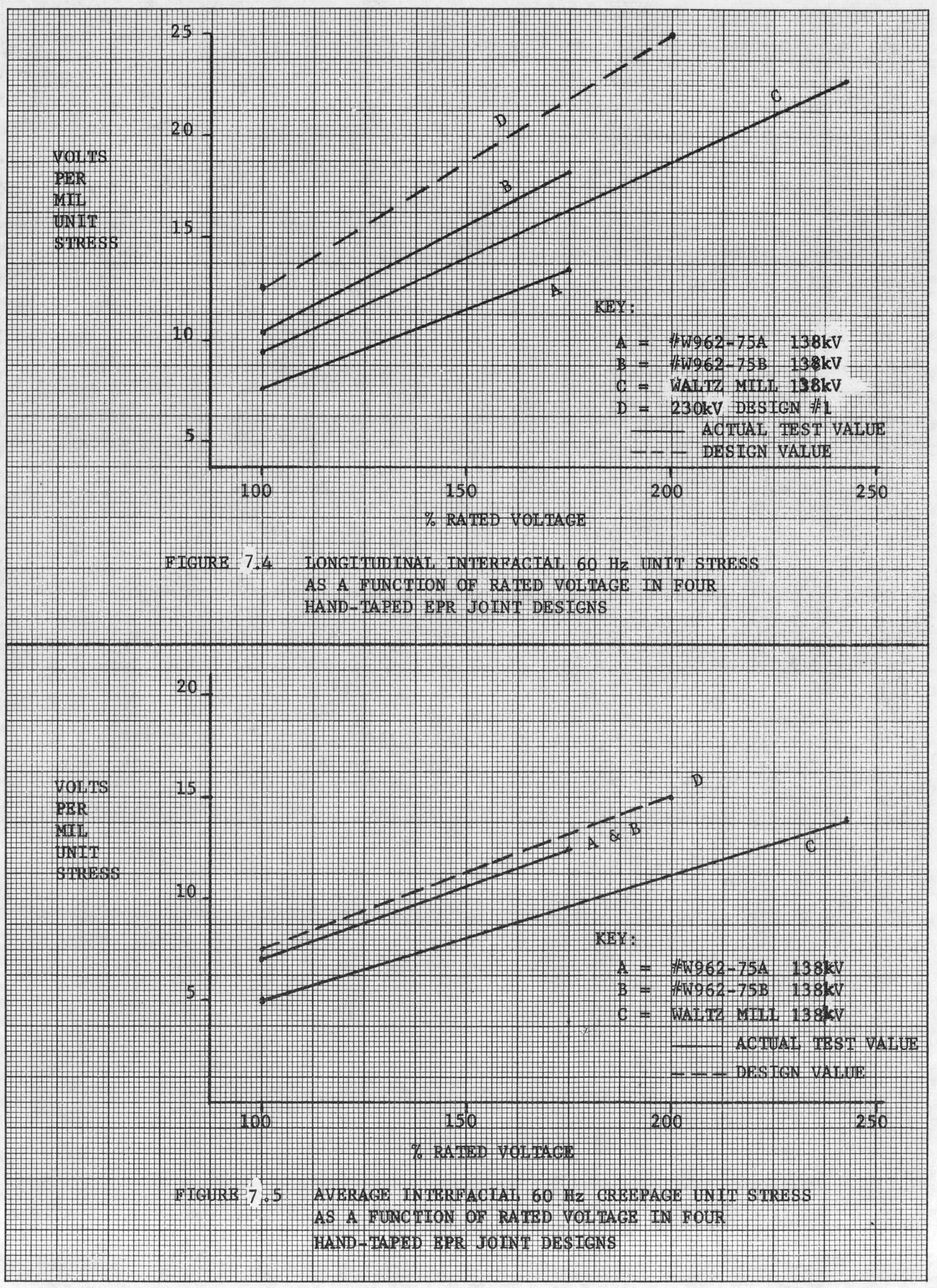




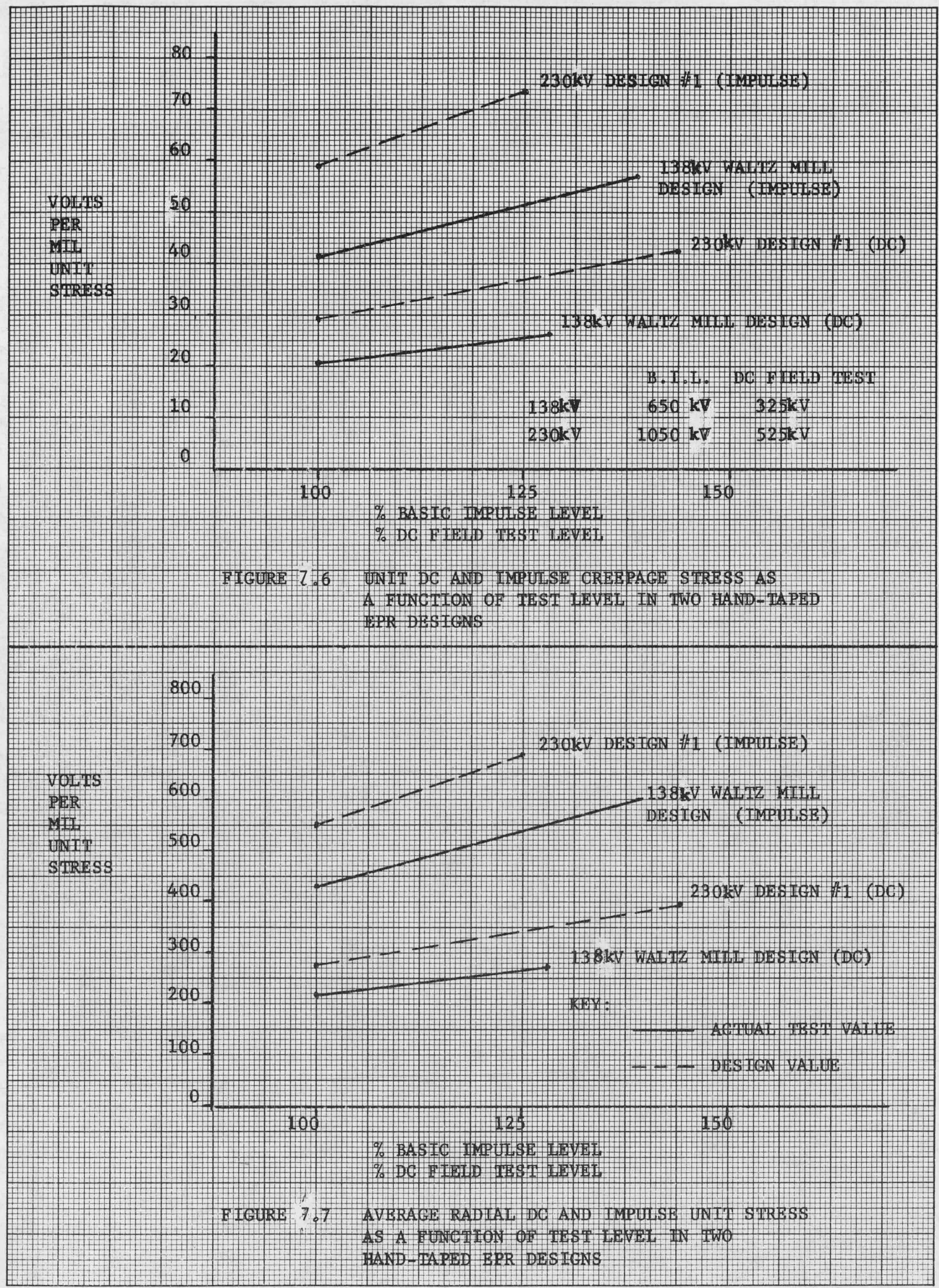


Considering that all construction details were properly carried out, the following observations on performance of the I38kV Waltz Mill design were made:

(F) Electrical interfacial stresses (pencil tangential stress and stress cone longitudinal stress) might be increased for use in a $230 \mathrm{kV}$ design while still retaining a reasonable design margin of safety. This was based upon the absence of any interfacial breakdowns in Kaiser's test experience even though interfacial stresses as high as 22.5 volts per mil were experienced (Fig. 7.3 and 7.4).

(G) The Waltz Mill qualification joint withstood maximum radial $60 \mathrm{~Hz}$ stress in excess of 270 volts per mil before eventually failing in the radial mode. It was felt that a designed maximum stress significantly greater than the rated 117 volts per mil value used for the $138 \mathrm{kV}$ joint would very likely be workable (Fig. 7.2).

(H) The creepage stress $(60 \mathrm{~Hz}, \mathrm{DC}$ and Impulse, Fig. 7.5 and 7.6$)$ might be increased to some extent. Since creepage stress is also an interfacial stress it was presumed that this might be done while still retaining a reasonable design margin of safety.

(I) The welded connector and conductor within the taped joint was found to be operating at about $170 \mathrm{C}$ when the cable conductor was at $130 \mathrm{C}$. Although the $I 30 \mathrm{C}$ emergency temperature would be imposed on the cable system for no more than 500 hours in a 40 -year life, it was necessary to ensure that the joint could also withstand the emergency rating of $130 \mathrm{C}$ without detriment. The higher temperature within the joint (I70C) was the result of the poorer heat dissipating properties of the joint layers as compared to cable layers. This is in part effected by the bulk of the joint, hence the shorter and smaller in diameter the joint, the more closely the joint will thermally "match" the cable in ability to dissipate heat.

The problem is partially due to the higher thermal resistivity (thermal rho) of the EPR tapes in comparison to the XLPE cable irisulation. The problem condenses to finding the steps that may be taken to reduce the over-temperature that occurs in the joint. Basically, this may be done by: (a) reducing $I 2$ heating by use of a connector having electrical resistance much lower than the conductor, and/or (b) designing the joint to be as close as possible to the cable in its heatdissipating properties. 
A formula derivedfrom Neher-Mc Grath (Reference 7.2) for use in the laboratory to calculate ampacities of test cables may be adapted to more clearly observe the importance of comparison between the cable and the joint heat dissipating properties. Rca' is a mathematical factor used in the calculation of cable/joint ampacity. It is derived by calculating the heat dissipating properties of the cable or joint. Figure 7.9 shows the ratio of Rca'(joint) to Rca' (cable) making the assumptions that cable and joint walls remain the same for all conductor sizes and that conductor size is the only variable. The data are derived from the formulae in Appendix 7.2. For the splice design, any reduction in the factor for heat dissipation (Rca') would cause the joint conductor to run cooler and thus reduce the Rca' joint/cable ratio in the direction of unity. If unity could be achieved than the joint would run at the same temperature as the cable (assuming Rac of the joint is identical to that of the cable). Referring again to the basic formula shown at the beginning of Appendix 7.2, it is also evident that any means by which the denominator product (Rac) (Rca') for the joint calculation may be made equal to the denominator product for the cable calculation, will result in the joint conductor running at the same temperature as the cable conductor. Thus if the joint Rac can be reduced to a value equal to Rac (cable) ratio $R_{c a}$ (joint) (cable)

the objective could be achieved. In actual practice a connector having a much lower resistance than this would be required because the connector comprises a relatively small portion of the total axial length of conductor enclosed within the joint.

\subsubsection{JOINT DESIGNS, EVALUATIONS AND TESTS}

The actual steps which have been taken will now be outlined. Reference Appendix 7.1.

\section{STEP I}

A $138 \mathrm{kV}$ taped joint using Bishop materials was designed and constructed. The electrical stresses in this joint are tabulated in Table I of Appendix 7.1. Individual electrical stresses are graphed in Figures 7.2, 7.3, 7.4 and 7.5. The joint was identified as $W-962-75 A$ and was installed in our laboratory long-term 138kV $400 \mathrm{kcmil}$ test circuit. The joint was tested at $150 \%$ rated voltage ( $120 \mathrm{kV}$ phase-to-ground) for 360 hours. Tangential interfacial stress at this test level was 21.4 volts per mil, an increase of $89 \%$ over the comparable stress in the Waltz Mill 138kV design. The objective of the test was to evaluate the joint for withstand ability for 360 hours and to dissect and inspect the joint following the test. Although partial discharge measurements were made on this joint, it was not possible to isolate 


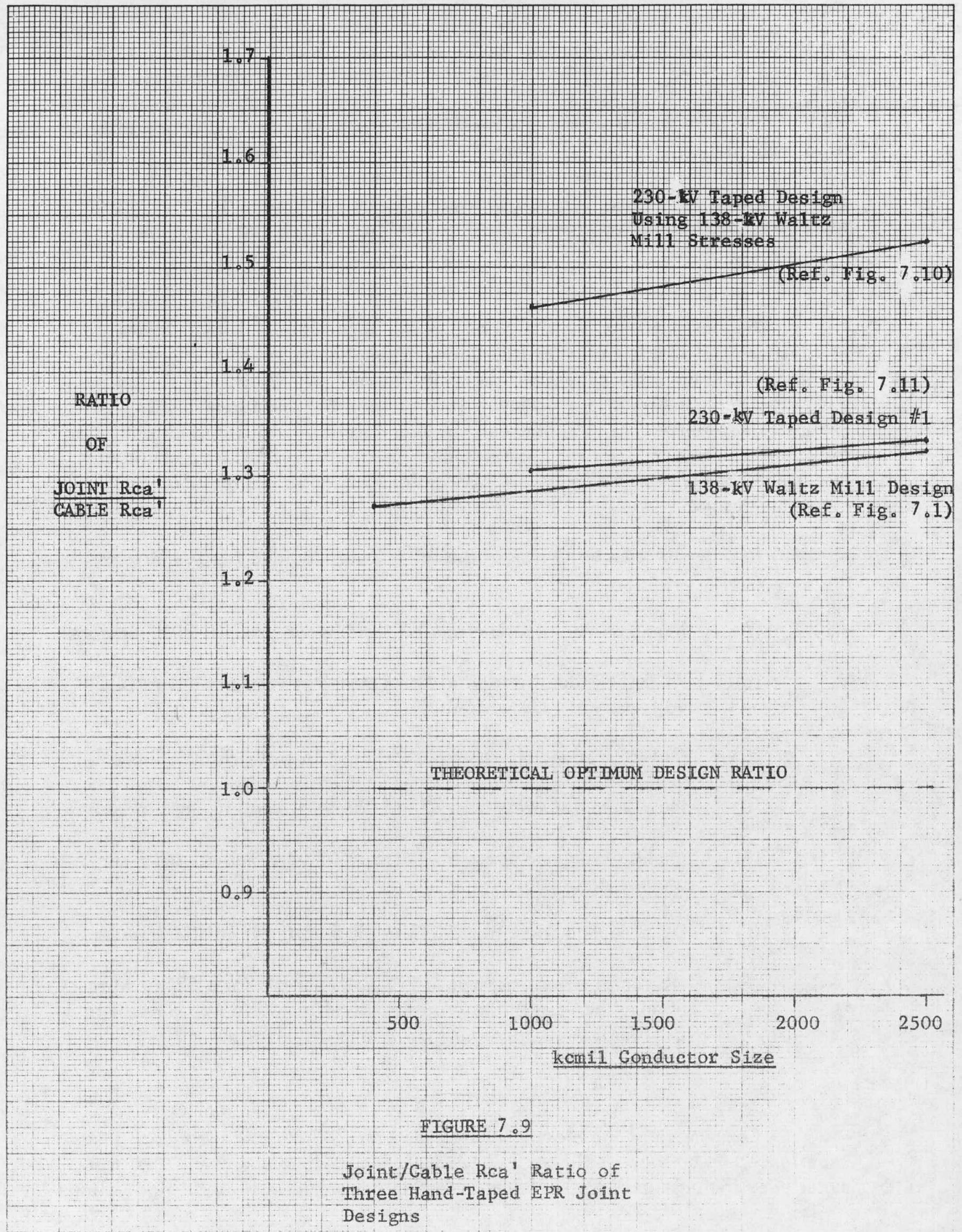


the joint sufficiently from a known source of discharge elsewhere in the test circuit. Discharge observed in the joint was 16 picocoulombs $(\mathrm{pC})$ at $120 \mathrm{kV}$ and $1.5 \mathrm{pC}$ at $98 \mathrm{kV}$. It could not be determined if this $16 \mathrm{pC}$ was emanating from the joint or the cable. This joint was dissected and carefully inspected for any indication of electrical degradation, particularly along the cable/joint insulation interfaces. No evidence at all was found indicating any electrical breakdown of this interface under IOX magnification. This was considered to be solid indication that higher tangential interfacial stress levels could be used in $230 \mathrm{kV}$ taped joint designs.

\section{STEP 2}

The next step was the design of a $230 \mathrm{kV}$ taped joint. If the stresses used in our successful $138 \mathrm{kV}$ Waltz Mill design were simply applied to a $230 \mathrm{kV}$ design, the joint would have the dimensions shown in Figure 7.10. While this design would keep electrical stresses at proven levels it would certainly represent a still greater mismatch (Reference Fig. 7.9) between cable and joint heat dissipating properties, resulting in joint conductor temperatures much greater than $170 \mathrm{C}$. Mechanical forces and construction difficulty are also design considerations that might not favor this design.

In order to reduce the size of the joint it was decided to raise stresses in the $230 \mathrm{kV}$ joint design as follows:

(A) Maximum radial stress from 117 to 152 volts per mil ( $30 \%$ increase)

(B) $\quad X L P E / E P R$ tape interfacial stress from 9.4 volts per mil to 12.5 volts per $\mathrm{mil}$ ( $33 \%$ increase)

(C) $60 \mathrm{~Hz}$ creepage stress from 5 to 7.5 volts per mil ( $50 \%$ increase)

(D) Impulse radial stress from 433 to 556 volts per mil ( $28 \%$ increase)

(E) Impulse creepage stress from 41.3 to 59 volts per mil (43\%. increase)

(F) DC creepage stress from 26.3 to 29.5 volts per mil (12\% increase)

(G) DC radial stress was kept at 277 volts per mil for a $525 \mathrm{kV}$ test level. Increase in the joint test level to $750 \mathrm{kV}$ would result in a DC radial stress increase from 277 to 397 volts per $\mathrm{mil}$ ( $43 \%$ increase)

Comparison of the electrical stresses in the $230 \mathrm{kV}$ design with past test experience can be seen in Figures 7.2, 7.3, 7.4, 7.5, 7.6 and 7.7. Past test experience includes over 12,000 hours of testing performed in Kaiser's high voltage 
NOTE: Only Electrical Stress

Exceeding 138-kV Wa1tz Mill

Design Value is Interfacial

Longitudinal Stress

Scale $1: 3$

Dimensions in Inches

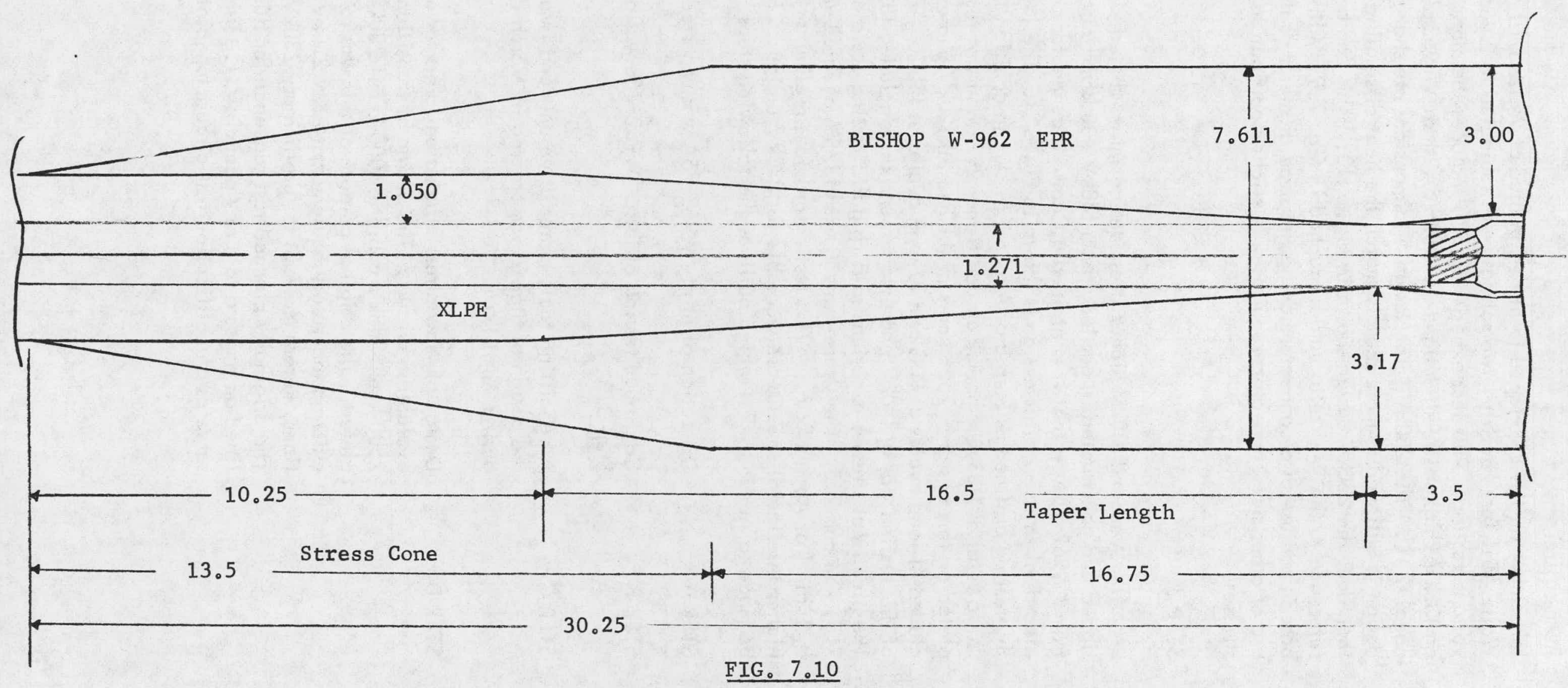

DESIGN OF A 230-kV TAPED EPR JOINT WITH ELECTRICAL STRESSES NOT EXCEEDING THOSE OF $138-\mathrm{kV}$ WALTZ MILL DESIGN 
laboratory on the EPR-taped joint design used at Waltz Mill. In addition, at the Waltz Mill Test Facility, two splices were subjected to 2 years of accelerated voltage testing. Past test experience also includes the more recent work performed on 138kV "higher stress" designs \#W-962-75A and \#W-962-75B. (Reference page 72 ). The $230 \mathrm{kV}$ joint design \#l dimensions are shown in Fig. 7.II. This design is believed to more closely match the heat dissipating properties of the cable than does the $230 \mathrm{kV}$ design shown in Fig. 7.10. This can be seen clearly by reference to the $R_{c a}$ ' ratio values graphed in Fig. 7.9. Although the design was based upon use of a connector having the same diameter as the cable conductor, use of other size conne ctors requires only slight modification of dimensions and stresses.

\section{STEP 3}

A second 138kV higher stress design joint labeled \#W-962-75B was designed and constructed in our long-term $138 \mathrm{kV} 400 \mathrm{kcmil}$ circuit. This differed from \#W962-75A in that it contained a Cadweld connector and slightly different electrical stresses. This design is shown in Fig. 7.I. The joint was subjected to the testing outlined as Step B of Appendix 7.1. In addition to that testing, which was a total of II33 test hours, an additional 2972 hours of testing have been completed on this design. 2526 hours of this was at $120 \mathrm{kV}$ phase-to-ground and included $4 \mathrm{I}$ load cycles at $90 \mathrm{C}$ and 10 load cycles at $130 \mathrm{C}$. An additional 446 hours of this testing was at $140 \mathrm{kV}$ phase-to-ground and included 15 load cycles at $90 \mathrm{C}$. The electrical stresses experienced during this testing are shown in Figures 7.2, $7.3,7.4$ and 7.5 . The stresses at $150 \%$ and $175 \%$ of rated voltage are also shown in Table I of Appendix 7.I. This testing provides preliminary indication that higher interfacial stresses are workable for $230 \mathrm{kV}$ designs. Further reference should be made to Appendix 7.I which outlines the following steps:

STEP A - Dissection of joint \#W962-75A was reported under Step I.

STEP B - $\quad$ Continued testing of joint \#W962-75B was reported under Step 3.

STEP C - $\quad$ A pencilling tool, motor drive unit and insulation stripper for the design of Step 2 was ordered in March 1976 and received during April 1976.

STEP D - Design of "low-stress" transition joints for a 230kV splice evaluation circuit. The design of transition joints to connect $2500 \mathrm{kcmil} 138 \mathrm{kV}$ cable to $1000 \mathrm{kcmil} 230 \mathrm{kV}$ cable was completed. The original purpose of this was to enable us to utilize existing laboratory equipment (G\&W $230 \mathrm{kV}$ paper roll terminations, Reference 7.3 ) for preliminary $230 \mathrm{kV}$ joint evaluation. The originally planned test sequence for this circuit was outlined on pages 6 to 8 of Appendix 7.1. This circuit was to serve as a qualification test circuit for joint designs in order 
TAPED SPLICE DESIGN 非 1

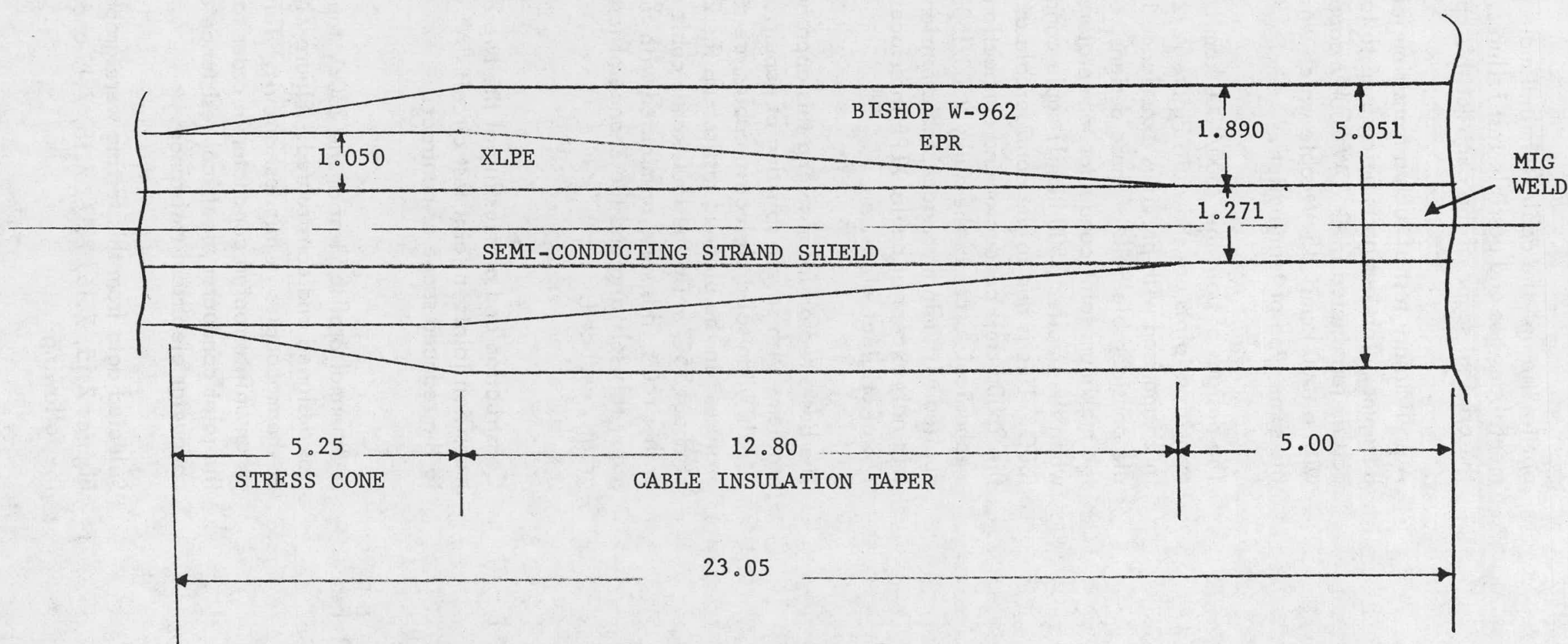

CABLE INSULATION TAPER ANGLE $=4.69^{\circ}$

STRESS CONE ANGLE $=9.09^{\circ}$ 
not to "tie up" the cable/terminal main test circuit with experimental designs and possible test failures. Due to modification of the original scope of the contract this approach could not be used.

A preliminary test of such a transition joint is being conducted, however. This design is being used to join a $2500 \mathrm{kcmil} I 38 \mathrm{kV}$ cable, terminated in G \& W $230 \mathrm{kV}$ paper roll terminations, with a $1500 \mathrm{kcmil} I I 5 \mathrm{kV}$ cable which was already terminated in the same type of termination.

The designs of both the $2500 / 1000 \mathrm{kcmil}$ and the $2500 / 1500 \mathrm{kcmil}$ transition joints are shown in Figure 7.12. Stresses are shown in comparison with previous experience in Table 7.1. In spite of the considerable bulk of these designs, calculations indicate that the maximum joint conductor temperature would be about 145C when the smaller ( $1500 \mathrm{kcmil})$ cable conductor was operating at I30C. This is due to the considerable axial "heat sink" effect of the $2500 \mathrm{kcmil}$ conductor and connection. In order to minimize mechanical forces in the bulky $2500 / 1500 \mathrm{kcmil}$ design, tapes were applied with minimum acceptable tension (tape width $=3 / 4$ of original) except at cable XLPE interfaces where tape width was $2 / 3$ of original width.

The basic reason for planning this approach was to avoid the known problems with severe splitting of paper rolls in $230 \mathrm{kV}$ G \& W terminals when solid dielectric cables are run at I30C conductor temperature. In the planned test set-up the $2500 \mathrm{kcmil}$ cable would run at about $75 \mathrm{C}$ while the $1500 \mathrm{kcmil}$ cable was at I30C. Thus, if both circuit ends were terminated with the $2500 \mathrm{kcmil}$ cables, paper roll splitting and the chance of terminal failure would be greatly reduced.

STEP E - Construction and pre-testing of the two $2500 \mathrm{kcmil} / 1000 \mathrm{kcmil}$ transition joints in joint test circuit " $A$ " was not accomplished due to the reduced scope of contract.

STEP F - A "thermal profile" test of the 230kV taped joint design of Step 2 was designed and constructed. Figure 7.13 shows the location of thermocouples in this test circuit. This joint was constructed on an uninterrupted conductor in order to provide basic data with the joint conductor electrical resistance exactly equal to the cable conductor electrical resistance.

Selected data from this testing were graphed and are shown in Figures $7.15,7.16,7.17,7.18,7.19$ and 7.20 . The data provides the following: 


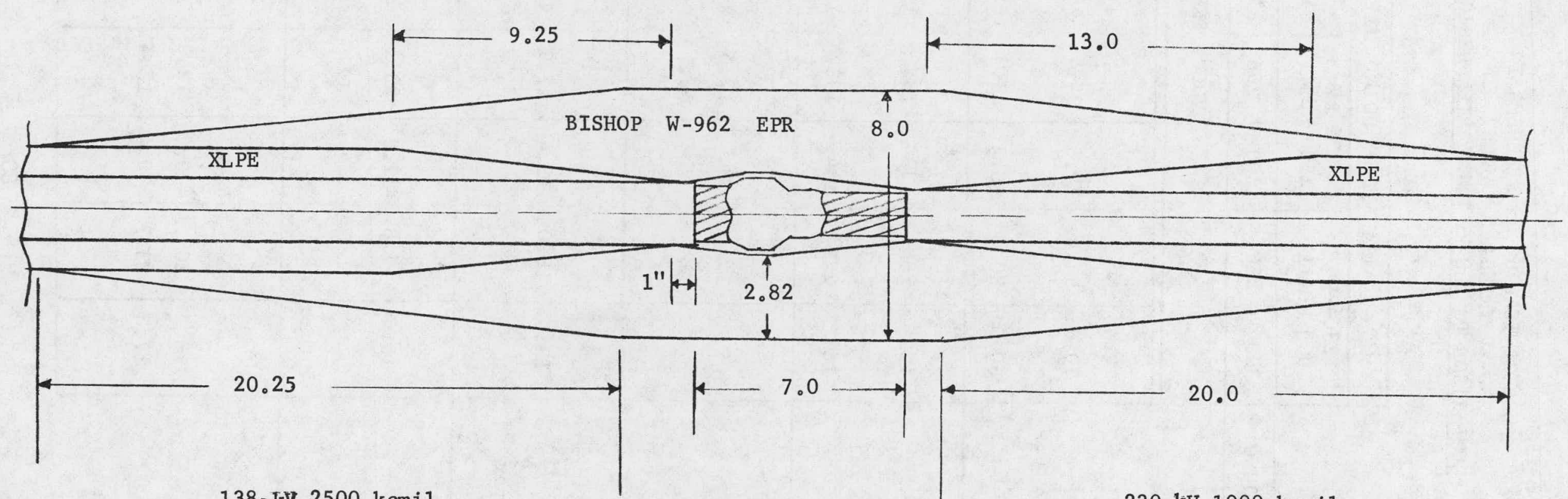

$138-\mathrm{kV} 2500 \mathrm{kcmi1}$

$230-\mathrm{kV} 1000 \mathrm{kcmil}$

$$
\text { FIG. } 7.12
$$


ELECTRICAL $60 \mathrm{~Hz}$ STRESSES IN

230-kV TRANSITION JOINTS IN

COMPARISON TO 138- $\mathrm{kV}$ WALTZ MILL DESIGN

\begin{tabular}{|c|c|c|c|c|c|c|c|c|}
\hline \multirow[b]{3}{*}{ KILOVOLTS, PHASE-TO-GROUND $\rightarrow$} & \multicolumn{6}{|c|}{ TRANSITION JOINT HALF } & \multirow{2}{*}{\multicolumn{2}{|c|}{$\begin{array}{l}138-k V \\
\text { WALTZ } \\
\text { MILL } \\
\text { DESIGN }\end{array}$}} \\
\hline & \multicolumn{2}{|c|}{$\begin{array}{c}230-\mathrm{kV} \\
1000 \mathrm{kcmil}\end{array}$} & \multicolumn{2}{|c|}{$\begin{array}{c}138-\mathrm{kV} \\
2500 \mathrm{kcmil}\end{array}$} & \multicolumn{2}{|c|}{$\begin{array}{c}115-\mathrm{kV} \\
1500 \mathrm{kcmil}\end{array}$} & & \\
\hline & 200 & 266 & 200 & 266 & 200 & 266 & 120 & 160 \\
\hline \multicolumn{9}{|c|}{ VOLTS PER MIL } \\
\hline $\begin{array}{l}60 \mathrm{~Hz} \text { Stress } \\
\text { Average Radial Stress }\end{array}$ & & & & & & & & \\
\hline At Splice Center & 70.8 & 94.4 & 70.8 & 94.4 & 70.8 & 94.4 & 80.0 & 106.6 \\
\hline $\begin{array}{l}\text { At Cable Insulation } \\
\text { Taper Edge }\end{array}$ & 60.0 & 80.0 & 66.2 & 88.3 & 62.0 & 82.7 & 70.5 & 94.0 \\
\hline \multicolumn{9}{|l|}{ Maximum Radial Stress } \\
\hline At Splice Center & 139 & 185 & 139 & 185 & 139 & 185 & 157 & 209 \\
\hline $\begin{array}{l}\text { At Cable Insulation } \\
\text { Taper Edge }\end{array}$ & 167 & 222 & 144 & 193 & 156 & 208 & 176 & 235 \\
\hline \multicolumn{9}{|l|}{ Average Interfacial } \\
\hline Creepage Stress & 9.4 & 12.5 & 9.4 & 12.5 & 9.4 & 12.5 & 7,5 & 10.0 \\
\hline $\begin{array}{l}\text { XLPE/EPR Interface } \\
\text { Tangential Stress } \\
\text { Across First } 0.25^{\prime \prime} \\
\text { of Cable Insulation Taper }\end{array}$ & 13.5 & 18.0 & 13.4 & 17.9 & 13.5 & 18.0 & 10.5 & 14.0 \\
\hline $\begin{array}{l}\text { XLPE/EPR Interface } \\
\text { Longitudina1 Stress } \\
\text { Across First } 0.25^{\prime \prime} \\
\text { At Stress Cone Base }\end{array}$ & 13.4 & 17.8 & 17.6 & 23.5 & 21.5 & 28.6 & 12.5 & 16.6 \\
\hline \multicolumn{9}{|l|}{$\begin{array}{l}\text { Connector Area } \\
\text { Longitudinal Stress } \\
\text { Across First } 0.25^{\prime \prime} \\
\end{array}$} \\
\hline At Shield Shoulder & 15 & 20 & 9.0 & 12.0 & 15 & 20 & - & - \\
\hline At Shield Taper Base & 17.8 & 23.7 & 9.4 & 12.5 & 16.8 & 22.4 & 11.3 & 15.0 \\
\hline
\end{tabular}



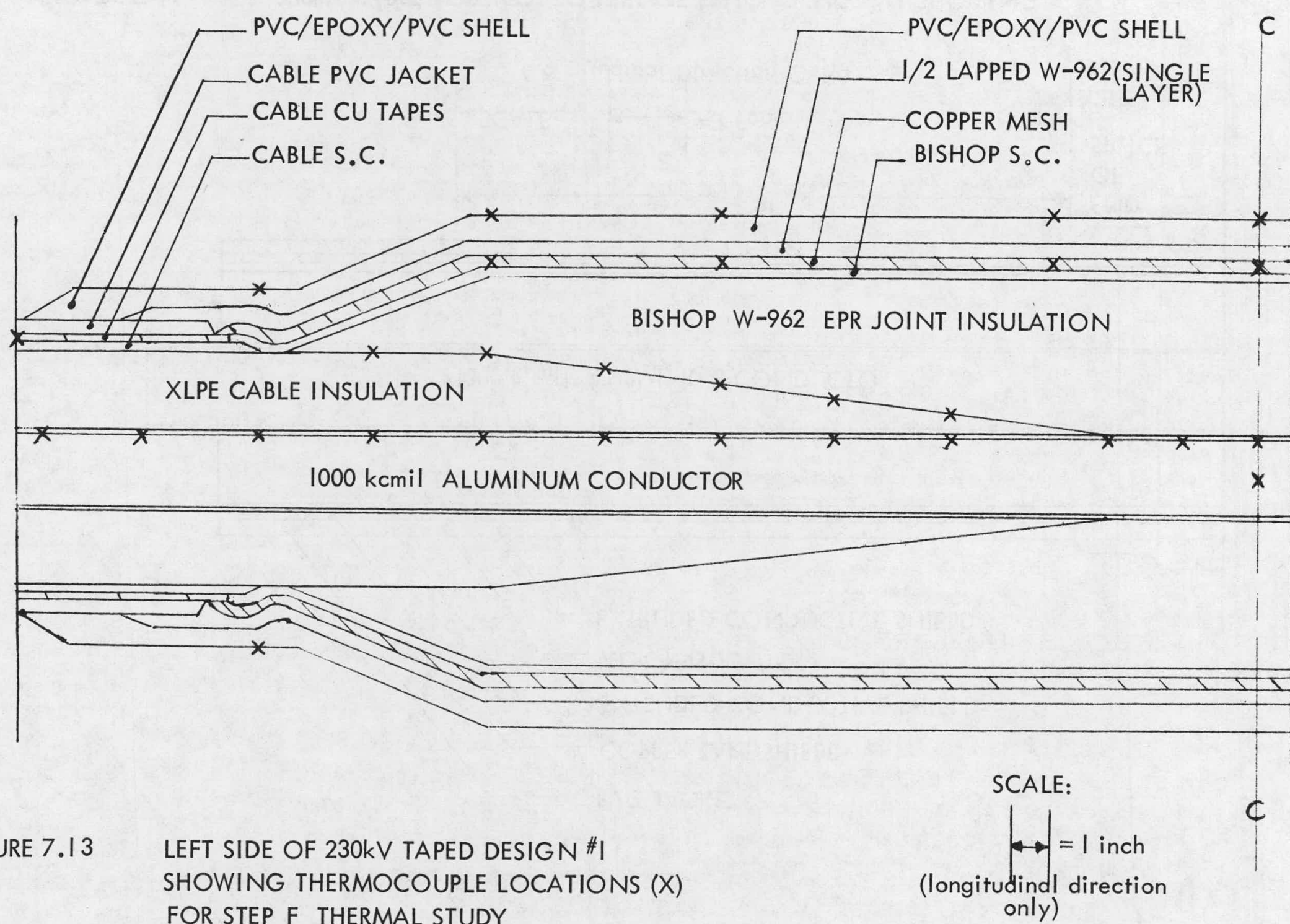


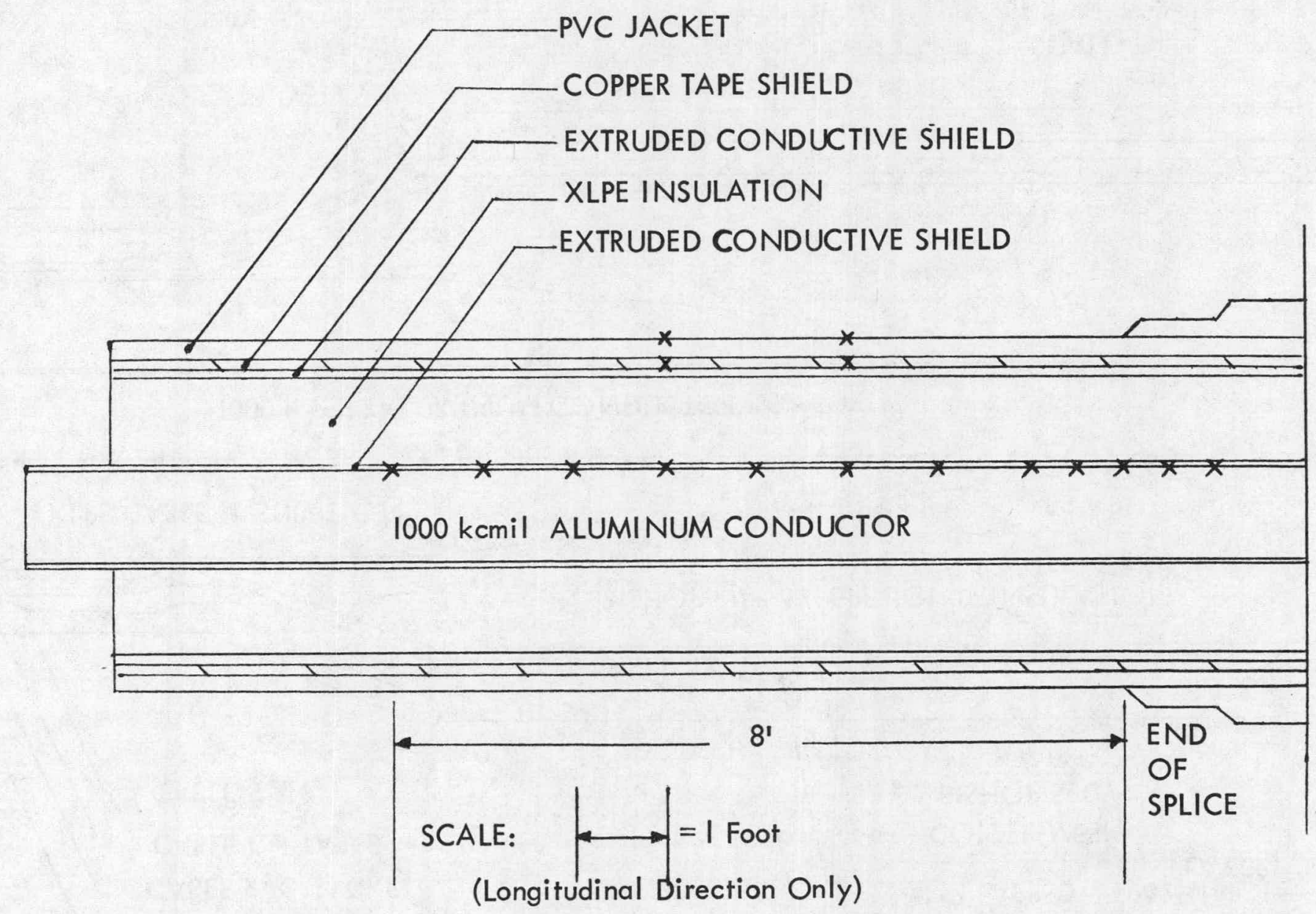

FIGURE 7.14. 230kV CABLE PORTION TO LEFT OF SPLICE DESIGN \#I SHOWING THERMOCOUPLE LOCATIONS ( $X$ ) 


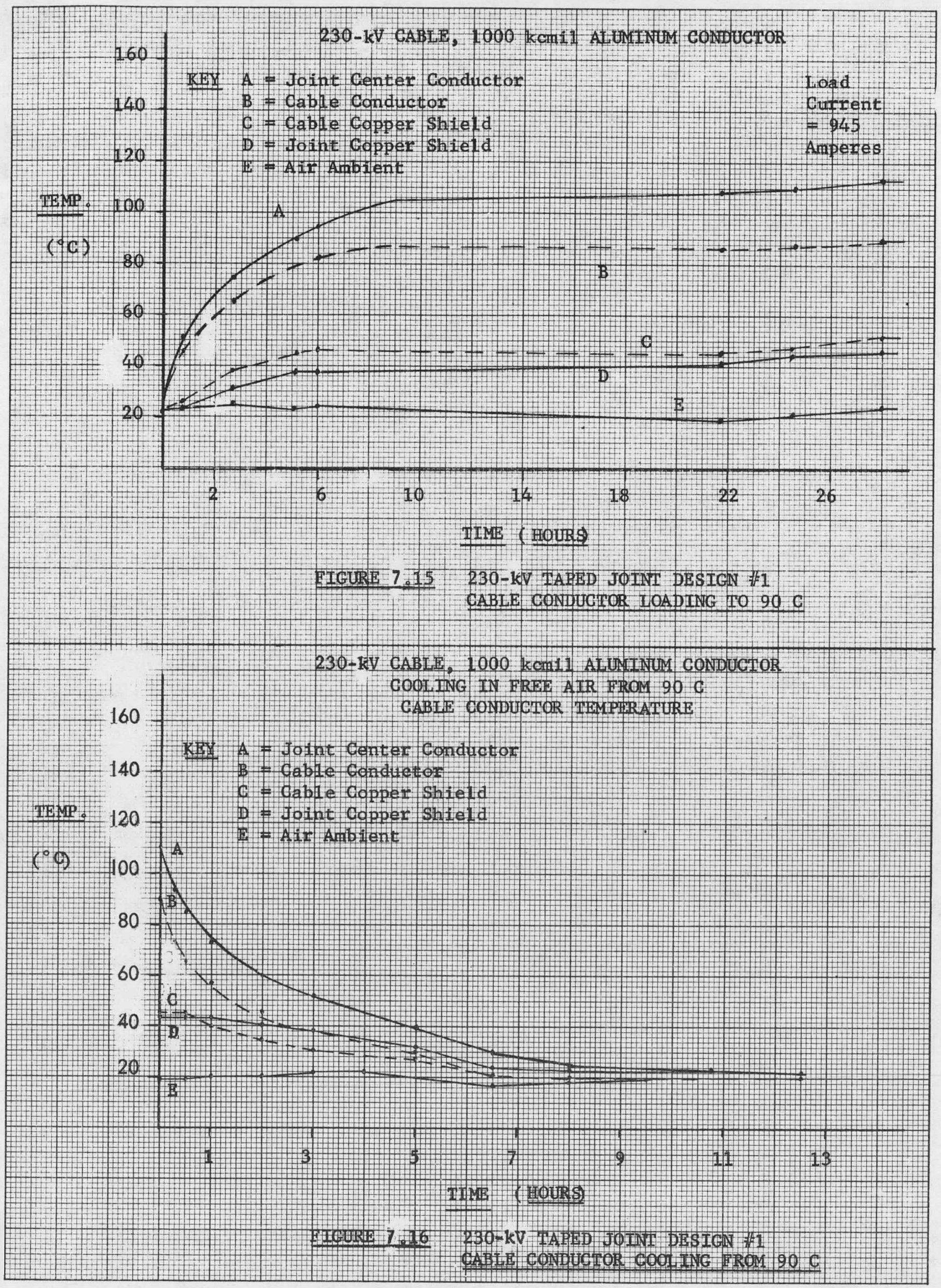




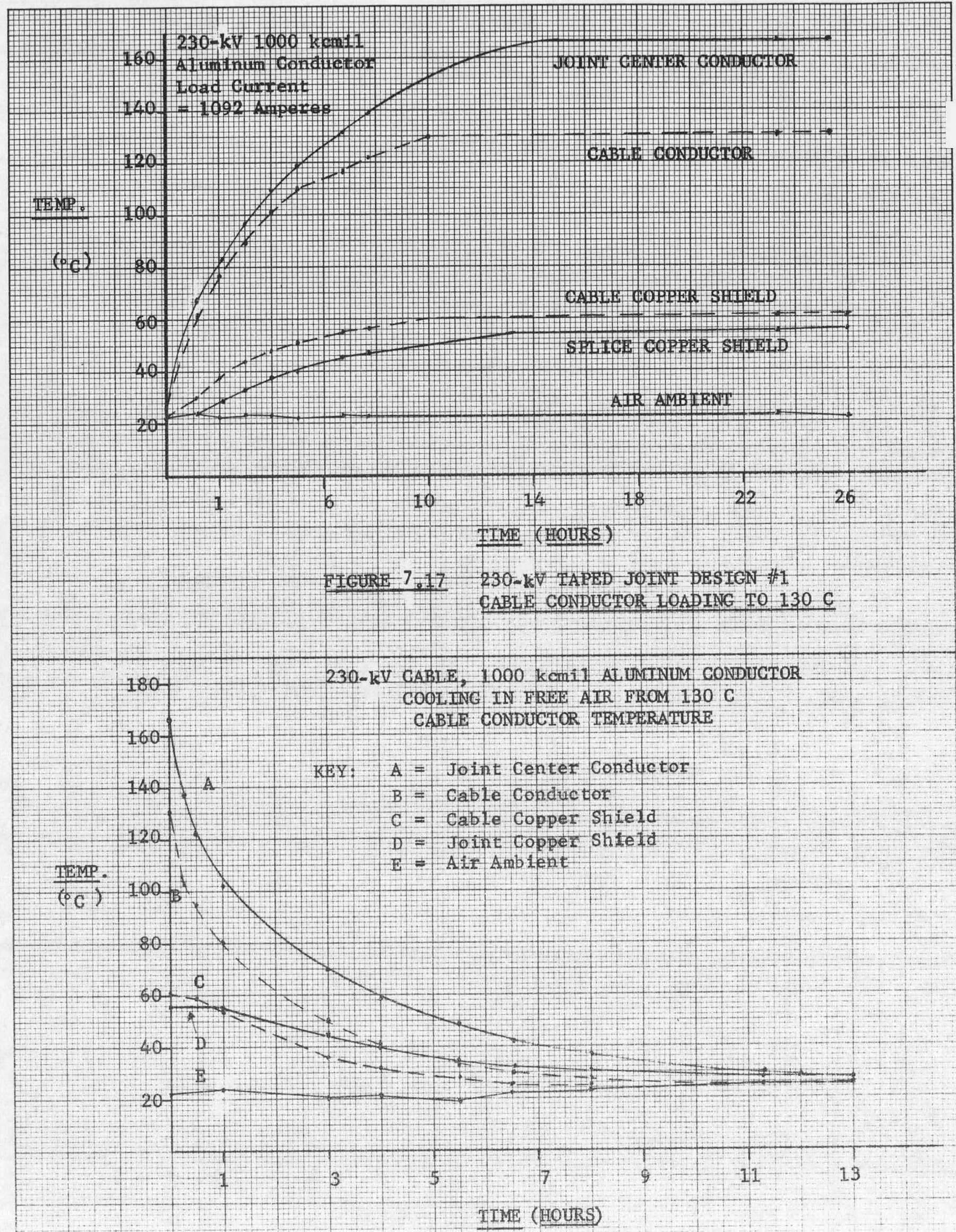

ZIGURE 7.18 230-kV TAPED JOINI DESTGN \# 1

CABLE CONDUCTOR COOLING FROM $130 \mathrm{C}$ 


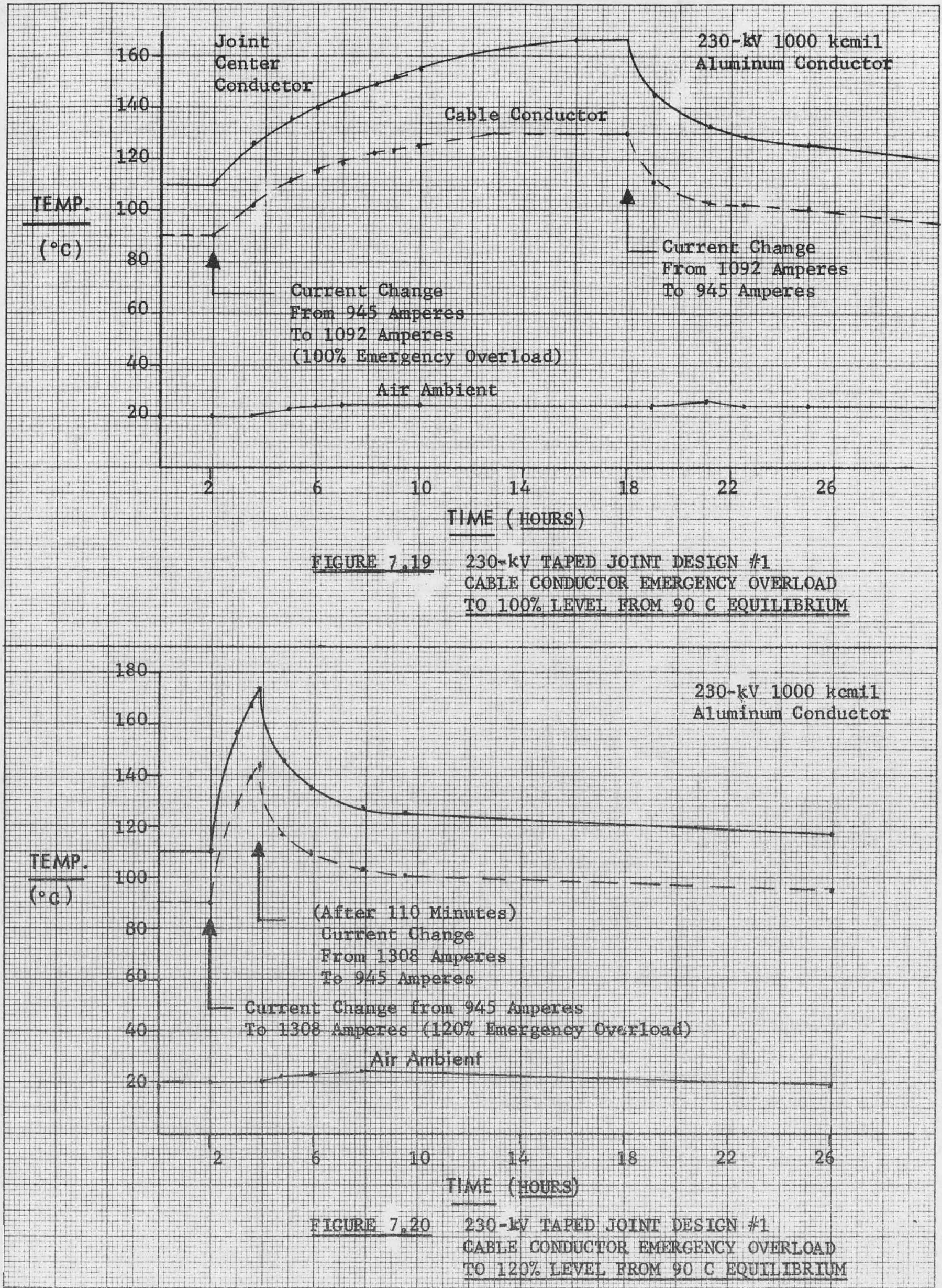


(1) An indication of the degree of overheating which may be expected in $230 \mathrm{kV}$ Joint Design \#I.

(2) Data for use in developing the thermal field computer program (Category 4, Part 3).

(3) Loading curves for $90 \mathrm{C}$ and $130 \mathrm{C}$ cable operation.

STEP G - $\quad$ The determination of methods for evaluating taped joint insulation was not pursued due to contract modification.

STEP H - Working relationships with tape manufacturers were established or re-established with the following manufacturers during the period October 1976 to January 1977:

$\begin{array}{lll}\text { BISHOP ELECTRIC, } & \text { Cedar Grove, N. J. } & \text { (REF. 7.I) } \\ \text { PLYMOUTH RUBBER, } & \text { Canton, Mass. } & \text { (REF. 7.4) } \\ \text { GENERAL ELECTRIC, } & \text { Schenectady, N. Y. } & \text { (REF. 7.5) } \\ \text { 3-M COMPANY, } & \text { St. Paul, Minn. } & \text { (REF. 7.6) }\end{array}$

As stated previously, our development work on $230 \mathrm{kV}$ taped joints was done using Bishop Electric materials. Although working relationships with the other three manufacturers were established, work was not brought out beyond the discussion stage due to the expected contract modification.

The planned electrical test sequence outlined in APPENDIX 7.I, pages 138140 , was not followed due to contract modification. A single $230 \mathrm{kV}$ taped joint was installed in the $60 \mathrm{~Hz} 230 \mathrm{kV}$ cable/terminal evaluation circuit and a single $230 \mathrm{kV}$ taped joint was installed in an impulse test circuit for a modified test program .

\subsubsection{ELECTRICAL TESTING OF 230kV TAPED JOINT DESIGN \#I}

\section{$60 \mathrm{~Hz}$ ACCELERATED LOAD CYCLE TESTING}

Following 809.5 hours, and 35 load cycles, of accelerated testing on the $230 \mathrm{kV}$ cable/terminal evaluation circuit, it was decided to install a single $230 \mathrm{kV}$ taped joint. Construction of the joint was in accordance with the design shown in FIGURE 7.II except that an exothermic weld was used. This resulted in an increase of 0.29 " in all diameters and a slight decrease in maximum radial $60 \mathrm{~Hz}$ stress. Complete construction of the joint required 18 hours ( 36 man-hours). 
In order to permit dielectric isolation of the splice insulation from the cable insulation, shield interrupters were installed at each end of the $230 \mathrm{kV}$ joint. This permitted individual dissipation factor, capacitance and partial discharge measurements to be made for the splice, cable half length with $G$ \& W terminal, and cable half length with Joslyn terminal.

The $230 \mathrm{kV}$ taped joint was then subjected to an accelerated (overvoltage) test program. This included 36 load cycles at rated $(90 \mathrm{C})$ cable conductor temperature (Load cycles \#36-5I and \#68-87). In addition to this, 16 load cycles were completed at emergency $(\mathrm{I} 30 \mathrm{C}$ ) cable conductor temperature (Load cycles \#52-67). These $130 \mathrm{C}$ load cycles were performed with the circuit energized at rated voltage (Load cycles \#52-55) and at $125 \%$ rated voltage (Load cycles \#5667). Nearly all of the $90 \mathrm{C}$ testing was performed with the circuit energized at $150 \%$ rated voltage ( $200 \mathrm{kV}$ line-to-ground). In total the joint was subjected to 1338.5 hours of high voltage testing. Of this total 116.6 hours were at $100 \%$ rated line-to-ground $230 \mathrm{kV}$ voltage $(133 \mathrm{kV}), 317.2$ hours were at $125 \%$ rated voltage $(166 \mathrm{kV})$ and 904.7 hours were at $150 \%$ rated voltage $(200 \mathrm{kV})$.

Measurements of partial discharge characteristics of the $230 \mathrm{kV}$ test circuit (including joint) were made initially, at several intervals during the test, and near the end of the testing program. These results are reported in Section 6.0, Tables 6.18 through 6.22. In general, the measurements indicated satisfactory partial discharge levels. When measurements were taken with the circuit at room temperature partial discharge levels were as high as $10 \mathrm{pC}$ at $150 \%$ rated voltage but always were below $5 \mathrm{pC}$ at $125 \%$ rated voltage. When measurements were taken at the elevated temperatures of $90 \mathrm{C}$ and $130 \mathrm{C}$ results were excellent, with partial discharge levels below the measuring sensitivity of the detection equipment $(\mathrm{I} \mathrm{pC})$. The comparison of measurements over the course of the testing indicates the stability of the partial discharge characteristics of the $230 \mathrm{kV}$ evaluation circuit, including joint.

Measurements of capacitance and \% dissipation factor were made initially, at several intervals during the test, and near the end of the testing program. These results are reported in Section 6.0, Tables 6.13 through 6.17 In addition, a series of measurement runs were made to determine the effect of load current and continuous applied voltage on the dissipation factor of the joint. These test results are graphed in Figures 7.20A and 7.20B. The dissipation factor of an EPR taped joint is of interest with regards to stability over a period of time with a load current applied. In Figure 7.20A, at a conductor temperature of $90 \mathrm{C}$ the dissipation factor reaches stability when energized continuously at $100 \%$ rated ( $133 \mathrm{kV}$ line-to-ground) and at $125 \%$ rated (16ókV line-to-ground) voltage. At $150 \%$ rated voltage the \% dissipation factor appears to be rising steadily after 12 hours of current loading. It is believed that had these measurements continued beyond the 12 hour point (length of heating portion of 24 houl load cycle) the \% dissipation factor would have reached stability. This was verified by 


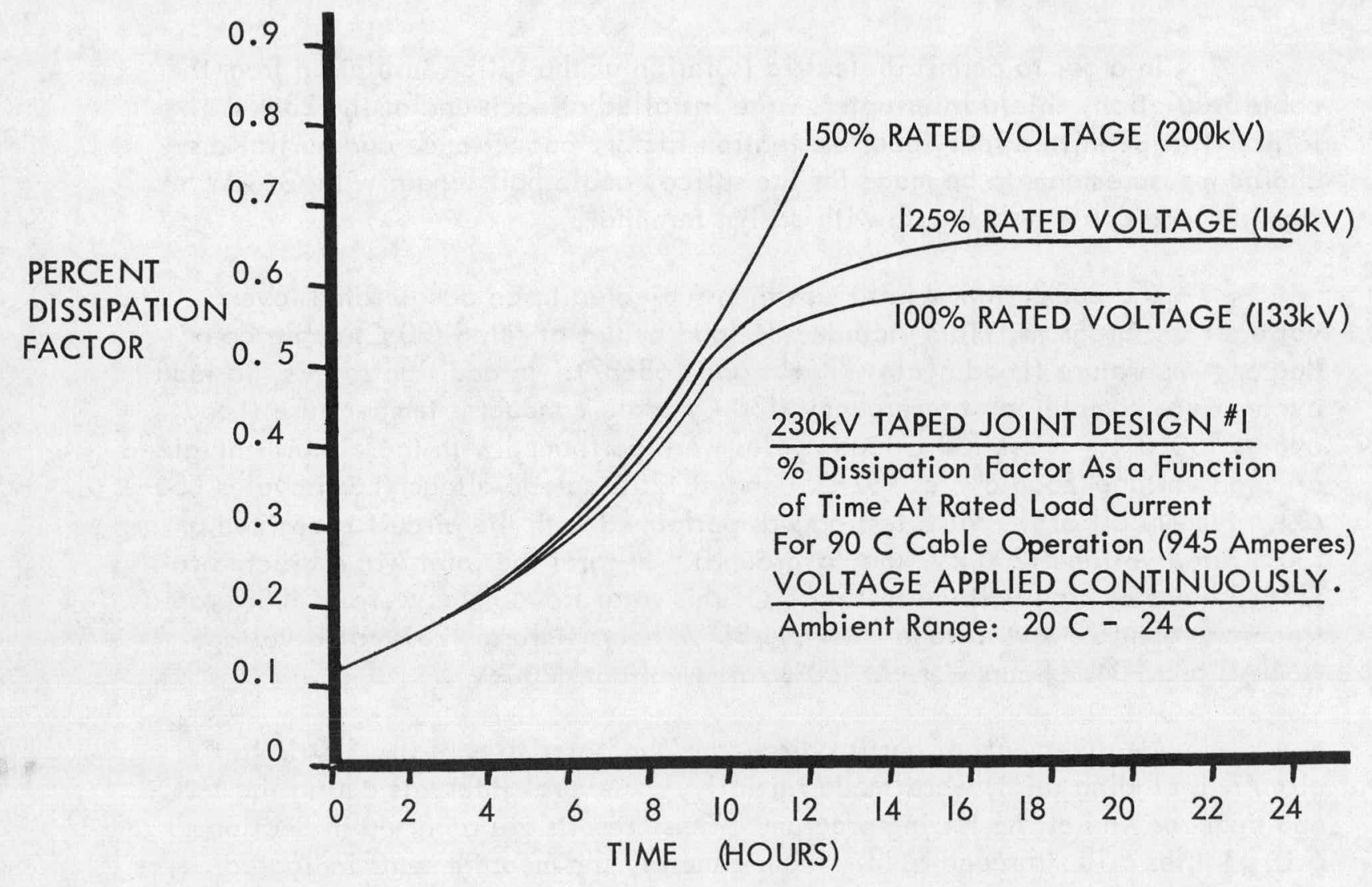

FIGURE 7.20 A

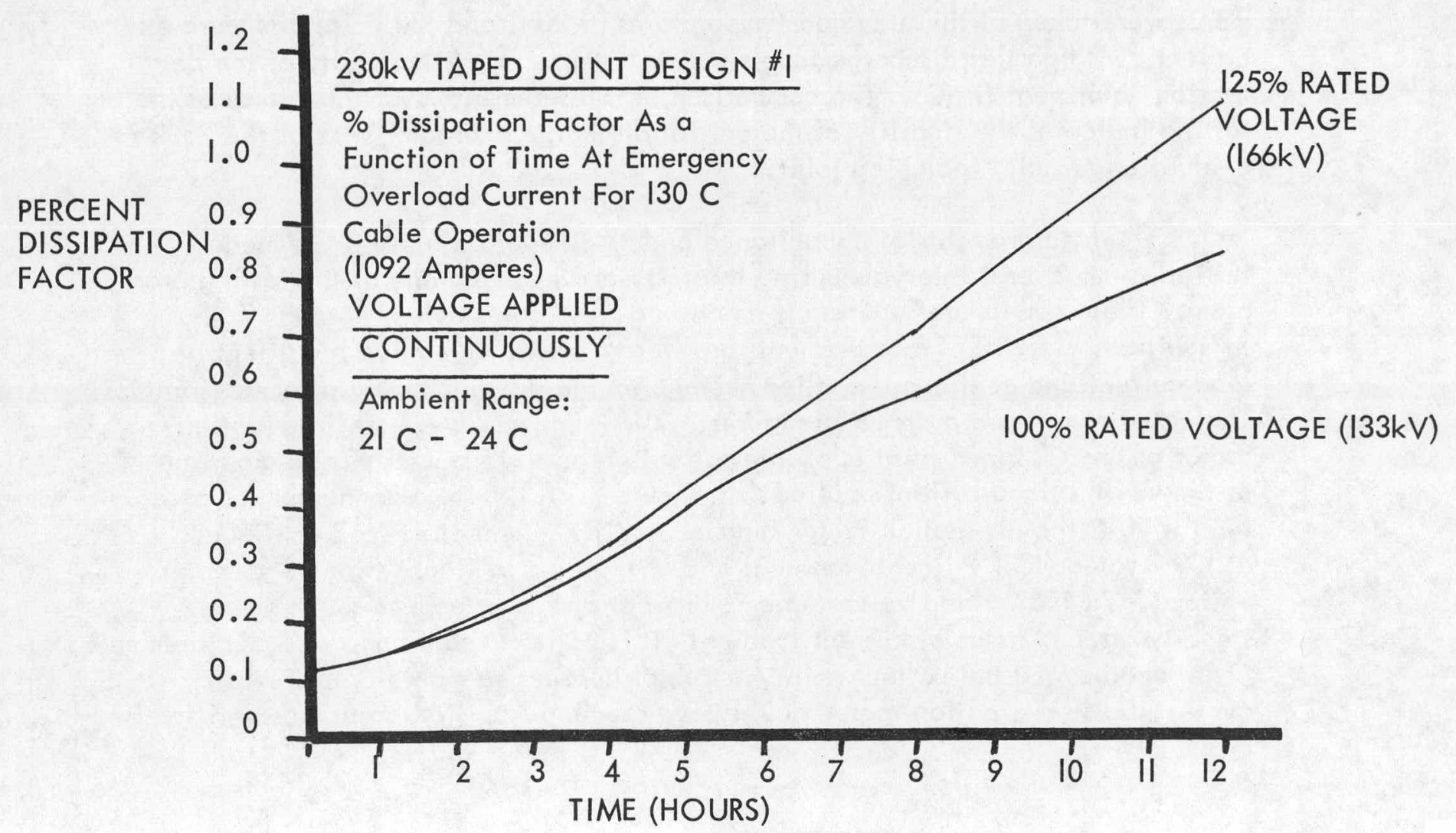

FIGURE 7.20 B 
a later test where \% dissipation factor was measured at $90 \mathrm{C}$ and with continuous $150 \%$ rated voltage applied, with a load current of 945 amperes applied for 18 hours continuously. By the 18 hour point the $\%$ dissipation factor was stabilizing at slightly above $0.6 \%$. It is concluded that the joint would be electrically stable at $150 \%$ rated voltage and $90 \mathrm{C}$ continuous operation.

It was noted that $\%$ dissipation factor readings for the joint tended to decrease in numerical value over the course of the test. In example, the readings just discussed represented a decrease of about 0.15 (decrease from $0.761 \%$ to $0.610 \%)$. Also, the initial room temperature readings, compared with the final readings, indicate a decrease from $0.121 \%$ to $0.100 \%$ (Reference Tables 6.14 and 6.17. This tendency for the dissipation factor to improve may be due to a gradual increase in the degree of cure of the EPR splice insulation.

Figure $7.20 \mathrm{~B}$ depicts the increase in \% dissipation factor of the $230 \mathrm{kV}$ joint when subjected to 12 hour heating periods at emergency $(130 \mathrm{C})$ conductor loading. A 1092 ampere load current was induced while the conductor was continuously energized at $100 \%$ and at $125 \%$ rated voltage. The $130 \mathrm{C}$ measurements were not carried out beyond the 12 hour point. The $1.1 \%$ dissipation factor observed at the 12 hour point (at 125\% rated voltage) compares very favorably with the $3.5 \%$ dissipation factor observed with our $138 \mathrm{kV}$ Waltz Mill design at the 12 hour point of a $125 \%$ overvoltage test.

\section{IMPULSE TESTING}

In order to test a single joint for impulse withstand, a series of steps were taken. First, a length of $230 \mathrm{kV}$ cable was tested (Sample 1). The results of this test at room temperature are shown in Table 6.24 , page 54 . Termination failure occurred. A separate length of $230 \mathrm{kV}$ (manufacturing run \#3) cable (Sample 2) was set up for impulse test and the results of this series of tests are shown in Table 6.25, page 55. In brief, the cable passed all tests at room temperature but a failure occurred at BIL while testing at $90 \mathrm{C}$ conductor temperature. The fault was cut out and a $230 \mathrm{kV}$ joint constructed that was identical to the $60 \mathrm{~Hz}$ test joint (Taped joint design \#I, Fig. 7.II).

The cable and joint were then impulse tested as shown in Table 6.26, page 56. Both cable and joint passed BIL requirements at room temperature. When tested with the cable conductor at $90 \mathrm{C}$, (joint conductor at about $114 \mathrm{C}$, reference Figure 7.15) a joint failure occurred on the third impulse at BIL. Examination of the fault revealed that a radial dielectric puncture occurred at a point about 2-3/4" from the center of the connector near the edge of the factory conductor strand shielding. The cause of this fault was uncertain. 


\section{CONCLUSION}

The 230kV Taped Joint Design \#I $60 \mathrm{~Hz}$ test results indicate compatability with the $230 \mathrm{kV} \times$ XPE-insulated cable. Overvoltage testing at $150 \%$ rated voltage with the joint carrying rated $90 \mathrm{C}$ load current indicates a substantial margin of safety in the design. Overvoltage testing at $125 \%$ rated voltage with the joint carrying emergency overload $130 \mathrm{C}$ load current also indicates a reasonable margin of safety in the design. The design appears to be reliable and satisfactory for normal $60 \mathrm{~Hz}$ operation. Measurements indicate electrical stability and freedom from partial discharge at voltages significantly higher than $230 \mathrm{kV}$ ratings.

The occurrence of a radial dielectric fault on the third impulse at $90 \mathrm{C}$ and Basic Impulse Level indicates that the joint might require a somewhat thicker insulating wall with consequent lower unit voltage stresses. Verification of this would require the construction and testing of two additional joints based on design \#I. Based upon the single test, Taped joint design \# must be considered marginal on impulse test at $90 \mathrm{C}$.

\subsection{CATEGORY 2 - VULCANIZED JOINT}

In order to continue work on this type of joint at the point where it was stopped in 1974, the program outlined in Appendix 7.1 was laid out. The objective was the eventual application of the vulcanized joint at the $230 \mathrm{kV}$ level.

Work was begun at the $69 \mathrm{kV} 500 \mathrm{kcmil}$ level. Steps that were completed between the beginning of the $230 \mathrm{kV}$ ERDA contract and $12 / 31 / 75$ are outlined under Category 2 of Appendix 7.1. The final status of each of the planned program steps referring to Appendix 7.1 will now be reported.

STEP A - Evaluation of the vulcanized polyethylene joint method at the $69 \mathrm{kV}$ level. In order to perform this task, a series of $1069 \mathrm{kV} 500 \mathrm{kcmil}$ vulcanized joints were constructed in a cable which had been pre-terminated and tested. Five laboratory people made two joints each. This was done in order to assess the transferability of the method. The joints were made according to the design shown in Figure 7.21. An electrical evaluation test sequence was planned and followed accordirig to the outline shown in Table 7.2.

During the conduci of the test as outlined, a series of 4 failures occurred. Two of these were legitimate joint failures which occurred early in the test program. These 
69-kV KAISER VULCANIZED POLYETHYLENE SPLICE DESIGN

$500 \mathrm{kcmil}$ ALUMINUM

SCALE $=1.1$

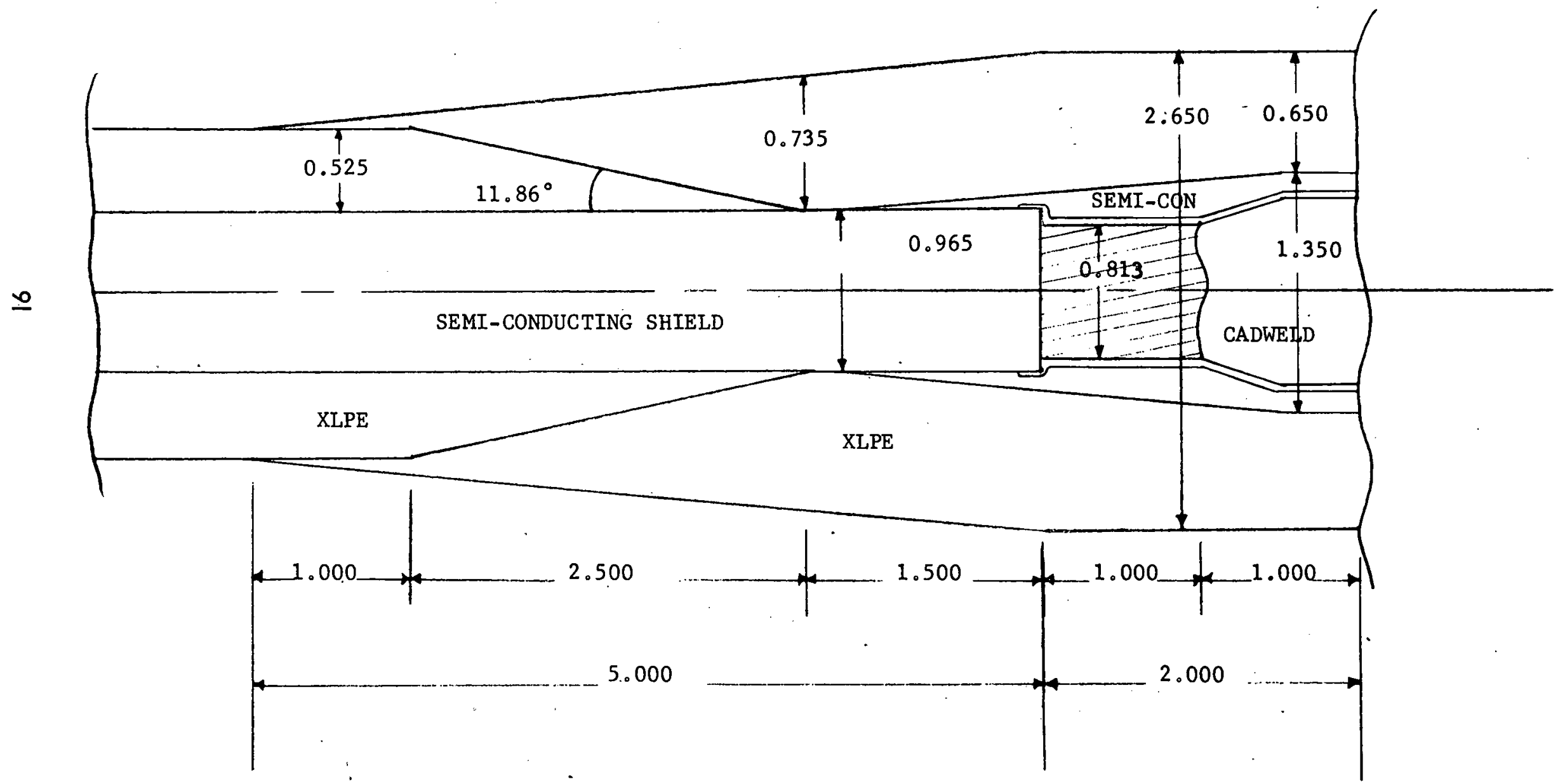

FIGURE 7.21

r. 


\section{TABLE 7.2}

\section{TEST PROCEDURE FOR EVALUATION OF 69-kV VULCANIZED POLYETHYLENE SPLICES}

1. Measure dissipation factor and capacitance of individual splices and terminals at room temperature with $100 \%, 150 \%, 200 \%$, and $250 \%$ rated voltage.

2. Measure partial discharge characteristics of individual splices and terminals at room temperature with voltage up to the $250 \%$ rated level.

3. Energize at $200 \%$ rated voltage continuously for 240 hours. Load cycle with 670 amperes for a total of 20 cycles at $90 \mathrm{C}$ conductor temperature (8 hours on/ 4 hours off).

4. During last two hours of Load Cycles $\# 19$ or $\# 20$, repeat Steps $\mid \& 2$ up to $200 \%$ rated voltage with conductor at $90 \mathrm{C}$.

5. Repeat Steps $1 \& 2$ at room temperature following completion of Step 3 (20th Load Cycle).

6. Impulse test circuit (terminals short-circuited) at B.I.L. (350kV) 10 impulses with negative polarity. Impulse test circuit at I.25x B.I.L. (438kV) 10 impulses with negative polarity. All impulsing to be performed with conductor temperature of $90 \mathrm{C}$. NOTE: Terminals taken out of the effective test circuit during impulse tests to prevent their premature failure.

7. Repeat Steps I \& 2 at room temperature.

8. Energize at $150 \%$ rated voltage continuously for 240 hours. Load cycle with 780 amperes ( $130 \mathrm{C}$ conductor) 8 hours on $/ 4$ hours off for 20 cycles.

9. During last two heating hours of Load Cycles \#39 or \#40, repeat Steps I \& 2 up to $150 \%$ rated voltage with conductor at $130 \mathrm{C}$.

10. Repeat Steps I \& 2 at room temperature.

11. Repeat Step 6.

12. Repeat Steps I \& 2 at room temperature.

13. Repeat Step 3.

14. During last two heating hours of Load Cycles \#59 or \#60, repeat Steps 1 \& 2, up to $200 \%$ rated voltage with conductor at $90 \mathrm{C}$. 
15. Repeat Steps I \& 2 at room temperature.

16. Repeat Step 6.

17. Repeat Steps I \& 2 at room temperature.

18. Energize at $250 \%$ rated voltage continuously for 240 hours. Load Cycle with 670 amperes for a total of 20 cycles at $90 \mathrm{C}$ conductor temperature ( 8 hours on $/ 4$ hours off).

19. During last two heàting hours of Load Cycles \#79 or \#80, repeat Steps 1 \& 2, up to $250 \%$ rated voltage with conductor at $90 \mathrm{C}$.

20. Repeat Steps 1 \& 2 at room temperature:

21. Repeat Step 6.

22. Repeat Steps I \& 2 at room temperature.

23. DC Test at $175 \mathrm{kV}$ positive polarity at room temperature.

24. With conductor temperature at $90 \mathrm{C}$ and with terminals in the effective test circuit, apply 10 negative polarity impulses at $80 \%, 90 \%$, and $100 \%$ of B.I.L. Continue in $5 \%$ increments of B.I.L. until failure occurs.

25. Remove all shield interrupters.

26. Perform $60 \mathrm{~Hz}$ step test at $90 \mathrm{C}$ conductor temperature. Begin at IIOkV test level and increase in $10 \mathrm{kV}$ increments (30 minute durations) until breakdown occurs. 
two failures were determined to be due to a discrete lack of bond between applied and cable insulation. The lack of bond was considered to be due to the use of Teflon tape used to "protect" the cable insulation during connector shield processing. It was believed that adhesive from this tape randomly deposited on the cable surface and the occurrence was noted on only 2 of the original 10 joints. After this observation the use of this Teflon tape was discontinued and no further problems occurred. A third failure occurred due to a defective cable shield interrupter and was not related to joint quality. In the effort to repair this failure a "patch" was attempted using vulcanized polyethylene. Due to close proximity to another joint, the processing of the "patch" resulted in damage to the joint which was not visually obvious. Soon after re-energizing the test circuit, this joint failed. Failure was due to distortion of the joint during patch processing. The joint was remade. Since all these problems occurred early in the test program it was decided to restart the test from the beginning and this was done. The entire test program was completed without further incidents. The considerable test data obtained was condensed into Tables 7.3 and 7.4. Following the test program as outlined, a $60 \mathrm{~Hz}$ step test to breakdown was performed with the conductor at $90 \mathrm{C}$. The result was a cable failure at $170 \mathrm{kV}$. Each of the ten test joints was then cut from the circuit and "slinkies" of the total insulation from each of these joints were prepared.

STEP B - The insulation and connector shielding from each of the ten $69 \mathrm{kV}$ tested joints, prepared in slinky form, was inspected according to the inspection format shown as Table 7.5. The detailed visual inspection data, which fills 84 pages of data books, was condensed to show typical insulation quality. This condensation is shown as Table 7.6. These data provide a reference for future work with the polyethylene vulcanized joint. It can be seen that quite a wide range of voids (both size and quantity) occurred, as well as contaminants in considerable quantity. Some of the joints met AEIC 5-75 cable insulation void requirements while others did not. With regard to contaminants, the joint insulations did not meet AEIC 5-75 (Ref. 7.7) requirements. In spite of this, test joints ${ }_{1} 1,2,3 \mathrm{~A}, 4,5,6 \mathrm{~A}, 7 \mathrm{~A}, 8 \mathrm{~A}, 9$ and 10 completed the test without failure. The results indicated that the next steps in the vulcanized polyethylene joint program should focus upon reduction of voids, contaminants and joint wall eccentricity. 


\section{DISSIPATION FACTOR MEASUREMENTS \\ OF TEN $500 \mathrm{kcmil} 69-\mathrm{kV}$ \\ VULCANIZED POLYETHYLENE JOINTS}

ALL READINGS BELOW AT 200\% RATED PHASE-GROUND VOLTAGE ( $80 \mathrm{kV}$ )

\begin{tabular}{|c|c|c|c|c|c|c|}
\hline TEST PERIOD & 1 & 4 & 10 & 14 & 19 & 22 \\
\hline CONDUCTOR TEMP. & $20 \mathrm{C}$ & $90 \mathrm{C}$ & $22 \mathrm{C}$ & $90 \mathrm{C}$ & $90 \mathrm{C}$ & $23 \mathrm{C}$ \\
\hline $\begin{array}{l}500 \mathrm{kcmil} \quad 69-\mathrm{kV} \\
\text { Vulcanized } \\
\text { Polyethylene Joint \#⿰ }\end{array}$ & \multicolumn{6}{|c|}{ PERCENT DISSIPATION FACTOR } \\
\hline 1 & 0.085 & 0.065 & 0.065 & 0.040 & 0.034 & 0.045 \\
\hline 2 & 0.193 & 0.068 & 0.060 & 0.033 & 0.027 & 0.040 \\
\hline $3 \mathrm{~A}$ & 0.107 & 0.061 & 0.020 & 0.034 & 0.035 & 0.045 \\
\hline 4 & 0.103 & 0.049 & 0.050 & 0.035 & 0.035 & 0.045 \\
\hline 5 & 0.100 & 0.044 & 0.051 & 0.025 & 0.026 & 0.034 \\
\hline $6 \mathrm{~A}$ & 0.046 & 0.058 & 0.051 & 0.029 & 0.036 & 0.042 \\
\hline $7 \mathrm{~A}$ & 0.194 & 0.056 & 0.050 & 0.027 & 0.031 & 0.040 \\
\hline $8 \mathrm{~A}$ & 0.196 & 0.048 & 0.048 & 0.026 & 0.030 & 0.040 \\
\hline 9 & 0.107 & 0.043 & 0.051 & 0.025 & 0.038 & 0.041 \\
\hline 10 & 0.120 & 0.036 & 0.048 & $0.078 *$ & $0.054 *$ & $0.065 *$ \\
\hline Cable \& 10 Joints & 0.077 & 0.016 & 0.029 & 0.017 & 0.032 & 0.019 \\
\hline Reference Cable Only & 0.046 & 0.030 & 0.033 & 0.019 & 0.010 & 0.025 \\
\hline
\end{tabular}

*Defective Shield Interrupter

**Reference Table 7.2 
TABLE 7.4

MEASURED PARTIAL DISCHARGE CHARACTERISTICS OF A $500 \mathrm{kcmil} 69 \mathrm{kV}$ SOLID DIELECTRIC CABLE TEST CIRCUIT INCLUDING TEN VULCANIZED POLYETHYLENE JOIN TS AND TWO RAYCHEM 69kV THERMOFIT TERMINATIONS

TEST*

PERIOD

CONDUCTOR

TEMPERATURE

$\begin{array}{lllllllllll}2 & 4 & 5 & 9 & 12 & 14 & 15 & 17 & 19 & 20 & 22\end{array}$

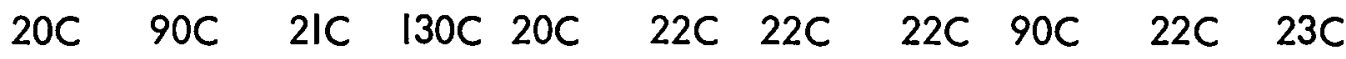

TEST LEVEL

$60 \mathrm{~Hz}$ KILOVOLTS

PICOCOULOMBS - PARTIAL DISCHARGE ***

40

NM NM NM NM NM NM NM NM NM NM NM

60

NM NM NM 2 NM NM NM NM NM NM NM

80

5.7

$5 \quad 5 \quad-$

5. NM 5

5 NM NM NM

84

100

35

**

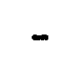

80

60

40

NM NM NM NM NM NM NM NM NM NM NM

* Reference TABLE 7.2 for Test Program.

** Indicates no measurement was taken.

*** The calibration pulse (equal to 5 pico-coulombs per inch) is a reference against which any discernible discharges are compared. Where no visible discharges are evident, the letters NM (not measurable) are shown. Measurable discharges are denoted by an actual numerical value. 
TABLE 7.5

FORMAT FOR XLPE SPLICE. INSULATION DATA RECORDING

SPLICE \#

UNAIDED VISUAL INSPECTION

Amount of splice inspected:

No. of slinkies:

No. of apparent voids:

Voids/in. ${ }^{3}=$

Primary void shape: (spherical, radial disc, axial disc, (cylindrical, etc.

Secondary void shape:

Remarks:

\section{INSPECTION UNDER MAGNIFICATION}

Magnification power:

(Select 20 consecutive slinkies of worst-appearing section of splice)

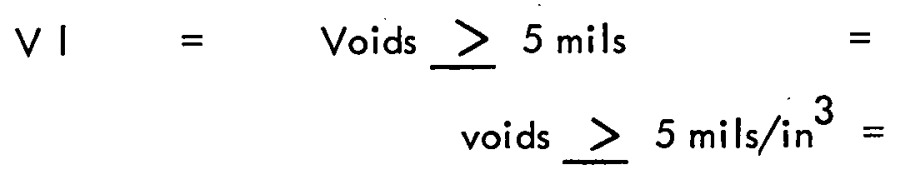

V2 $=$ Voids $\geq 2$ mils $\leq 5$ mils $=$

$\checkmark 2 /$ in $^{3}=$

$\mathrm{Cl}=$ Contaminants $\geq 10 \mathrm{mils}=$

$\mathrm{Cl} /$ in. $^{3}=$ 
TABLE 7.5 (Cont'd.)

C $2=$ Contaminants $\geq 2$ mils $\leq 10 \mathrm{mils}=$
C $2 / \mathrm{in.}^{3}=$

REMARKS: (report any significant or unusual observations)

ECCENTRICITY

Insulation minimum at splice center=

Insulation maximum at splice center=

Total minimum at splice center =

Total maximum at splice center =

PROCESS DATA

CONNECTOR SHIELD

Shield process temperature \& time:

Special measures taken:

Material: (i.e. UC 0590)

Method of Application:

INSULATION

Insulation process temperature \& time:

Special measures taken:

Material: (i.e. Cooke 52l)

Method of Application:

R.H. and air ambient during application:

Cooling Method:

PERCENT EXTRACTABLES (Modified Method )

Sample location:

\% Extractables:

REMARKS: (report any significant or unusual observations) 
TABLE 7.6

TYPICAL TEST JOINT DATA - 69kV $500 \mathrm{kcmil}$ VULCANIZED PE JOINT

\begin{tabular}{|c|c|c|c|c|}
\hline PROCESS DATA: & $\begin{array}{l}0580-1.5 \mathrm{H} \\
52 \mathrm{I}-12 \mathrm{H}\end{array}$ & $\begin{array}{l}@ 370 \mathrm{~F} \\
@ 330 \mathrm{~F}\end{array}$ & $\begin{array}{l}\text { Semi-Con } \\
\text { Step-Cooled }\end{array}$ & Insulation \\
\hline TEST DATA: & $\begin{array}{l}261.3 \mathrm{H} \\
235.5 \mathrm{H} \\
285.5 \mathrm{H} \\
484.0 \mathrm{H}\end{array}$ & $\begin{array}{l}@ 80 \mathrm{kV} \\
@ 60 \mathrm{kV} \\
@ 80 \mathrm{kV} \\
@ 100 \mathrm{kV}\end{array}$ & $\begin{array}{r}90 \mathrm{C} \\
130 \mathrm{C} \\
90 \mathrm{C} \\
90 \mathrm{C}\end{array}$ & \\
\hline BOND: & \multicolumn{2}{|c|}{$\begin{array}{l}\text { Insulation/Insulation: } \\
\text { Insulation/Semi-Con: } \\
\text { Semi-Con/Semi-Con: }\end{array}$} & \multirow[t]{2}{*}{$\begin{array}{l}\text { Good } \\
\text { Fair } \\
\text { Good }\end{array}$} & \\
\hline $\begin{array}{l}\text { ECCENTR ICITY: } \\
\text { (Splice Center) }\end{array}$ & $\begin{array}{l}\text { High: } \\
\text { Low: }\end{array}$ & $\begin{array}{l}.802 \\
.488\end{array}$ & & \\
\hline INSULATION: & $\begin{array}{l}\text { Avg. High: } \\
\text { Avg. Low: } \\
\text { Avg. Spread: }\end{array}$ & $\begin{array}{l}.736 \\
.586 \\
150 \mathrm{Mils}\end{array}$ & \multicolumn{2}{|c|}{$\begin{array}{l}\text { Maximum Spread: } 223 \text { Mils } \\
\text { Minimum Spread: } \quad 31 \text { Mils }\end{array}$} \\
\hline VOIDS: & 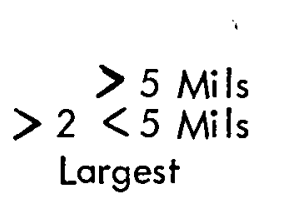 & $\begin{array}{l}\text { HIGH } \\
46.5 / \ln .3 \\
173.5 / \ln .3 \\
35 \mathrm{Mils}\end{array}$ & $\begin{array}{l}\text { LOW } \\
0 / \ln .3 \\
2 / \ln .3 \\
3 \mathrm{Mils}\end{array}$ & $\begin{array}{l}\text { AVG. } \\
5.7 / \ln .3 \\
26.6 / \ln .3 \\
13 \mathrm{Mils}\end{array}$ \\
\hline CONTAMINANTS: & $\begin{array}{l}>10 \mathrm{Mils} \\
2<10 \mathrm{Mils} \\
\\
\text { Largest }\end{array}$ & $\begin{array}{l}\quad \text { HIGH } \\
392.5 / \ln .^{3} \\
474.5 / \ln .^{3} \\
60 \mathrm{Mils}\end{array}$ & $\begin{array}{l}\text { LOW } \\
259 / \ln .^{3} \\
330.5 / \ln .^{3} \\
45 \text { Mils }\end{array}$ & $\begin{array}{l}\text { AVG. } \\
311.9 / \ln .^{3} \\
431.5 \\
49 \text { Mils }\end{array}$ \\
\hline EXTRACTION: & & $\begin{array}{l}\text { HIGH. } \\
31.01 \%\end{array}$ & $\begin{array}{l}\text { LOW } \\
17.36 \%\end{array}$ & $\begin{array}{l}\text { AVG. } \\
22.48 \%\end{array}$ \\
\hline
\end{tabular}


STEP C - Four additional $69 \mathrm{kV} 500 \mathrm{kcmil}$ vulcanized polyethylene joints were constructed and processed by the same procedure as used in the 10 test joints except that the final part of the process, cooling, was performed by "rapid cooling", rather than step cooling. Careful microscopic inspection of the insulations from these four joints indicated that the quality was comparable to that obtained using step cooling. This is significant because step cooling required a 6 hour time period, whereas rapid cooling required only a 2 hour time period.

STEP D - As a step before attempting a $230 \mathrm{kV}$ vulcanized polyethylene joint, experiments were performed on an intermediate cable size. The size selected was a $1500 \mathrm{kcmil} 115 \mathrm{kV}$ XLPEinsulated cable construction. The design for this cable joint is shown in FIG. 7.22. First a joint was constructed with a number of thermocouples imbedded at key points. The graphed data obtained for both connector shield processing and for insulation processing is shown in FIGURES 7.23 and 7.24. A comparison of the times and temperatures for this design versus those for the $69 \mathrm{kV} 500 \mathrm{kcmil}$ design is shown as FIG. 7.25. This graph shows clearly the much greater thermal lag of the former design. This is due largely to the greater axial heat sink effect of the $1500 \mathrm{kcmil}$ conductor.

Next, a series of three $115 \mathrm{kV} 1500 \mathrm{kcmil}$ joints were constructed and processed for purposes of visual examination. The first of these developed sufficient compound pressure to split the epoxy processing shell thus resulting in destruction of the joint. The second joint did not experience this occurrence but did experience excessive extrusion of compound from one end of the epoxy casting. A third joint experienced little problem and appeared to possess good insulation quality. The main point to be made here is that an obviously high degree of variability of results occurred with these three joints of identical construction and process parameters. It is apparent that the technique which produces suitable joints at the $69 \mathrm{kV} 500 \mathrm{kcmil}$ level does not at the $115 \mathrm{kV} 1500 \mathrm{kcmil}$ level. This is related to the greater volume of both joint and cable insulation in the latter design as well as the need to use higher process temperatures to achieve satisfactory compound temperatures. The proposed solution to this problem is discussed under Step $F$. 


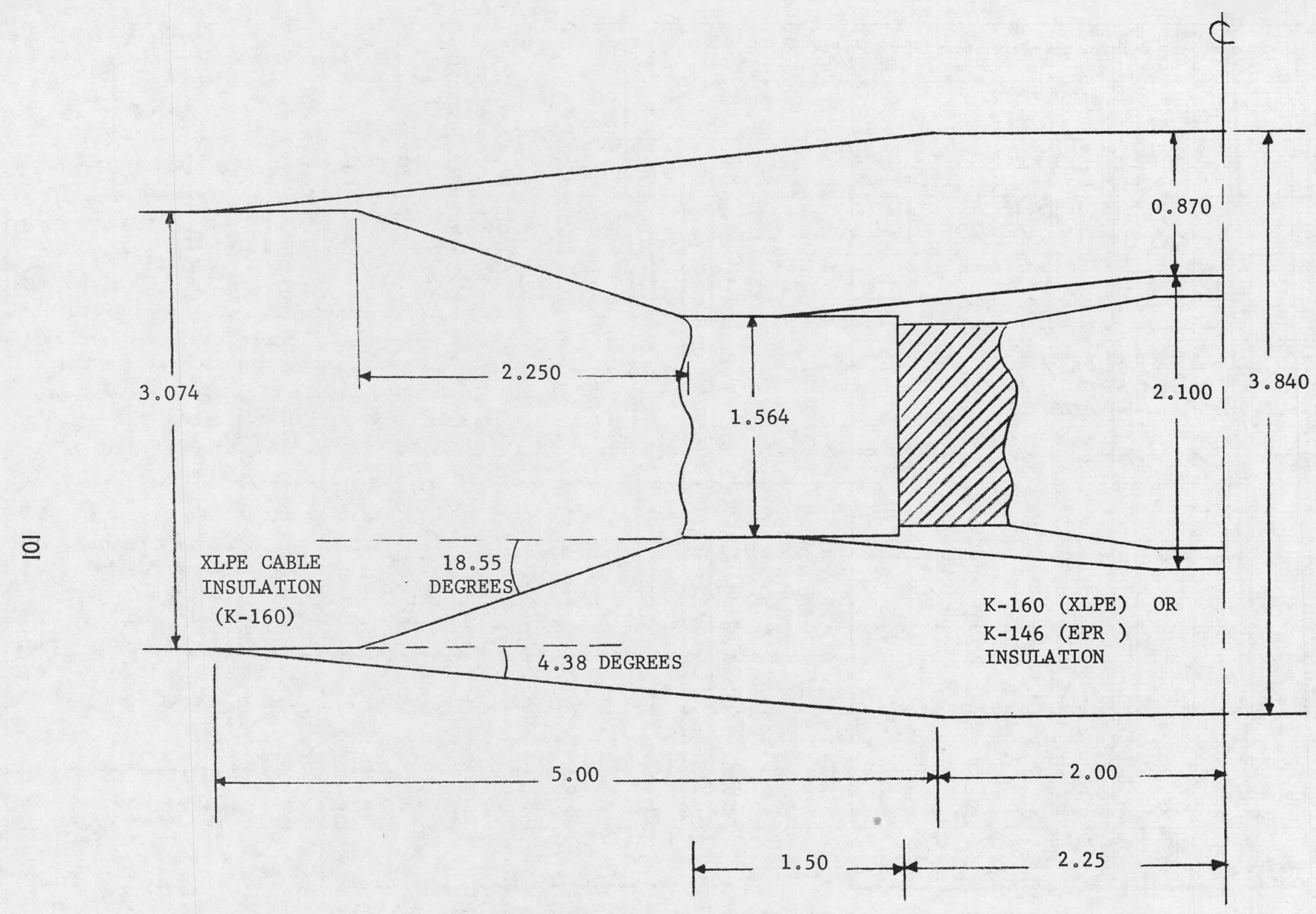

$115 \mathrm{kV} \quad 1500 \mathrm{kcmil}$ VULCANIZED JOINT DESIGN 

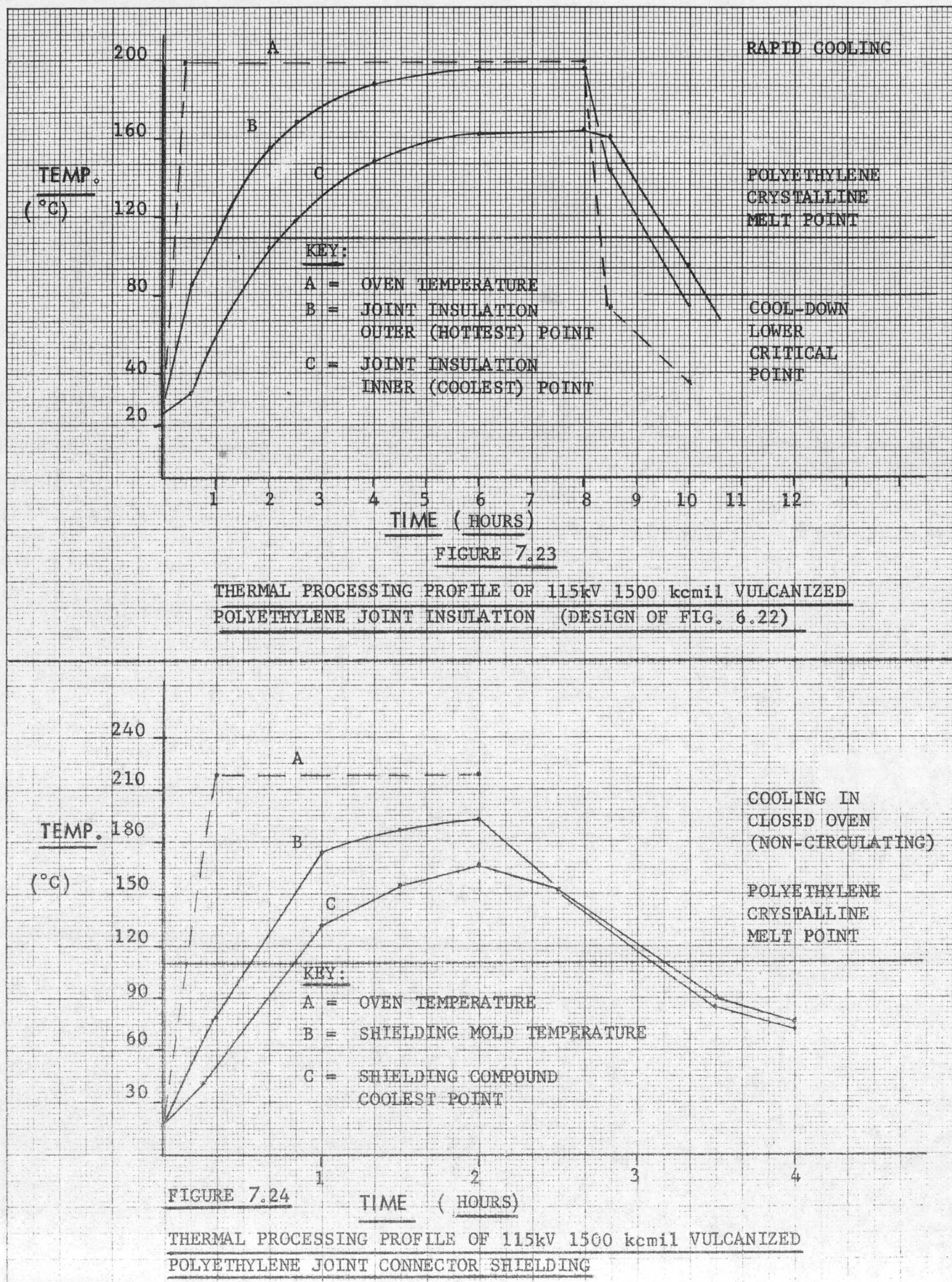


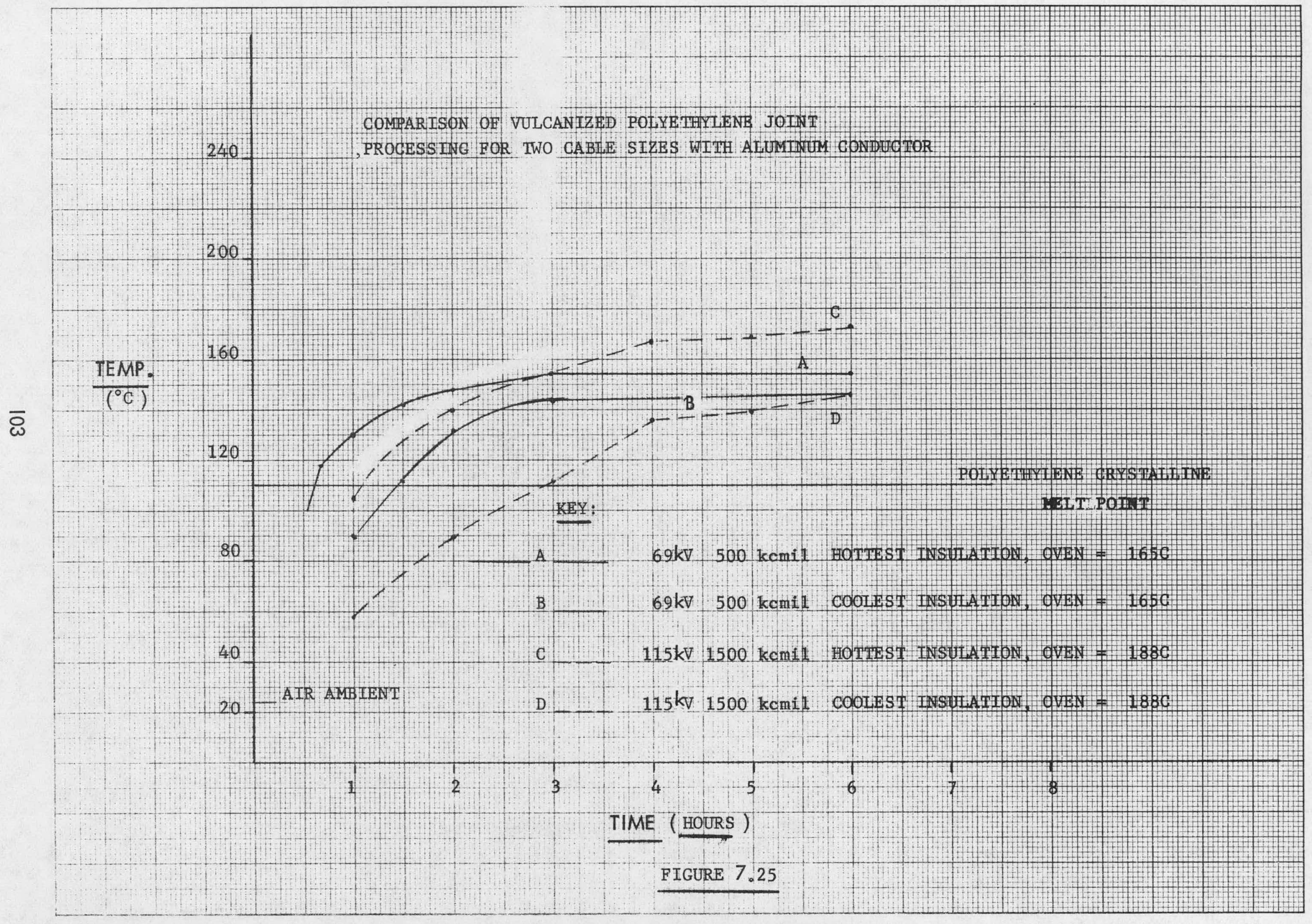


STEP E - The design of a $230 \mathrm{kV} 1000 \mathrm{kcmil}$ vulcanized polyethylene joint is shown in FIG. 7.26. Although the results of Step $D$ had indicated that the epoxy containment shell method was probably not workable in larger cable designs, a $230 \mathrm{kV}$ joint made according to this design was constructed with thermocouples at key points. "Thermal Profile" data were recorded and are graphed in FIG. 7.27 and 7.28. It is of interest to note that despite the greater wall thickness of this joint, process temperatures and times are similar to the $115 \mathrm{kV}, 1500 \mathrm{kcmil}$ processing characteristics (FIG. 7.24).

STEP F - The use of induction heating to speed and improve the process is considered to be a possible approach. The work up to this point indicates that for cable sizes much greater than $69 \mathrm{kV} 500 \mathrm{kcmil}$, a new means of processing would be required. It was theorized that the present method utilizing a heat-shrinkable Teflon sleeve applied over the joint insulation would be retained. The epoxy-saturated polyester used over this as a pressure shell would be eliminated and replaced instead with a porous malleable jacket. The purpose of this jacket would be the supporting and shaping of the joint insulation while in the molten process stage. The underlying separator sleeve (of Teflon or other material) would provide both separation and a smooth, defect-free joint insulation surface. This assembly would then be inserted in a nitrogen processing chamber equipped with both induction heating coils (for conductor/connector heating) and with radiant heaters for heating of the splice insulation from without. The basic design for such a process chamber would appear similar to that shown in FIG.7.29. One of the persistent problems with the present method is the occurrence of "sagging" during processing resulting in joint insulation eccentricity. In order to overcome this problem a pneumatic joint tensioning device would be constructed, similar to the design shown in the sketch of FIG. 7.30 .

The use of nitrogen pressure (probably in the range of 50150 PSI) would provide a positive means of applying uniform pressure to the processing joint, particularly during the critical cooling process. The present method which utilizes pressure developed by compound expansion while restricted in a pressure shell provides non-controllable pressure which may become excessive and result in unsatisfactory joints. 
230-kV KAISER VULCANIZED POLYETHYLENE JOINT DESIGN 非1

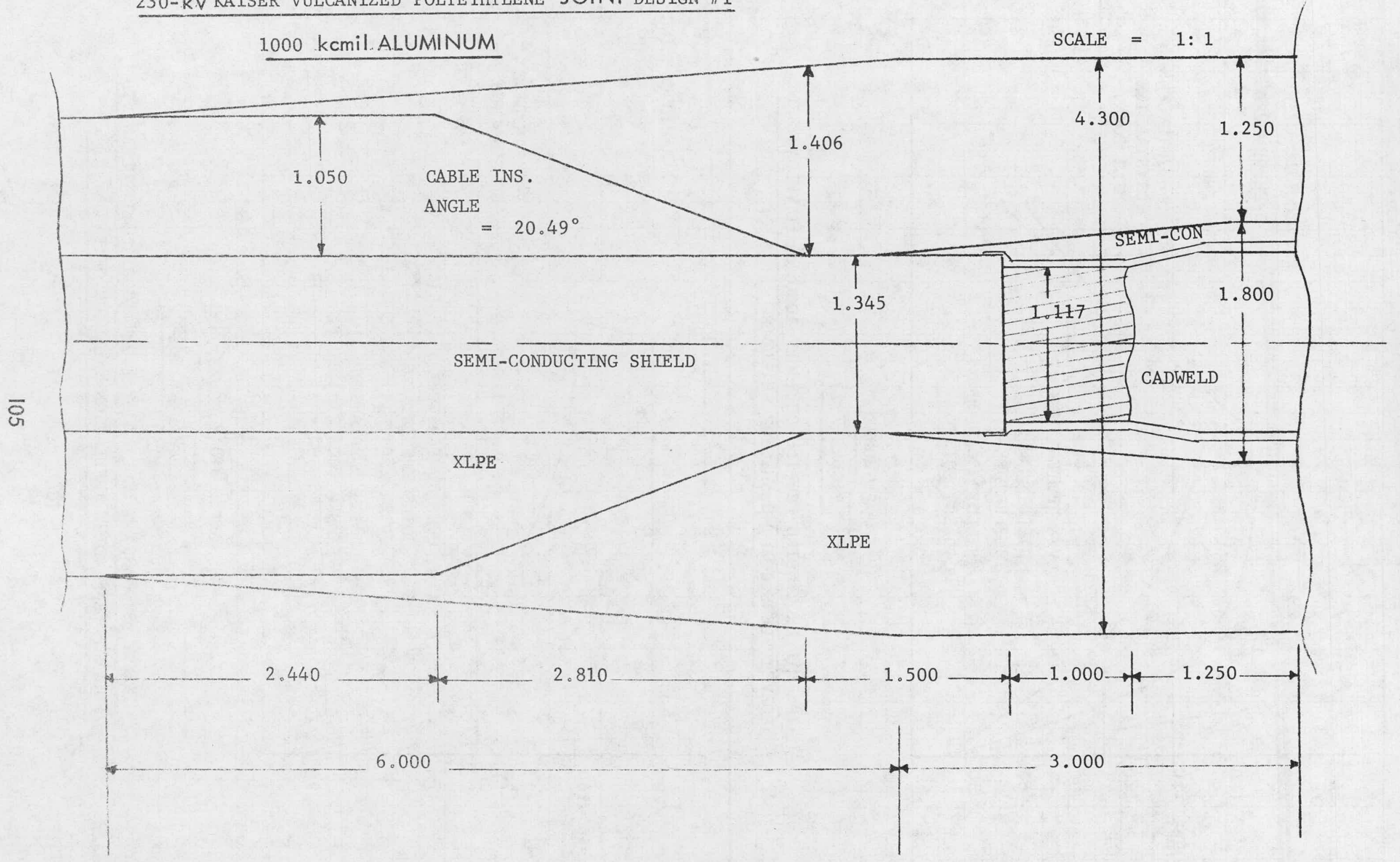

FIGURE 7.26 

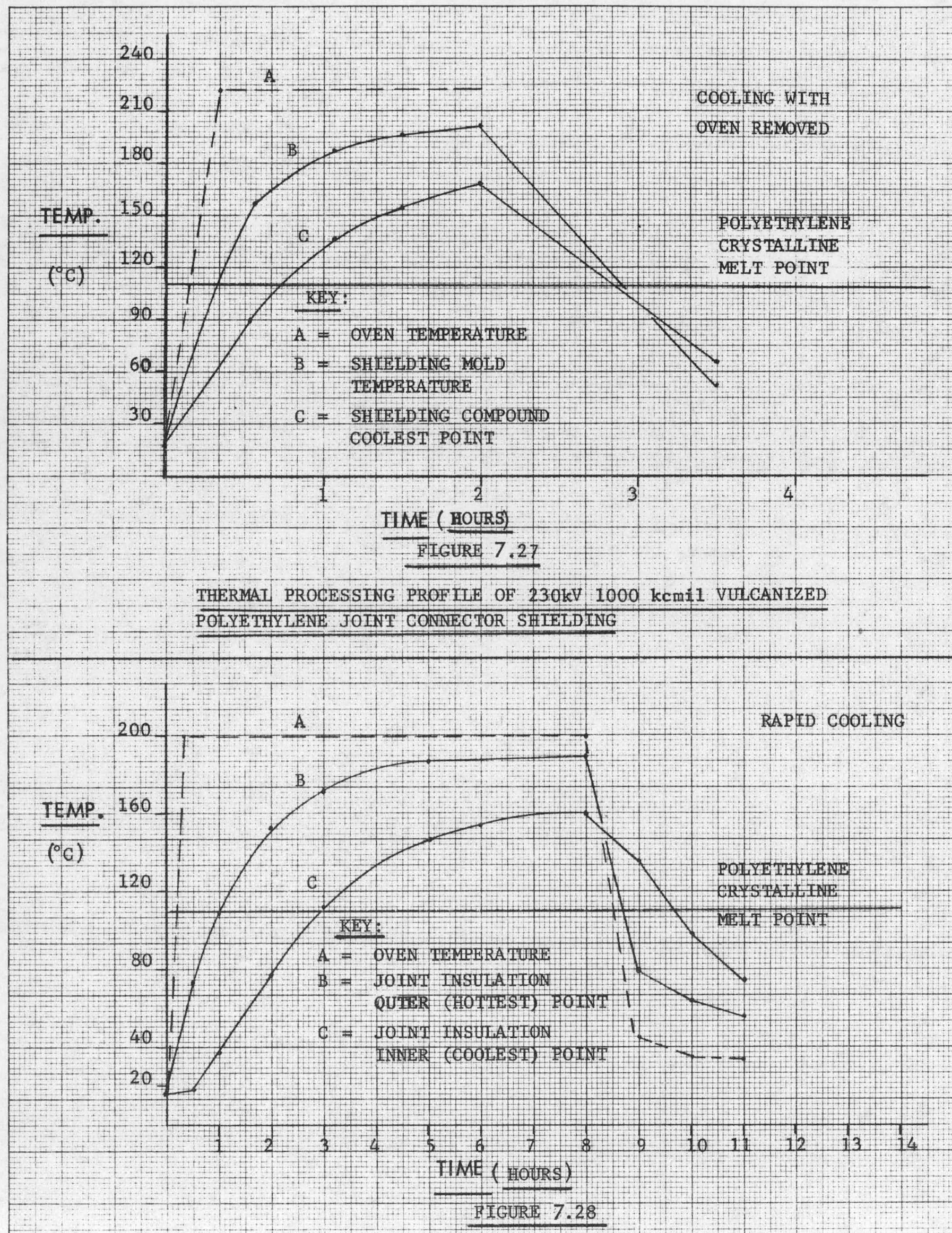

THERMAL PROCESSING PROFTLE OF $230 \mathrm{kV}$ 1000 kcmII VULCANIZED POLYETHYLENE JOINT INSULATION (DESIGN OF FIG。7.26) 


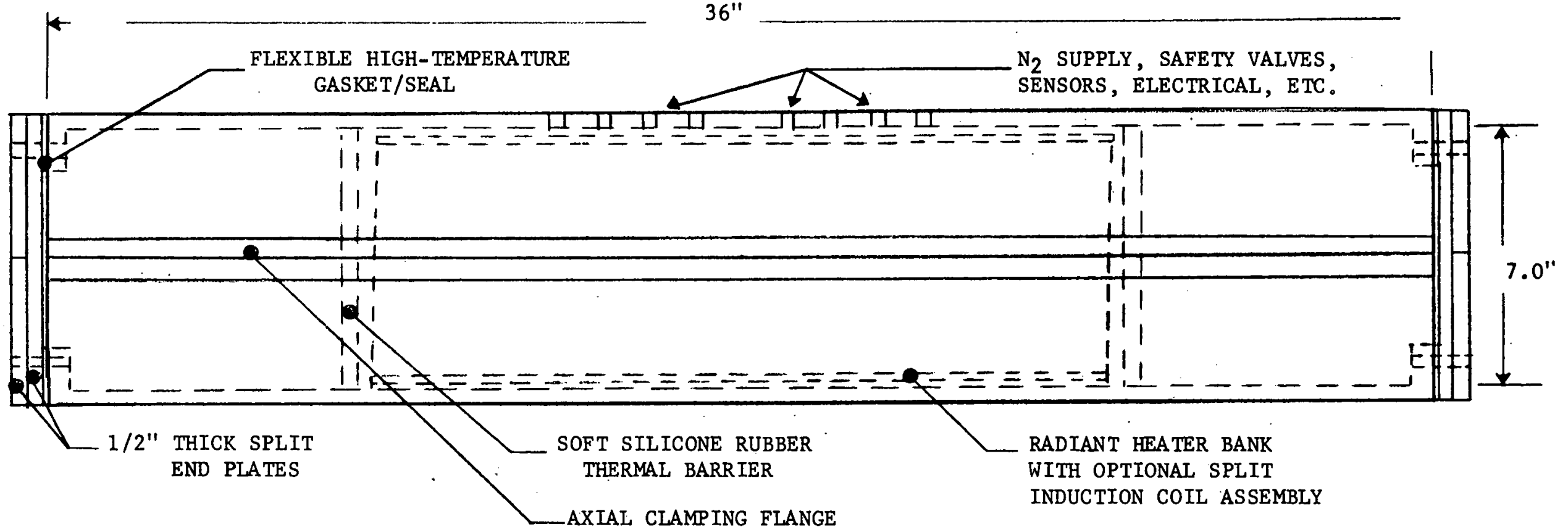

(TEN $1 / 2 "$ BOLTS, NOT SHOWN)
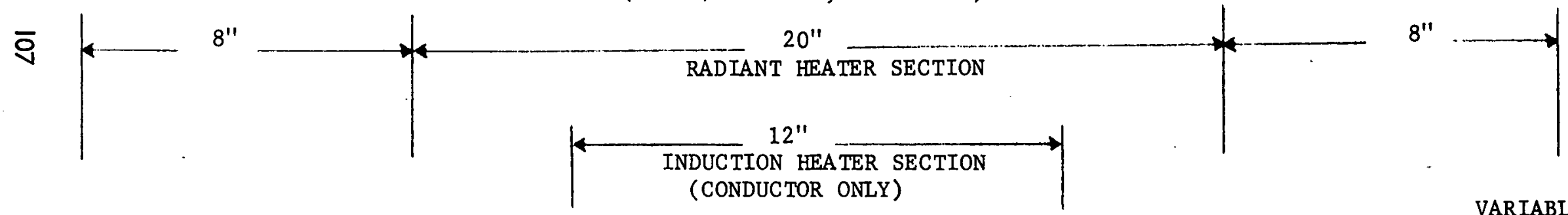
(CONDUCTOR ONLY)

VARIABLE INNER DIAME TER FOR EACH CABLE SIZE RANGING FROM 2.25" FOR $69 \mathrm{kV} 500 \mathrm{kcm}$ TO 4.60" FOR $230 \mathrm{kV} 2500 \mathrm{kcm}$ SILICONE RUBBER GASKETING

8- $5 / 8^{\prime \prime}$ TAPPED HOLES

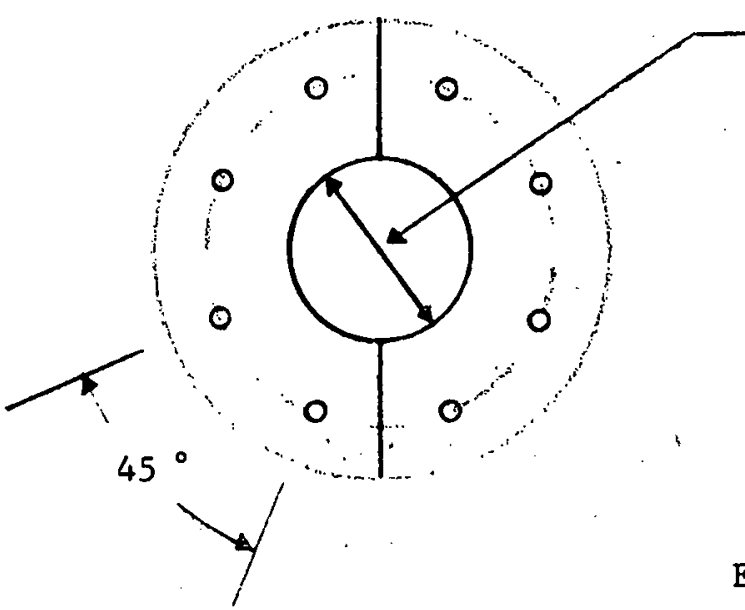

END PLATE 


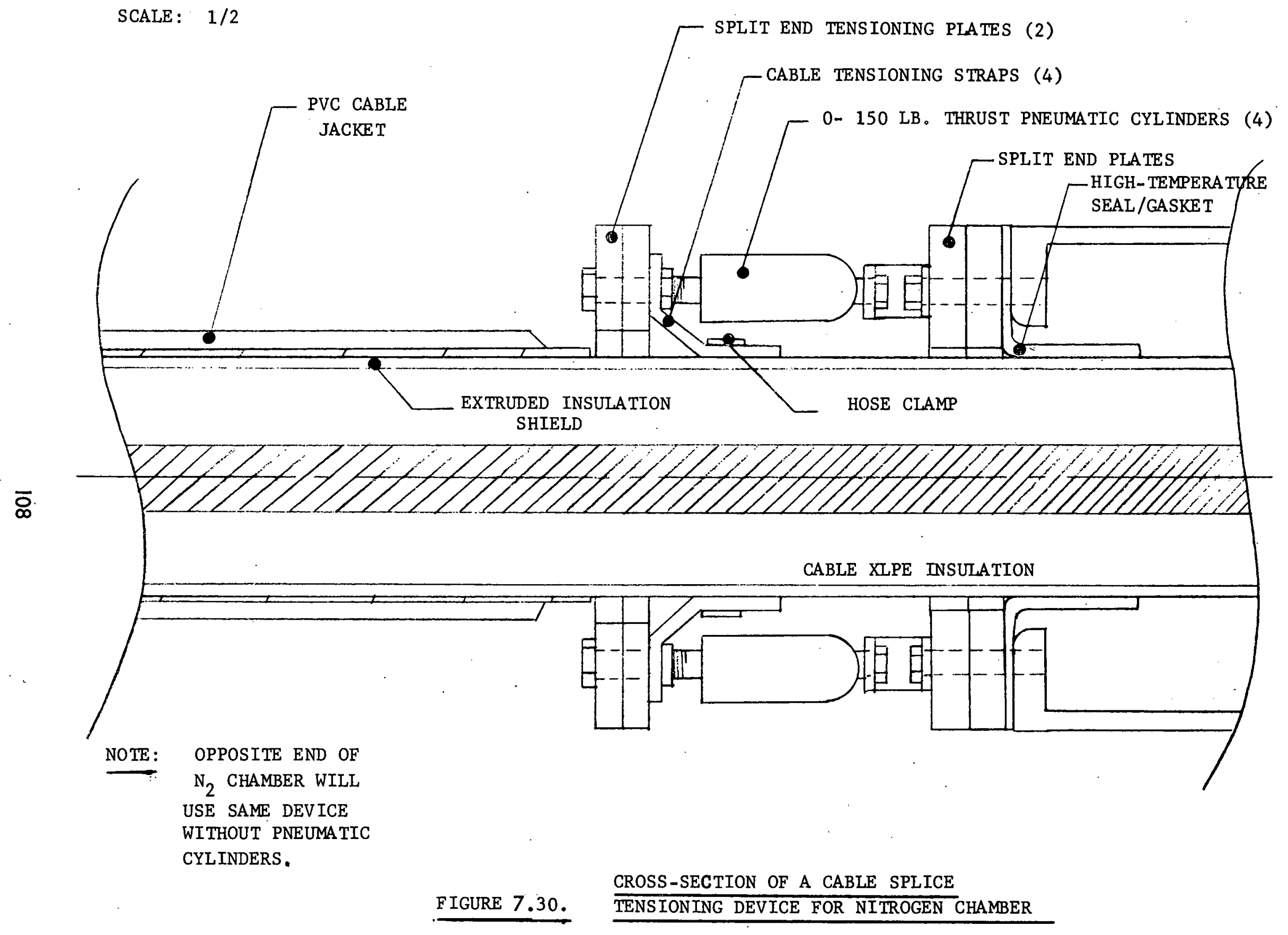


Also, the present technique may lose adequate process pressure during the critical cool-down process, resulting in unacceptable insulation voids. This appears to be a significant problem at some cable size greater than $69 \mathrm{kV} 500 \mathrm{kcmil}$. It is believed that nitrogen pressure with or without induction heating would provide a great advance in the State-of-the Art for vulcanized process jointing. Although basic design work was done, the approach has not been pursued due to modification of the original $230 \mathrm{kV}$ ERDA contract.

STEP G - The use of microwave frequency joint compound heating was not pursued.

STEP H - Some steps were taken to assess the use of heat-shrinkable semiconducting tubing as the means of shielding the connector in the vulcanized joint process. In particular, Gilbreth International (Reference 7.8) manufactures an EPR (ethylene propylene rubber) semi-conductive heat-shrinkable tubing in various sizes. One type is \#362l-EPR which has a $2: 1$ shrink ratio, while another type is \#3631-EPR which has a $3: 1$ shrink ratio. Both appear to have excellent conductive properties.

An experiment was performed in order to check the compatability of such a material, during processing, with crosslinked polyethylene joint insulation. This experiment utilized the same process technique used with the ten $69 \mathrm{kV} 500$ $\mathrm{kcmil}$ test joints discussed previously. In brief, the results of this test indicated excellent compatability with XLPE, and insulation voids were reduced below usual levels. Further tests for compatability were made, followed by microscopic inspection of the sleeve/joint insulation interfacial area. Results showed that washing of the EPR sleeving with Inhibisol (trichlorethylene) created a still more satisfactory interface possessing both excellent bond and low void content. No voids greater than 2 mils were found in these "washed" samples. Both \#3621 and \#3631 EPR sleeving were tested. The conclusion from this work is that XLPE and the EPR sleeving are process-compatible and their use would provide a still higher quality vulcanized joint. In addition to this, construction time for the joint would be reduced by 3 to 4 hours. No further work was performed on this beyond the use of \#3631 EPR sleeving in an experimental EPR insulated vulcanized joint reported under Step $K$. 
STEP I - Study of the use of transfer molding or extrusion in place of present hand-taped application was not pursued.

STEP J - The study of alternate (other than dicumyl peroxide) crosslinking agents for use in joint insulation compounds was not pursued.

STEP K - A 100-pound quantity of Kaiser's K-146 EPR (ethylene propylene rubber) uncured vulcanizable compound was converted to tape. Previously, a small quantity had been converted and used to construct two vulcanized $K-146$ joints in our $138 \mathrm{kV}$ laboratory long-term test circuit. One of these joints withstood 4600 hours of over-voltage testing while the other withstood 4100 hours of test, both without failure. Since these joints were made on a purely experimental basis without any previous work, and since they have performed so well, this approach was considered to warrant some investigation.

An experimental "thermal profile" joint was made using the design shown in FIG. 7.22 , substituting K-146 EPR for $X L P E$ joint insulation. Thermocouples were imbedded at key points in the joint. The resulting graphed results are shown as FIG. 7.31, and indicate that the thermal drop through this EPR insulation is slightly higher than through the comparable XLPE insulation. However, the difference is small enough that all previous process data on XLPE joint insulation can be adapted for the use of K-146 EPR.

A second $\mathrm{K}-146115 \mathrm{kV} 1500 \mathrm{kcmil}$ vulcanized EPR joint was constructed for visual inspection. This joint had Gilbreth \#363l heat-shrinkable conductive sleeving as connector shielding. After processing, the joint was dissected and slinkied. Results indicate a high degree of promise for this method. The only problem found was the occurrence of a few circumferential striations and non-bonded tape layers. It is thought that this condition would be corrected by the use of a controllable pressurizing method such as the nitrogen method discussed in Step F. No further work was done. 


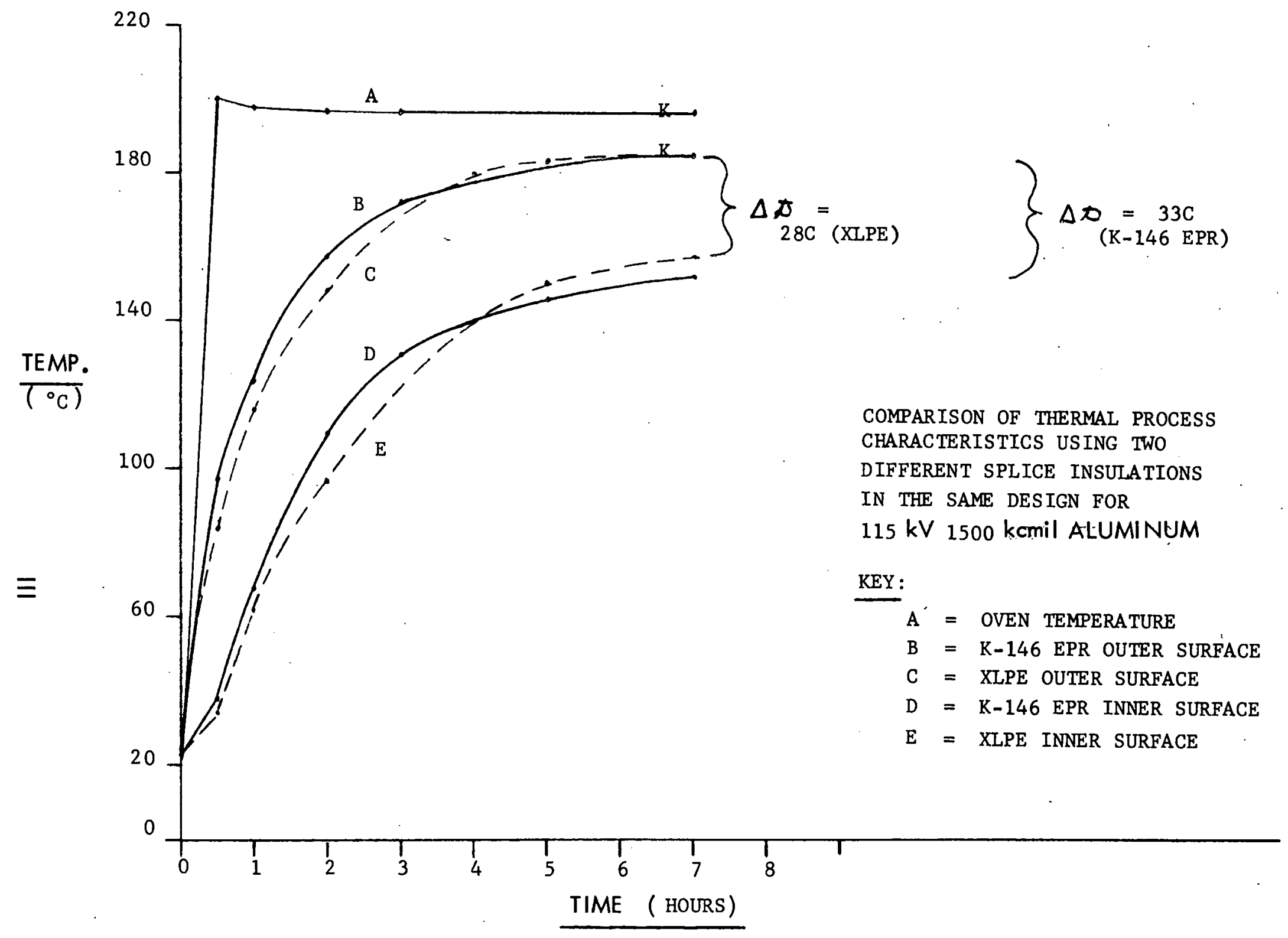

FIGURE 7.31 
STEP L - Other than work done on the use of heat-shrinkable connector shielding, no further work was done on reduction of process time for $230 \mathrm{kV}$ vulcanized joints.

STEP M - In discussions with Hexcel (Hotsplicer) (REFERENCE 7.9) personnel, a mutual interest has been expressed in the development of a joint insulation compound for use in a $230 \mathrm{kV}$ Hotsplice. Kaiser has worked with Hotsplicer to evaluate their joints at the $35 \mathrm{kV}, 69 \mathrm{kV}$ and $138 \mathrm{kV}$ levels. Hotsplicer has expressed the interest and need to develop a different compound for use at $230 \mathrm{kV}$ and Kaiser has expressed interest in cooperative evaluation. Due to reduction in the $230 \mathrm{kV}$ contract scope, further work has not been done.

STEPS $N, O, \& P-$

The final selection, process checks and electrical testing of the best practical method for vulcanized joint construction has not been carried out. 
Our work on the vulcanized joint indicates that future work should be directed towards the use of a controllable pressure method, such as the nitrogen method previously described, the use of simplified means of applying connector shielding and the use of EPR as a more easily processed joint insulation. In addition, the use of induction heating may quicken and improve the process. The use of a joint tensioning device would greatly reduce joint insulation eccentricity. Further steps towards improving basic joint insulation compounds and toward improved means of insulation application would tend to improve joint insulation quality.

In general, our work was done starting at the 69kV level. It is known that the joint insulation quality is very important in regards to electrical performance of the vulcanized joint insulation. The work reported on $69 \mathrm{kV}$ vulcanized joint electrical performance, and subsequent examination in detail of the tested insulation quality, had the objective of establishing a baseline for "acceptable" insulation defects such as voids and contaminants. In the case of the $230 \mathrm{kV}$ vulcanized joint design (shown in FIG. 7.26) the electrical stresses are still higher than previous test experience on $69 \mathrm{kV}$ and $138 \mathrm{kV}$ joints. The radial stresses are tabulated in Table 7.7. Also, the tangential stresses in various designs are tabulated in Table 7.8 in conjunction with the sketches in FIGURES 7.32 and 7.33. It can be seen that interfacial stresses (which are not a problem in wellbonded interfaces) are significantly higher in the $230 \mathrm{kV}$ design than in previous designs. All of this points clearly to the need to exercise every possible means to ensure both the highest possible joint quality, and subsequent reliable troublefree service. 
TABLE 7.7

RADTAL ELECTRICAL STRESSES IN VULCANIZED POLYETHYLENE JOINT DESIGNS

VOLTS PER MIL $(60 \mathrm{~Hz})$

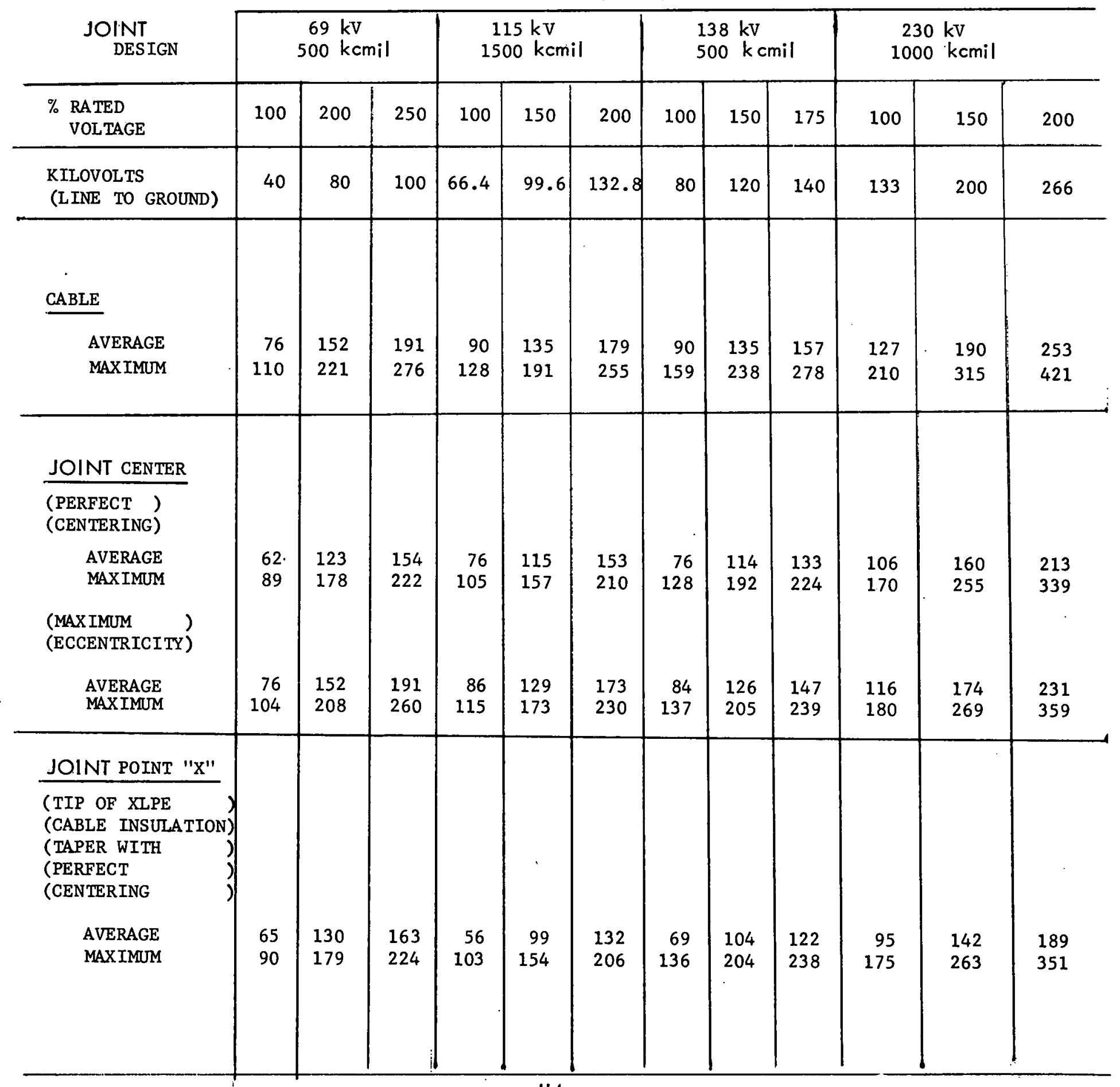


TABLE 7.8

TANGENTIAL ELECTRICAL STRESSES IN VULCANIZED POLYETHYLENE JOINT DESIGNS

VOLTS PER MIL $(60 \mathrm{~Hz})$

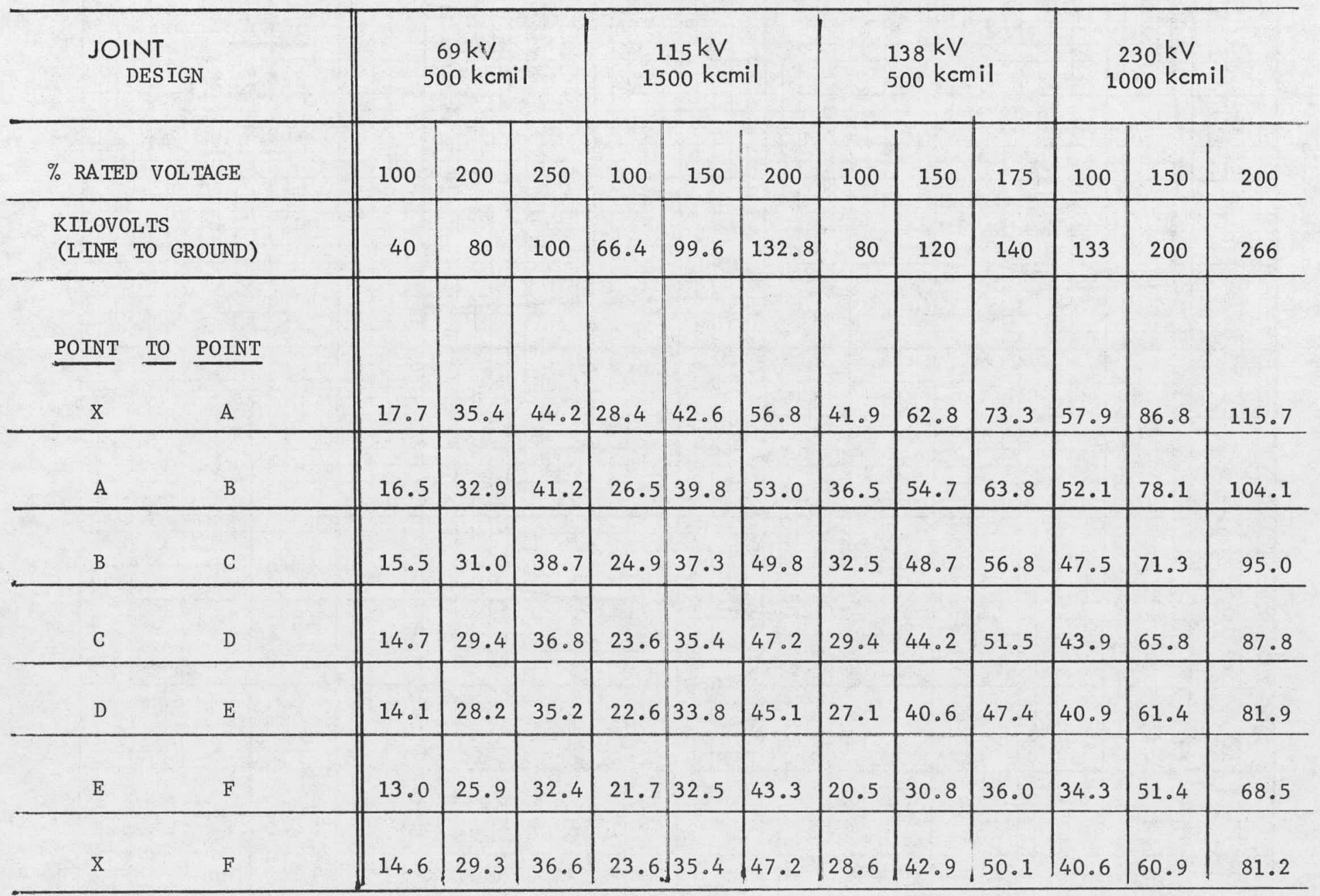




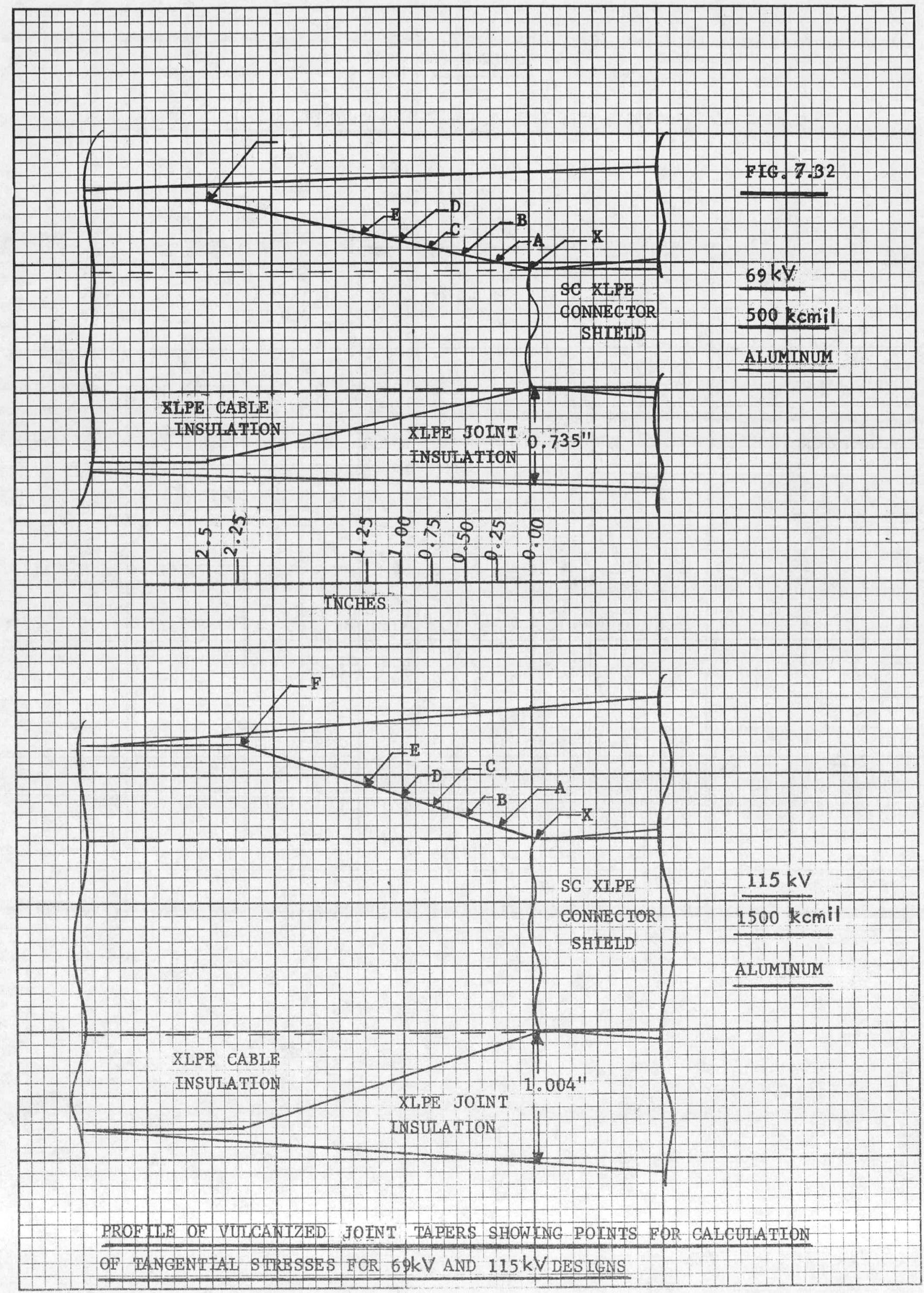




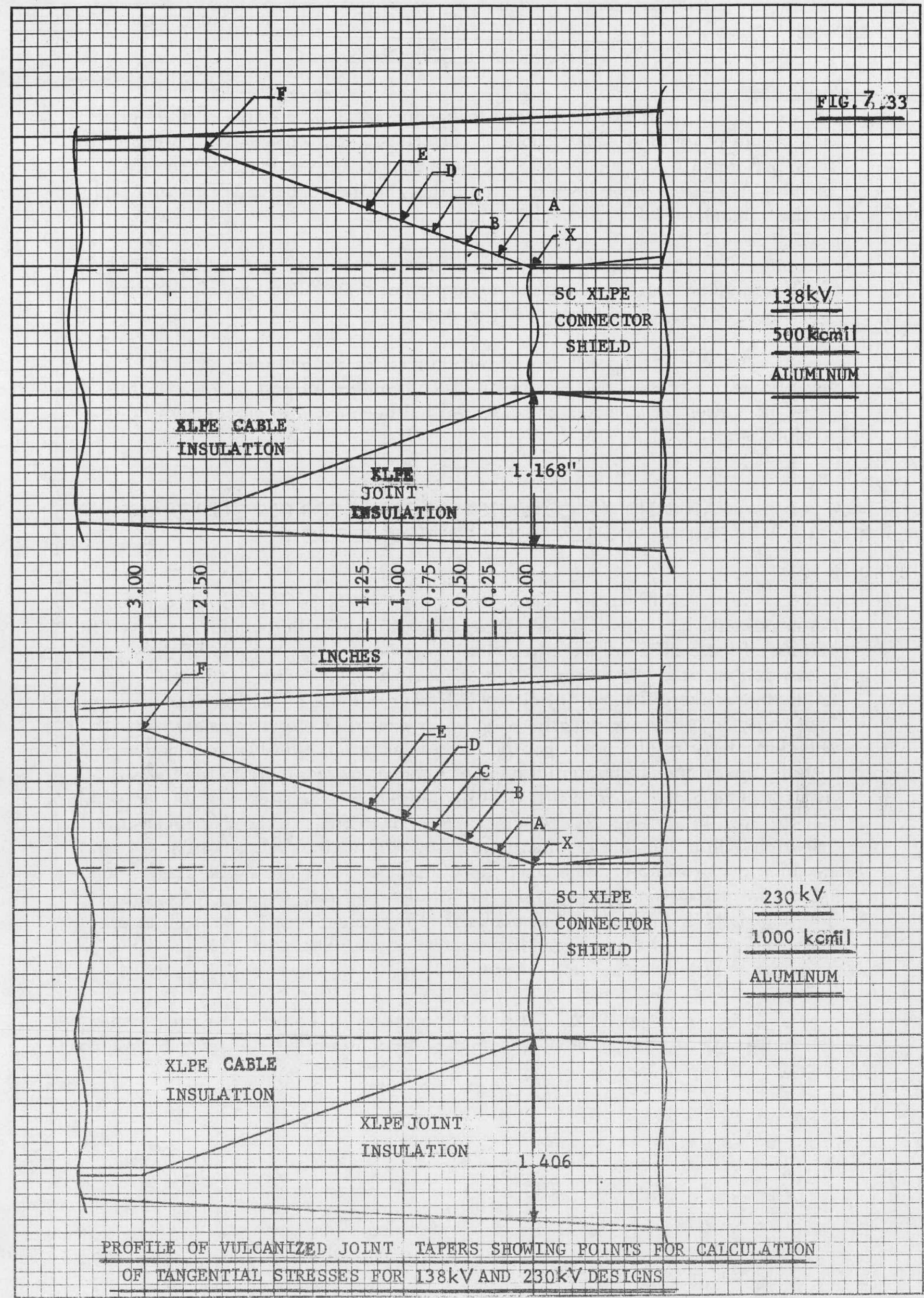


Reference is made to Appendix 7.1 where five possible alternate means of jointing $230 \mathrm{kV}$ cable are described. No work on this category has been performed. Although several of these approaches would appear to offer promise, our efforts have been devoted largely to the hand-taped EPR joint and to the vulcanized joint approaches.

Discussions have been carried out with Elastimold (REFERENCE 7.10) regarding Kaiser testing and evaluation of their $\mid 38 \mathrm{kV}$ premolded joint which was developed under an EPRI contract.

The possibility of testing this pre-molded joint on a $230 \mathrm{kV}$ cable has also been discussed and Elastimold also has active interest in this. At this time, no Kaiser committment or agreement has been made to proceed with this evaluation.

\subsection{CATEGORY 4 - COMPUTER PROGRAMS FOR DESIGN AID AND FAILURE ANALYSIS OF HIGH VOLTAGE JOINTS}

It was felt that with the wide variation of materials available for manufacturing joints and the number of combinations that could be derived in the use of these different materials, that a computer program could be developed that would assist in the determination of specific requirements to suit the needs of the user. There is a multiplicity of different methods of joining conductor ends that could be used in conjunction with various forms of insulating materials. If the characteristics of a major portion of these materials could be obtained and listed it would form a substantial bank of information available to the industry. The computer aided program first investigated the voltage stress distribution within $230 \mathrm{kV}$ taped joint design \#I. A second step was to analyze the thermal stress distribution within the same configuration. The next logical step would have been to combine the two into a single computer aid program which could be used to determine joint parameters for use on any installation and with any combination of jointing methods and insulating materials. The reduced scope of this effort prevented the completion of the program. The program stopped at a point preceding the incorporation of the voltage and thermal analyses into a single entity.

Appendix 7.3 shows the approach to both the electrical field and thermal field computer programs. Included are copies of both of these Fortran programs. 
A reliable connector is essential to a reliable high voltage joint. Due to the possibility of inadequacies in the industry testing of aluminum connectors. with regard to use in high voltage insulated joints the basic program outlined in Appendix 7.1 was planned. The objective of this was to provide data to indicate reliable connectors for use in $230 \mathrm{kV}$ joint designs. Concentration was upon connections for the $1000 \mathrm{kcmil}$ die-sized aluminum conductor. The progress on various steps of this plan will now be outlined.

STEP A - In general, the sum result of our own knowledge and literature searches indicate that the testing of aluminum connectors in the industry has been particularly limited with regard to conductor sizes of $1000 \mathrm{kcmil}$ and larger and for application within systems rated higher than $35 \mathrm{kV}$. We are not aware of any comprehensive, systematic test which has been done on $1000 \mathrm{kcmil}$ connectors supplied from various manufacturers. In particular we know of no test standard that is comprehensive of the thermal effects which would occur in $138 \mathrm{kV}$ and $230 \mathrm{kV}$ taped EPR joints. For this reason it was considered essential that these gaps in testing and test procedure should be filled.

STEP B - The methods of joining insulated aluminum conductors are adequately outlined in Appendix 7.1.

STEP C - Based upon EEI TDJ-162 (REF. 7.11), a test standard for aluminum connectors was developed. Essentially, this incorporates the basic EEI TDJ-162 500 cycle test at $130 \mathrm{C}$ conductor temperature but goes beyond that test by testing at $160 \mathrm{C}, 190 \mathrm{C}, 220 \mathrm{C}$ and $250 \mathrm{C}$ conductor temperatures. This is for the purpose of defining the temperature levels which connectors could withstand without experiencing progressive electrical degradation and subsequent overheating followed by thermal runaway. Because it is known that connectors in 138kV taped EPR designs may reach $170 \mathrm{C}$ or more when the cable conductor is at $130 \mathrm{C}$ it is obvious that, for example, a suitable $138 \mathrm{kV}$ connector would have to pass the $190 \mathrm{C}$ level to indicate suitability at this level. Our tests have indicated that the $190 \mathrm{C}$ level would also be required for connector suitability at the $230 \mathrm{kV}$ level in taped EPR joint design \#l. 
In particular, the performance of compression connectors on aluminum at temperatures above $140 \mathrm{C}$ is a concern. Data obtained will also be of use to the industry at lower voltage levels where such severe over-temperatures do not occur. Connectors that are not suitable for the $230 \mathrm{kV}$ level may be suitable for lower voltages.

STEP D - $\quad$ A circuit consisting of about 30 feet of bare $1000 \mathrm{kcmil}$ die-sized Class B stranded ECH-19 aluminum was set up in the high current laboratory. Thermocouples were attached to the conductor at various points and currentloading runs were made to determine $60 \mathrm{~Hz}$ load current required to raise the conductor to a steady $130 \mathrm{C}, 160 \mathrm{C}$, $190 \mathrm{C}, 220 \mathrm{C}$ and $250 \mathrm{C}$. When the correct current was identified, a total of three separate loading runs were made to verify the data. Cooling curves were also recorded. The composite data for the 15 verifying loading runs is shown in FIG. 7.34. A sample heating and cooling data sheet is shown as TABLE 7.9. From these data it was seen that heating equilibrium for all 5 conductor temperatures was reached within 2 hours. Likewise, all points were within $2 \mathrm{C}$ of ambient temperature at the 2hour point in time following current shut-off. A 4-hour load cycle time was established, with 2 hours on and 2 hours off. 


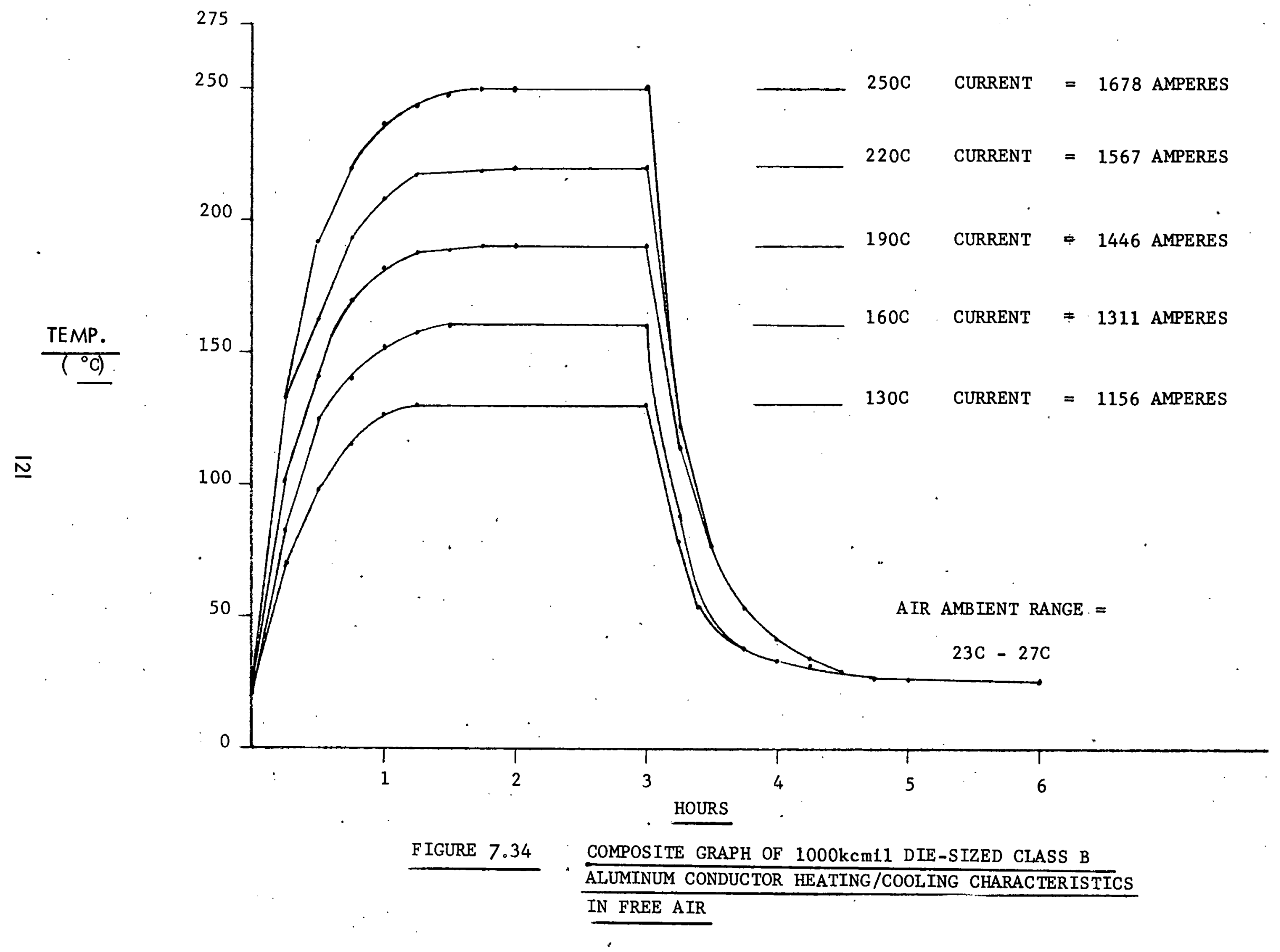


MASTER DATA SHEET

THERMAL CHARACTERISTICS - - $230 \mathrm{kV}$ SPLICE CONNECTOR PROGRAM

$I=\quad 1156$ Amps AMBIENT $=-25^{\circ} \mathrm{C}$

Nomina1 Conductor Temp. $130^{\circ} \mathrm{C}$

Data Objective: $130^{\circ} \mathrm{C}$ THERMAL PROFILES

HEATING PROFILE 非 1

\begin{tabular}{c|c|c|c|c|c|c|c|c|c|c|c|c|c|c|c}
\hline TIME /MI & 15 & 30 & 45 & 60 & 75 & 90 & 105 & 120 & 135 & 150 & 165 & 180 & & & \\
\hline TC;! 1 & 56 & 80 & 91 & 99 & 101 & 103 & 104 & 105 & 106 & 106 & 106 & 106 & & \\
\hline 2 & 70 & 102 & 116 & 126 & 129 & 130 & 131 & 131 & 131 & 131 & 131 & 131 & & & \\
\hline 3 & 70 & 102 & 117 & 127 & 129 & 130 & 131 & 131 & 131 & 131 & 131 & 131 & & \\
\hline 4 & 67 & 98 & 112 & 120 & 123 & 125 & 126 & 126 & 126 & 126 & 126 & 126 & & \\
\hline 5 & 70 & 102 & 115 & 124 & 126 & 128 & 129 & 130 & 130 & 130 & 130 & 130 & & & \\
\hline 6 & 70 & 102 & 114 & 124 & 126 & 128 & 129 & 130 & 130 & 130 & 130 & 130 & & & \\
\hline 7 & 70 & 102 & 114 & 124 & 126 & 128 & 129 & 130 & 130 & 130 & 130 & 130 & & & \\
\hline 8 & 56 & 75 & 89 & 98 & 101 & 103 & 104 & 105 & 106 & 106 & 106 & 106 & & & \\
\hline 9 & 56 & 80 & 91 & 99 & 101 & 103 & 104 & 106 & 106 & 106 & 106 & 106 & & & \\
\hline 10 & 56 & 75 & 89 & 98 & 101 & 103 & 104 & 106 & 106 & 106 & 106 & 106 & & & \\
\hline 11 & 25 & 25 & 25 & 25 & 25 & 25 & 25 & 25 & 25 & 25 & 25 & 25 & & & \\
\hline
\end{tabular}

COOLING PROFILE 非 1

\begin{tabular}{c|c|c|c|c|c|c|c|c|c|c|c|c|c|c|c}
\hline TIME /MIN & 15 & 30 & 45 & 60 & 75 & 90 & 105 & 120 & 135 & 150 & 165 & 180 & & & \\
\hline TC 非 1 & 67 & 56 & 45 & 37 & 33 & 31 & 28 & 27 & 27 & 27 & 27 & 27 & & & \\
\hline 2 & 75 & 56 & 47 & 38 & 33 & 31 & 28 & 27 & 27 & 27 & 27 & 27 & & & \\
\hline 3 & 75 & 56 & 47 & 38 & 33 & 31 & 28 & 27 & 27 & 27 & 27 & 27 & & & \\
\hline 4 & 75 & 56 & 47 & 38 & 33 & 31 & 28 & 27 & 27 & 27 & 27 & 27 & & & \\
\hline 5 & 75 & 56 & 47 & 38 & 33 & 31 & 28 & 27 & 27 & 27 & 27 & 27 & & & \\
\hline 6 & 75 & 56 & 47 & 38 & 33 & 31 & 28 & 27 & 27 & 27 & 27 & 27 & & & \\
\hline 7 & 75 & 56 & 47 & 38 & 33 & 31 & 28 & 27 & 27 & 27 & 27 & 27 & & & \\
\hline 8 & 67 & 56 & 48 & 39 & 34 & 31 & 28 & 27 & 27 & 27 & 27 & 27 & & & \\
\hline 9 & 67 & 56 & 45 & 37 & 33 & 31 & 28 & 27 & 27 & 27 & 27 & 27 & & & \\
\hline 10 & 67 & 56 & 48 & 40 & 33 & 31 & 29 & 27 & 27 & 27 & 27 & 27 & & & \\
\hline 11 & 26 & 26 & 26 & 26 & 26 & 26 & 26 & 27 & 27 & 27 & 27 & 27 & & & \\
\hline & & & & & & & & & & & & & & & \\
\hline
\end{tabular}


STEPE - Working relationships with aluminum connector suppliers were established. The following manufacturers were contacted:

Mac Products Inc.

Kearny, New Jersey

(REF. 7.12)

Erico Products

Cleveland, Ohio

$" 7.13$

Thomas \& Betts Co.

Elizabeth, New Jersey

$" 7.14$

Electrical Specialty

Products Co.

Montevallo, Al.

17.15

Utility Industries

Pennsauken, N. J.

" 7.16

Homac Manufacturing Co.

Ormand Beach, Fla.

" 7.17

Burndy Corporation

Norwalk, Conn.

" 7.18

Frankel Connector Co.

Bronx, New York

" 7.19

AMP Inc.

Harrisburg, Pa.

" 7.20

Teldyne-Penn Union

Electric

Edinboro, Pa.

" 7.21

Anderson Electric

Leeds, Ala.

" 7.22

Kearney Company

Atlanta, Ga.

11

7.23

Of these, the first 9 expressed interest in the connector test program. Connectors from the first three have been purchased, installed and are under test. Also, connectors from the fourth supplier have been purchased but not placed under test as of the date of this report. Due to load cycle equipment unavailability, no further work is anticipated beyond that in progress with these first four suppliers. As of the date of this report, connectors from the first three suppliers have completed the $130 \mathrm{C}$ Test Phase (500 load cycles) and the $160 \mathrm{C}$ Test Phase (100 load cycles). 
Work was also pursued to determine sources of inert gas welding equipment, materials and expertise. No further work was performed on this due to shortening of the Contract.

STEP F - Five of each type of connector were installed in a load cycling circuit as depi cted in FIG. 7.35. An additional six of each connector type were installed in the center of straight 8-foot sections of bare conductor, for later tensile strength tests. Three of these were to be heat cycled at the temperature step just below the failure level observed in the load cycle test, while three were to be non-heatcycled connectors.

Thermocouples were permanently attached to the five load cycling connectors and control conductors using porcelainized cement.

Five of each of three types of connectors were load cycled in air according to the connector test standard presented in Appendix 7.4. All connectors were installed on $1000 \mathrm{kcmil}$ ECH-19 Class B compressed die-sized aluminum conductor, the same conductor used in the manufactured $230 \mathrm{kV}$ cable. The three types of connectors tested were:

(I) Mac \#MTAP 1000 NE (compression)

(2) Thomas \& Betts (Somerset) \#1000 A S 150 (compression)

(3) Erico (Cadweld) $1000 \mathrm{kcmil}$ Aluminum (exothermic weld)

A total of 15 connectors were tested through the first 600 load cycles of the projected 900 load cycle test program. The first 500 load cycles were with a control conductor temperature of $130 \mathrm{C}$ (II56 ampere load current) while the last 100 load cycles were with a control conductor temperature of $160 \mathrm{C}$ ( $|3| 1$ ampere load current). In all cases the load cycle consisted of 2 hours with load current applied followed by 2 hours cooling to ambient temperature .

Measurements of connector temperature and dc resistance were taken at approximate 25 load-cycle intervals. Temperature measurements were taken during the final 5 minute segment of heating portions of the load cycles, while dc resistance measurements were taken following 2 full hours of cooling. The temperature readings were compared with measurements, concurrently taken, of conductor temperature. DC Resistance measuring equalizers are $I$ inch long compression sleeves 


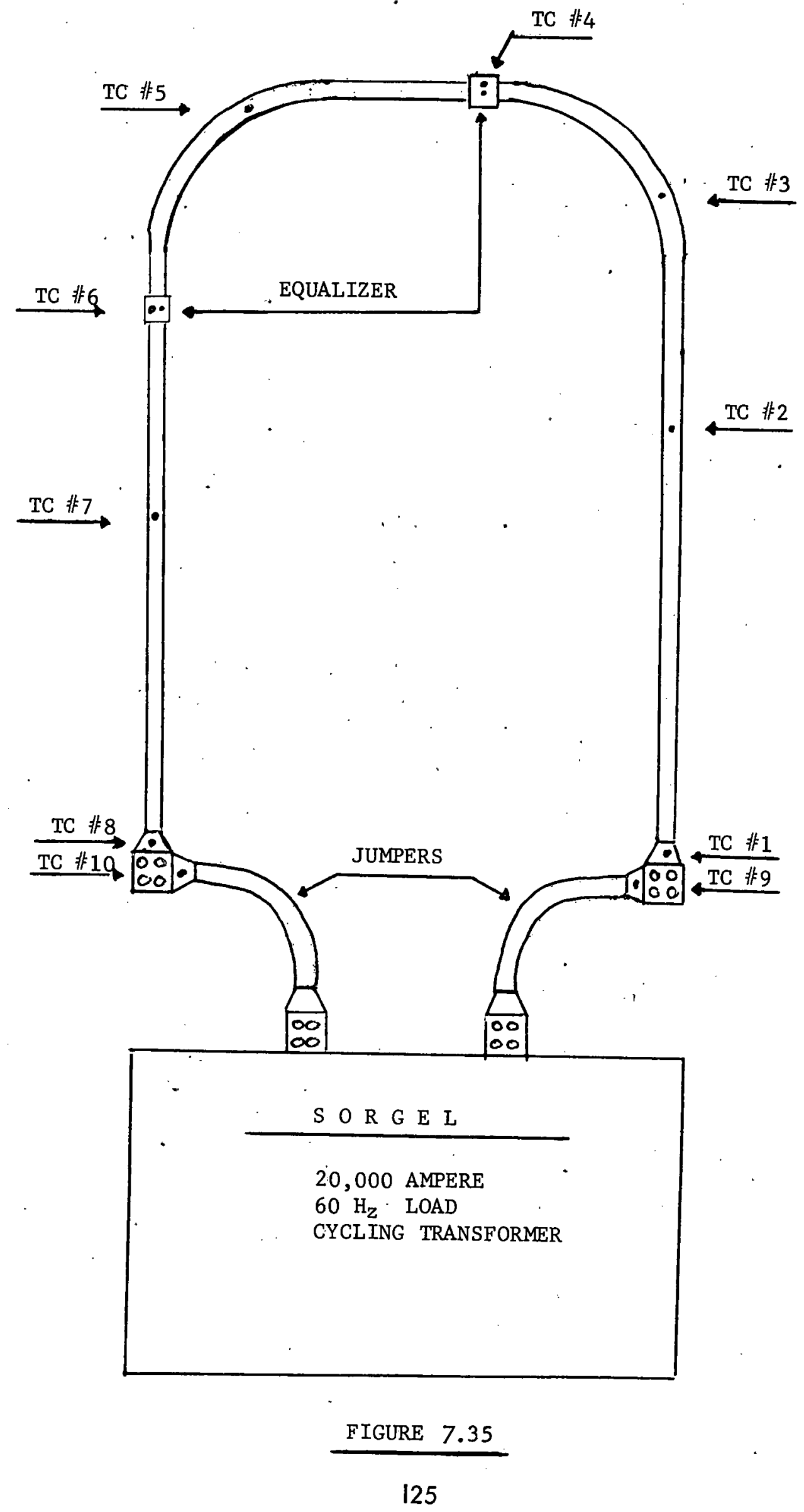


which were applied to the conductor on either side of the test connector. The near edge of the equalizer was spaced 1 inch from the end of the connector. For each connector type, a set of equalizers was also applied to a length of control conductor. These equalizers were spaced the same distance apart as those used adjacent to each connector. For example, equalizer spacing for the Mac connectors was 13.5 inches, for the T \& B connector was 11.5 inches, and for the Cadweld connector was 5.0 inches. The identical spacing, of dc resistance equalizers, over connectors and control conductors allowed direct comparison of connector resistance to the conductor resistance and to calculated nominal conductor resistance. Calculated dc resistance at $25 \mathrm{C}$ for various equivalent $1000 \mathrm{kcmil}$ aluminum conductor lengths are:

$\begin{array}{ll}13.5 \text { inches: } & 19.90 \mathrm{microhms} \\ 11.5 " 1 " & 16.95 \mathrm{"} \\ 5.0 \mathrm{~N} & 7.37\end{array}$

Results of the connector load cycling tests are graphed in FIGURES 7.36, 7.37, and 7.38. The following are general conclusions based upon the graphed data:

\section{MAC CONNECTORS (FIGURE 7.36)}

The data indicate that the Mac connectors run significantly cooler than the control conductor in air. The graphs of both de resistance and temperature indicate stability over the first 600 load cycles and no apparent trend toward degradation. Fluctuations in the plotted data are mainly due to variations in air ambient temperature. At the end of 600 load cycles all five Mac connectors appear to be intact.

\section{T \& B CONNECTORS (FIGURE 7.37)}

The data indicate that the dc resistance of the T \& B connectors, as a group of 5 , tended to increase over the first 500 load cycles. It is noteworthy that both temperature and dc resistance of these connectors tends to be significantly higher than that of the control conductor. During the final 100 load cycles at $160 \mathrm{C}$, and particularly during the last 25 load cycles, substantial increases in both resistance and temperature are evident. This characteristic is indicative of electrical degradation of the connectors which would be expected to result in thermal destruction of one or more of the 5 test connectors. Had the test extended beyond the 100 load cycles at the $160 \mathrm{C}$ level it is likely that further increases in temperature and resistance would have occurred. 


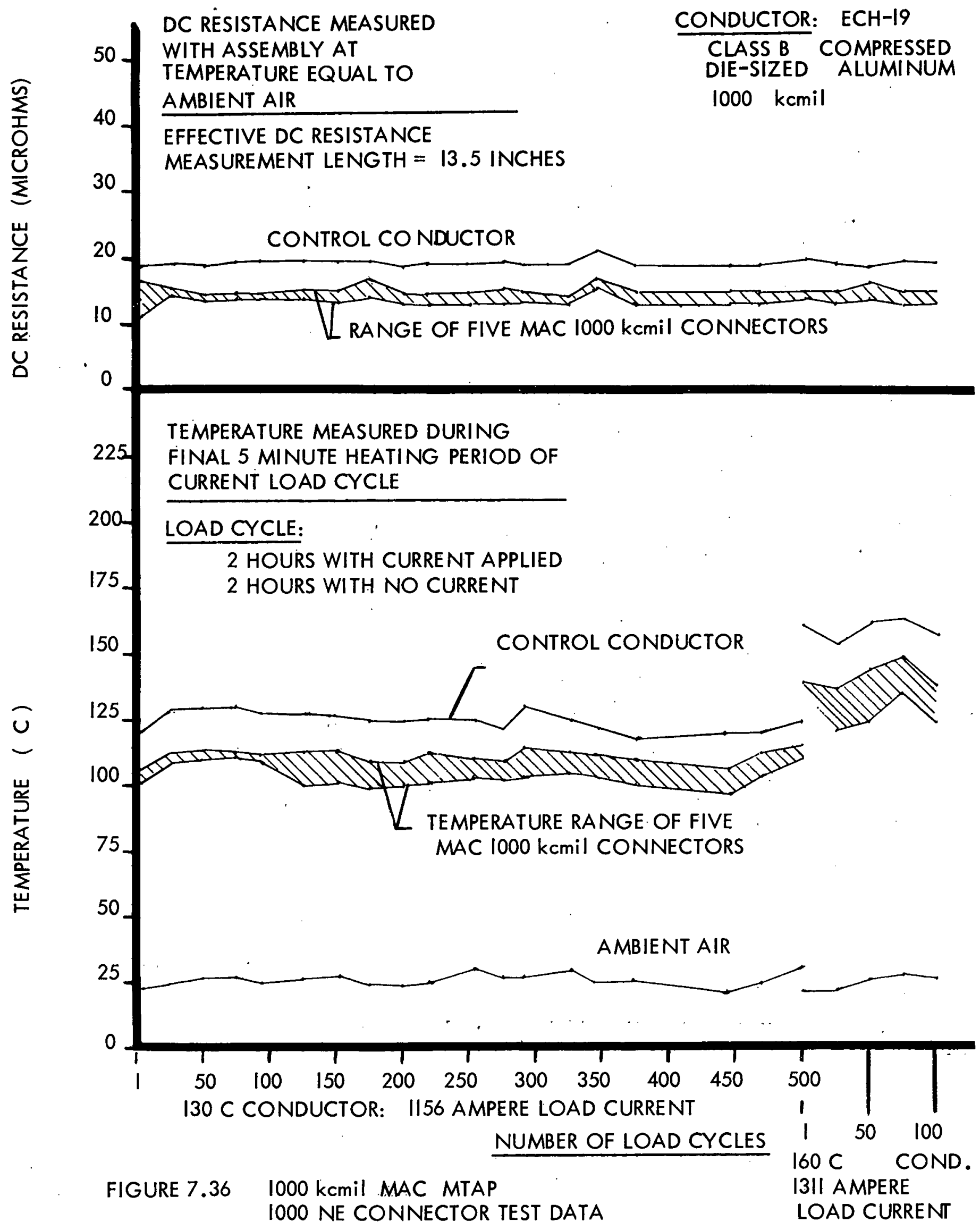




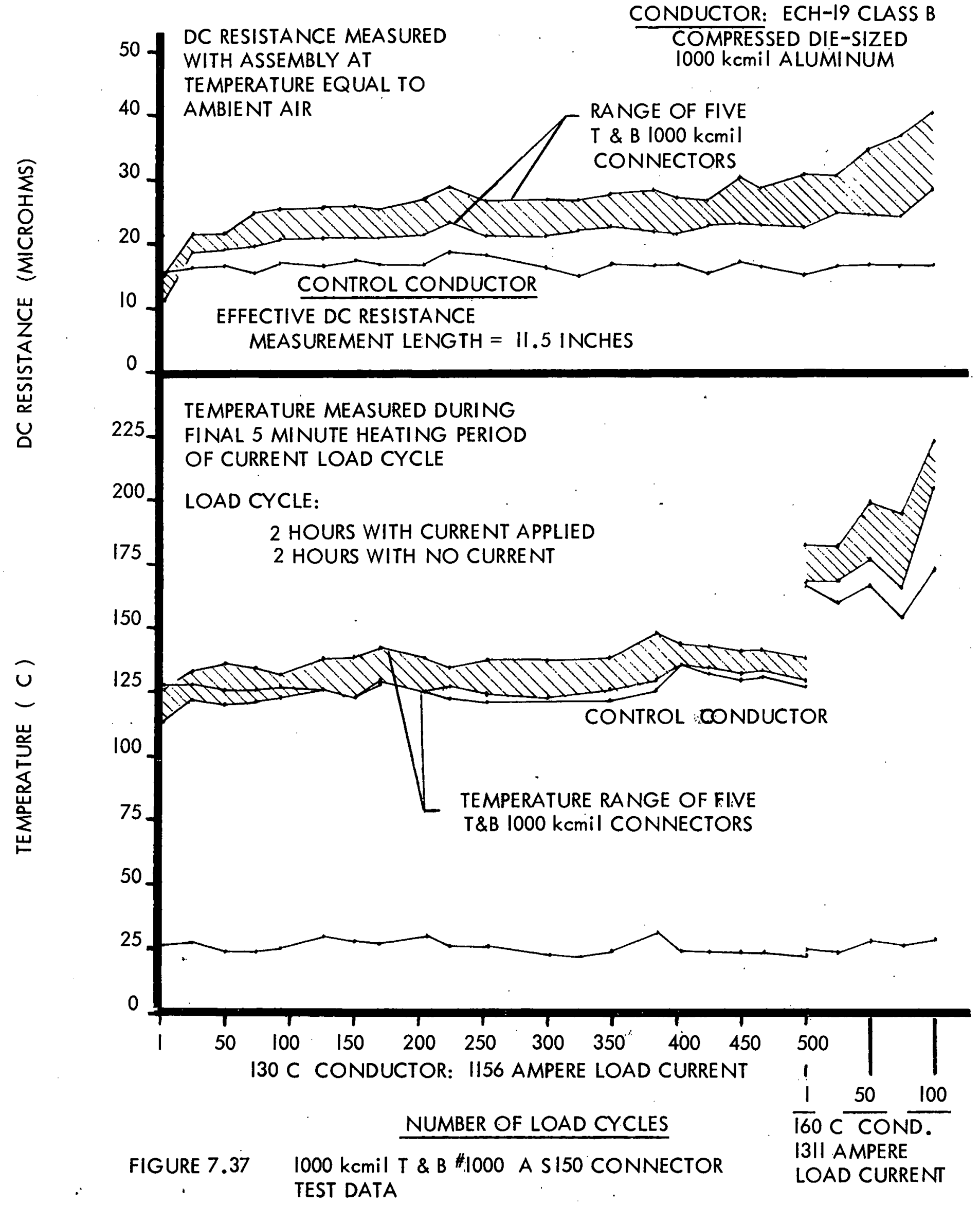




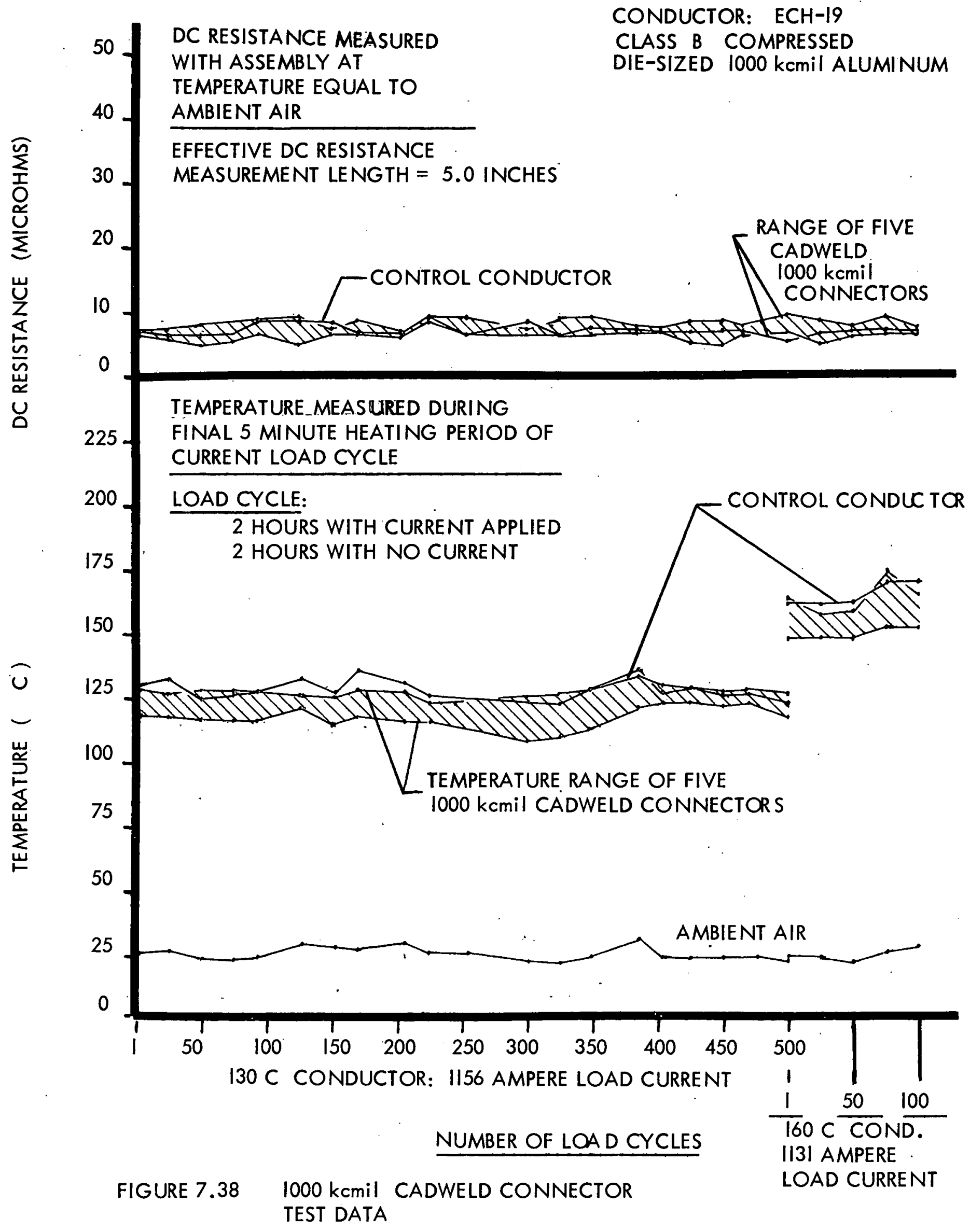




\section{CADWELD CONNECTORS (FIGURE 7.38)}

The data indicate that the Cadweld connector resistances tend to closely match the dc resistance of the control conductor. It is noted that the connectors generally tend to run slightly cooler than the conductor. This later occurrence may be due to the slightly better heatdissipating properties of the Cadweld as compared to the conductor. The data indicate stable temperature and resistance characteristics over the 600 load cycle test with no indication of degradation.

It is evident that the Mac and Cadweld connectors tend to retain satisfactory electrical characteristics, and to operate generally below conductor temperature. The T \& B connector does not appear to possess long-term stability beyond the first 500 load cycles and tends to operate above conductor temperature. Final conclusions on all of these connectors cannot be reached, particularly with regard to application in a $230 \mathrm{kV}$ joint, due to the need to complete at least the next, $190 \mathrm{C}$, portion of the load cycle test in order to subject the connectors to temperatures higher than might be encountered in a $230 \mathrm{kV}$ taped joint design. Earlier thermal tests (Category I, Step F) indicated that connector temperatures in $230 \mathrm{kV}$ taped joint design \# $\mid$ would be in the vicinity of $170 \mathrm{C}$ when the cable conductor was $130 \mathrm{C}$. This indicates that, in order to test with a reasonable margin of design safety, the connectors should exhibit stability at the $190 \mathrm{C}$, or higher, test level.

STEP G - The mechanical test requirements for connectors were covered in Appendix 7.4. A means of measuring actual mechanical forces within $230 \mathrm{kV}$ splices was not devised.

STEP H - A bibliography on aluminum connector design, use and research was not compiled.

STEP I - Due to the contract modification, the tests that were underway could not be completed through the 900 load cycles required to evaluate suitability for use in $230 \mathrm{kV}$ splice designs. Therefore, it was considered best to use the Erico (Cadweld) connector for the actual construction of $230 \mathrm{kV}$ taped EPR joint design \#I in the electrical test circuit. This was based upon past favorable experience with this connector type at the $138 \mathrm{kV}$ level. 
BISHOP ELECTRIC

10 Canfield Rd.

Cedar Grove, N. J., 07009

2

J. H. Neher and M.H. McGrath

"The Calculation of the Temperature Rise and Load Capability of Cable Systems"

Transactions of AIEE, pp 752-72, October 1957

ERICO PRODUCTS, INC.

34600 Solon Rd.

Cleveland, Ohio, 44139

PLYMOUTH RUBBER COMPANY, INC.

Canton, Mass., 02021

GENERAL ELECTRIC COMPANY

One Campbell Rd.

Schenectady, New York, 12306

6

$3 M$ Company

$3 \bar{M}$ Center, Bldg. 223-4N

St. Paul, Minnesota, 5510l

Association of Edison Illuminating Companies (AEIC) No. 5-75 "Specifications For Polyethylene and Crosslinked Polyethylene Insulated Poer Cables Rated 5 Through 69kV" 5th Edition, December, 1975

GILBRETH INTERNATIONAL CORP. 3300 State Road

Cornwells Heights, Pa., 19020

HEXCEL CORPORATION

Electrical Products Dept.

San Diego, Calif., 92109

ELASTIMOLD DIVISION

Amerace Corporation, ESNA Park

Hackettstown, N. J., 07840 

Connectors For Aluminum Conductors, NEMA Pub. No. SG 14.10-1962, EEI Pub. No. TDJ-162

MAC PRODUCTS, INC. 60 Pennsylvania Ave.

Kearny, N. J., 07032

Same as REFERENCE 7.3

14

THOMAS \& BETTS COMPANY

8838 Butler Street

Elizabeth, N. J., 07207

ELECTRICAL SPECIALTY PRODUCTS CO. P.O. Box 21

Montevallo, Alabama, 35I15

UTILITY INDUSTRIES, INC.

5075 Central Highway

Pennsauken, N. J., 08109

HOMAC MANUFACTURING COMPANY

P. O.Box 1118

Ormond Beach, Florida, 32074

BURNDY CORPORATION

Norwalk, Conn., 06856

FRANKEL CONNECTOR CO.

1733 East chester Blvd.

Bronx, N. Y., 1046I

AMP INCORPORATED

Harrisburg, Pa., 17105

TELEDYNE-PENN UNION ELECTRIC

229 Waterford Street

Edinboro, Pa., 16412

ANDERSON ELECTRIC CORP.

P. O. Box 455

Leeds, Alabama, 35094

KEARNEY COMPANY

P. O. Box 49167

Atlanta, Ga., 30329 
The objective of the jointing research program is to develop at least one fully reliable jointing technique at the $230 \mathrm{kV}$ level.

In order to achieve the objective, the program is planned to follow five avenues of research. These divisions of the program are being carried on in parallel. They are:
(I) Taped Joint
(Category l)
(2) Vulcanized Joint
(Category 2)
(3) Alternate Jointing Concepts
(Category 3)
(4) Computer Programs
(Category 4)
(5) Connector Evaluation
(Category 5)

\section{CATEGORY I - TAPED JOINT}

Steps completed as of 12/31/75:

(1) Designed, constructed and tested a higher stress taped joint design in the 138kV $400 \mathrm{kcmil}$ joint test circuit ( $\left.{ }^{\#} W-96275 \mathrm{~A}\right)$. This was tested at $150 \%$ rated voltage for 360 hours.

Designed a $230 \mathrm{kV}$ taped joint for the $1000 \mathrm{kcmil} 230 \mathrm{kV}$ cable using the higher stress design concepts. This is designated $230 \mathrm{kV}$ taped design \#l.

Designed and constructed a second higher stress taped joint in the I38kV 400 kcmil joint test circuit (\#W-962 75B). 
Future Plans As of January, 1976:

(A) Dissect higher stress design joint \#W962-75A (which had to be removed due to a defective cable section in the $138 \mathrm{kV}$ test circuit). Examine for evidence of any electrical degradation due to the testing completed. This will provide an indication of the feasibility of the higher stress concept.

(B) Continue testing the 138kV joint evaluation circuit (with emphasis on higher stress design taped joint $\left.{ }^{\#} \mathrm{~W}-962-75 \mathrm{~B}\right)$ as follows:

(1) $10 \quad 90 \mathrm{C}$ load cycles at $100 \mathrm{kV}$

(2) $10 \quad 90 \mathrm{C}$ load cycles at $110 \mathrm{kV}$

(3) $10 \quad 90 \mathrm{C}$ load cycles at $120 \mathrm{kV}$

(4) $10 \quad 90 \mathrm{C}$ load cycles at $130 \mathrm{kV}$

(5) $10 \quad 90 \mathrm{C}$ load cycles at $140 \mathrm{kV}$

(6) $10 \quad 130 \mathrm{C}$ load cycles at $100 \mathrm{kV}$

A comparison of joint design stresses is tabulated here (Table I).

Completion of Test Step B 3 provides a strong indication that $230 \mathrm{kV}$ design \#I will be workable. Completion of Test Step B 5 would indicate that the $230 \mathrm{kV}$ design \#I would perform at $150 \%$ rated voltage (200kV, phase-to-ground).

(C) Based upon successful completion of Step B3 order pencilling tool for 230kV joint Design \#I.

(D) Design "low stress" transition joints for connection of a length of 1000 $\mathrm{kcmil} 230 \mathrm{kV}$ cable to an existing $2500 \mathrm{kcmil} 138 \mathrm{kV}$ cable which is terminated in $230 \mathrm{kV}$ terminals. These joints will be designed to avoid the likelihood of their failure at voltages up to $266 \mathrm{kV}$, phase-toground. This will provide a full scale test circuit with capacity for electrically evaluating $230 \mathrm{kV}$ splice designs.

(E) Construct and pre-test the two joints of Step D, "jointing in" about 50feet of $230 \mathrm{kV}$ cable.

(F) Design and construct a "thermal profile" test on 230kV Joint Design \#I. This joint will be constructed in the center of a 24-foot length of 1000 kcmil $230 \mathrm{kV}$ cable. Thermocouples will measure temperature occurring at numerous locations in the joint and cable. In order to avoid the 
ELECTRICAL STRESSES IN TAPED JOINT DESIGNS

\begin{tabular}{|c|c|c|c|c|c|c|c|c|}
\hline \multirow[b]{3}{*}{$\%$ RATED VOLTAGE } & \multirow{2}{*}{\multicolumn{2}{|c|}{$\begin{array}{c}\text { Waltz Mill } \\
138 \mathrm{kV} \text { ERC } \\
\text { Design }\end{array}$}} & \multicolumn{4}{|c|}{$\begin{array}{c}138 \mathrm{kV} \text { Higher Stress } \\
\text { Design }\end{array}$} & & \\
\hline & & & \multicolumn{2}{|c|}{ W-962-75A } & \multicolumn{2}{|c|}{$W-962-75 B$} & \multicolumn{2}{|c|}{$\begin{array}{c}230 k V \\
\text { Design 非1 }\end{array}$} \\
\hline & 150 & 175 & 150 & 175 & 150 & 175 & 100 & 150 \\
\hline KILOVOLTS & 120 & 140 & 120 & 140 & 120 & 140 & 133 & 200 \\
\hline \multicolumn{9}{|l|}{$60 \mathrm{z}$ UNIT STRESS (V/M) } \\
\hline $\begin{array}{l}\text { Maximum Radial } \\
\text { Average Radial } \\
\text { Pencil Tangential } \\
\text { Stress Cone Longitudinal } \\
\text { Average Creepage } \\
\text { Connector Longitudinal }\end{array}$ & $\begin{array}{r}176 \\
80 \\
11.3 \\
14.1 \\
7.5 \\
11.3\end{array}$ & $\begin{array}{r}205 \\
93 \\
13.1 \\
16.5 \\
8.8 \\
13.1\end{array}$ & $\begin{array}{r}201 \\
95 \\
21.4 \\
11.6 \\
10.7 \\
--\end{array}$ & $\begin{array}{c}234 \\
111 \\
25 \\
13.5 \\
12.5 \\
--\end{array}$ & $\begin{array}{r}173 \\
95 \\
21.4 \\
15.6 \\
10.7 \\
20.1\end{array}$ & $\begin{array}{r}202 \\
111 \\
25 \\
18.2 \\
12.5 \\
23.5\end{array}$ & $\begin{array}{r}152 \\
70.4 \\
12.3 \\
12.5 \\
7.5 \\
--\end{array}$ & $\begin{array}{c}228 \\
105.6 \\
18.4 \\
18.8 \\
11.3 \\
--\end{array}$ \\
\hline IMPULSE UNI'T STRESS (V/M) & & & & & & ; & & \\
\hline B.I.L. KILOVOLTS & 650 & & 650 & & 650 & . & 1050 & \\
\hline $\begin{array}{l}\text { Average Radial } \\
\text { Average Creepage }\end{array}$ & $\begin{array}{r}433 \\
41.3\end{array}$ & & $\begin{array}{r}514 \\
58\end{array}$ & & $\begin{array}{r}514 \\
58\end{array}$ & & $\begin{array}{r}556 \\
59\end{array}$ & \\
\hline $125 \%$ B.I.L. KILOVOLTS & 813 & & 813 & & 813 & & 1313 & \\
\hline $\begin{array}{l}\text { Average Radial } \\
\text { Average Creepage }\end{array}$ & $\begin{array}{r}541 \\
51.6\end{array}$ & & $\begin{array}{r}643 \\
73\end{array}$ & & $\begin{array}{r}643 \\
73\end{array}$ & & $\begin{array}{r}695 \\
73.8\end{array}$ & \\
\hline$\frac{\text { DC UNIT STRESS }(\mathrm{V} / \mathrm{M})}{\text { KILOVOLTS }}$ & 415 & & 415 & & 415 & & 525 & 750 \\
\hline $\begin{array}{l}\text { Average Radial } \\
\text { Average Creepage }\end{array}$ & $\begin{array}{r}277 \\
26.3\end{array}$ & & $\begin{array}{r}328 \\
37\end{array}$ & & $\begin{array}{r}328 \\
37\end{array}$ & & $\begin{array}{r}277 \\
29.5\end{array}$ & $\begin{array}{r}397 \\
42.3\end{array}$ \\
\hline
\end{tabular}




\section{CATEGORY I (Cont'd.)}

effects of a connector, in this initial test, the splice will be constructed on an uninterrupted conductor. This test will yield:

(1) An indication of the degree of overheating which may be expected in $230 \mathrm{kV}$ Joint Design \#I.

(2) Data for use in developing the thermal field computer program (Category 4, Part 3).

(3) Loading curves for $90 \mathrm{C}$ and $130 \mathrm{C}$ cable operation.

(G). Determine methods for evaluating taped joint insulation. In order to develop the best taped joint design a thorough knowledge of the characteristics of each jointing tape must be obtained. To the greatest extent possible this data will be obtained using standard industry tests, ASTM methods, etc. In cases where no method exists, we will develop techniques for measurement. The characteristics to be measured are listed below.

Each of these characteristics will be determined with the sample at $25 \mathrm{C}, 60 \mathrm{C}, 90 \mathrm{C}, 130 \mathrm{C}, 150 \mathrm{C}, 175 \mathrm{C}$, and $200 \mathrm{C}$.

(1) $60 \mathrm{~Hz}$ dielectric withstand and breakdown as a function of thickness and temperature.

(2) DC dielectric withstand and breakdown as a function of thickness and temperature.

(3) Impulse dielectric withstand and breakdown as a function of thickness and temperature.

(4) Dielectric constant and dissipation factor as a function of electrical stress and temperature.

(5) Tendency toward dielectric heating (through measurements of dissipation factor) as a function of electrical stress, temperature and time.

(6) Joint insulation modulus (tensile \& elongation) as a function of temperature.

(7) Insulation thermal conductivity as a function of temperature. 
CATEGORY 1 (Cont'd.)

(8) Joint insulation/cable insulation $60 \mathrm{~Hz}$ interfacial dielectric withstand as a function of temperature.

(9) Same as 8, except on DC.

(10) Same as 8, except on Impulse.

(II) Joint insulation/cable insulation interfacial adhesion as a function of temperature and pressure.

The determination of these characteristics may be performed by the $R$ \& $D$ group in conjunction with tape manufacturers and independent research and development laboratories.

Develop working relationships with tape manufacturers for cooperative efforts in evaluating tape insulations and designs for use at $230 \mathrm{kV}$ levels. Bishop, General Electric, 3M, Plymouth, etc., are companies in this category.

A test procedure will be outlined for evaluation of joints developed from Categories I, 2 \& 3 . The tests will be performed by installing test joints in two separate test circuits:

(I) $60 \mathrm{~Hz}$ testing - Using the circuit described in Steps D \& E of Category I (Joint Test Circuit A).

(2) DC \& Impulse Testing- A circuit will be set up which will allow DC tests and impulse tests to be done on the same circuit. With a total circuit length of $80^{\prime}$, the effective test length for $D C$ testing will be $60^{1}$ and the effective test length for impulse testing will be 30' (Joint Test Circuit B).

As joint designs are developed and evaluated, some designs may not merit consideration beyond the design stage while others will appear to be acceptable. The first step in evaluating the designs that hold promise is a relatively short-term electrical test. Following are the steps involved in evaluating a given joint design:

(A) Construct one joint in Test Circuit A. 
CATEGORY I (Cont'd.)

(B) Subject joint to following $60 \mathrm{~Hz}$ tests:

(I) Pre-test @ $166 \mathrm{kV}$ for 5 minutes

"@200kV for 5
" @ $233 k V$ for 5
" $266 k V$ for 5 "

(2) Measure dissipation factor and capacitance of splice @ I33kV, 166kV, 200kV, 233kV, and 266kV.

(3) Measure partial discharge characteristics of joint at voltages up to $200 \mathrm{kV}$.

(4) Load cycle 8 hours on $/ 4$ off at $90 \mathrm{C}$ cable conductor temperature.

$$
\begin{aligned}
& \text { Load Cycle I - voltage } 166 \mathrm{kV} \\
& \text { " } 2 \text { - voltage } 200 \mathrm{kV}
\end{aligned}
$$

During final hour of Load Cycle 2, repeat Steps $2 \& 3$.

(5) Allow circuit to cool to room temperature and repeat Steps 2 \& 3.

(6) Current load cable for $130 \mathrm{C}$ conductor temperature for a period of at least 8 hours with circuit energized at $166 \mathrm{kV}$. Monitor and record dissipation factor measurements at one-hour intervals. Continue test until three hour-interval readings show no significant change.

(7) Repeat Step 5 .

(8) Load cycle 12 hours on $/ 4$ off at $90 \mathrm{C}$ cable conductor temperature for a total of 8 additional load cycles at $200 \mathrm{kV}$.

The short-term test outlined above would require 12 days for completion (after joi tat construction).

(C) When Part B is successful, install three joints of the same design in joint test circuit B. DC test as follows:

(I) 15 minutes at $525 \mathrm{kV}(0.5 \times$ B.I.L. $)$

(2) 15 minutes at $655 \mathrm{kV}(0.624 \times$ B.I.L. $)$ 


\section{CATEGORY I (Cont'd.)}

Impulse test as follows:

(I) 10 shots Positive at B.I.L. (1050 kV)

(2) 10 shots Negative at B.I.L.

(3) 3 shots Negative at I.05 B.I.L. (ll03 kV)

(4) 3 shots Negative at I.10 B.I.L. (II55kV)

(5) 3 " " at I.15 B.I.L: (1208kV)

(6) 3 " at I.20 B.I.L. (260kV)

(7) 3 " at I.25 B.I.L. (I3I3kV)

Heat circuit overnight to $90 \mathrm{C}$ conductor temperature and repeat impulse tests.

(D) Install additional two joints in Splice Test Circuit A for long-term tests. The steps in this test are:

(I) Pre-test at $166 \mathrm{kV}$ for 5 minutes

$\begin{array}{lll}" & \text { at } 200 \mathrm{kV} \text { for } 5 & " \\ " & \text { at } 233 \mathrm{kV} \text { for } 5 & \end{array}$

(2) Measure dissipation factor and capacitance of each splice at $133 \mathrm{kV}, 166 \mathrm{kV}, 200 \mathrm{kV}, 233 \mathrm{kV}$ and $266 \mathrm{kV}$.

(3) Measure partial discharge characteristics of splices at voltages up to $200 \mathrm{kV}$.

(4) Load cycle 12 hours on/4 off as follows:

(a) 10 load cycles at $90 \mathrm{C}$ and $200 \mathrm{kV}$

(b) Repeat Steps $2 \& 3$ at room temperature

(c) 10 load cycles at $130 \mathrm{C}$ and $166 \mathrm{kV}$

(d) Repeat (b)

(e) 10 load cycles at $90 \mathrm{C}$ and $233 \mathrm{kV}$

(f) Repeat (b)

(g) 10 load cycles at $90 \mathrm{C}$ and $266 \mathrm{kV}$

(h) Repeat (b)

(E) Upon completion of Step D, subject three joints (from joint test circuits $A$ or $B$ ) to mechanical tests and tests to assure watertight construction. 


\section{CATEGORY I (Cont'd.)}

(F) Evaluate test results and select best joint design(s) for use in complete $230 \mathrm{kV}$ test circuit.

(G) Install three joints of each acceptable design in the complete $230 \mathrm{kV}$ test circuit. Following completion of tests on this circuit, a total of at least 9 joints for each given design which is accepted will have been tested ( 3 on Joint Circuit A $60 \mathrm{~Hz}$ tests, 3 on Joint Circuit B Impulse \& DC tests, and 3 on the complete $230 \mathrm{kV}$ Test Circuit).

\section{CATEGORY 2 - V VULCANIZED JOINT}

Steps Completed as of 12/31/75:

(I) $\quad 69 \mathrm{kV}$ level evaluation of vulcanized joint using present meth ods.

(A) Thermal profile tests were completed on process temperatures for shielding and insulating the $69 \mathrm{kV} 500 \mathrm{kcmil}$ joint.

(B) Twelve experimental joints were made, using various process parameters, for visual inspection.

(C) Seven of the twelve joints were very closely examined after being slinkied. Data on void and contaminant quantity, size, and location were obtained and recorded under microscopic inspection.

(D) A $69 \mathrm{kV} 500 \mathrm{kcmil}$ test cable was terminated and pre-tested.

(E) Ten- $69 \mathrm{kV} 500 \mathrm{kcmil}$ vulcanized joints were constructed by five $R$ \& D people in the test circuit of Step $D$.

(F) $\quad X$-rays of each of the 10 test joints were made.

(2) A sample order was placed with a small company specializing in custom tape extrusions. Steps have been taken to reduce contamination of the tape through use of clean packaging methods.

It is expected that this supplier will be able to produce the small experimental tape quantities that are required for this development. 
A vulcanized EPR ( $K-146) 138 \mathrm{kV} 400 \mathrm{kcmil}$ joint was built in the $138 \mathrm{kV}$ long-term test circuit. Testing continues on this joint, one other vulcanized EPR joint, seven vulcanized polyethylene joints, and three taped joints. A total of 7500 test hours have now been completed on the original components of this circuit.

A search has begun to find suitable heat-shrinkable semi-conductive tubing as a possible improvement over the present connector shielding method.

Future Steps: (As of January, 1976)

(A)

Evaluation at $69 \mathrm{kV}$ level. Perform accelerated load cycling program on 10 test joints and evaluate electrical test results.

Following Step $A$, dissect and slinky insulations from 10 test joints. Correlate microscopic inspection of joint insulations with $X$-rays. Compare insulation quality and repeatability with that of earlier visual evaluation joints. Determine effect of accelerated load cycle testing on joint insulation.

Use an additional sequence of experimental joint constructions on the $69 \mathrm{kV} 500 \mathrm{kcmil}$ cable for the purpose of additional experiments to shorten process time and improve quality.

As an intermediate step, design and construct four vulcanized joints on a length of either $750 \mathrm{kcmil}$ or $1000 \mathrm{kcmil} 69 \mathrm{kV}$ cable. The first of these will be used for a thermal profile of the process, while the last three will be used for visual examination of joint insulation helixes.

Design and construct a vulcanized XLPE joint for the $230 \mathrm{kV} 1000 \mathrm{kcmil}$ cable for the purpose of determining the processing thermal profile using present technique (oven heating). As a second step use auxiliary heating tapes along cable adjacent to oven ends to determine their effect on the thermal profile (expected reduction of axial heat loss).

Pursue means of heating the conductor/connector within the joint using radio frequency induction heating. Determine suitability of this technique, and possible improvements resulting, in the process.

Pursue study of means of heating the joint insulation through use of higher (microwave) frequency. Determine feasibility of this approach. 


\section{CATEGORY 2 - (Cont'd.)}

(H) Pursue use of semi-conducting heat-shrinkable tubing as connector shielding (in place of present molded shielding).

(I) Pursue study of use of transfer molding or extrusion in place of present taped joint insulation application. Determine feasibility.

(J) Pursue study of alternate (other than dicumyl peroxide) crosslinking agents for use in joint insulation compounds. Convert small quantities of such compounds to tape form for experiment.

(K) Convert a quantity of EPR uncured compound (such as K-146) to tape form. Design and construct experimental joints for thermal profile and visual evaluation.

(L) Study means of reducing process time required. Design and construct experimental $230 \mathrm{kV}$ joints for evaluation of these means.

(M) Pursue development with Hotsplicer of a $230 \mathrm{kV}$ Hotsplice.

(N) Based upon results of Steps $E$ through $L$, determine best practical method for vulcanized joint construction.

(O) Design and construct one thermal profile $230 \mathrm{kV}$ joint and three visual inspection joints based upon Step $N$.

(P) If results of Step (0) are favorable, proceed into electrical test sequence. 


\section{CATEGORY 3 - ALTERNATE JOINTING CONCEPTS}

There are several possible methods of joining $230 \mathrm{kV}$ cable besides the taped and vulcanized approaches. There are also concepts which might use taped or vulcanized joint insulation but which would employ significantly different approaches to joint design. Alternate approaches which may hold promise appear to be the following:

(A) Use of a design approach which would eliminate the necessity to taper the cable insulation. This would use a concept presently used in premolded $35 \mathrm{kV}$ joints where no insulation tapering is required. The basic feasibility of the concept as applied to $230 \mathrm{kV}$ jointing would depend upon whether or not the inner electrode of the joint could be shaped in such a way as to reduce localized electrical stresses to acceptable levels.

(1) Run an analog field plot on a preliminary design to determine if electrical stresses appear to be within an acceptable range.

(2) Based upon $A(1)$ run additional field plots as necessary on additional designs.

(3) If the basic concept appears workable, study possible methods for practical construction of such a joint.

(4) Design a practical connector for use in the design.

(5) Study possible means (i.e., taped, vulcanized PE or EPR, poured elastomer, premolded elastomer, partially premolded insulation, etc.) of constructing such a joint.

(6) In order to actually test the concept, determine the most promising approach. Design and construct the joint for thermal analysis.

(7) Based upon the successful completion of Step 6, proceed into electrical test sequence.

(B) The second possible means of developing an improved joint design would use the concept of a graded dielectric joint design. Much of the practical use of this approach will depend upon the dielectric characteristic measurement of Category 1, Step G, and upon determination of the characteristics of possible (developmental) joint insulations. 
(I) Design a graded dielectric joint based upon use of two or more joint insulations having different dielectric constants.

(2) Evaluate electrical stress levels through use of the electrical field computer program (Category 4, Step A) and through comparison of design values with proven design values.

(3) Construct a graded dielectric joint for thermal analysis.

(4) If the concept appears to be acceptable, proceed into the electrical test sequence.

(C) The third possible means of developing an improved joint design would be through the use of a poured (rather than taped) joint insulation. A number of elastomeric materials with good dielectric properties exist at present. Other improved materials may be possible. These materials are supplied in liquid form and are then mixed with a catalyst and poured. They cure at room temperature into a permanent elastomeric dielectric. The following steps will be used to evaluate this concept:

(I) Study and define all presently available poured dielectrics.

(2) Eliminate materials which would not be suitable. Select one or more of the most promising materials. Subject this material to measurement of the insulation characteristics as outlined in Step $G$ of Category I.

(3) Determine possible suitability of the insulation(s) in Step C2 for use in $230 \mathrm{kV}$ jointing.

(4) Design a poured joint and obtain necessary equipment.

(5) Construct one poured joint for thermal analysis.

(6) If the concept appears to be workable, proceed into the electrical test sequence. 
(D) The fourth possible means of developing an improved joint design would use the concept of forced grading of longitudinal electrical stresses based upon location of conductive "shells" at various radial dimensions throughout the joint insulation. This concept might be combined with the taperless insulation concept (Step 3A) or might yield a variation of any of the other jointing techniques. Steps in the development are as follows:

(I) Design a "forced graded" taped joint. Conductive "shells" will be included in the design to grade tangential and longitudinal stresses. Possibly use analog field plotting to evaluate the design.

(2) Construct a joint of this design for thermal analysis.

(3) Construct one joint in Test Circuit A for preliminary electrical evaluation. If results are satisfactory, proceed with electrical evaluation sequence.

(4) Review results of Steps DI, D2 \& D3, and evaluate. Proceed to design and test additional forced-graded designs.

(E) The fifth possible means of developing an improved joint design would be through the use of a pre-molded joint. At the present time, there is a possibility that the Elastimold $138 \mathrm{kV}$ concept may be upgraded to the $230 \mathrm{kV}$ level. Except for this there does not appear to be any possibility that any other U.S. pre:-molded joint manufacturer could conceivably develop such a joint within the time and money constraints of the present contract. Therefore, the steps toward developing a suitable pre-molded $230 \mathrm{kV}$ joint would be:

(I) Study of possible use of the Elastimold concept at the $138 \mathrm{kV}$ and $230 \mathrm{kV}$ levels. This would include evaluation of Elastimold test results.

(2). Installation of a $138 \mathrm{kV}$ and/or $230 \mathrm{kV}$ Elastimold joint for thermal evaluation.

(3) Installation of a $138 \mathrm{kV}$ and/or $230 \mathrm{kV}$ Elastimold joint for electrical testing. If testing of the first joint at the $230 \mathrm{kV}$ level is successful, proceed with electrical evaluation sequence. 


\section{APPENDIX 7.I (Continued)}

\section{CATEGORY 4 - COMPUTER PROGRAMS}

A key to a full evaluation is the ability to assess joint designs in a thorough manner. Computer programs to allow more thorough data on certain joint characteristics were considered to be the logical means of taking a closer look at designs, due to the time-consuming nature of similar hand calculations. The three programs which will be developed are as follows:

(A) Electrical Field Program - This program has been developed and yields the capability of looking closely at the electrical stress distribution in joint designs.

(B) Joint Design Program - The initial program is presently being being worked upon and is expected to be developed by mid-1976. The purpose of the program is to allow study of numerous possible designs and to design joints based upon knowledge of insulation dielectric properties (from Category I, Step G). This program will actually design joints based upon variable inputs of dielectric design values and stress values.

(C) Thermal Field Program - This program is presently being worked upon. The purpose of the program is to allow quick assessment of the thermal profiles of various joint designs. Initially, the experimental data from Category I, Step F, will be used in developing and de-bugging the program. The thermal characteristics of joint designs have been shown to be very important from the view of joint reliability. It is hoped that a program can be developed which will provide accuracy in predicting thermal profiles of various joint designs, thus reducing the very time-consuming process of experimentally checking each joint design under consideration.

In brief, use of these programs is expected to yield a more complete capability for evaluating and designing joints. The basic purpose of the programs is to aid in the development of $230 \mathrm{kV}$ joint designs for fulfillment of requirements of the ERDA contract. The programs will supplement design work and aid in the analysis of modes of joint failure. 


\section{CATEGORY 5 - CONNECTOR EVALUATION}

In order to develop a fully reliable $230 \mathrm{kV}$ joint, it is essential that the selected connector be reliable and that there be a knowledge of the characteristics of the connector. In order to take a thorough look at the problem of connector selection, the following steps will be taken to obtain data for evaluation.

(A) Outline the experience to date with various types of connectors.

(I) Kaiser experience

(2) Utility and Industry experience. Contact individuals who are involved in connector testing and evaluation.

(B) Define the methods for joining stranded aluminum conductors sized from $1000 \mathrm{KCM}$ to $2500 \mathrm{KCM}$. These methods would all fall within one of the following classes:

(I) Inert gas welding (MIG; TIG)

(2) Exothermic (Cadweld, Alutherm)

(3) Compression (Burndy, T\&B, etc.)

(4) Mechanical

(5) New concepts (Cryocon, Ampact, etc.)

(C) Define test criteria for connector evaluation. Using present standards (such as EEI TDJ-162, etc.), develop a realistic test specification.

(D) Based on Step C, set up a test circuit for connector evaluation. Perform initial experiments for measurements of $A C$ resistance, DC resistance and temperature.

(E) Establish working relationships with connector suppliers. Arrange for a cooperative test program using the specification of Step $C$ and the test circuit of Step D. 
CATEGORY 5 - (Continued)

(F) Perform specification tests on each connector type under consideration. Evaluate connectors for degree of acceptability.

(G) Determine mechanical requirements for a fully reliable connector.

(I) Set up tests to measure mechanical forces within joints

(2) Establish mechanical test criteria for evaluating connectors passing Step F.

(3) Test and evaluate mechanical properties of connectors passing Step F.

(H) Compile a bibliography of literature on aluminum connector design, use and research.

(I) Determine connectors which are fully suitable for $230 \mathrm{kV}$.

Finally, in order to outline the concurrent nature of each of these five divisions of the $230 \mathrm{kV}$ joint research program, a flow chart is shown. From time to time as changes are needed in the overall program the plan will be updated. Progress will be measured at one to three month intervals. 


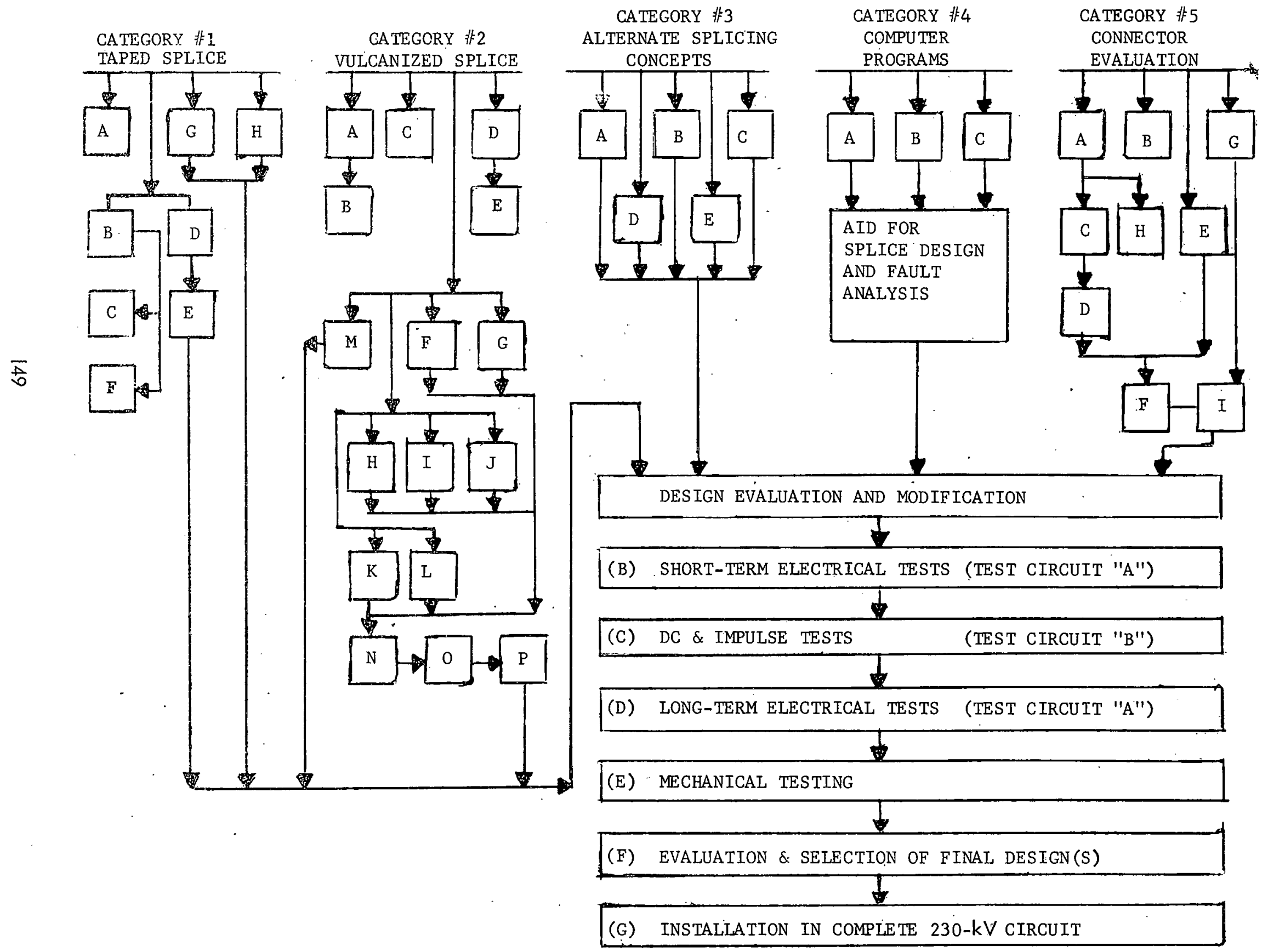


From Neher-McGrath (Reference 7.2) a formula was derived which is commonly used in laboratory testing of solid dielectric cables. This formula is:

$$
I_{t c}=\sqrt{\frac{(T c-T a) \times 10^{6}}{\left.(\operatorname{Rac})(\operatorname{Rca})^{+}\right)}}
$$

The elements of this formula are defined:

$$
\begin{aligned}
& \mathrm{I}_{\mathrm{tc}}=60 \mathrm{~Hz} \text { current in amperes to maintain conductor temperature } \\
& \text { Tc. } \\
& \text { Tc } \quad \text { Conductor temperature }\left({ }^{\circ} \mathrm{C}\right) \\
& \mathrm{Ta} \quad=\quad \text { Ambient air tempe rature }\left({ }^{\circ} \mathrm{C}\right) \\
& \text { Rac }=\text { The } 60 \mathrm{~Hz} \text { electrical resistance of the conductor at } \\
& \text { temperature TC (milliohms/1000 ft.) } \\
& \text { Rca }^{\prime}=\text { Thermal factor derived from application of several formulae. } \\
& \text { It is equal to the sum of the factors } R E \text {, Ri and } R j \text {. } \\
& \text { RE is a factor dealing with the thermal emissivity of the } \\
& \text { cable (or joint) } \\
& \mathrm{Ri} \text { is a factor dealing with the geometric thermal resistivity } \\
& \text { of the cable (or joint) insulation } \\
& \mathrm{Ri}_{\mathrm{i}} \text { is a factor dealing with the geometric thermal resistivity } \\
& \text { of the cable (or joint) jacket. }
\end{aligned}
$$

The derivation of these factors. will not be discussed here, in the interest of brevity. It is sufficient to note that Rca' is a factor which describes the heat dissipating properties of a cable or joint. It is evident that if the unit value for Rca' is reduced the result will be higher cable ampacity to maintain a given conductor temperature. If $\mathrm{I}$ is held constant and $\mathrm{Rca}^{\prime}$ is decreased the conductor will run cooler, having an effect similar to a reduction in Rac. 
In the interest of joint design the ideal situation would be for the separately calculated ITC values for joint and cable to be identical due to the denominator within the radical [(Rac) (Rca')] for the joint being equal to the demoninator for the cable. Then the ratio of joint/cable. Rca' would be unity and the cable and joint would have equal conductor temperatures. Obviously, the reduction of Rac within the joint could also result in the same ratio. Calculations were performed to derive the ratio joint/cable for Rca' of three taped EPR splice designs. Assumptions in the calculations were:

1. All layers of both cable and splice remain the same value of thickness, only conductor size varies.

2. The joint was treated as an infinite cable length having dimensions equal to the joint center cross-section. Some axial heat flow actually occurs, but this is neglected in these calculations.

The values are seen graphed in FIGURE 7.9. Note that the 230kV design using electrical stresses based on the 138kV Waltz Mill design (FIGURE 7.10) has a substantially higher ratio than that of $230 \mathrm{kV}$ taped splice Design ${ }^{\# I}$ (FIGURE 7.II).

This indicates that the former design would experience joint conductor overheating significantly greater than the approximately $170 \mathrm{C}$ actually observed in both the latter design and the $138 \mathrm{kV}$ Waltz Mill design. 
APPENDIX 7.3 - COMPUTER AIDS

JOINT DESIGN PROGRAMS FOR ELECTRICAL

AND THERMAL FIELDS

(AS OF MARCH, 1976)

SUMMARY:

The purpose of this work is to develop a user-oriented computer program that will aid the joint design for the ERDA $230 \mathrm{kV}$ project. The program is to have three parts:

(I) The first part will calculate the electric stresses at all points in the joint insulation

(2) The second part will calculate the temperature at all points in the joint, both conductor, semi-conduc tor and insulation

(3) The third part will use the preceding calculations and any additional design limitations (i.e., maximum joint diameter, maximum conductor temperature at connector, maximum radial stress, etc.) to predict optimum joint dimensions for a given conductor size, thermal conductivities of insulations, etc.

To date, the first part is about $75 \%$ complete, the second $25 \%$ complete and the third part is still in the discussion state (no programming has been done on the third part).

\section{ELECTRIC STRESS CALCULATION:}

The electric stress in the joint insulation may be calculated if one knows the voltage at all points. The voltage distribution in the joint insulation may be calculated by solving Laplace's Equation * in suitable form and applying the boundary conditions (voltage of shield and conductor). Equation (I) is Laplace's equation in cylindrical coordinates with symmetry assumed in the angular dimension -- it applies to a dielectric space with no free charge:

* Laplace's Equation is a differential form of Gauss' Law where there is no electric charge present. 
(i) $\frac{1}{r} \frac{\partial u}{\partial r}+\frac{\partial 2 u}{\partial r^{2}}+\frac{\partial 2 u}{\partial z^{2}}=0$

This can be converted to an equivalent difference equation which lends itself to a numerical solution *.

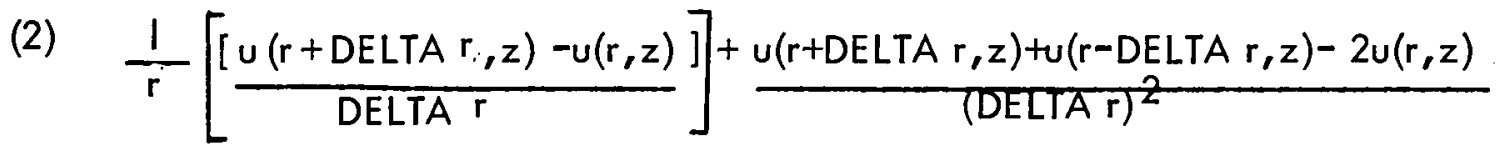

$$
\frac{+u(r, z+\operatorname{DELTA} z)+u(r, z-\operatorname{DELTA} z)-2 u(r, z)}{(\text { DELTA } z)^{2}}=0
$$

Rearranging this equation one can express the voltage at the point $(r, z)$ in terms of the four surrounding voltages.

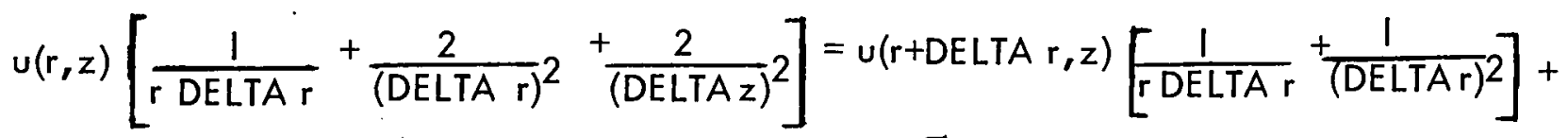

$$
\begin{aligned}
& +u(r-\text { DELTA } r, z)\left[\frac{1}{\left(\operatorname{DELTA}^{2}\right)^{2}}\right]+u(r, z+\operatorname{DELTA} z)\left[\frac{1}{\left(\operatorname{DELTA}^{2}\right)^{2}}\right] \\
& \left.+u(r, z-\operatorname{DELTA} z)\left[\frac{1}{(\operatorname{DELTA} z)}\right)^{2}\right]
\end{aligned}
$$

or multiplying by DELTA $r^{2}$ :

(3) $u(r, z)=\frac{\left.u(r+D E L T A r, z)\left[\frac{D E L T A r}{r}+1\right)\right] u(r-D E L T A r, z)+[u(r, z+D E L T A z)+u(r, z-D E L T A z)]\left(\frac{D E L T A}{D E L T A} z\right)^{2}}{\frac{\text { DELTA } r}{r}+2+2\left(\frac{\text { DELTA } r}{\text { DELTA } z}\right)^{2}}$ 
If one draws an axial section of the joint insulation and superimposes . a suitable grid as in FIGURE I, one can convert Equation (3) into a form suitable for numerical computation. To this end choose a grid fine enough (i.e., with enough grid points) to be able to describe the joint dimensions accurately as being so many grid points up or to the right of the origin.

* The difference equation may be derived from the differential equation by noting the definition of a derivative:

$$
d f / d x=\frac{f(x+\text { DELTA } x)-f(x)}{\text { DELTA } x} \text { where DELTA } x \rightarrow 0
$$

Next, choose a radial and axial distance increment, $\mathrm{Hr}$ and $\mathrm{H}_{\mathrm{z}}$, respectively, so that: :

$$
\begin{aligned}
& \text { DELTA } r=H_{r} \\
& \text { DELTA } x=H_{z}
\end{aligned}
$$

Where $H_{r}$ and $H_{z}$ are the radial and axial distances between grid points in Figure 1. A good fit of the joint dimensions is accomplished with a grid of $24 \times 100$ points. Thus $H_{r}$ and $H_{z}$, are:

$$
\begin{aligned}
& \mathrm{H}_{\mathrm{r}}=.106 \text { inches } \\
& \mathrm{H}_{\mathrm{z}}=.200 \text { inches }
\end{aligned}
$$

and the overall dimensions of the splice shown in Figure I are 2.544 " $\times 20.000 "$ " Referring to this figure at grid position $(I, J)$ and noting that the grid line $I=1$ corresponds to $r=0$ and $J=I$ corresponds to $z=0$, we have:

$$
\begin{aligned}
& r=(I-1) H_{r}=.106([-1) \\
& z=(J-1) H_{z}=.200(J-1)
\end{aligned}
$$

Thus in terms of the grid we can rewrite Equation (3) letting

$$
\begin{array}{ll}
U(r, z) & U(I, J) \\
r & (I-1) \text { DELTA } r=(I-1) H_{r} \\
z & (J-1) \text { DELTA } z=(J-1) H_{z}
\end{array}
$$

154 


$$
\begin{aligned}
U(I, J) & =\frac{U(I+I, J)\left[\frac{1}{(I-I)}+1\right]+U(I-I, J)}{\left(\frac{I}{I-I}\right)+2\left[I+\left(\frac{H_{r}}{H_{z}}\right)^{2}\right]}+ \\
& +\frac{\left(\frac{H_{r}}{H_{z}}\right)^{2}[U(I, J+I)+U(I, J-I)]}{\left(\frac{I}{I-1}\right)+2\left[1+\left(\frac{H_{r}}{H_{z}}\right)^{2}\right]}
\end{aligned}
$$

The program simply applies this equation to all the non-bound.ary points of the grid in sequence and repeats this process until the chan ge of voltage values from one complete iteration to the next becomes arbitrarily small.

The accuracy of this method is limited only by the cost of using the computer to do the repeated calculations and by the fineness of the grid relative to the idealized joint cross-section, and to the accuracy of the boundary values specified.

\section{BOUNDARY CONDITIONS ON STRESS:}

As noted above, the accuracy of the calculated voltages depends on the accuracy of the boundary values. Fortunately the voltage of the grid points corresponding to the outside of the strand shield and to the inside of the insulation shield are nearly identical to the voltages of the conductor and the shield, respectively. The voltage values - referring to Figure $I$ - at the boundary points $J=I, I=8$ to 16 and at $J=|0|, I=8$ to 24 are not exact but are taken equal to those values that we know are true for a simple coaxial geometry:

$$
U(r, z)=\frac{D E L T A V}{\ln \left(r_{0} / R\right)} \ln (r / R)
$$

where $r_{0} \quad-\quad$ is the inside radius of the coax

DELTA $V \quad$ - is the phase-to-ground voltage

or in the terms of the grid of Figure I we have:

At $\mathrm{J}=1$ 


$$
U(I, I)=\frac{D E L T A V}{\ln (6 / 16)} \ln
$$

At $J=|0|$

$$
U(I, \mid 01)=\frac{D E L T A V}{\ln (6 / 24)} \ln \cdot(I-1 / 24)
$$

\section{MULTIPLE DIELECTRIC LAYERS:}

As was stated on Page (152), Laplace's Equation applies to any uniform uncharged dielectric space. If the joint consisted of only one dielectric material, this equation would apply to the whole insulating region and the preceding boundary conditions would be sufficient for a solution. In the joint of Figure l, however, the dielectric constant of the crosslinked polyethylene cable insulation is somewhat different from that of the joint tape insulation. At this dielectric interface, Laplace's equation will not hold true because of the presence of polarization change. Instead, a grid point on the interface is related to adjacent grid points by the boundary equation:

$$
\epsilon_{1}\left[\frac{v_{0}-v_{1}}{H_{r}}\right]=\epsilon_{2} \quad\left[\frac{v_{2}-v_{0}}{H_{r}}\right]
$$

where

$$
\begin{aligned}
& v_{0} \equiv \quad \begin{array}{l}
\text { voltage of point on interface } \\
\text { voltage of adjacent point in dielectric } 1 \\
v_{1} \equiv \quad \text { voltage of adjacent point in dielectric } 2
\end{array} \\
& v_{2} \equiv \equiv
\end{aligned}
$$

This equation is rigorously true only for a pencil slope of zero. However, since normally the pencil slope is no more than 10 degrees, it is applicable to the joint shown in Figure I.

When the grid points do not fall precisely on the interface, a slightly more complex form of Equation (6) is used.

\section{STRESS PROGRAM FLOW:}

We have faced a limitation in the amount of available storage in the IBM 360-30 that has been used to date. This is a result of the relatively large number of grid values that must be stored simultaneously $(24 \times 100=2400$ words $\times 4=9600$ bytes) out of some 15,000 to 20,000 bytes for the Fortran Program, library function and any storage combined. Thus, to date, I have approached the stress program using. two simpler programs. Program B calculates voltages in a joint of constant outside 


\section{STRESS PROGRAM FLOW (Continued)}

diameter, constant dielectric interface diameter but variable conductor/strand shield diameter (Cadweld connector) with the results presented graphically (see listing of Program B attached and Figure 2). Program A calculates voltages in a joint of variable outside diameter, variable interface diameter and constant conductor/strand shield diameter (see listing of Program A attached and Figure I). The results of this calculation are simply listed at the end of the Program Listing.

Presently we are replacing the IBM 360-30 with a remote link to an IBM 370 with no such memory limitation. Thus we will combine these two programs within the next twelve months. The new longer program will be more user oriented and will provide a number of output options.

\section{TEMPERATURE DISTRIBUTION CALCULATION:}

The temperature distribution in the joint insulation follows Laplace's equation if one ignores dielectric losses. This was done in the initial program to calculate the joint temperature distribution.

previously.

The dielectric interface is handled in the same manner as outlined

One can specify the shield temperature as a single value. One can then calculate the end boundary values using Equations (5) with DELTA $V$ replaced by DELTA T (the difference between conductor temperature and shield temperature). The conductor/strand shield temperature is not so simply determined.

In considering methods of determining the temperature of the insulation/strand shield boundary consider the following:

(I) The temperature should be higher at the joint center because of the higher thermal resistance of the thick joint wall.

(2) Total current through the conductor is the same for all $z$.

(3) The heat generated in the conductor can either flow axially down the phase conductor or radially through the joint insulation.

(4) Neglect temperature drop across ohmic heating in strand shield. In order to calculate the temperature at the inside of the insulation wall one finds the following equation by expressing (3) above mathematically: 
TEMPERATURE DISTRIBUTION CALCULATION (Cont'd.)

(7)

$$
\begin{aligned}
& \frac{\sigma_{\mathrm{IT}}}{\sigma_{\mathrm{ECT}} \mathrm{R}_{0}} \cdot\left[\left.\frac{\partial \mathrm{T}}{\partial \mathrm{r}}\right|_{R_{0, z}}+\left.\frac{\partial T}{\partial r}\right|_{R_{0, z}+\operatorname{DELTA} z}\right]+ \\
& +\left[\frac{\frac{\partial T}{\partial z} \mid R_{0, z+D E L T A} z-\frac{\partial T}{\partial z} R_{0, z}}{\Delta z}\right]+I_{0} 2 / A^{2} \sigma_{E C C} \sigma_{E C T}=0
\end{aligned}
$$

where:

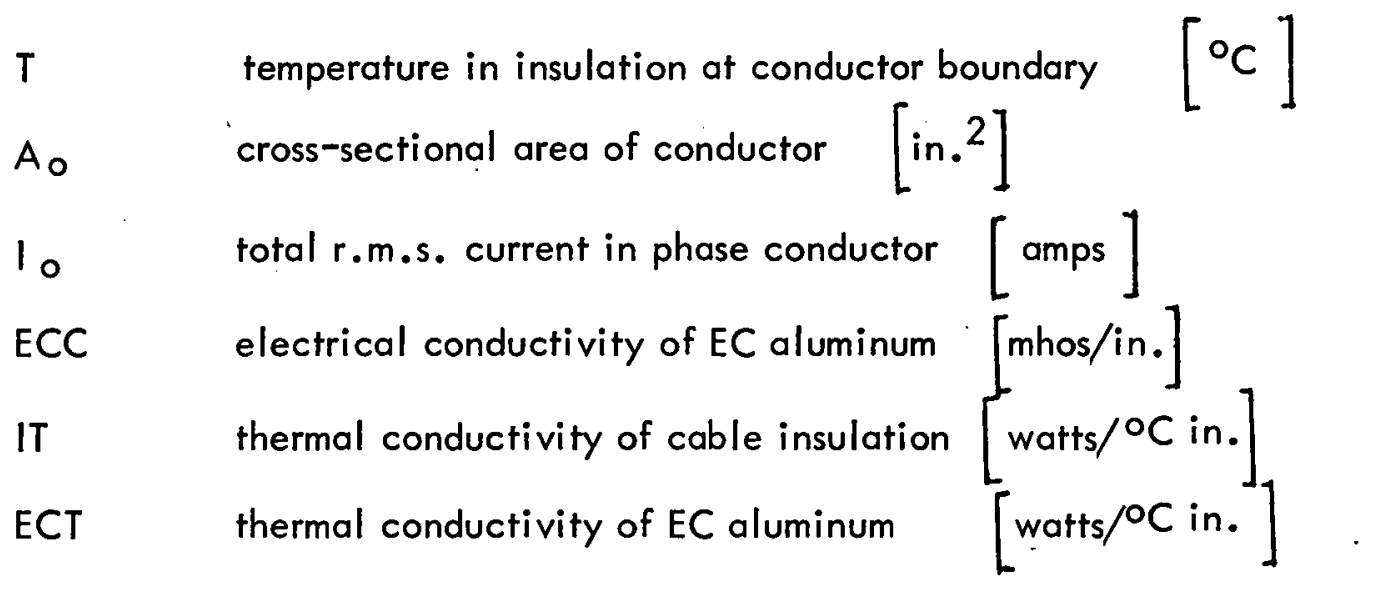

As with Equation (I) this is converted to a form suitable for compotation in Equation (8).

$$
\begin{aligned}
& \text { (8) } U(I I, J)=\left[\frac{1}{\frac{\sigma \Pi}{\sigma_{E C T}(I I I)}+2\left(\frac{H_{r}}{H_{z}}\right)^{2}}\right] \\
& \cdot\left\{H_{r}{ }^{2} I_{0}^{2} / \sigma_{E C C} \sigma_{E C T} A^{2}+\left(\frac{H_{r}}{H_{z}}\right)^{2} \cdot[U(I I I, J+I)+U(I I, J-I)]\right. \\
& \left.+\left(\frac{\sigma_{I T}}{\sigma_{E C T}(I I I-I)}\right) \cdot[U(I I I+I, J)+U(I I I+I, J+I)-U(I I I, J+I)]\right\}
\end{aligned}
$$

where $\quad U(I I I, J)$ is the temperature at the inside boundary of the insulation.

158 
The temperature calculation process begins with an initial assumed set of array values including boundary values. By use of Equation (4) and these boundary values a new set of array values is calculated. Then a new set of $U(I I I, J)$ values are calculated by Equation (8). Using these new boundary values in combination with the constant boundary values for sheath temperature and end values calculated by Equations (5), the array values are recalculated using Equation (4) again.

\section{JOINT DESIGN PROGRAM:}

This program will eventually incorporate the preceding two programs and will present the joint designer with the capability of quickly coming up with approximate joint dimensions given performance requirements and material limitations. This is still in the discussion and flow chart state.

In addition to providing approximate joint dimensions, the program should be able to rapidly review various material refinements, indicating the most profitable areas of study (i.e., thermal conductivity of tape, shape of connector, etc.). 


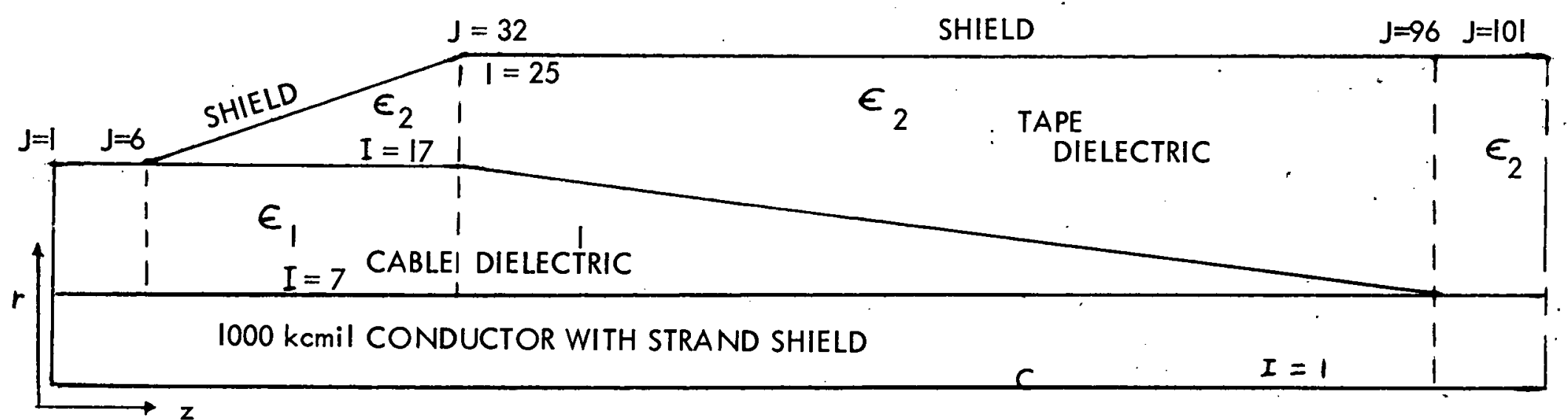

FIGURE I AXIAL SECTION OF HALF OF IDEALIZED, 230kV JOINT WITH MIGWELD CONNECTOR AND $1000 \mathrm{kcmil}$ CONDUCTOR 


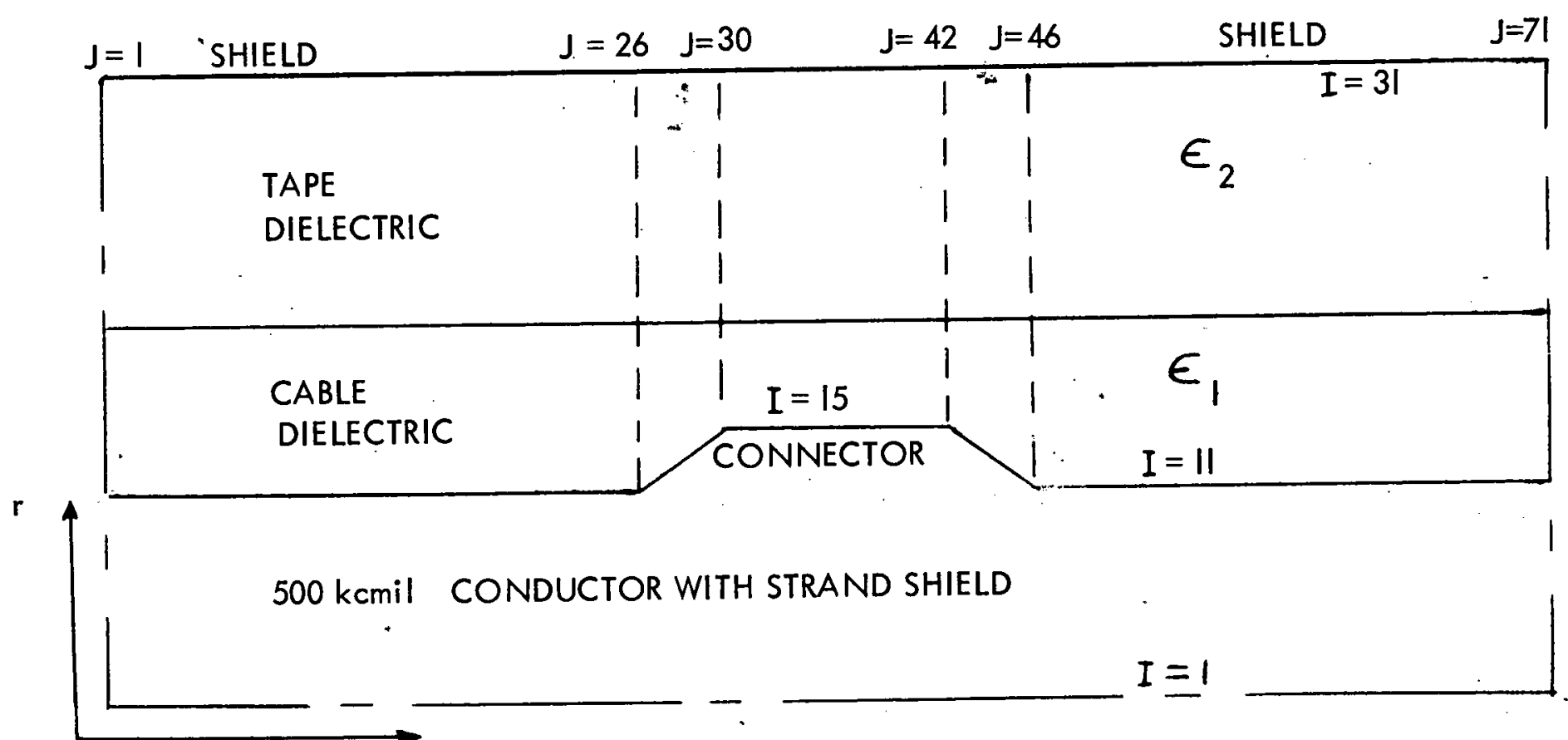

FIGURE 2

AXIAL SECTION OF I38kV JOINT WITH CADWELD CONNECTOR ON $500 \mathrm{kcmil}$ ALUMINUM CONDUCTOR, CONSTANT O.D. AND ZERO PENCIL SLOPE 
IO PPQ50 $230 K V$ SPLICE POTENTIAL PLOT

EXECTORRAN

\& SECONO PROJECT SOLUTION OF LAPLACE'S EOUATION TO FIND POTENTIAL IN

REQL Y (3) 71 ) I INE (I 18$), \mathrm{H}(5)$

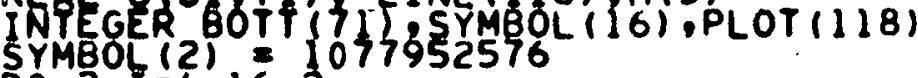

2 DYM

2 SYMBOL (I) $=5 Y$ SYBOL $(1-2)$

1 SYMPOL (J = SYMBOL (I-2) + 16777216

$H(2)=0.6$

$H(3)=0.2$

$H(4)=0.8$

$H(5)=0.4$

3 REAO (1, 4; VIN,MAXIT, EPS, OMEGA, I I I, I 22, I33, I44, J1 I, J22, J33, J44, J55

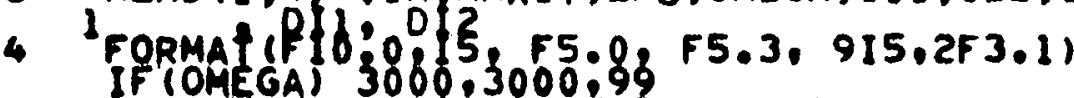

C LOCA FE BOUNDARY OF CONDUCCOOR RADIUS. SUBSCRIPTS STORED IDENTIFY

C INTERIOR PTS. NOT GOUNOARY PTS. ALL DEFINED PTS LIE IN THE INSULATION

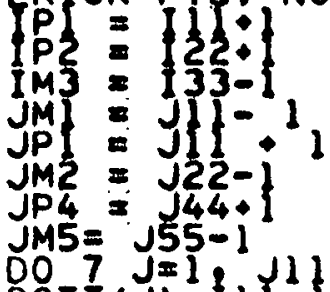

7 BOTT(J)=11!!

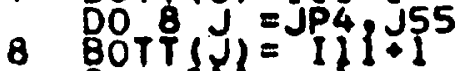

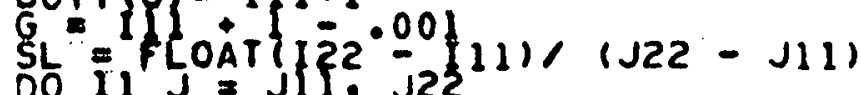

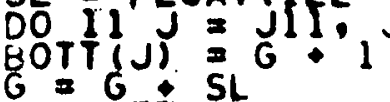

11.

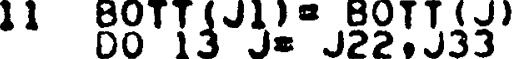

13 Botf(J) $=123+1$

98 FORMAT (IH' ' BOITOROINATES OF CONOUCTOR BOUNOARYI/20I5/

C ICLEAR ARRAY' TO APPROX.LOGARTHMIC DEPENOENCE LO BOTI

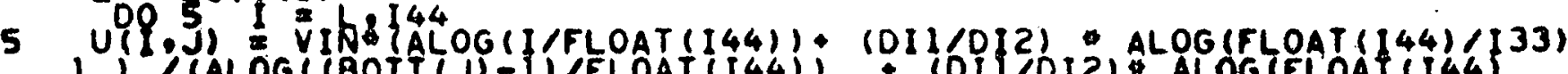
11 /(ALOG (BOTT(J)-I)/FLOAT (I44)) * (OII/OI2)\&ALOG(FLOAT(I44) $1 / 1331$

51 UPI:J) $=$ VIN: $\{33$ II/OI2) ALOG (FLOAT(I)/I33)) 
\& (ALOG (BOTT(J)-1)/FLOAT(I44)) * (DII/DI2)*ALOG (FLOAT(I44) $10(133) 1$ $006 \mathrm{~J}=1.055$

Do 6 g

6 U(I:Ji= $V I N$

00 14 J JP J.JMZ

$I=$ BotT(J) -1

$x=$ FLOATII

G $=G+S L$

U(I.J) YIN (ALOG $(x / I 33) / A L O G(G / 133))$

14. UIIDI) $=$ U (I.U)

C IEY THE ITERATION COUNTER TO 1

C PUT FITEKES ON COLUMNS

91 FORMAI (IHO!) NO. V(12.46) V(16.51) V(21.56) V(26.61) V(16.65)

C SET SUMSYF RESIOUES TO ZERO

C THELEFT

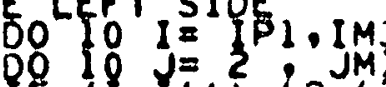

If $\left\{0, I=\left\{\begin{array}{l}\text { If } \\ \text { If }\end{array}\right.\right.$

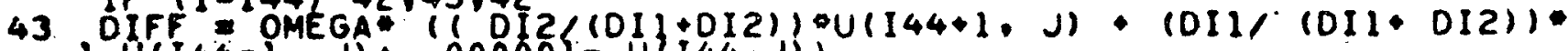
$1 U(I 44-1, J)+.000001-U\{144 . J)$

42 OIFFEOMEGA $(1(1+1, / I) \cup U(I+1, J)+U(I-1 \cdot J) \cdot U(I, J+1) \cdot U(I, J-1)) /(4$.

$44 \quad U(I: J)=U(I, J)+D(F F)$ Ji $=355+1-j$ $U(I . J I)=U(I, J)$

C ${ }^{10}$ THE CENTTER SE CYISON AROUNO CONNECTOR

$L=$ BOTT(J)

DO 12 I $1: 1 M 3$

46 DIFF = OMEGA $(1,052 /(0 I 1+0 I 2)) U(I 44+1, J)+(0 I 1 /(D I I+0 I 2)) *$ $1 U(144-1, J)+.000001-U([44, J))$

45 GIFFEOMEGA $((1)+1 \cdot /[) \cup U(I+1 \cdot J)+U(I-1 \cdot J)+U(1 \cdot J+1)+U(1 \cdot J-1)) /(4$.

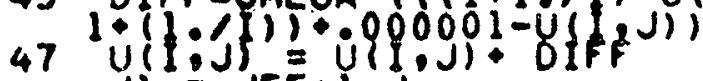

Ji $=155+1-j$

$U(I \cdot J I)=U(I, J)$

c THE RUM ETT SUME ABS (DIFF)

DO $40 I=I P I, I M 3$

DO $40 \mathrm{~J}=\mathrm{JP} 4 \mathrm{JM}$

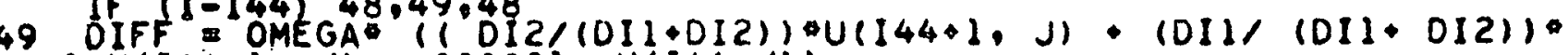
1 U(I44-1. J). $.000001-U(144 . J))$

48 DIFFIIMEGA $(1(1+1 . / I) * U(I+1, J)+U(I-1, J)+U(I, J+1)+U(I, J-1)) /(4$. 


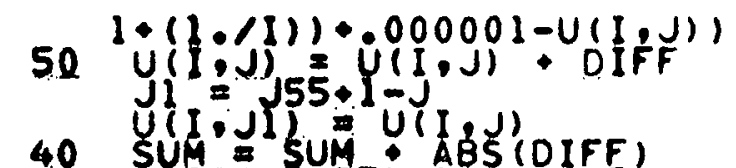

40 SUMITE(3.95) ITN.U\{I2, 46).U(16.51),U(21.56).U(26.61).

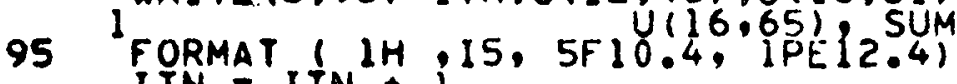

C CHECK FOR FAILURE TO CONVERGE IN MAXIT ITERATIONS

IT 21 i ITNMAXIT

C CHECK FOR CONVERGENCE

C NOT CONVERGEO YET--GO BACK FOR ANOTHER ITERATION

C EITHER THE PROCESS HAS CONYERGED OR MAXIT HAS BEEN EXCEEDED WANT TO

C PLOT RESUTTS EITHER WAY IF THERE IS ANY DOUBT ABOUT WHICH OCCURRED, A

C CQUNT OF NO.OF RESIDUES PRINTER OUT WILK TELSTE IN INSULATION

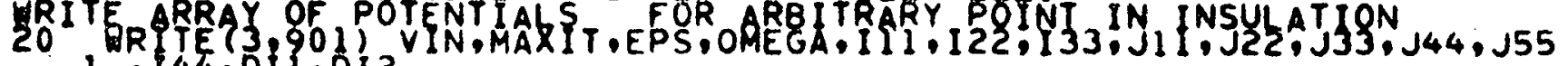

1.844 .011 .012

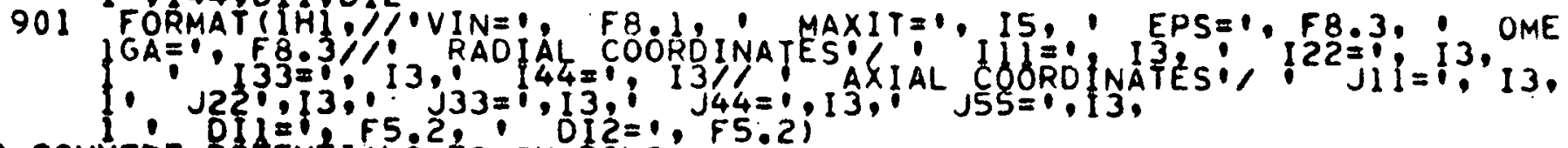

C CONVERT POSENTIALS TO SYMBOLS

to $=10$. OFLOAT $(355)) / 6$

o $37, K=1: L 1,133$

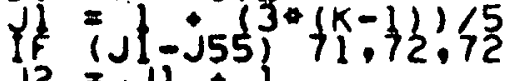

71 J2 $=. J 1$

73 GQ TO 73

$73 \quad \mathrm{~J}^{2}=J i \mathrm{I}$ MOD $(K-1,5)$

LINE(K) $=U(I, J\{\} \bullet H(M) *(U(I, J 2) \cdot .0001-U(I, J I))$

Kl = BOTT(J)

36 PLof(KK) $=-415219648$

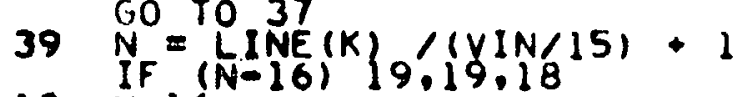

18 N $=16$ (K) $9 Y M B O L(N)$

37 CONIINUE

9011 WRI EE 3.9014$)$ PLOT

9014 FORMAT (1H.15) 18AI)

9015 FQREAT (IHI)

3000 STOP 9999

$\%$ EXEC LNKEDT 
PANSOPHIC SYSTEMS, INCORPORATED TRIAL INSTALLATION BR.TEST.PANLIB

¿ WRITE PRJNTEES951 EP95I

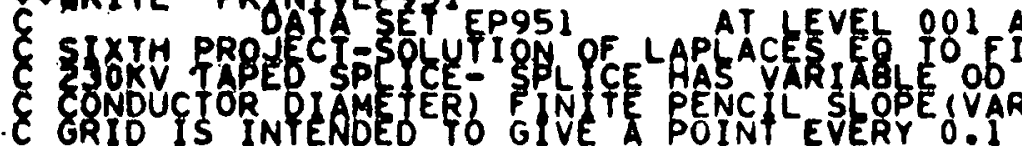

C ORIP. IS INTENDER TO GIVE A POIN

REAT U(255,260) LINE $(1000), H(4)$

INTE GER BOTT 260 ) FOPP (260), DINT (260), SYMBOL (20) , PLOT (118)

SYMBOL (2) 1077952576

2 SYMBOLII $\$$ SYMBOL $(I-2)$

SYMBOL (I) $=-1052753856$

$001=3,17.2$

1 SYMB $(16)=$ SYMBOL $(1-2)+16777216$

SYMB

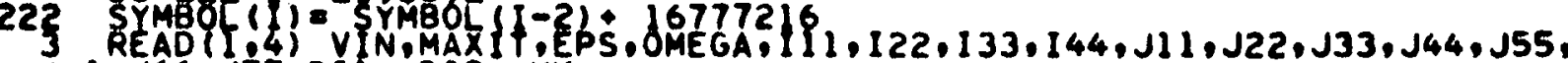

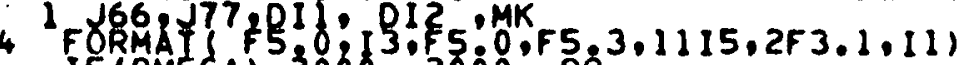

99

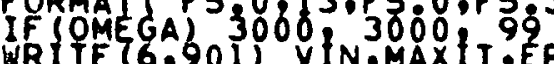

WR I TE\{6,9011 VIN,MAX T , EPS, OMEGA, $111,122,133,144, \mathrm{~J} 11, \mathrm{~J} 22, \mathrm{J33}, \mathrm{J44}, \mathrm{O}$

$1,55, J 66.577$, DII, OI2, MK
HR $=8: 90$
If\{pi $=\left\{\frac{1}{2} 2+1\right.$
$\left\{\begin{array}{l}33 M \\ 4\end{array}=133-1\right.$
$144 M=144-$

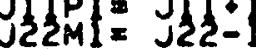
Jट्रिए।
J3
$J 44 M I=J 44-$
$J 44 P 1=J 44+1$
$J 55 M=J 55-$
$J 66 \mathrm{MI}=\mathrm{J66-1}$
$J 66 P=166+$

C LOCATE BOUNDARY PIS OF NON-HORIZONTAL BOUNDARIES.ALL OEFINEO POINTS

C. ARE IN THE INSULATION NOT ON SHIELO OR PHASE CONOUCTOR.

-C REGION

DINT $J=1=0.13 \frac{1}{3}$

5 GOTT

SLS : FLOAT $(144-133) /(J 22-J 11)$

GS $=133+00000$

$006 J=J 11,222$

BОTI (J) = $\{1\}+1$

DINT $(J)=133$

$C^{6}$ REG GS: 3

TOPP (J) = GS- 1

GS = GS + SLS

$\left.S L F={ }^{3} F L O T A T(1) 11-133\right) /(J 44-J 22)$

$007 \mathrm{JF} J \mathrm{~J}_{2} \mathrm{J33}$

BOTT $(J)=111+1$

DINT $(J)=G P+0.500001$

TOPP $(J)=G S-1$

C REGION 4 GP. SLP

DO \& J=J33,J44

ROTI (J)=Iff:1

TOPP $(J)=144-1$

C REGION 5

- SLP

$009^{5} \mathrm{~J}=\mathrm{J44}, J 55$

BOt' $(J)=1\}$ i.

$9 \operatorname{TOPP}(J)=144-1$

80036

80037

00039

80040

08041

80042

80043

80044

00045

00046

00047

88048

80049

00051

80052

80053

00055

88055

80058

80059

80060

88861

08062

80063

88064

80065

00067

08068

00069

00070

88071

80073

80074 
BANSOPHIC SYSTEMS. INCORPORATEO TRIAL INSTALLATION

C REG $Q Q^{N}={ }^{6} I 1$

$S L C=F L O A I(122-111) /(J 66-J 55)$

0. 10 ja $\mathrm{J} 55 . \mathrm{j} 66$

$\operatorname{TOPP}(J)=I 44-1$

C REG

BOTT (4) $=\mathrm{g} C+1$

OINT $(J)=$ BOTT(J)

ION 3

OOJ J $=560,177$

DINT(J)= BOfT(J)

c INITIAPIZE A ARRAY IN SPLICE INSULATION

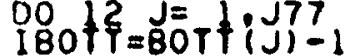

IDINT =DINT (J)

¿OOPPEIOPP (

R3 =

BENPM I I ALOGIROIRI) $(D 11 / 012) * A L O G(R I / R 2)$

$13 U(I, J)=(V I N / D E N O M) *(A L O G(1 I-1) / R I)+(D I 1 / O I 2) * A L O G(R I / R 2))$

P9I IS I $=$ IDINIJENOM) * (IDII/DIZ)*ALOG $(1-1) / R 2)$ )

C SET SONH OF RESIDUES TO ZERO ANO BEGIN ITERATION

C ITERATION-REGION,

Oo 16 J J J

TOPP = TOPP J)

80 LF

1If+U(I.J-I)

U(I.J) SU UII.J):

C ITERATION- REGION $2,3 \div 4$

DO IT J J JIPI. J44

BBOT = BOIJ (J)

TTPP = Tope (J)

ODINI = DINTIS

Q 17 IBOTT 1 TOPP

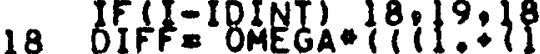

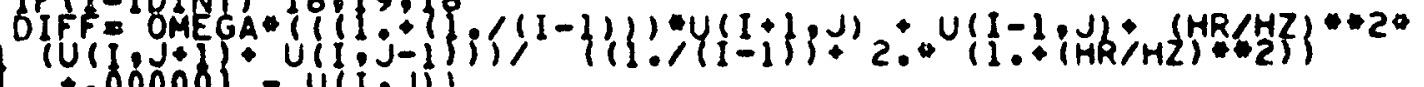

$\because 000001-U(1, j)$

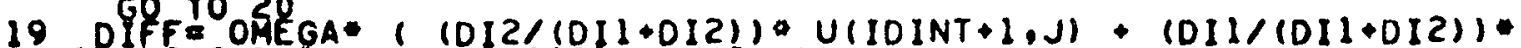

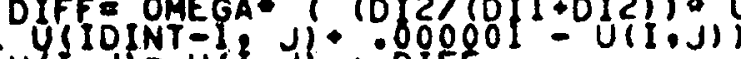

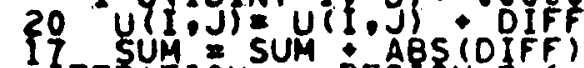

C ITERATION - REGION 5,6 AND 7

OO

Trope a tope

6O? 1 I

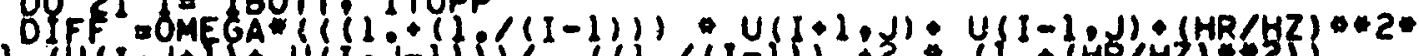

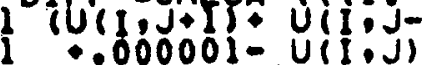

21 SUM SUM:ABSIDIFF)

$U(I ; j)=U(I, j) T^{\circ}+D I F F$

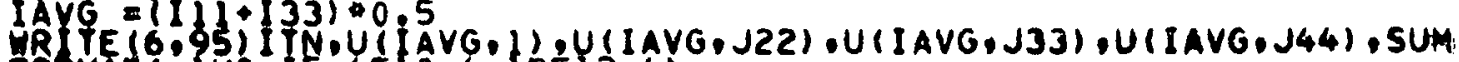

95 FORMAT IHO: 5.4F (0.4, P PEI2.4)

C CHECK POR CONVERENCE OF ITERATION

IT $=1$ IIN, MAXIT

C NOT CONVERGED TOREI IERATE

C ITHER thE PROCESS HAS CONVERGED OR MAXIT HAS BEEN EXCEEDED. WANT TO

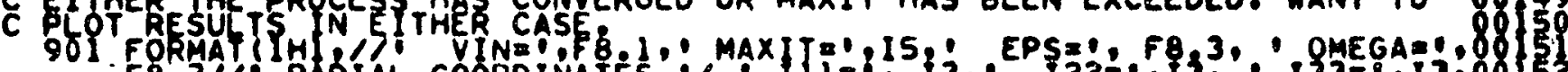

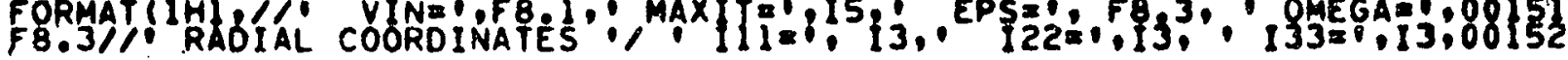


PANSOPHY SYSTEMS, INCORPORATED TRIAL INSTALLATION

YER. 89.

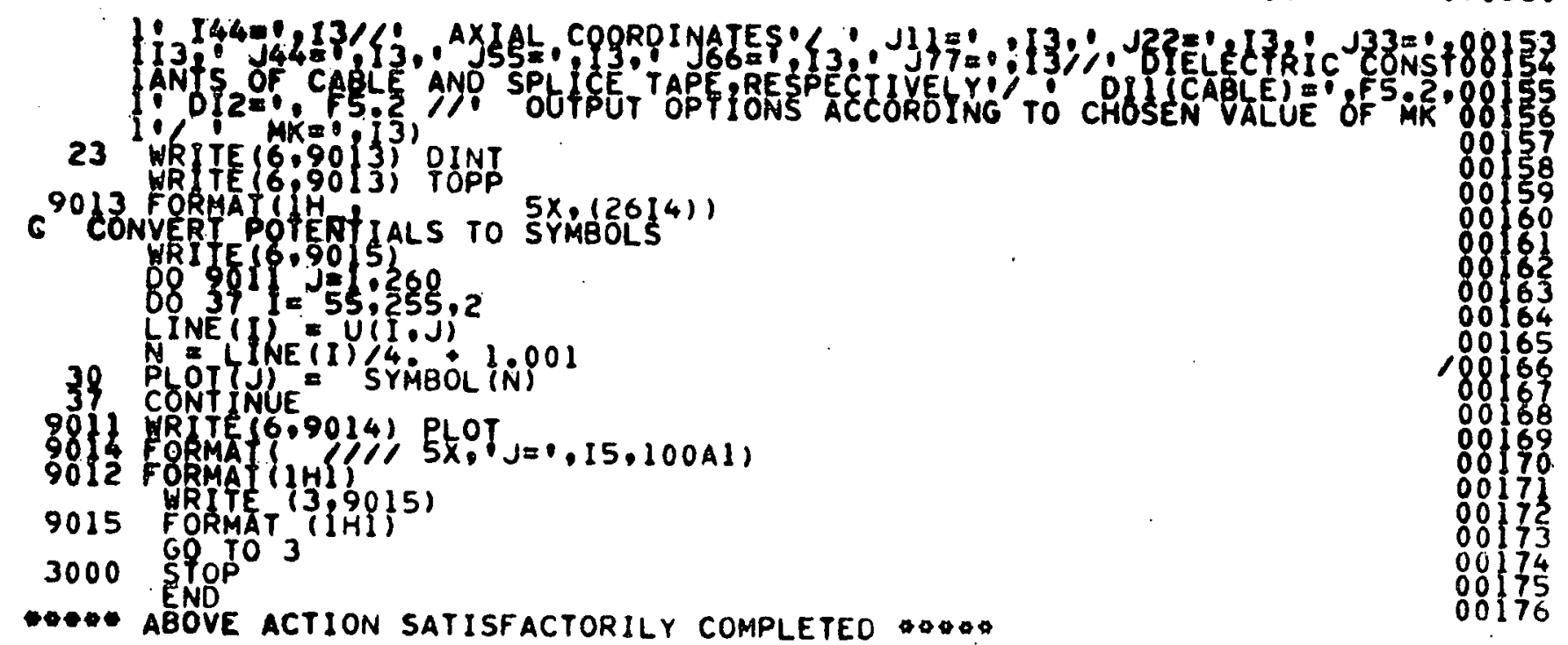

167 


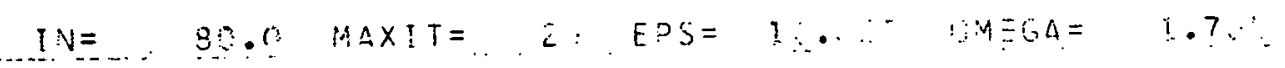

RADIAL COCRDINATES

$111=11 \quad 122=i 4.132=31.144=20$

AXIAL COORUINATEZ

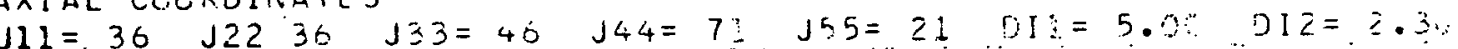

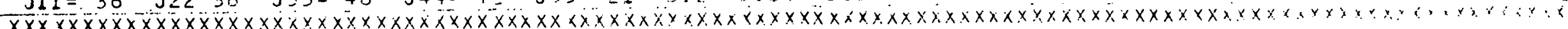

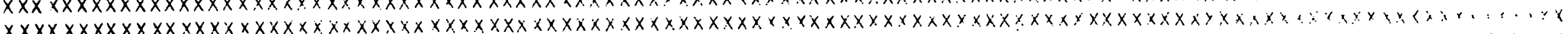

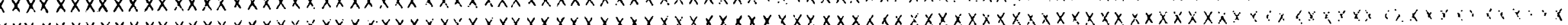

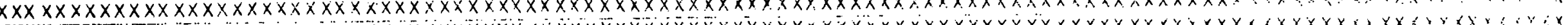

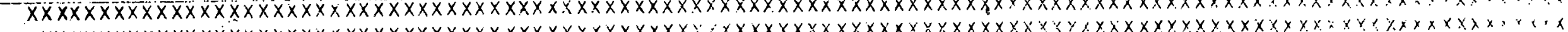

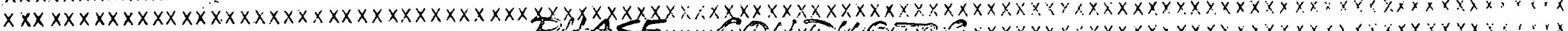

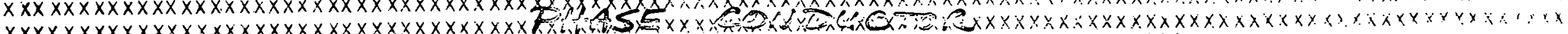

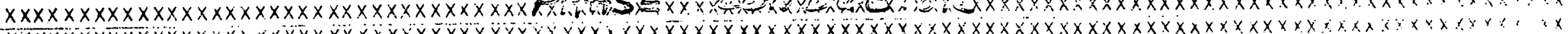

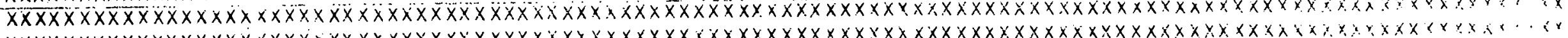

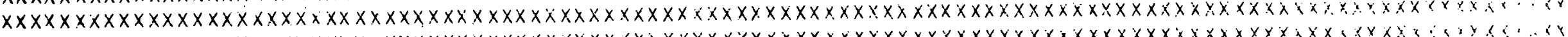

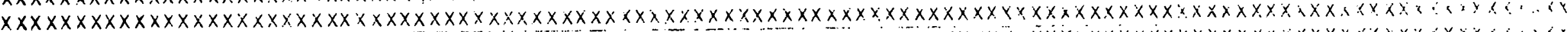

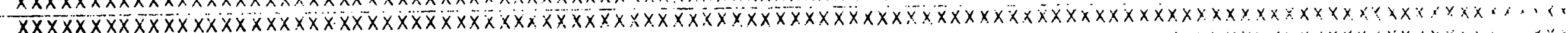

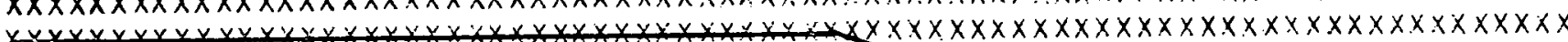

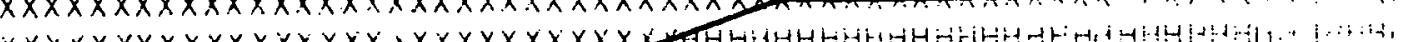
व $\mathrm{HHHHHHHHHHHHHHHHHHIHHHIHHHHHHHHHHHHHHHHHHH}$ GGGGGGGGGGGGGGGGGGSGGGGGGGGGGGGG6GGOGGGGGG:3G

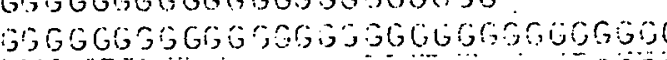

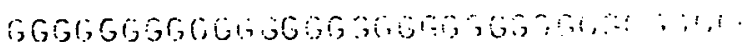

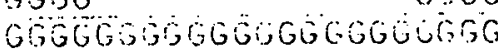

FFFFFFFFFFFFFFFFFFFFFF

FFFFFFFFFFFFFFFFFFFFFFFFFFFFFFFFFFFFFFF FFFFFFFFF FFH

FFF EEEEEEEEEEEEEEFEFEEEEEEEEEEFEEEET:ZE:

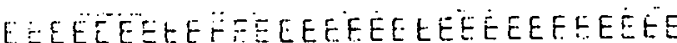

L r

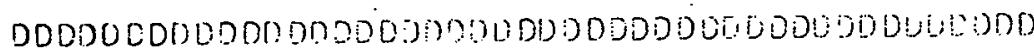

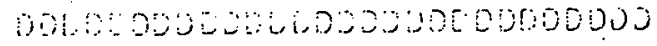

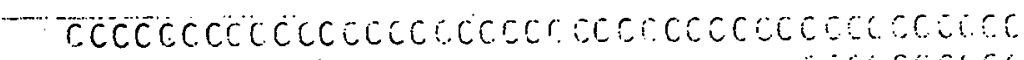

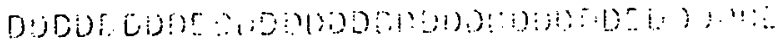

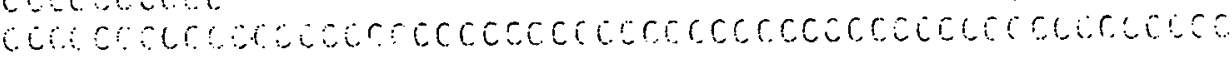

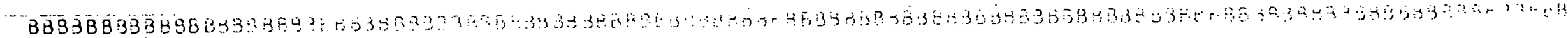

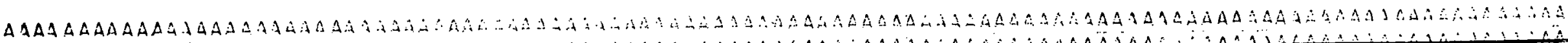
SHIELD 
PRINTEEPY5O

AT LEYEL 001 AS OF $02 / 15 / 77$

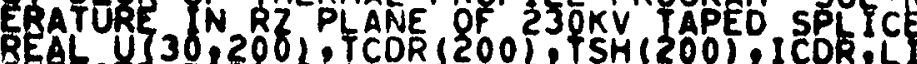

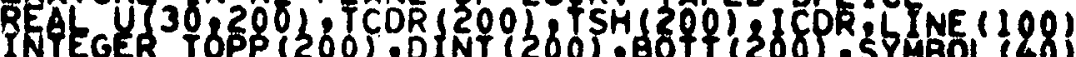

A

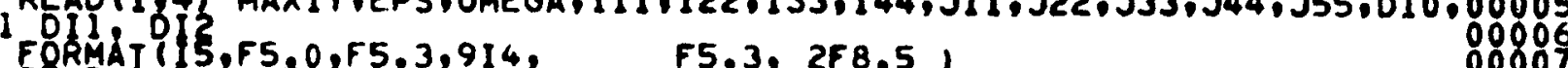

IGAC

104 FORMAI (2F $1085, F 1003,510.1,3 F 5.3$,F5.3.15,F5.31

FORMA IIHI 2

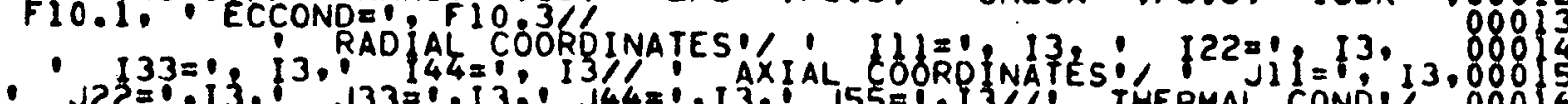

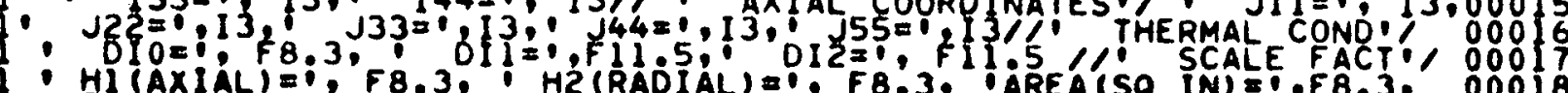

I: EPSCDRE OF8:3: MAXITC=O I57\% INITIAL TEMPERATURES:

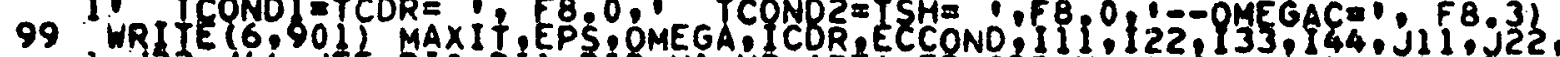

I $33, J 44, J 55,0 I 0,0 I I, D I 2, H I, H 2$, AREA,ESSCDR,MAXITC, TCONDI, TCONDZ

88818

00020

C SET UP SYMBOLS FQR ARRAY PLOT

2

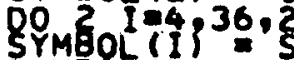

SYMEOL (I) $=$ SYMBQL 1 (1-2)

DO $Y=3,17,2$

1 SYMEOL $(f)=$ SYMBOL $(1-2)+16777216$

00232 I 21.35 .2

222 SYMB́LL ( ) = SYMBOL $(I-2) \cdot 16777216$

C LOCAIE BOUNOARY OF CABLE INSYL AND TAPE DIELECTRICS ALL

C OINT JI LIE IN CABLE OR TAPE INSULATION OR ON BOUNDARY ALWAYS GIRO SOROZU

8 IN

C INITIALIZE COR TEMP ARRAY ION NOT ON SHIELO BOUNDARY.

DO $5 \mathrm{~K}=1$. $\mathrm{J} 4 \mathrm{4}$

$K I=j 55-K$

TCDR $(K)=$ TCONOI

TSH(K) $=$ TCONDZ

5

TCOR $(K)=$ TCDR $(K)$

TSH (KI) = TSH $(K)$

J2ZM $=$ J2Z

J33M3 $=$ J33-3

$|1| P|=| 11+1$

I22H = $223-1$

$133 M=\{330$

J22P $=J 22+1$

C SET PHASE COR ARRAY PTS TO TCOR - REGION (O)

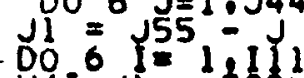

U(I.J) =

C FENCIL RËLION(3)-CALCULATE DINT(J) ANO TOPP(J)

$G=I 22$

SL $=$ FLOAT $(111-122) /(J 33-J 22)$

00

IOPP (J) = 133-

DINT (J) $=$ G $: 5001$

TOPP (JI) =TOPP (J)

DINT $=G, \operatorname{DINT}(J)$

00036

00038

00039

00040

00041

00042

00043

00044

00045

00046

00047

00048

00049

00050

89051

00053

00054

08055

00056

00058

80059

00060

00061

80062

00063

80065

00066

80067

00068

00069 
BRASPPYI SARYSIEMS, INCORPORATED TRIAL INSTALLATION

YER

89.22:!

U $\{2: j\}=$ ELOAT $(K)$

$U(3, j)=133$

$U(1, j)=4(1 . J)$

$U(2, J)=U(2, J)$

$U(3, J i)=U(3, J)$

c SET SHOULOER KEGION (5) ARRAY OUTSIDE INSUL TO SHEATH TEMP OO $14 \mathrm{~J}=1 . \mathrm{J} 22$ $J I=\sqrt{5} 5-\mathrm{J}$

0014 I $=122,133$

$14 \quad U(I ; J)=T S H(J)$

C INITYAIIZE UU(I jJ) ARRAY IN REGION (1)

$X I \Sigma$ a FLOAT (I $22-1)$

D $101, J=1$ J

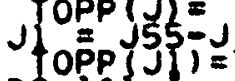

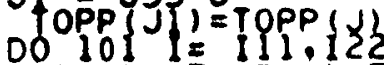

$U(I, J)=(T C D R(j)-T S H(J)) * A L O G((I-1) / X I 2) / A L O G((111-1) / X I 2)+T S H(J)$

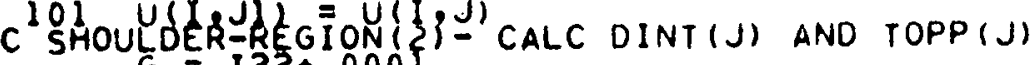

$G=I 22^{+}+000$

SL

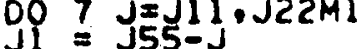

DINT $(J)=122$

DINT(J) $=D I N T(J)$

$X I Z=F L O A T(D I N T(J)-1)$

TOPP $(J)=G-1$

TOPP $(J)=T O P P(J)$

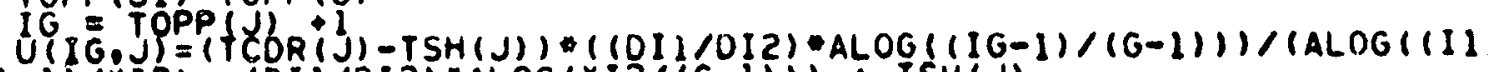

$1-1(1 \times I 2)+(011 / 012) \cdot A L O G(X I 2 /(G-1)))+T S H(J)$

$u(\{: j)=1,00$

U $\{3 . J\}=G$

$U(I G, J)=U(I G, J)$

U (1):Ji) = U

$U(3 ; j)=U(3 ; 0)$

C REGION $\{4)-$ INT IIALIZE U $(1, J)$ ARRAY

$X I 3=$ FLOAT $(133-1)$

OO $102 j=J 33 M 1 . J 44$

POPP (J)= $133-1$

TOPP J J

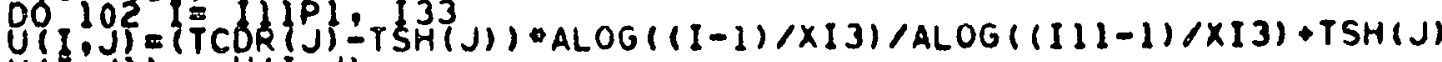
$102 U(I, J])=U(I, J)$

C INITIALIZE U(I j) ARRAY IN REGIONS (2) AND. (3)

J1 $=155-j$

If $=$ YOPP ( $) \cdot 1$

209 U (IT:J) = TSH(J)

DO $5 \mathrm{I} J=\mathrm{Jl}$. J33M3

$J 1=J 55-J$

$X M=F L O A T(T O P P(J) \cdot 1)-1$.

$M 1=$ TOPP (र)

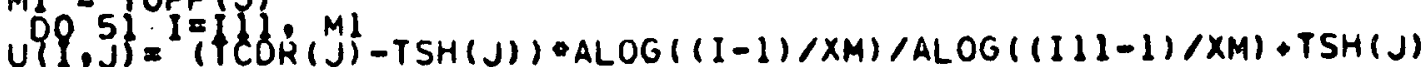

Yर(I) $=U(I, J)$

C 51 SEQT PHE ITERATION COUNTER TO 1

C SEF SUM OF RESIDUES TO ZERO

C REG SOM İ

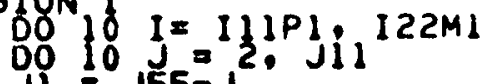

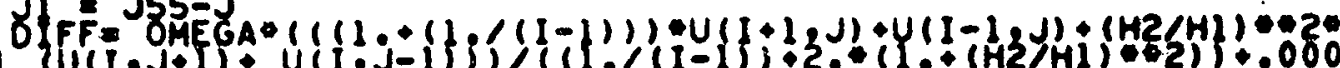

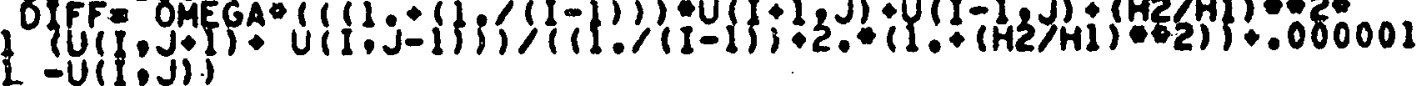

8889

80094

00095

00097

00099

00100 
BANSQPHIS SYSIEMS, INCORPORATED TRIAL INSTALLATION

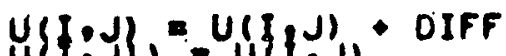

IgEG SUA SUM * AÉS(OIFF)

${ }_{00} \mathrm{O}_{3} \quad I=111 \mathrm{PI}, 133 \mathrm{MI}$

$00103, j=333,344$

J1 $3255=5$

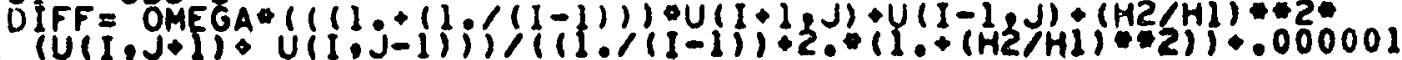

(U)

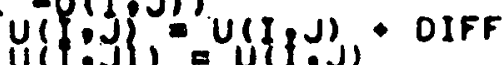

$U(1 . J)=U(1, J)$

$C$ REGIONS 2 AND 3 A

DON $12^{2}$ AND JIPI. J33MI

$J 1=5 s^{2}-3$

$\frac{1}{M}=$ TOPPT (J)

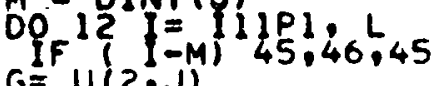

46

$G=U(2 ; j)$

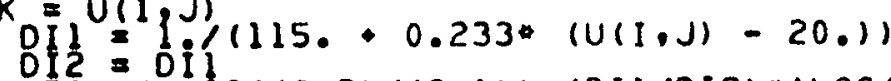

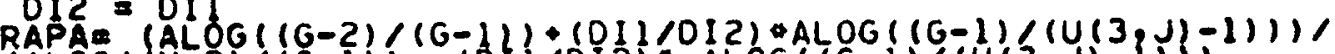

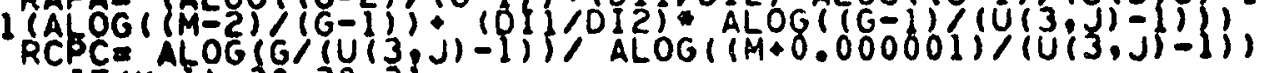

RCPCE ALOG $\{0,30,31$

30 RBPB=ALOG( $(G-1) /(U(3, J)-1)) / A L O G((M-1) /(U(3, J)-1))$

$G 0$ TO 39

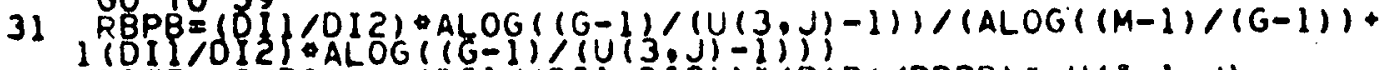

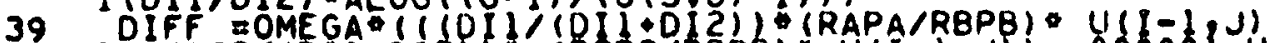

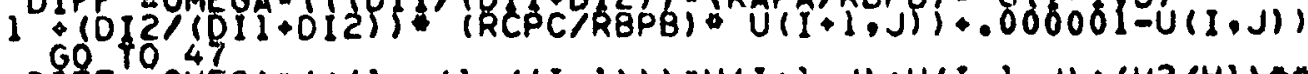

45

DIFF OMEGAQ $((1,+(1, /(I-1))) \cdot U(I+1, J)+U(I-1, J)+(H 2 / H I) * 2 *$

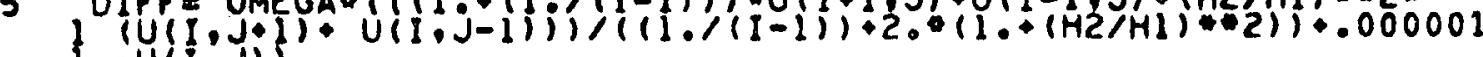

I

$47 U(I, J)=U(I, J) \cdot D I F F$

12 SUM SUM ÁS (DIFF)

WRITE (6.95) ITN.U 10,2$), U(10,20), U(10,51), U(10,81), U(20,51)$, SUM,

1 D I ECCOND

95 FOKMAT (1H, $15,5 F 10.4,1 P E 12.4, F 10.6, F 10.11$

C CHECK YOR FAILURE TO CONVERGE IN MAXIT ITERATIONS

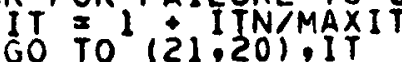

C ÇECK FOR CONVERGENCE

C NOT CONVERGED YET--GO BACK FOR ANOTHER ITERATION

C AFTER RECALCULATING THE CONDUCTOR TEMP ARRAY, TCDR (J)

22 DO $88 \quad K M=1$, MAXITC

SUMCDR $=0.0$

ECCONO $=2: J 44.113 E-6 *(1 .+4.03 E-3 *(U(1) 1+1 . J)-20.1) 1)$

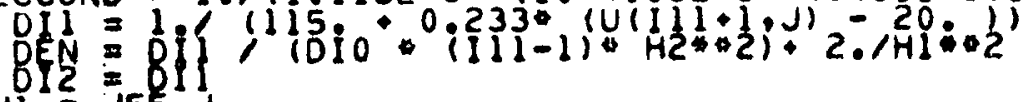

Ji $=355-j$

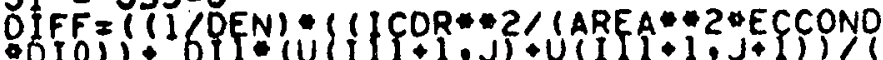

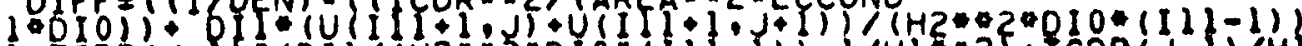

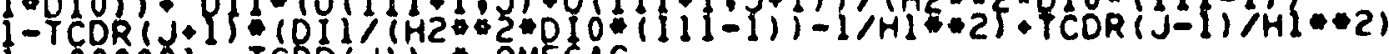

I+.000001- ICDR(J)) " OMEGAC

ICPR (J)= TCDR (J) + OIFF

TEDR (JI) = FCDR (J)

SUMCOR = SUMCOR $\triangle A B S$ (DIFF)

$U(I J) J)=T C D R(J)$

49

CONT NUE

IF (EPSCDR- SUMCDR) $88,90,90$

88 CONTINUE

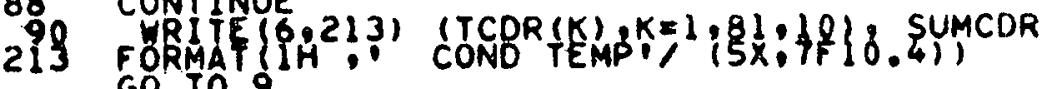

GO IO 9 PROCESS HAS CONVERGED OR MAXIT HAS BEEN EXCEEDED WANT TO

¿ EITHER THE PROCESS HAS CONVERGED OR MAXIT HAS BEEN EXCEEDED WANT TO 


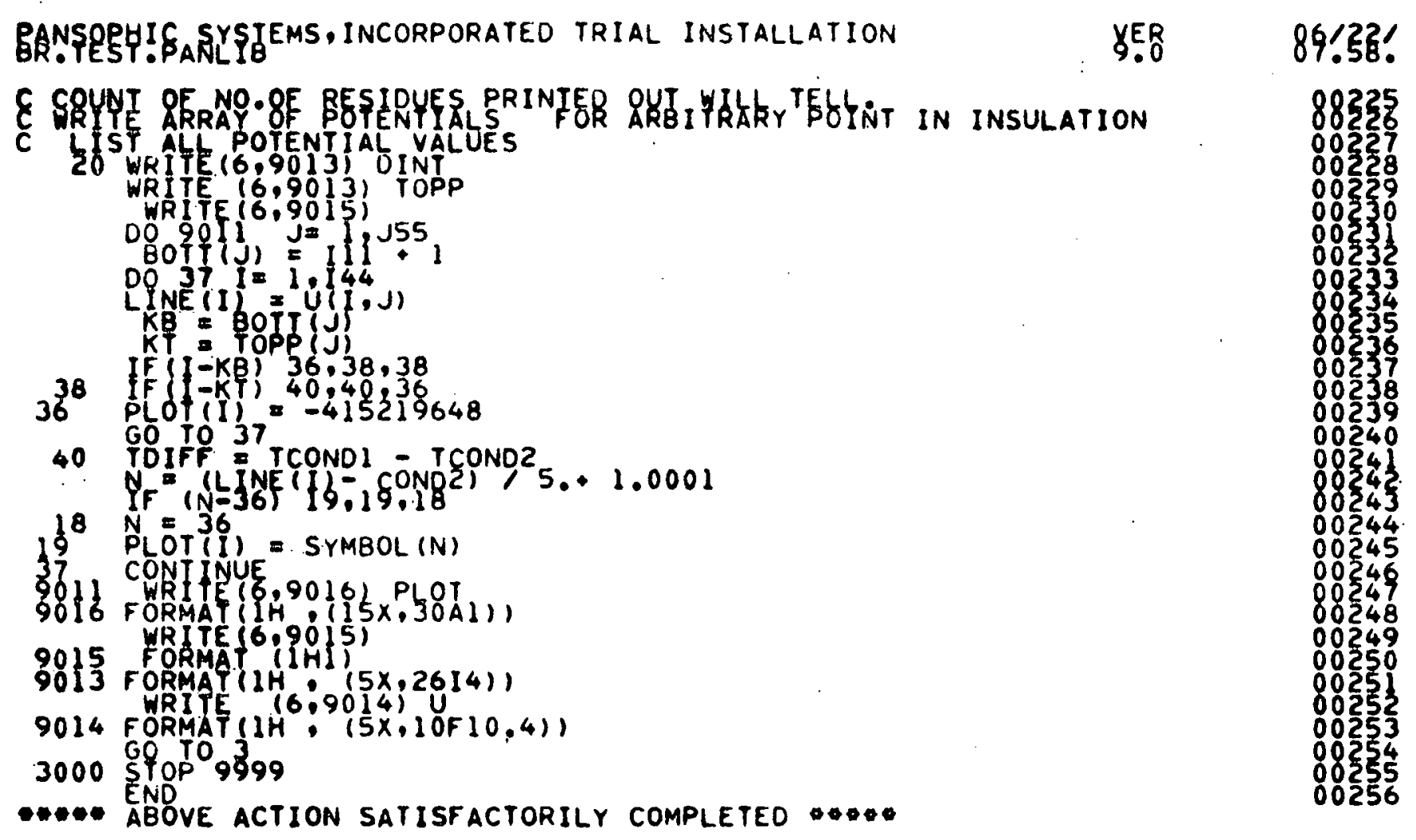

172 
FOR

\section{UNDERGROUND TRANSMISSION AND DISTRIBUTION}

CONNECTORS FOR ALUMINUM CONDUCTORS

1. SCOPE

These standards identify devices used for making electrical connections between like-sized aluminum conductors and specify their performance in meeting electrical and mechanical requirements.

II. GENERAL

These standards are intended to give reasonable assurance to the user that the connectors deemed acceptable under these requirements will perform in a satisfactory manner, provided that they are installed correctly and properly used.

III. TEST CONDITIONS - GENERAL

A. Test Connectors

I. Description: A complete description of each connector for proper identification must be included in the test results

2. Number of Sizes: If a line of connectors of different sizes are to be qualified, a representative selection of sizes, including the largest and smallest, must be acceptable.

3. Multirange: If a multirange connector is to be qualified, a representative selection of conductor sizes, including the largest and the smallest, must be acceptable.

B. Test Conductors: All test conductors used in connector evaluation shall be new bare conductor conforming to the applicable ASTM standards.

C. Test Assembly Methods: All details of the installation not covered in this section must be included in detail in the test results. 
I. Connector Preparation: All connectors shall be installed in the original condition from the manufacturer without additional preparation of their contact surfaces.

2. Conductor Preparation: The contact area of the Aluminum Conductor shall be mechanically cleaned with a clean steel wire brush until the entire contact area is completely scoured.

3. Installation Method: Connectors shall be installed by the method and tooling recommended by the manufacturer.

\section{HEAT CYCLE TESTS}

Heat Cycle Tests shall be carried out in accordance with Section III and the following sub-sections:

\section{A. Test Connectors:}

1. Connector Combinations: All connectors shall be installed in series in a heat cycle loop.

2. Number of Samples: In each of the tests, a minimum of five connectors of each size and type are required for test.

B. Equalizers: In order to provide equipotential planes for resistance measurements compression equalizers shall be installed on each side of each connector in the stranded conductor. One sheet metal screw shall be imbedded into each equálizer to provide taps for resistance leads.

C. Conductor Length: . The exposed length of conductor between connector and equalizer shall be one inch. The exposed length of conductor between equalizers shall be four feet. These lengths do not include the amount within the connector or equalizer. The loop shall be joined to an appropriate power source with additional lengths of conductor of not less than four feet.

D. Ambient Conditions: All heat cycle tests shall be carried out in a draft-free environment at an ambient temperature which is controlled between temperatures $20 \mathrm{C}$ to $30 \mathrm{C}$. A draft-free environment is an area where the control conductor temperature does not vary more than $5 \mathrm{C}$ at the end of each heating period during the evaluation section of the test. 
E. Control Conductor: . In order to monitor conductor temperature, a control conductor of equal type and size, shall be installed in the heat cycle loop between two equalizers. The length of this conductor shall be eight feet.

F. Test Conditions: Heat Cycle Tests shall be of the following duration:

Class G 125 Cycles @ $130^{\circ} \mathrm{C}$

Class F 250 Cycles@ $130^{\circ} \mathrm{C}$

Class E 500 Cycles@ $130^{\circ} \mathrm{C}$

Class D 500 Cycles@ $130{ }^{\circ} \mathrm{C}$

100 Cycles@160 ${ }^{\circ} \mathrm{C}$

Class C 500 Cycles@ $130^{\circ} \mathrm{C}$ 100 Cycles Each @160 ${ }^{\circ} \mathrm{C} \& 190^{\circ} \mathrm{C}$

Class B 500 Cycles@ $130^{\circ} \mathrm{C}$ 100 Cycles Each @ 160 $\mathrm{C}, 190^{\circ} \mathrm{C} \& 220^{\circ} \mathrm{C}$

Class A $\quad 500$ Cycles @ $130^{\circ} \mathrm{C}$

100 Cycles@160 ${ }^{\circ} \mathrm{C}, 190^{\circ} \mathrm{C}, 220^{\circ} \mathrm{C} \& 250^{\circ} \mathrm{C}$

Each user must make the decision regarding which class is best for a given application.

G. Heat Cycle Current: The Heat Cycle Current shall be adjusted to result in a steady-state temperature on the control conductor. This adjustment may be made during the heating periods of the first 26 cycles. From this point on, no adjustment can be made for the remainder of test, regardless of control conductor temperature variation.

H. Heat Cycle Period: Each cycle of the Heat Cycle Test shall consist of a "Current On" period and a "Current Off" period. The length of these periods shall be chosen to allow equilibrium temperature to be reached within $2^{\circ} \mathrm{C}$. The length of these periods can be extended for the time necessary to take measurements. 
I. Loop Configuration: The loop assembly shall be mounted in a "U" or "Zig-Zag" shape in which each connector shall be lying in a horizontal plane with at least eight inches of separation between adjacent conductors. The assembly must be at least one foot from any walls and at least two feet above the floor.

J. Measurements: Temperature and resistance me asurements shall be taken at the beginning and end of the test and approximately after each 25 cycles. The actual number of cycles between measurements may be adjusted to conform to normal working hours.

D.C. resistance measurements shall be made at the end of the current-off period. These measurements shall be made across each connector, between potential points on the equalizers. For D.C. measurements the current must be of sufficiently low magnitude to avoid heating.

The ambient temperature must be recorded concurrently with each set of resistance measurements. The resistance measurements are then corrected to $20 \%$.

Temperature measurements shall be made at the end of the current-on and current-off cycle. These temperatures shall be measured by the use of thermocouples permanently attached to the center of each connector and the control conductor.

K. Thermocouples:

I. Test Connectors: Thermocouples shall be installed so as to obtain a good thermal and mechanical bond with the surface of the connector and without causing an appreciable change in the temperature of the connector (e.g. by peening or use of a thermally conductive adhesive).

2. Test Conductors: The thermocouple shall be secured to the control conductor by soldering, use of a thermally conductive adhesive or other equivalent means which will not require the penetration of the conductor surface (e.g. Drilling and peening is not permitted). 
L. Number of Heat Cycles: The number of heat cycles at the completion of the test may be extended so that final measurements may be made during normal working hours.

M. Evaluation Interval: The evaluation of each connector will be based on those measurements taken during an interval which includes the me asurements taken on or about the 25th cycle, the end of the test, and approximately every 25 th cycle between them.

N. Performance Criteria: When installed in an assembly and tested with the methods above, the connectors shall conform to the following performance criteria.

1. The resistances measured shall show a condition of stability by a variation of not more than $5 \%$ from the average measured values.

2. The temperatures measured shall not exceed the temperature of the control conductor. The temperature difference be tween the control conductor and the connector shall decrease not more than $10^{\circ} \mathrm{C}$ from the average measured values.

V. MECHANICAL TESTS

Mechanical Tests on non-heat cycled connectors shall be conducted in accordance with Section III and the following paragraphs. Mechanical tests on heat cycled connectors shall be conducted in accordance with Section III, Section IV, and the following paragraphs.

A. Test Conductors:

I. Non-Heat Cycled: Three samples of each connector/conductor combination shall be subjected to Mechanical Test.

2. Heat Cycled: Three samples of each connector/conductor combination heat cycled to its rated temperature (Section III, Paragraph F) shall be subjected to Mechanical Test.

B. Test Conductors:

1. Pullout Strength Tests shall be performed on each connector/ conductor combination. 
V. MECHANICAL TESTS: (Cont'd.)

2. If qualifying a line of connectors at least the largest and smallest connector/conductor combination must be tested.

3. If qualifying a multirange connector, at least the largest and the smallest conductor size must be tested.

C. Test Conditions: Connectors shall be classified regarding tensile strength as follows:

$\begin{array}{llll} & \text { Non-Heat Cycled } & & \text { Heat Cycled } \\ \text { Class 1 } & \text { Full Tension } & & \text { Full Tension } \\ \text { Class 2 } & \text { Full Tension } & & \text { Non-Tension } \\ \text { Class 3 } & \text { Non-Tension } & & \text { Non-Tension }\end{array}$

D. Tensile Strength:

1. Care shall be taken to insure that all conductor strands are loaded simultaneously in the tensile testing machine.

2. Crosshead speed shall not exceed $1 / 4$ inch per minute per foot of length between jaws.

3. The length of free conductor between connector and gripping device shall not be less than two feet.

4. Tensile strength shall be measured as the maximum load applied at failure. An accuracy of $1 \%$ for Class I and $5 \%$ for the other classes shall be measured with ASTM Specification E-4 calibrated instruments. The mode of failure shall be recorded.

E. Performance Criteria: The tensile strength of sample tested in accordance with Section $D$ above shall be at least equal to the following values.

1. Class I- Full Tension-Full Tension: $100 \%$ of the rated breaking strength of the conductors joined, for both Non-Heat Cycled and Heat Cycled Connectors. 
APPENDIX 7.4 (Continued)

V. MECHANICAL TESTS (Cont'd.)

2. Class 2- Full Tension-Non Testion: $100 \%$ of the rated breaking strength of the conductors joined, for Non-Heat Cycled Connectors. $40 \%$ of the rated breaking strength of the conductor joined for Heat Cycled connectors.

3. Class 3- Non Tension-Non Tension: $40 \%$ of the rated breaking strength of the conductors joined, for both NonHeat Cycled and Heat Cycled connectors.

\section{ACCEPTANCE CRITERIA:}

A. Heat Cycled: All sample sets shall be rated one step below the point of the first failure within the set.

B. Mechanical: All sample sets shall be rated at the lowest level within the set.

C. Non-Acceptance: Any sample within a set which does not meet the minimum requirements (e.g.125 cycles@130 and 40\% breaking strength) shall result in a non-acceptance of the set. 


\section{0

Several manufacturers of cable terminations were approached

relative to their ability and interest in developing terminations suitable for use on 230kV extruded solid dielectric cable. The G \& W Electric Specialty Company (REF. 8.I ) and Joslyn Manufacturing \& Supply Company (REF. 8. 2 ), expressed an interest in undertaking such a project. Subsequently, we collaborated with each on the design parameters and arrangements were formally entered into to procure one terminal from each manufacturer.

\subsection{THE G \& W TERMINATOR}

The G \& W 230kV terminator consisted of a conventional $230 \mathrm{kV}$ porcelain housing designed and used traditionally for oil-filled cable terminations. The customary reinforcing paper roll build-up and several other inner components were replaced or modified as follows:

8.1.1 Oil-impregnated paper roll build-up and stress relief cone: repl aced with hand-applied varnish-dacron-glass (VDG) tape, constructed on the prepared cable insulation.

8.1.2 Semi-conducting elastomeric sleeve to provide stress cone shielding.

8.1.3 Pre-cast epoxy stress control assembly in lieu of porcelain stress control assembly.

8.1.4 Accumulator oil reservoir unit attached to base of terminal.

The accumulator provided an expansion chamber which makes allowances for volume changes in the approximately 22 gallons of de-gassified oil contained in the pothead. Volume changes would occur as a function of temperature. Additionally, the accumulator diaphragm is pressurized with an inert gas, typically nitrogen, such that a positive pressure is maintained within the terminal. The recommended pressure of 16 PSIG was used. The cable conductor was terminated with a Cadweld connector (REF. 8.3 ) provided by the terminal manufacturer. Ordinarily, this terminator would be provided pre-assembled. However, since the porcelain housing was already in the laboratory, the inner components were procured and assembly was done in the laboratory.

The basic design parameters of the $G \& W$ termination was an extension of their standard $138 \mathrm{kV}$ slip-on terminal, extrapolated to conform to the 
$230 \mathrm{kV}$ stress conditions anticipated. The $138 \mathrm{kV}$ terminal was thoroughly tested and found to conform to the requirements of IEEE Standard No. 48 for terminators (REFERENCE 8:4).

As a result of tests performed on the $69 \mathrm{kV}$ and $138 \mathrm{kV}$ terminators, considerable data were collected which defined the radial stresses at various points in the assembly. These tests were conducted using several voltage references -- relative to magnitudes, duration and waveforms. The one minute 60 hertz dry test is the reference most commonly used by terminator manufacturers when defining radial stresses. The following summary of radial stresses at selected points in the termination, were arrived at through the aforementioned tests on the $138 \mathrm{kV}$ terminal. Through extrapolation, corresponding data for the $230 \mathrm{kV}$ terminal were established. These calculated results are referenced to a one minute 60 hertz dry test of $460 \mathrm{kV}$; the required $230 \mathrm{kV}$ terminator reference voltage:

8.1.5 Stress Control assembly base plate/semi-conducting elastomer top edge
a) 121 Volts/mil@ $@ 38 \mathrm{kV}$ level
b) $120 \mathrm{Volts} / \mathrm{mil} @ 230 \mathrm{kV}$ level

8.1.6 Oil gap at base of stress control assembly taper

a) 231 Volts/mil@ @ $38 \mathrm{kV}$ level

b) 202 Volts/mil @ 230kV level

8.1.7 VDG Tape in flat adjacent to lip of stress control assembly

a) 74 Volts/mil@138kV level

b) 76 Volts/mil@230kV level

8.1.8 Oil bulk in region adjacent to lip of stress control assembly

a)140 Volts/mil@138kV level

b)127 Volts/mil@230kV level

8.1.9 Innermost region of stress control assembly, in-line with lip of assembly

a) 50 Volts/mil@ @ $38 \mathrm{kV}$ level

b) 50 Volts/mil@230kV level

The stress data developed for the $230 \mathrm{kV}$ terminator were based on a crosslinked polyethylene insulation wall thickness of 1.050 inches, and a VDG tape 
build-up of 0.375 inches at the stress cone apex. In most instances, it can be seen that the $230 \mathrm{kV}$ termination was projected to operate at stresses lower than those observed in the operational $138 \mathrm{kV}$ terminal, at comparable points.

\subsection{THE JOSLYN TERMINATOR}

The Joslyn terminal was designed specifically as a slip-on for the $230 \mathrm{kV}$ cable. Here too, the basic concept was an extension of their operational $138 \mathrm{kV}$ terminal for extruded solid dielectric cables. Additionally, considerable laboratory test data had been gathered with a much earlier $230 \mathrm{kV}$ cable design, terminated with a prototype of the current termination. As in the first case, this manufacturer's $138 \mathrm{kV}$ terminator had been tested and found to conform to the requirements of IEEE Standard No. 48 for terminators (REFERENCE 8.4).

The Joslyn terminal consisted of a conventional porcelain housing, pre-assembled with a semi-conducting elastomeric stress cone, solid insulating phenolic-like tubes and compression mounted terminal cover. Silicone fluid is utilized to supplement the solid terminating components after the assembly is properly and securely installed on cable end. Termination of the cable conductor is accomplished with a compression connector provided by the terminal manufacturer. The design concepts were based on the maximum stresses that the stress cone would experience during the required one minute $60 \mathrm{hertz}$ dry test of $460 \mathrm{kV}$. These calculated values using a stress cone contour of 7 degrees, are as follows:

(a) SIC of Urethane compound (stress cone material): $\quad 3.89$

(b) Maximum longitudinal stress: $18.99 \mathrm{volts} / \mathrm{mil}$

(c) Maximum radial stress: $\quad 160.06 \mathrm{vol} / \mathrm{s} / \mathrm{mil}$

The preceding values were calculated on the basis of $20 \mathrm{C}$ ambient temperature. At $60 \mathrm{C}$ ambient, the following parameters applied:

(a) SIC of Urethane compound: $\quad 3.50$

(b) Maximum longitudinal stress: $21.05 \mathrm{volts} / \mathrm{mil}$

(c) Maximum radial stress: $\quad 177.79 \mathrm{volts} / \mathrm{mil}$

Cable preparation and terminating instructions were provided by both terminal manufacturers and did not conflict with the standards of workmanship that are customarily observed. Finally, both terminals were designed to meet the required $230 \mathrm{kV}$ rating of $1050 \mathrm{kV}$ BIL, based on a standard I-I/2 $\times 40$ microsecond impulse wave, in accordance with IEEE Standard No. 82 (REFERENCE 8.5).

Detailed drawings which describe the features of each termination, are included herewith as Figures 8.1 and 8.2. 
8.3 REFERENCES TO SECTION 8.0

I. G \& W ELECTRIC SPECIALTY COMPANY 3500 West 127th Street

Blue Island, Illinois 60406

2. JOSLYN MANUFACTURING \& SUPPLY COMPANY I55 North Wacker Drive

Chicago, Illinois 60638

3. CADWELD R ERICO PRODUCTS, INC. Cleveland, Ohio 44139

4. IEEE STD. 48-1975. IEEE Standard Test Procedures And Requirements for High Voltage Alternating Current Cable Terminations. The Institute of Electrical And Electronics Engineers, Inc., New York, N.Y.

5. IEEE STD. 82. Test Procedures For Impulse Voltage Tests On Insulated Conductors. The Institute Of Electrical and Electronics, Engineers, Inc., New York, N.Y. 


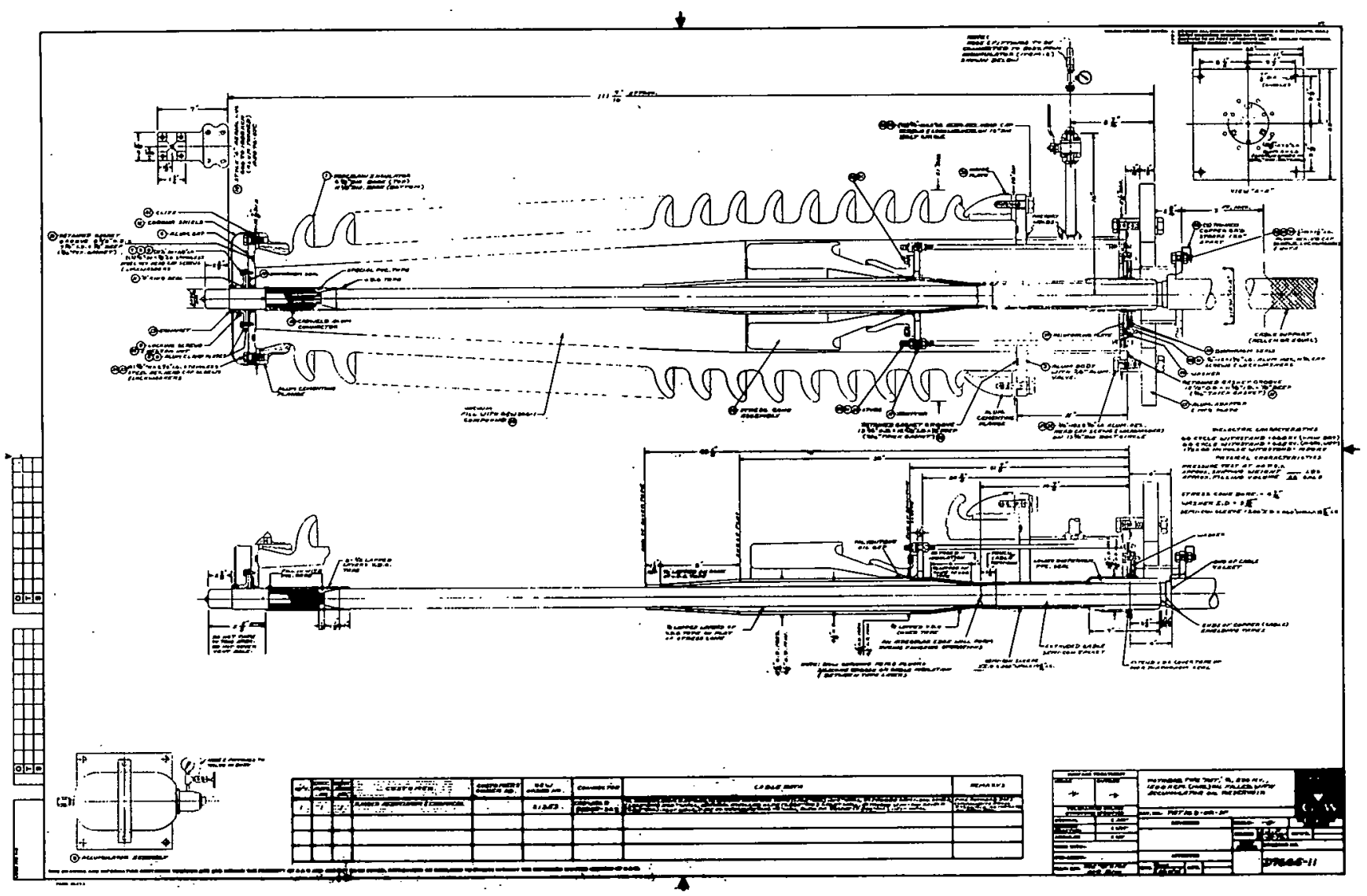

FIGURE 8.1

DETAILED ASSEMBLY DRAWING OF $G \& W$

230kV TERMINATOR 


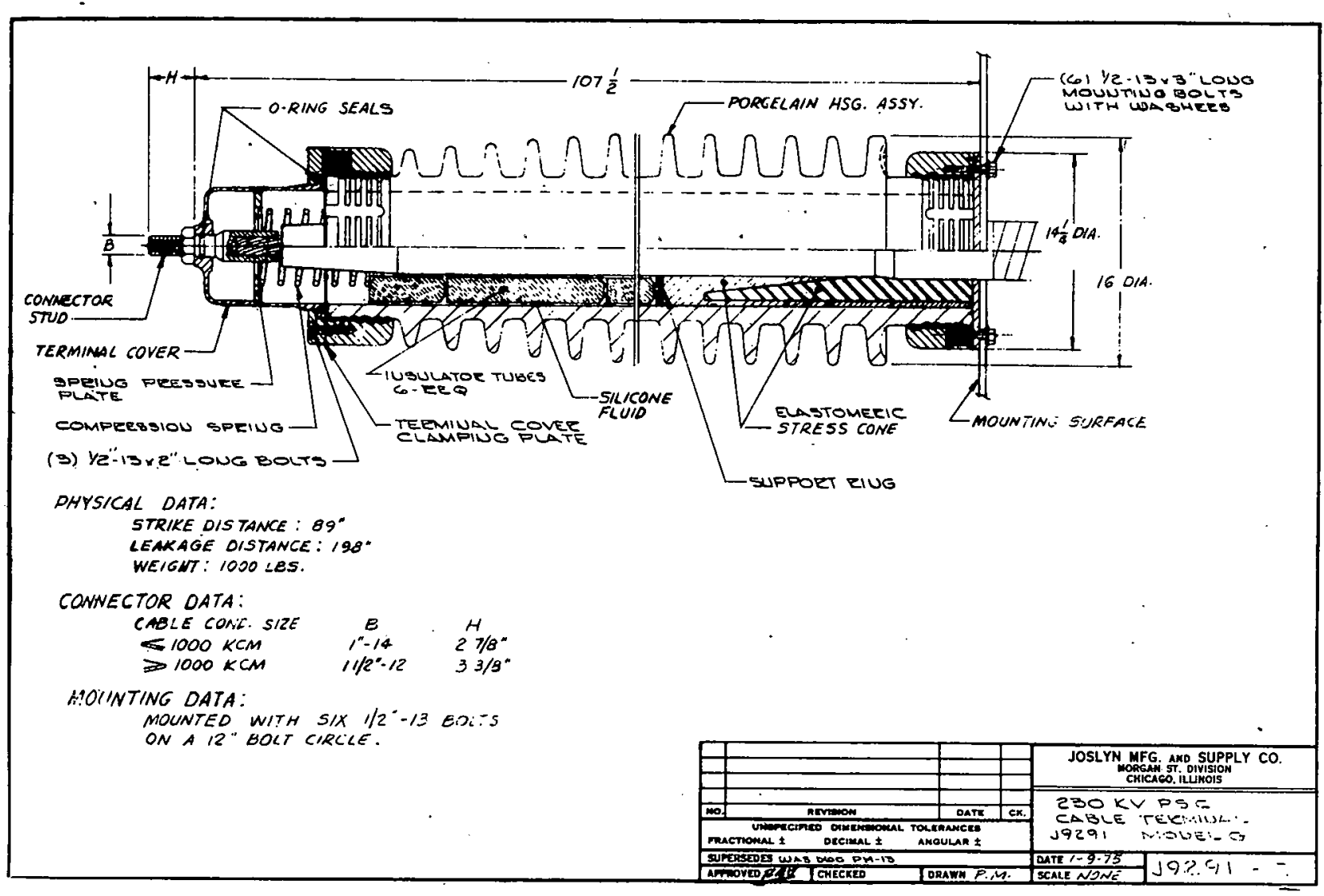

FIGURE 8.2

DETAILED ASSEMBLY DRAWING OF JOSLYN 230kV TERMINATOR 


\subsection{SUMMARY}

The project was able to show that, based upon a minimal amount of cable produced and short term testing performed, that the extruded solid dielectric cable could be used for cable systems through the $230 \mathrm{kV}$ voltage class. The 400 feet of cable, produced after several attempts, did provide reasonably satisfactory interfaces at the semi conducting/insulation interfaces. The construction behaved reasonably well under $60 \mathrm{Hertz}$ testing at both elevated and room temperatures. The construction appeared to experience difficulties in being capable of withstanding voltage impulses at the System Basic Insulation Level (BIL) while the conductor temperature was elevated to $90 \mathrm{C}$. Two impulse voltage failures were experienced while the conductor temperature was at $90 \mathrm{C}$. One failure was located in the cable itself, the other in the joint. Both failures were at a voltage level of $1050 \mathrm{kV}$. There were no impulse failures in the system while the conductor was at room temperature.

Two cable joints, of the hand-applied variety were constructed. One joint was the one mentioned above, which suffered a failure under impulse voltage. The second joint was constructed in the sample for voltage endurance and current cycling tests. That test simulated actual installation characteristics. The constructed joint successfully withstood all of the $60 \mathrm{Hertz}$ voltages applied and exhibited no signs of failure despite voltages in excess of normal operating levels and conductor temperatures as high as $130 \mathrm{C}$.

Additional work was performed on the development of alternative methods for joining cables. Considerable effort was expended on the field vulcanization of cross-linked polyethylene joints. No field vulcanized joints were constructed at the $230 \mathrm{kV}$ voltage level. Ten field vulcanized joints were constructed and tested at the $69 \mathrm{kV}$ voltage level. This testing pointed out the need for controlled pressure and environmental conditions for this type of jointing method at levels above $69 \mathrm{kV}$ and conductor sizes larger than $500 \mathrm{kcmil}$. Work on alternate methods of applying semi-conducting strand shields in field vulcanized joints showed that semi-conducting heat shrinkable sleeves are an improvement over hand applied semi-conducting tapes. Further testing indicated that the curing cycle, at least at the $69 \mathrm{kV}$ level, can be reduced in time by rapid cooling without degradation of joint characteristics.

Testing on compression type connectors and exothermic type welded connectors showed that some are capable of operating capably at temperatures at or near levels anticipated in cable joints.

Terminations manufactured by two U.S. manufacturers performed satisfactorily under short term $60 \mathrm{Hertz}$ testing under overvoltage conditions and at conductor temperatures elevated to as high as $130 \mathrm{C}$. Time did not permit testing of the terminators under impulse voltage conditions. 
Based upon the limited data collected and the abbreviated scope of work performed, we are led to conclude the following:

\subsection{METHOD OF MANUFACTURING EXTRUDED SOLID DIELECTRIC CABLES}

Normal methods for making extruded solid dielectric cables employing conventional extruder processes and steam curing is a possible means of producing $230 \mathrm{kV}$ Cables. This is based on only a short sample - 400 feet - and minimal amount of testing performed. Provisions must be made for the melting or softening temperatures of the individual extruded layers. Obviously, long term and accelerated testing must be completed to assure that this type of cable will provide the long term reliable performance required for utility system operation.

\subsubsection{CAPABILITY OF EXTRUDED SOLID DIELECTRIC CABLES}

Based on short term testing and a single sample, extruded solid dielectric cables, manufactured as stated above, employing crosslinked polyethylene insulation and extruded semi-conducting conductor and insulation shields appear to be capable of operating at voltage stresses higher than previously used. However, further testing is required to ensure that the long term performance of cables operating at higher voltage stresses is not adversely affected.

\subsubsection{0kV TAPED JOINTS}

Hand applied taped joints made with Ethylene-propylene rubber (EPR) tapes appear to have the capability of operating at significantly higher stresses than those previously considered as maximum stresses allowable. When properly constructed, they appear to have the capability of operating at levels as high as $230 \mathrm{k} V$ and to be compatible with crosslinked polyethylene insulations.

\subsubsection{0kV TERMINATIONS}

Terminations capable of operating at $230 \mathrm{kV}$ voltages and suitable for use on extruded solid dielectric cable are commercially available, relatively easy to install, provided that normal precautions for circuits of this type are taken, and are compatible with the crosslinked polyethylene insulation and semi-conducting insulation shield. 